A]1706 979265

NBSIR 83-2665

\title{
An Investigation of the Forced Ventilation in Containership Holds
}

U.S. DEPARTMENT OF COMMERCE

National Bureau of Standards

National Engineering Laboratory

Center for Fire Research

Washington, DC 20234

May 1983

Sponsored by:

U.S. Coast Guard

Washington, DC 

NBSIR 83-2665

...

\section{AN INVESTIGATION OF THE FORCED VENTILATION IN CONTAINERSHIP HOLDS}

Howard R. Baum

John A. Rockett

U.S. DEPARTMENT OF COMMERCE

National Bureau of Standards

National Engineering Laboratory

Center for Fire Research

Washington, DC 20234

May 1983

Sponsored by:

U.S. Coast Guard

Washington, DC

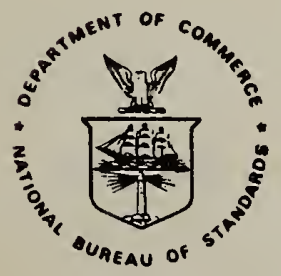

U.S. DEPARTMENT OF COMMERCE, Malcolm Baldrige, Secretary NATIONAL BUREAU OF STANDARDS, Ernest Ambler, Director 

LIST OF FIGURES................................. iv

LIST OF TABLES $\ldots \ldots \ldots \ldots \ldots \ldots \ldots \ldots \ldots \ldots \ldots \ldots \ldots \ldots \ldots \ldots \ldots \ldots \ldots \ldots \ldots \ldots$

NOMENCLATURE....................................... vili

Abstract.......................................... 1

1. INTRODUCTION. ................................ 1

2. BASIC ASSUMPTIONS OF THE THEORETICAL MODEL............... 10

3. SLOT FLOW IN A STABLY STRATIFIED ENVIRONMENT............. 12

4. THE SLOT PRESSURE DISTRIBUTION...................... 20

5. THE END VOID PRESSURE............................ 26

6. THE воTTOM MOTION. .............................. 32

7. THE VAPOR PICKUP............................... 42

8. NUMERICAL PROGRAMS.............................. 50

8.1 Main Numerical Program.......................... 50

8.2 Subroutines.................................... 54

8.3 Input Data.................................. 61

9. NUMERICAL RESULTS............................... 62

10. EXPERIMENTAL PROGRAM............................ 67

11. ConcLusions................................... 71

12. REFERENCES................................... 72

APPENDIX 1. Example of Input Data......................... 107

APPENDIX 2. Output for the Input Data of Appendix 1.............. 109

APPENDIX 3. Computer Code Listing.......................... 120 
Page

Flgure 1. Cross section of a typical containership near its mid section. To the right is shown the contalner stacking and to the left the bulkhead framing.........

F1gure 2. Vapor pressure versus temperature for heptane. Rich and lean 1 lmits are for an alr environment.......

Figure 3. Idealized containershlp hold loaded with containers.... 76

Figure 4. Geometry of the space between two stacks of contalners

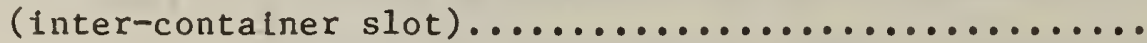

Flgure 5. Conformal mapplngs used to obtain the Greens function,

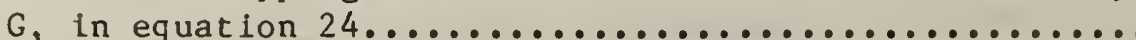

Figure 6. Plan view to the end void showing the location of the forced ventilation extraction point (suction). Ventllation flow enters from the top of the vold and from the Intercontainer slots (one of $\mathrm{N}$ slots indicated

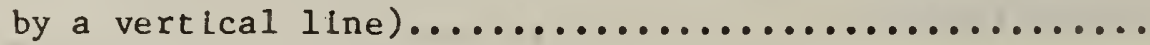

Figure 7. Cross section of the bottom of an intercontalner slot. Velocity distribution of the gas as tt approaches the slot bottom is indicated next to each wall...........

Figure 8. Universal velocity proftles for the axial flow in the boundary layer of a slot bottom. The flow is symmetrical about the slot centerline so only one half the slot width is shown. The velocity is zero at the slot bottom and increases toward an asymptotic profile as helght, $y$, above the bottom increases.............

Figure 9. Universal velocity profiles for the transverse flow in the boundary layer of a slot bottom. The flow is ant isymmetric about the slot centerline so only one half the slot width is shown. The velocity is zero at the slot bottom and increases toward an asymptotic proflle as helght, $y$, above the slot bottom increases.........

Figure 10. Perspective sketch of an intercontainer slot showing air flow streamlines. The alr plcks up evaporated splll vapor as it moves in the boundary layer along

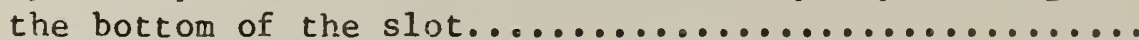

Flgure 11. Simplified flow diagram for the computer program...... 84

Figure 12. Universal slot bottom axtal veloclty plotted versus helght for a fixed transverse location (centerline).... 
Figure 13. Slot bottom stream function near the intersection of the slot with the hold end vold as a function of distance from the intersection (at $x=-1 / 2) \ldots \ldots \ldots \ldots$

Figure 14. Dimenstonless slot pressure as a function of

dimensionless helght above the slot bottom for two slots: solid line, slot nearest the suctlon and dotted line, slot furthest from the suction. Pressures calculated single precision. Compare with figure 20-a which is the same case calculated in double-precision.

Figure 15. Computed mass plck-up by evaporation and removal by forced ventilation as a function of suction height above the slot bottom for two different amounts of stable stratificatilon.........................

Figure 16. Dimensilonless mass pick-up as a function of slot number for a hold contalning 11 slots ( 10 stacks of containers) for two forced ventilation suction locations: solid line, suction on hold centerline; dotted line, suction at the out-board corner of the hold........................................

Figure 17. Dimensionless pressure as a function of dimensionless height (double precision calculation) stable stratiflcation $0.1^{\circ} \mathrm{C}$ over helght of hold..................

Figure 17a. Physical height of suction $0.05 \mathrm{~m}$, dimensionless

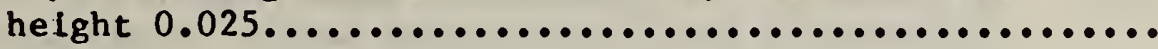

Figure $17 \mathrm{~b}$. Physical helght of suction $0.60 \mathrm{~m}$, dimensionless height 0.294 .

Flgure 18. Slot bottom boundary layer streamlines corresponding to the pressures shown In figure $17 a \ldots \ldots \ldots \ldots \ldots \ldots \ldots .$.

Figure 18a. Streamlines for slot at center (nearest suction)......

Figure 18b. Streamlines for slot at hold side (furthest from suction) $\ldots \ldots \ldots \ldots \ldots \ldots \ldots \ldots \ldots \ldots \ldots \ldots \ldots \ldots \ldots \ldots \ldots \ldots \ldots$

Figure 19. Slot bottom boundary layer steamlines corresponding to the pressures shown in figure $17 \mathrm{~b} . \ldots . \ldots \ldots \ldots . . . .$.

Figure 19a. Streamlines for slot at centerline (nearest suct lon)...

Figure 19b. Streamlines for slot at hold side (furthest from suction) .....................................

Figure 20a. Dimensionless pressure as a function of dimensionless helght (double prectsion calculation, compare with figure 14). Suction $1 \mathrm{~m}$ above hold bottom............ 
Figure 20b. Slut buttum buundary layer streamlines curresponding

to the pressure shown in figure 20a. Centerline

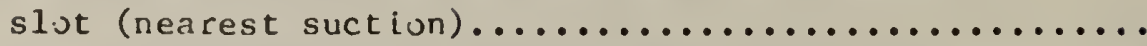

Figure 20c. Slut buttum buundary layer streamlines currespunding

to the pressures shown in figure 20a. Side slut

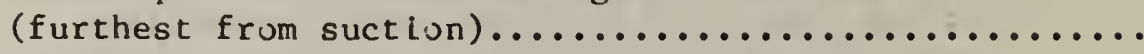

Figure 2la. Dimensionless slot pressure as a function of

dimensiunless height (duuble precisiun-calculation)

stable stratification $1^{\circ} \mathrm{C}$ over height of hold

(cumpare wlth figure 17).

Figure 21b. Slut buttum buundary layer streamlines currespunding to the pressures shown in figure $21 \mathrm{a}$. Centerline

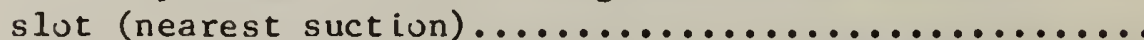

Figure 21c. Slut buttsm buundary layer streamlines currespunding to the pressures shown in figure 2la. Side slot

(furthest frum suction) $\ldots \ldots \ldots \ldots \ldots \ldots \ldots \ldots \ldots \ldots \ldots$

Figure 22. Simplified schematic of experimental apparatus........

Figure 23. Cuncentration of cumbustible vapor in the exhaust duct for several ventilation rates and two suction

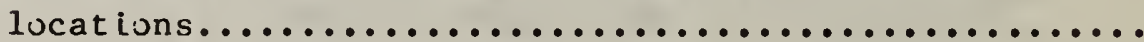

Figure 24. Cuncentration to cumbustible vapur inside the experimental enclusures versus height of the sampling puint. One air change per huur furced vent llation fluw, low suction. 
List of Tables

Page

Table 1. Vertical pressure gradient effectiveness $f(\omega)$ dependence.................................... 105

Table 2. Dimensionless mass pick-up, suction helght $5 \mathrm{~cm}$ mass pick-up........................................ 106 
At

C

$c_{0}$

D

d

$\mathbf{f}$

G

8

$\mathrm{h}$

1

k

$\ell_{\mathrm{n}}$

m

m

A

$\mathrm{N}$

n

$\vec{n}$

$p *$

p

$\operatorname{Pr}$

$Q^{\prime \prime}$

$\mathrm{Q}_{\mathbf{v}}$

$Q_{n}$
Alry function

Vapor concentration in alr

Equilibrium vapor concentration of splll materlal

Fuel diffustvity in alr

Slot half width

Function defined by eq. (10)

Grashof Number

Acceleration of gravity

Slot helght

Unte vector in the $x$ direction

Unit vector in the $y$ direction

Unit vector in the $z$ direction

Length of slot " $n$ "

Number of alr changes per hour

Local mass flux plcked up, defined in eq. (73)

Total mass flux picked up in a slot, defined in eq. (76)

Number of slots

slot number

Outward pointing normal to integration centure

Thermodynamic pressure

Perturbation due to flow pressure

Prandtl Number

Slot source flow per unit area

Total flow through end vold

Total flow through the nth slot

Total flow drawn through hold 
$t$

Normalized slot flow

Reynolds Number $=m d^{2} / v \tau$

Schmidt Number

Temperature

time

Gas velocity

Gas velocity component parallel to $x$

Gas velocity component parallel to $y$

Gas velocity component parallel to $z$

Coordinate parallel to slot or vold length

Coordinate parallel to slot or vold helght

Dimensionless coordinate defined in eq. (38)

Coordinate parallel to slot or vold width

Dimensionless coordinate defined in eq. (38)

Location of alr extractor in end vold

Dirac Delta Function

Dimensionless coordinate parallel to $x$

Also, real part of complex vartable defined in eq. (25)

Dimensionless coordinate parallel to $y$

Also, imaginary part of complex variable defined in eq. (25)

Dimensionless coordinate parallel to $z$

Gas density

Concentration layer vertical coordinate defined in eq. (66)

Gas viscosity

Gas kinematic viscosity

Time unit (hours)

Also, complex varible defined in eq. (33) 


\section{Subscripts}

0

1

n

v

\section{Superscripts}

$\star$

$\sim$

\section{Operators}

$\nabla$

$\Delta$
Dimens Lonless temperature

Scale factor defined in eq. (6)

Gamma function

Stream function def Ined in eq. (64)

Reference value for $T, p$

Value at top of hold

Value associated with nth slot

Value assoclated with end vold

Dimensionless, perturbation values, defined in eq. (38)

Dimensionless, perturbation value, defined in section 3

Dimensionless vartables defined in eq. (20)

Vector gradient

Laplacian 
AN INVESTIGATION OF THE FORCED VENTILATION IN CONTAINERSHLP HOLDS

Howard R. Baum

John A. Rockett

\section{Abstract}

An analysis of the fluid flow and mass transfer Induced by ventilation systems in containership holds was carried out. The result of the work was used to support the U.S. position before a committee of the International Convention on Safety to Life at Sea. The analysis consists of a detailed calculation of the forced motion through an interconnected set of narrow, stably stratifled vertical air passages, which represent an idealized containership hold. The results of this calculation we re then used to predict the vapor concentration of spilled volatile material assumed to lie at the bottom of the vertical air passages. The result is a set of formulae which determine the rate of extraction of volatile material as a function of hold geometry, ventilation parameters, and amblent stratification. The results are incorporated in a computer program which ts described in detall. A variety of computed results are presented. The results indicate the cruclal importance of locating the extractor as close to the hold bottom as technically possible.

\section{INTRODUCTION}

The purpose of this study was to obtain the information necessary to prepare a quantitative statement on the degree of fire hazard that might exist In the hold of a large containership as a function of the amount and nature of the hold ventilation and amount and kind of leakage of flammable liquid or gas cargo. The effort was mainly analytic although some scale model tests were 
conducted. Sea tests were conducted by Sealand Corporation to determine the degree to which the thermal conditlons assumed by the analysis were found in practice.

Contalnerships play a major role in the U.S. Merchant Marine. The majority of the non-bulk sea-going cargo into and out of the U.S. is now moved in containers. Some of thls cargo is classtfled as "dangerous cargo", such as flammable liquids and gases and are regulated in treaty provisions based on recommendations of the International Maritime Consultative Organization ( IMCO).

Under existing regulations stowage limitations, resulting from the types and amounts of cargo classed as dangerous, reduce shipment scheduling flexiblitty. IMCO has considered new regulations which would somewhat relax the dangerous category definitions for ships with adequate hold ventilation or detection and inerting systems. The basls for their action is the bellef, by some members of the committee, that ventilation would keep the concentration of leaking and vaportzing flammable gas below the flammable or explostve 1imlt. However, prlor to thls study, there did not appear to be a ratlonal basts for establishing a sultable rate of ventllation. A study on the scale of this one could not address the full range of situations which might arlse but the most prevalent sltuation was considered. Using the results of this study a position was developed and presented by the U.S. representative to IMCO as a counter to the ad hoc opinlons originally put forward by others. After discusston, a posttion close to the U.S. posttion was adopted by the committee. 
Contalner freight forwarding is a highly automated process using shlps of ten specifically built for container freight and complex dock side equipment matched to the ship design. Containers of a uniform size are closely stacked within the holds, filling all the space available after allowance for structure, container guides and spaces at the sides, especially near the ends of the ship, due to the non-rectangular shape of holds. Current practice loads a hold to its maximum capacity. In the center portion of a ship, with wing tanks occupying the space between the hull plating and the side combing of the hatch, the only significant volds would be between the top of the containers and the underside of the hatch covers; and at one end of the contalner stacks, where deep framing of the transverse bulkhead result in a array of rectangular spaces interconnected by lightening holes in the frames. The spaces between stacks of containers, between the containers and the wing tank walls, or between the end of the container stacks and the smooth (non-framed) side of a transverse bulkhead would be only that needed for the contalner guides, typlcally about $10 \mathrm{~cm}$ between stacks of containers and half this between the containers and bulkhead, see figure 1 . On some ships there may be fixed, heavy longltudinal beams to support the hatch cover. The gaps between container stacks on etther side of such a beam would be somewhat wider. Where wing tanks are not used and at the ends of the ship, a fairly large vold will exist between the hull plating and the outermost container stack. This will be partially subdivided by the transverse and longitudinal framing. The container stacks rest on the flat, smooth double bottom tank top. Although an air space some $10 \mathrm{~cm}$ deep exists under the containers this is cut off from the inter-contalner gaps and end volid by side and end rails or skirts of the container so that effective communication with this space is limited by the thickness of the corner pads of the containers, a gap perhaps 
less than $2 \mathrm{~cm}$. Should a liquid be spilled on the tank top it would be able to flow under the contalners as the ship rolled but liquid evaporated under the containers would not easily escape to the rest of the hold.

The accident scenario envisaged involves a container carrying general cargo including some flammable liquid in cans or drums. For any of a number of reasons -- a defective drum, inadequate dunnage and securing, rough handling of the contalner, etc. -- flammable liquid is assumed to escape into the interior of the container. Although a container in good condtion is quite weather tight, an older contalner, especlally if it has been roughly treated (a situation likely to accompany disruption of its cargo), may allow a 1 lquid, spilled inside, to leak out. It is assumed that 1 iquid does escape and flows down over the outside of the containers below to the botton of the hold, where it accumulates in a puddle which is spread by rolling and pitching of the ship to wet the entire bottom of the compartment. In the case considered for the numerical examples used throughout this paper, the 1iquid is heptane and the tank top area is $324 \mathrm{~m}^{2}$. If 208 liters (55 U.S. gallons) of liquid reached the bottom of the hold and spread uniformly over the tank top, the liquid layer would be only $2 / 3 \mathrm{~mm}$ thlck.

Consider the implications of this accident first as it affects conditions Inside the container and next as it affects conditions in the hold. Inside the container the alr will be essentlally stagnant for any plausible hold ventilation scheme. Accumulated liquid will evaporate reaching a local equilibrtum concentration depending on the contalner temperature. Hold temperatures measured by Sealand on a run from Houston to Rotterdam [1] ${ }^{1}$ in

1 Numbers in brackets refer to references 1 isted at the end of this report. 
the fall of 1978 ranged from 10 to $28^{\circ} \mathrm{C}\left(50\right.$ to $\left.83^{\circ} \mathrm{F}\right)$. Fron figure 2 [2] it is seen that the equilibrium vapor pressure of heptane, for these temperatures, ranges from 20 to $53 \mathrm{~mm}-\mathrm{Hg}$ yielding corresponding volume concentrations of 2.6 to $7.0 \%$. Lewis and Von E1be [3] give the flammability limits for heptane in a Ir as 1.2 and $6.7 \%$. Thus the undiluted heptane vapors will lie within the flammable limits throughout the expected temperature range. Heptane $\left(\mathrm{C}_{7} \mathrm{H}_{16}\right)$ vapors are heavier than air. The mean molecular weight at standard temperature and pressures of the equilibrium heptane-air mixture for this range of vapor pressures is 30.84 to 34.11 compared to 28.97 for air. This will tend to inhibit mixing of the heavy vapors with the rest of this air in the container but, over a long period of time, through diffusion, a substant lal volume of combustible vapor could accumulate inside the container (121 to $312 \mathrm{gm}$ of heptane $/ \mathrm{m}^{3}$ of a $\mathrm{lr}$ in a container with total volume about $90 \mathrm{~m}^{3}$ and vold volume estimated at $10 \mathrm{~m}^{3}$ ). Our accident scenario supposed that the container would allow the spilled liquid to leak out but, of course, it might not, or might leak very slowly. Thus, if an ignition source of sufficient strength to ignite the vapors were found within the container, a vapor deflagration could occur followed by fire. Recall that this situation is Independent of the amount and type of hold ventilation and that, for the chemical and temperatures chosen, there is little possibility of escaping danger by exceeding the rich flammable limit after a long the.

If the contalner leaks, some or most of the liquid can escape, poss lbly alleviating the hazard just described but creating another in the ship's hold. As already noted the liquld will form a thin but extensive puddle on the tank top. If there is a low point sump in the hold, a substantial amount of the spill may drain into it and could be pumped to a safe holding tank. 
Such an arrangement seems the most suitable way to remove any substantial amount of liquid. However, evaporation will occur in the hold just as lt does In the contalner, but, in the hold, ventilation can greatly reduce the hazard.

Consider first the zero ventilation situation in an unstratifled hold. While, as just discussed, there might be 1 to 3 kilograms of fuel vapor in the contalner where the spill originated, the ship's hold is so large that, for a plausible spill volume, evaporation followed by thorough mixing might exhaust the avallable vapor before the lean limit concentrations were reached. For a hypothetical ship with wing tanks, 1.e., minimal side volds, loaded with 10 rows of 35 foot containers across the hold each row 7 containers high, the total hold volume might be about $6,500 \mathrm{~m}^{3}\left(230,000 \mathrm{ft}^{3}\right)$ and the vold volume $1,760 \mathrm{~m}^{3}\left(62,000 \mathrm{ft}^{3}\right)$. This void volume could carry, for the range of temperatures expected, from 210 to $550 \mathrm{~kg}$ heptane, or approximately the contents of $1-1 / 3$ to $3-1 / 255$ gallon drums. A very large ship without wing tanks would have considerably more vold volume in its midships holds while, in the ends a ship, there could be considerably less vold volume. In any event, the advantage of a low point sump becomes clearer in this context since th could remove much of the spill liquid before it evaporated. As noted earlier, the film of liquid from a 55 gallon spill, spread evenly over the tank top of a large shlp is quite thin. Since some residual $\mathrm{f} 1 \mathrm{~m}$, puddles in irregular low spots, etc., must be antlclpated, there would be a signiflcant reservoir for evaporation even with an efficlent sump. This residual volume is difficult to estimate but, for a low viscosity liquid might be about 20 to 30 gallons ln so large a space. For the vold volume of our example $\left(1760 \mathrm{~m}^{3}\right)$ at the lean limit concentration there would be 94 kilograms of heptane vapor or the result of evaporating 33 gallons. Thus, by using a sump, there is the possibllity of keeping the average composition of the vapor below the flammable $1 \mathrm{im} L \mathrm{t}$. 
Although the average composition of the vapor might be kept below the flammable limits, during the evaporation process (while liquid remains) there will be a region near the liquid surface in which the vapor concentration will approach the equilibrium vapor concentration corresponding to the liquid temperature. As we have seen, this can be expected to be well within the flammable limits. The purpose of ventilation is to keep the volume of gas which is within the flammable limits as small as possible. If the air in the hold were continually stirred, for example, by natural convection created by an unstable vertical temperature gradient -- bottom of the hold warmer than the top, the same situation described under zero ventilation would apply. However, an unstable temperature gradient was observed only intermittently on the Instrumented containership run from Houston to Rotterdam and then only in the upper portion of the hold. The lowest thermocouple was always the coolest. Throughout most of the voyage the hold air was stably stratified for a11 helghts measured. In addition to the temperature stratification, if there are pools of flammable liquid at the bottom of the hold, the vapor just above these pools will be heavier than pure air. This may be expressed as an added equivalent thermal stratification by giving the temperature difference required to produce the same density difference in pure air as is produced by the fuel vapor. For heptane at the temperature observed, this ranges from about 20 to $50^{\circ} \mathrm{C}$. By contrast the true thermal stratification on the Instrumented sea run never exceeded $3^{\circ} \mathrm{C}$, and was more typically less than $1^{\circ} \mathrm{C}$. Thus the combination of a stable temperature fleld and heavy evaporated liquid vapor tends to be extremely stable near the tank top (hold bottom) and generally stable, though much less so, elsewhere. 
If there were a transverse temperature difference, one side of the hold warmer than the other, a clrculation would develop $[4,5]$. In an empty hold a narrow boundary layer flow would move up the warmer side across the top of the hold and down the cooler side. Near-stagnant conditlons would be found in the interior of the hold. The flow across the tank top would also be confined to a thin boundary layer. In a loaded ship, due to the presence of the contalner stacks, this flow would be strongly inhiblted except in the end vold associated with the bulkhead framing and here the framing would considerably reduce the general flow. In practice, the flow induced by a transverse temperature gradient in the presence of a stable vertical gradient, would probably only be significant in the two side volds of a ship without wing tanks. The clrculation would be between the sides of the ship and the outer side of the outermost contalner stacks. Such flow has not been considered in this study.

The flow that seems most 11kely to affect the vapor bubble over evaporating liquid on the tank top is that associated with forced ventilation. Obviously, for the well mixed case (unstable stratification) the location of the suction and inlet for the forced flow are relatively unimportant although they should be well separated. In the stably stratifled case this is not true. Both since the stable case is more prevalent and since, in the unstable case, the suction may be located anywhere and might as well be placed advantageously for the stable sltuation, the stable case has been glven priortty in our study. With stable stratification and flammable vapors heavier than air originating from a liquid spill, the suction should be close to the bottom of the hold and the inlet placed well above $1 t$. As will be discussed in detail in the following sections, the air flow will at first spread laterally from the inlet with very limited vertical movement. There 
will be a relatively slow drift downward to the level of the suction followed by lateral movement in the plane of the suction, again with little vertical motion, to the suction location. If the suction is located above the tank top (at the bottom of the hold shown in figure 1) the gas below the suction will tend to be stagnant. In the stably stratified case, vertical movement of the gas is factlitated where it can exchange heat with its surroundings. The result is that the vertical drift from the level of the inlet to that of the suction is not uniform but concentrated in thin boundary layers adjacent to the container stacks and ship structure. The more stable the stratification the narrower these boundary layers become. For the geometry and temperature differences found in a typical container ship these boundary layers are only a few centimeters thick. The result is that virtually the same flow can move down the $10 \mathrm{~cm}$ wide gap between container stacks as down the several meter wide gap between the outermost container stack and the side of the ship. Only when the gap is narrower than the combined thickness of the two boundary layers is the flow decreased. This may occur in the gap between the end of the contalner stacks and the smooth side of the bulkhead.

In all the above, the accident was assumed to involve a liquid spill. Although this appears to be the most likely type of accident, some materials could be released whose vapors are lighter than air. To deal with this eventuality, it has been proposed that the forced ventilation inlet be located near but not at the top of the hold and that a suction pulling a minor fraction of the ventilation be provided at the highest point in the hold, just under the hatch cover. 
In order to develop a quantitatlve model, it is necessary to know the geometry and thermal stratiflcation of a typlcal container ship hold. The most obvious feature of such holds (on efflclently designed shlps) is that most of the available space is occupied by contalners. The only air spaces are narrow vertical slots between stacks of containers, similar but less narrow volds at ends and/or sides of the stacks, and a gap between the top of the container stacks and the hatches. The slze and shape of these vary from ship to shlp, and from one hold to the next on a given ship. The temperature distribution in each hold is dependent on both the ship and its thermal environment over a perlod of time. In general, the environment is highly dependent on the shlps route and both seasonal and dally weather patterns. The conditions prevalling in tanks adjacent to the hold are also important and may vary markedly during a voyage. Given this environment, the complete determination of the thermal balance on a ship is itself a formidable task.

Rather than attempt to model the detailed features of a single hold and thermal environment, a set of simplifying assumptions is introduced, which permits the analysis to be reduced to a tractable size and scope, and still retain some dependence on the physical and geometric parameters described above. These assumptions are:

(1) The hold is rectangular. The alr spaces consist of narrow rectangular vertical slots separating container stacks and a narrow rectangular vertical vold at one end of the hold. The ideallzed hold is shown schematically in figure 3. 
(2) The temperature distribution in the hold is stably stratifled and varles linearly from top to bottom. The containers and ship hull are in thermal equilibrium with this distribution. Thus, a11 motions are due to ventilation.

(3) The ventilation system is designed so that air enters at the top of the hold and exits in the end vold. The overall air volume flow is consistent with creeping motion (inertia forces unimportant).

Finally, in order to estimate the rate at which spilled material is picked up it is necessary to impose a spill scenario on the model. It is assumed that the spill material collects at the bottom of the slots between container stacks. The material is picked up as vapor in a concentration boundary layer formed at the bottom of the slot. All material caught up in this boundary layer is assumed to exit with the ventilation air. The analysis then proceeds as follows:

First, the condtions for low Reynolds number flow are established and the small scale motion in a single slot is determined. This leads to an equation for the pressure that governs the large scale motion in a single slot. This equation ts then solved assuming that the pressure in the end void where the flow exits is known. The next step is the solution for the pressure in the end void, which ties together the large scale motion in the entire hold. Then the local flow in the bottom of each slot is obtalned. The final step is the calculation of the concentration boundary layer in the slot bottom, which determines the actual pickup of spill material. 
As mentloned above, the volume available for air movement in a containership hold may be usefully tdealized as a collectlon of narrow vertical and horlzontal slots. The analysis of the motion In a single slot is thus a necessary precondition for a study of the air movement throughout the hold. In order to proceed, we must first establish that the creeping flow reglme is encountered for realistlc values of the governing flow parameters. Then, approximate solutions to the equations of motion valid in the approprlate flow reglme can be constructed. Finally, these solutions will be related to the large scale motion In the hold.

Consider a vertically oriented slot of width $2 d$, height $h$ and length $\ell$ (figure 4). The equatlons governing the steady motion of a viscous incompresslble fluid affected by buoyancy forces can be written in the Boussinesq approximation as:

$$
\begin{aligned}
& \nabla \cdot \vec{u}=0 \\
& (\vec{u} \cdot \nabla) \vec{u}+\frac{1}{\rho} \nabla p^{*}+\left(\frac{T-T_{0}}{T_{0}}\right) \vec{g}=\nu \Delta \vec{u} \\
& (\vec{u} \cdot \nabla) T=(\nu / P r) \Delta T
\end{aligned}
$$

Here $\vec{u}$ is the velocity vector, $\mathrm{p}^{*}$ the pressure, and $\mathrm{T}$ the temperature In the fluid. The density $\rho$, kinematic viscosity $\nu$ and Prandtl number Pr are properties of the fluid taken as constant corresponding to the hold bottom 
temperature $\mathrm{T}_{0}$. The gravitational acceleration $\vec{g}$ is directed vertically downward, while $\nabla$ and $\Delta$ are respectively the gradient and Laplaclan operators.

Equation (1) represents the conservation of mass, momentum, and energy respectively. It is anticipated that the ventilation system will be deslgned to induce mean (mass averaged) velocities in the slot whose order of magnitude is such that air actually in the hold bottom can be swept out several times per hour. Let $m$ be the number of times per hour that a slot is swept out horizontally. Then a typical horizontal velocity must be of order $\mathrm{m} \ell / \tau$, where $\tau$ is the period (one hour). The inertial terms (the non-linear terms) in the horizontal momentum balance are then of $\operatorname{order}(\mathrm{m} \ell / \tau)^{2} / \ell$; while the viscous terms are of order $\nu(\mathrm{m} \ell / \tau) / \mathrm{d}^{2}$. The ratio of these two terms indicates the relative importance of viscous and inertial effects. It will be called the "effective Reynolds number" in this report to distinguish it from more convent Lonally defined Reynolds numbers. This effective Reynolds number (Re) for horizontal motion in the slot, which determines the flow regime of interest, is given by

$$
\operatorname{Re}=\frac{\mathrm{md}^{2}}{\nu \mathrm{T}}
$$

For slot widths and sweep rates of interest the effective Reynolds number Re Ls typically in the range $1 \leq \operatorname{Re} \leq 10$

For this range of values, the horizontal flow is effectively one in which the pressure forces balance the viscous forces on the fluid, as in plpe flow and in bearing lubrication $[6,7]$. This occurs because the slot is so narrow in comparison to its length $(d / \ell \ll 1)$ that velocities perpendicular to the 
plane of the slot (1.e. - in the z-direciton, see figure 4) are negligibly small compared with those in the plane of the slot. Although the above argument strictly applies to horizontal motions, it will be shown in detail below that the effect of stable stratification will be to reduce even further the importance of inertial effects on the fluld motion.

We now turn to a detafled study of the motion in the slot. Let $\mathrm{P}_{0}$ and $\mathrm{T}_{0}$ be reference values of the pressure and temperature of the air in the slot. The fluid velocity $\vec{u}$ may be expressed in component form (see flgure 4 ) as:

$$
\vec{u}=u \vec{i}+v \vec{j}+w \vec{k}
$$

The dependent variables describing the state of motion may be represented as follows:

$$
\begin{aligned}
& p^{*}=p_{0}-\rho g y+\rho\left(\frac{T_{1}-T_{0}}{T_{0}}\right) \frac{g h}{2}\left(\frac{y}{h}\right)^{2}+p(x / l, y / h) \\
& T=T_{0}+\left(T_{1}-T_{0}\right) y / h+\theta(x / l, y / h, z / d) \\
& u=u(x / l, y / h, z / d) \\
& v=v(x / l, y / h, z / d) \\
& w=w(x / l, y / h, z / d)
\end{aligned}
$$


Here, $g$ is the magnitude of the gravitational acceleration and $p$ is the dynamical part of the pressure. The remaining terms in the expression for $p$ * are the hydrostatic values of the pressure. The term linear $\ln (y / h)$ in the expression for the temperature is the amblent stratification of the hold. This stratification is assumed to vary linearly between the upper temperature $\mathrm{T}_{1}$ and $\mathrm{T}_{0}$, where $\mathrm{T}_{1}>\mathrm{T}_{0}$. The velocity component normal to the plane of the slot, $w$, is smaller than the in-plane components $u$ and $v$ by a factor $d / \ell$ or $d / h$. The conservation of momentum in the $z$ direction immediately leads to the conclusion that the dynamic pressure $p$ must be nearly independent of $z$.

It is convenient to work with non-dimensional variables defined as follows:

$$
\begin{aligned}
& p=(\operatorname{Re}) \rho g h\left(\frac{T_{1}-T_{0}}{T_{0}}\right) \hat{p}(\xi, \eta) \\
& v=(\operatorname{Re}) g d\left(\frac{T_{1}-T_{0}}{T_{0}}\right) \hat{v}(\xi, \eta, \zeta) \\
& \theta=(\operatorname{Re})\left(T_{1}-T_{0}\right) \hat{\theta}(\xi, \eta, \zeta) \\
& \xi=x / l, \eta=y / h, \zeta=z / d
\end{aligned}
$$

Substitution of the non-dimensional variables defined in equation (3) into the vertical momentum and energy conservation equations and neglecting terms of $\operatorname{order}(d / h)^{2},(d / \ell)^{2}$, or Re yilelds: 


$$
\begin{aligned}
& \frac{\partial \hat{p}}{\partial \eta}-\hat{\theta}=(G)^{-1 / 2} \frac{\partial^{2} \hat{v}}{\partial \zeta^{2}} \\
& \hat{v}=\frac{(G)^{-1 / 2}}{P r}(h / d) \frac{\partial^{2} \theta}{\partial \zeta^{2}} \\
& G=\left(\frac{T_{1}-T_{0}}{T_{0}}\right) \frac{g d^{3}}{v^{2}}
\end{aligned}
$$

The dimensionless parameter G, the Grashof number, is the fundamental parameter controlling the nature of the vertical motion in the slot. Its Lnfluence will be discussed in detall below.

Since $p(\xi, n)$ is independent of $\zeta$, equation (4) can be solved for the dimensionless vertical velocity $\mathrm{v}$ and temperature perturbation $\hat{\theta}$ as functions of the vertical pressure gradient $\frac{\partial p}{\partial \eta}$. The boundary condit lons associated with equation (4) are:

$$
\begin{aligned}
& \hat{v}(-1)=\hat{v}(1)=0 \\
& \hat{\theta}(-1)=\hat{\theta}(1)=0
\end{aligned}
$$

The physical meaning of equation (5) is that the vertical velocity and temperature perturbation must vanish at the sides of the slot. The first boundary condition follows from the no-slip condition. The second comes from the assumption that the ambient stratification in the slot is controlled by the temperature distribution in the contalners, which varies linearly with height.

The solution to equations (4) and (5) is given by: 


$$
\begin{aligned}
& \hat{\mathrm{v}}=\frac{\partial \hat{\mathrm{p}}}{\partial \eta}(\mathrm{h} / \mathrm{dPr})^{1 / 2}\{\mathrm{a}(\omega) \cos (\omega \zeta) \cosh (\omega \zeta)-\mathrm{b}(\omega) \sin (\omega \zeta) \sinh (\omega \zeta)\} \\
& \hat{\theta}=\frac{\partial \hat{\mathrm{p}}}{\partial \eta}\{1+\mathrm{a}(\omega) \sin (\omega \zeta) \sinh (\omega \zeta)+b(\omega) \cos (\omega \zeta) \cosh (\omega \zeta)\} \\
& \mathrm{a}(\omega)=-\frac{\sin (\omega) \sinh (\omega)}{-\sin ^{2}(\omega)+\cosh ^{2}(\omega)} \\
& \mathrm{b}(\omega)=-\frac{\cosh ^{2}(\omega) \cos ^{2}(\omega)}{-\sin ^{2}(\omega)+\cosh ^{2}(\omega)} \\
& \omega=\frac{1}{\sqrt{2}}(\operatorname{Grd} / \mathrm{h})^{1 / 4}
\end{aligned}
$$

It should be noted that the above solution, while approximate in terms of the overall problem of interest, is in fact an exact solution of the equations of hydrodynamics for an infinitely long slot. This buoyancy layer was first found by Prandt1 [8], and by Gill [9], and used by Gill [9], in his analys is of thermally driven slot convectlon. Gill's analysis has been experimentally verified by Elder [10]. In the present application, the solution corresponds to a forced stratified channel flow. In the limit of zero stratification:

$$
\hat{\mathrm{v}}=-\frac{\partial \hat{\mathrm{p}}}{\partial \eta}(\mathrm{h} / \mathrm{dPR})^{1 / 2} \omega^{2}\left(1-\zeta^{2}\right)
$$

Returning to dimensional varlables, equation (7) can be rewritten in the classical form:

$$
v=-\frac{1}{2} \frac{d^{2}}{\mu} \frac{\partial p}{\partial y}\left[1-(z / d)^{2}\right] ; \quad u=-\frac{1}{2} \frac{d^{2}}{\mu} \frac{\partial p}{\partial x}\left[1-(z / d)^{2}\right]
$$


Here, $\mu$ is the viscosity of the air, and the solution for $u$ has been added. For large stratiflcation, $\omega$ is not small. As an example, for a stable stratification $\mathrm{T}_{1}-\mathrm{T}_{0}$ of $3^{\circ} \mathrm{C}$, with the reference temperature $\mathrm{T}_{0}=300^{\circ} \mathrm{K}$ and a slot half width of $10 \mathrm{~cm}$ and width to height ratio $\mathrm{d} / \mathrm{h}=.01, \omega=5.3$. For values of $\omega>3$, equation (6) simplifies to the form:

$$
\hat{v}=-\frac{\partial \hat{p}}{\partial \eta}(h / d P r)^{1 / 2}\left\{e^{-\omega(1-\zeta)} \sin [\omega(1-\zeta)]+e^{-\omega(1+\zeta)} \sin [\omega(1+\zeta)]\right\}
$$

Equation (9) represents a vertical flow that has effectively ceased except for a boundary layer of thickness $(\omega)^{-1}$ near each wall of the slot. Thus, for a given pressure gradient, there is much less vertical flow in the presence of stratification than in its absence. This can be seen more dramatically by calculating the vertical volume flux of air per unit of length. The vertical flux in dimensional variables is given by:

$$
\begin{aligned}
& \int_{-d}^{d} v d z=\frac{2 d^{3}}{3 \mu} \frac{\partial p}{\partial y} f(\omega) \\
& f(\omega)=\frac{3}{8 \omega^{3}} \frac{\sinh (2 \omega)-\sin (2 \omega)}{-\sin ^{2}(\omega)+\cosh ^{2}(\omega)}
\end{aligned}
$$

This should be compared with the horizontal volume flow per unit of height, which is:

$$
\int_{-d}^{d} u d z=\frac{-2}{3} \frac{d^{3}}{\mu} \frac{\partial p}{\partial x}
$$

Clearly, the function $f(\omega)$ is a measure of the effectiveness of the pressure gradient in producing a vertical flow. The function is presented in table 1. The decrease in effectiveness with increasing stratiflcation (increasing $\omega$ ) is quite obvious. 
The final stage of this part of the calculation is the determination of the pressure in the slot. The pressure distribution is governed by the requirement that mass be conserved in the slot. Let the quantity $Q^{\prime \prime}(x, y) d A$ be the rate at which fluid is introduced by some external agent into the slot, where $\mathrm{dA}$ is the element of surface across which the flutd crosses. This may be an inlet or exit from a ventilation system or vent, or a cutout in an end wa11. Using equations (10) and (11), the conservation of mass yields the following equation for the pressure:

$$
\frac{\partial^{2} p}{\partial x^{2}}+f(\omega) \frac{\partial^{2} p}{\partial y^{2}}=-\frac{3}{2} \frac{\mu}{d^{3}} Q^{\prime \prime}(x, y)
$$

There are three situations covered by equation (12) which are of Interest. First, if there is no opening into or out of the slot, then $Q^{\prime \prime}=0$. Second, if the flux through the opening is specified, then $Q^{\prime \prime}$ is a prescribed function. One such case of practical interest is a small opening at $x=x_{0}, y=y_{0}$ which a total flow rate $Q_{0}$ is specified, the dimenstons being small compared with the length or height of the slot. Then, Q" is given by :

$$
Q^{\prime \prime}(x, y)=Q_{0} \delta\left(x-x_{0}\right) \delta\left(y-y_{0}\right)
$$

Here, $\delta$ denotes the Dirac delta function. Finally, if the opening is large and the pressure is speclfied at the opening, then it is more convenient to consider the boundary of the opening as a boundary of the slot along which the pressure is specified. Then $Q^{\prime \prime}=0$ as before over the interior of the reglon of interest. However, the solution now must be obtalned over the rectangular slot, with the correct pressure being specified at the open edge. The second 
and third cases are complementary in that the flow is specified and the pressure is calculated In the second Instance; whlle the pressure is specified and the flow is calculated in the third.

\section{THE SLOT PRESSURE DISTRIBUTION}

The starting polnt for the analysis is equation (12), with $Q^{\prime \prime}=0$. The boundary condition at the closed end of each slot is (see equation (11) and figure 4):

$$
\frac{\partial p}{\partial x}(\ell / 2, y)=0
$$

At the open end, the pressure must be compatible with the end vold pressure at that height. If the end vold pressure at the $n^{\text {th }}$ slot ls denoted by $p_{v}(n, y)$; then the boundary conditlon at the open end is:

$$
p(-\ell / 2, y)=p_{v}(n, y)
$$

At the bottom, since there is no flow through the floor of the hold, the boundary condition is (see equation (10)):

$$
\frac{\partial p}{\partial y}(x, 0)=0
$$

Rather than consider the geometry of the air gap at the top of the hold and its interaction with the upper boundary of the slot, it is inore convenlent to note that most cases of practical interest correspond to values of $\omega$ (see equation (6)) such that $f(\omega) \ll 1$. If $\ell / h$ is of order unlty, then equations 
(12) and (14) imply that, away from the top or bottom of the slut, p depends only on $y$. Let $Q_{n}$ be the total flow of air drawn through the $n^{\text {th }}$ slot. Then equation (10) and (12) imply that the pressure distribution over most of each slot is given by:

$$
p=\frac{3}{2} \mu Q_{n} y / d_{n}^{3} l_{n} f\left(\omega_{n}\right)
$$

Now the same relation must hold in most of the end vold, away from the top or bottom. This means that the total flow, Q, drawn through the hold by the ventilation system can be related to $p$ by the formulae:

$$
Q \equiv \sum_{n=0}^{N} Q_{n}=\frac{2}{3} \frac{P}{y} \quad \sum_{n=0}^{N} d_{n}^{3} \ell_{n} f\left(\omega_{n}\right)
$$

The sum in equation (18) is assumed to extend over all slots and the end vold. Eliminating the pressure from this expression yields the result:

$$
Q_{n}=Q \ell_{n} d_{n}^{3} f\left(\omega_{n}\right) / \sum_{n=0}^{N} d_{n}^{3} l_{n} f\left(\omega_{n}\right)
$$

Equation (19) is extremely important in what follows. It permits the flow in each slot to be related to the total flow drawn through the hold, Q. Thus, since $Q$ is a prescribed system parameter, $Q_{n}$ can be determined in advance as a function of the hold geometry and stratification. Physically, equations (17)-(19) mean that the stratification completely suppresses horizontal motion everywhere except near the top and bottom of each slot and the end vold. Equation (12) then implies that the horizontal motion is only important in layers of order $\ell_{n} \sqrt{f\left(\omega_{n}\right)}$ in height near the top and bottom. The details of the motion near the top are of no interest. The only thing that 
matters is that the ventilation alr enters there. The bottom horizontal motion must be calculated because it determines the plckup of evaporated spill materlal. However, it can now be calculated as if the slot were semi-infinite In helght with the boundary condition as $y \rightarrow \infty$ given by equation (17).

To carry out the calculation, th is approprlate to proceed more formally. Let the pressure in the $n^{\text {th }}$ slot be made non-dimens lonal as follows:

$$
\begin{aligned}
& p=\frac{3}{2} \frac{\mu}{d_{n}^{3}} \frac{Q_{n}}{\sqrt{f\left(\omega_{n}\right)}} \tilde{p}(\tilde{x}, \tilde{y}) \\
& \tilde{x}=x / l_{n} ; \tilde{y}=y / l_{n} \sqrt{f\left(\omega_{n}\right)}
\end{aligned}
$$

Then the boundary value problem can be stated in the form:

$$
\begin{aligned}
& \frac{\partial^{2 \tilde{p}}}{\partial \tilde{x}^{2}}+\frac{\partial^{2 \tilde{p}}}{\partial \tilde{y}^{2}}=0 \\
& \frac{\partial \tilde{p}}{\partial \tilde{x}}(1 / 2, \tilde{y})=0 \\
& \frac{\partial \tilde{p}}{\partial \tilde{y}}(\tilde{x}, 0)=0 \\
& L i m \tilde{p}(\tilde{x}, \tilde{y})=\tilde{y} \\
& \tilde{y} \rightarrow \infty \\
& \tilde{p}(-1 / 2, \tilde{y})=\tilde{p} v(n, \tilde{y})
\end{aligned}
$$


Since the dimensionless end vold pressure $\tilde{p}_{v}(n, \tilde{y})$ is unknown at this point; il Is desirable to seek the solution in a form which displays the driendence on $\tilde{\mathrm{p}}_{\mathrm{v}}(\mathrm{n}, \tilde{\mathrm{y}})$ explicity. This can be done with the ald of a Greens function $G\left(\tilde{x}, x_{0}, \tilde{y}, y_{0}\right)$, defined as the solution of the problem:

$$
\begin{aligned}
& \frac{\partial^{2} G}{\partial \tilde{x}^{2}}+\frac{\partial^{2} G}{\partial \tilde{y}^{2}}=\delta\left(\tilde{x}-x_{0}\right) \delta\left(\tilde{y}-y_{0}\right) \\
& \frac{\partial G}{\partial \tilde{x}}(1 / 2, \tilde{y})=\frac{\partial G}{\partial \tilde{y}}(\tilde{x}, 0)=0 \\
& \begin{aligned}
G(-1 / 2, \tilde{y})= & \operatorname{Lim} G(\tilde{x}, \tilde{y})=0 \\
& \tilde{y} \rightarrow \infty
\end{aligned}
\end{aligned}
$$

The quantity $\delta$ in equation (22) denotes the Dirac delta function. Introduce $\mathrm{p}$ and $G$ as defined by equations (21) and (22) into the divergence theorem in the form:

$$
\oint(\tilde{p} \Delta G-G \Delta \tilde{p}) d x_{0} d y_{0}=\oint\left(\tilde{p} \frac{\partial G}{\partial n_{0}}-G \frac{\partial \tilde{p}}{\partial n_{0}}\right) d S_{0}
$$

Here $n_{0}$ denotes the outward pointing normal to the closed contour composed of the slot boundaries and a fixed large value of $\mathrm{y}_{0}$. Now letting $\mathrm{y}_{0} \rightarrow \infty$ and using equations (21) and (22), a formal solution is obtained for the slot pressure $\tilde{\mathrm{p}}(\tilde{\mathrm{x}}, \mathrm{y})$ as:

$$
\tilde{\mathrm{p}}(\tilde{\mathrm{x}}, \tilde{\mathrm{y}})=-\int_{0}^{\infty} \tilde{\mathrm{p}}_{\mathrm{v}}(\mathrm{n}, \mathrm{y}) \frac{\partial G}{\partial \mathrm{x}_{0}}\left(-1 / 2, \mathrm{y}_{\mathrm{o}} ; \tilde{x}, \tilde{y}\right) d y_{0}
$$

In order to make equation (24) useful, it is necessary to determine G and $\tilde{\mathrm{p}}_{\mathrm{v}}$. The solution for $\mathrm{G}$ is independent of $\tilde{\mathrm{p}}_{\mathrm{v}}$, and only involves the slot geometry. The solution for $\tilde{\mathrm{p}}_{\mathrm{v}}$ will be obtained in the next section. The 
Greens function $\mathrm{C}\left(\tilde{\mathrm{x}}, \tilde{\mathrm{y}}, \mathrm{x}_{0}, \mathrm{y}_{0}\right)$ can now be obtalned with the ald of a sequence of conformal mapplngs. The steps in the sequence are (see figure 5 for sketches of the mappings):

$$
\text { 1) } \begin{aligned}
\tau & =\sin (\pi \zeta) \\
\zeta & =\tilde{x}+i \tilde{y}
\end{aligned}
$$

This transforms the slot into a half space with the open end of the bottom at $\tau=-1$ (f L gure $5 b)$.

$$
\text { i i) } \tau_{1}=\tau+1
$$

This moves the open end of the bottom to the origin (figure $5 c$ ).

$$
\text { ili }) W=\xi+i n=\left(\tau_{1}\right)^{1 / 2}
$$

This converts the slot into a quarter plane with the open end on the positive imaginary axis (figure 5d). Thus:

$$
\begin{aligned}
& W=\xi+\text { in }=1+\sin (\pi \zeta)^{1 / 2} \\
& \xi=\left\{\left(a+\sqrt{a^{2}+b^{2}}\right) / 2\right\}^{1 / 2} \\
& n=\left\{\left(\sqrt{a^{2}+b^{2}}-a\right) / 2\right\}^{1 / 2} \\
& a=1+\sin (\pi \tilde{x}) \cosh (\pi \tilde{y}) \\
& b=\cos (\pi \tilde{x}) \sinh (\pi \tilde{y})
\end{aligned}
$$


The Greens function can be written down immediately in the $W$ plane. A solution is required with a logarithmic singularity at a point $\tilde{x}=x_{0}, \tilde{y}=y_{0}$ which vanishes for $\xi=0$ and whose normal derivative vanishes for $n=0$. The solution must be odd in $\xi$ and even in $n$. The result is readily obtained in complex form as:

$$
\begin{aligned}
& G+i J=\frac{1}{2 \pi}\left\{\log \left(W-W_{0}\right)+\log \left(W-\bar{W}_{0}\right)-\log \left(W+\bar{W}_{0}\right)-\log \left(W+W_{0}\right)\right\} \\
& W_{0} \equiv W\left(x_{0}, y_{0}\right)=\xi\left(x_{0}, y_{0}\right)+\ln \left(x_{0}, y_{0}\right) \\
& \bar{W}_{0} \equiv \xi\left(x_{0}, y_{0}\right)-\ln \left(x_{0}, y_{0}\right)
\end{aligned}
$$

Equations (24) and (26) constitute the solution for the pressure in the slot once the end void pressure is known. For later use, it is necessary to compute the pressure gradient along the bottom of the slot. This calculation requires considerable care, due to the nearly singular nature of the integral. The result, after considerable algebra, is:

$$
\begin{aligned}
& \frac{\partial \tilde{p}}{\partial \tilde{x}}(x, 0)=\frac{\cos (\pi \tilde{x})}{\sqrt{1+\sin (\pi \tilde{x})}} K(\tilde{x}) \\
& K(\tilde{x})=\int_{0}^{\infty} \frac{d \tilde{p}_{v}}{d y_{0}}\left(y_{0}\right) \frac{\left\{\cosh \left(\pi y_{0}\right)-1\right\}^{1 / 2} d y_{0}}{\sin (\pi \tilde{x})+\cosh \left(\pi y_{0}\right)}
\end{aligned}
$$




\section{THE FIND VOID PRESSURE}

The final stage In the determination of the large scale motion is the calculation of the end vold pressure distribution. In order to proceed, it is necessary to assume that the end void can be treated in the same manner as the slots between container stacks, even though in many applicatlons the relevant vold width $d_{v}$ and length $\ell_{v}$ are such that the ratios $d_{v} / \ell_{v}$ and $d_{v} / h$ are not small. If these parameters are assumed to be sma11, then equation (12) applies, with $\mathrm{x}$ now measuring horizontal distance along the end void. The major difference between the slots and the end vold 1 les in the appearance of non-trivial sources and sinks $Q^{\prime \prime}(x, y)$ in the end vold.

The slots between container stacks are narrow compared with the length or height of the end vold. Hence, the fluid issulng from them can be represented as line sources of fluid in the form:

$$
Q_{s 10 t}^{\prime \prime}(n)=Q_{n} \delta\left(x-x_{n}\right) q_{n}(y)
$$

Here $Q_{n}$ is the total flux issuing from the $n^{\text {th }}$ slot, as given by equation (19), $\delta$ is again the Dirac delta function operating at the horizontal location of the $n^{\text {th }}$ slot, and $q_{n}(y)$ determines the distribution of flow with respect to height. The distribution function $q_{n}(y)$ is normalized so that:

$$
\int_{0}^{\infty} q_{n}(y) d y=1
$$


The air extraction system is assumed to have physical dimensions which are small compared with the dimensions of the end void. Hence, it can be represented as a delta function sink of strength $Q$, since $i t$ exhausts all the air drawn into the hold. The geometry is sketched in figure (6).

The pressure in the end vold is then determined by the solution to the following system of equations:

$$
\begin{aligned}
& \frac{\partial^{2} p}{\partial x^{2}}+f\left(\omega_{v}\right) \frac{\partial^{2} p}{\partial y^{2}}=\frac{-3}{2} \frac{\mu}{d_{v}^{3}} Q^{\prime \prime}(x, y) \\
& Q^{\prime \prime}(x, y)=\sum_{n=1}^{N} Q_{n} \delta\left(x-x_{n}\right) q_{n}(y)-Q \delta\left(x-x_{v}\right) \delta\left(y-y_{v}\right) \\
& \frac{\partial p}{\partial x}\left(\frac{\ell v}{2}, y\right)=\frac{\partial p}{\partial x}\left(\frac{-\ell v}{2}, y\right)=0 \\
& \frac{\partial p}{\partial y}(x, 0)=0 \\
& \text { Lim } p(x, y)=\frac{3}{2} \mu Q_{o} y / d_{v}^{3} v^{\ell} f\left(\omega_{v}\right) \\
& y \rightarrow \infty
\end{aligned}
$$

Here $\left(x_{v}, y_{v}\right)$ is the location of the air extractor, and $Q_{0}$ is the flow which originates in the end vold, as determined by equation (19) with the void geometric parameters.

The solution procedure is similar to that employed in the previous section. The equations are made non-dimensional in the form: 


$$
\begin{aligned}
& p=\frac{3}{2} \frac{\mu}{d_{v}^{3}} \frac{Q_{0}}{\sqrt{f\left(\omega_{v}\right)}} \tilde{p}(\tilde{x}, \tilde{y}) \\
& \tilde{x}=x / \ell_{v} ; \tilde{y}=y / l_{v} \sqrt{f\left(\omega_{v}\right)} \\
& \frac{\partial^{2 \tilde{p}}}{\partial \tilde{x}^{2}}+\frac{\partial^{2} \tilde{p}}{\partial \tilde{y}^{2}}=-\sum_{n=1}^{N} \frac{Q_{n}}{Q_{0}} \delta\left(\tilde{x}-\tilde{x}_{n}\right) q_{n}(\tilde{y}) \\
& \quad+\left(1+\sum_{n=1}^{N} \frac{Q_{n}}{Q_{0}}\right) \delta\left(\tilde{x}-\tilde{x}_{v}\right) \delta\left(\tilde{y}-\tilde{y}_{v}\right) \\
& \frac{\partial p}{\partial \tilde{x}}\left( \pm \frac{1}{2}, \tilde{y}\right)=\frac{\partial p}{\partial \tilde{y}}(\tilde{x}, 0)=0 \\
& L i m \tilde{p}(\tilde{x}, \tilde{y})=\tilde{y} \\
& \tilde{y}+\infty
\end{aligned}
$$

A Greens function is again introduced, this time solving the following system of equations:

$$
\begin{aligned}
& \frac{\partial^{2} G}{\partial \tilde{x}^{2}}+\frac{\partial^{2} G}{\partial \tilde{y}^{2}}=\delta\left(\tilde{x}-\tilde{x}_{0}\right) \delta\left(\tilde{y}-\tilde{y}_{0}\right) \\
& \frac{\partial G}{\partial \tilde{x}}\left(\tilde{x}= \pm \frac{1}{2}, \tilde{y}, \tilde{x}_{0}, \tilde{y}_{0}\right)=0 \\
& \frac{\partial G}{\partial \tilde{y}}\left(\tilde{x}, 0, \tilde{x}_{0}, \tilde{y}_{0}\right)=0 \\
& \operatorname{Lim} C\left(\tilde{x}, \tilde{y}, \tilde{x}_{0}, \tilde{y}_{0}\right)=y \\
& \tilde{y} \rightarrow \infty
\end{aligned}
$$

Substitution of equations (30) and (31) into equation (23) then yields the result: 


$$
\begin{aligned}
& \cdot \tilde{p}(\tilde{x}, \tilde{y})=\left(1+\sum_{n=1}^{N} \frac{Q_{n}}{Q_{0}}\right) G\left(\tilde{x}, \tilde{y}, \tilde{x}_{v}, \tilde{y}_{v}\right) \\
& -\sum_{n=1}^{N} \frac{Q_{n}}{Q_{0}} \int_{0}^{\infty} q_{n}\left(\tilde{y}_{0}\right) G\left(\tilde{x}, \tilde{y}, \tilde{x}_{n}, \tilde{y}_{0}\right) d \tilde{y}_{0}
\end{aligned}
$$

The solution is completed by spectfying $G$ and $q_{n}$. The Green's function is determined by noting that the first of the transformations employed in the previous section maps the end void Into a half plane. The solution for $G$ is then readily obtained as:

$$
\begin{aligned}
& G+1 J=\frac{1}{2 \pi}\left\{\log \left(\tau-\tau_{0}\right)+\log \left(\tau-\bar{\tau}_{0}\right)\right\} \\
& \tau=\sin (\pi \zeta)=\sin (\pi \tilde{x}) \cosh (\pi \tilde{y})+1 \cos (\pi \tilde{x}) \sinh (\pi \tilde{y}) \\
& \tau_{0}=\sin \left(\pi \tilde{x}_{0}\right) \cosh \left(\pi \tilde{y}_{0}\right)+1 \cos \left(\pi \tilde{x}_{0}\right) \sinh \left(\pi \tilde{y}_{0}\right) \\
& \bar{\tau}_{0}=\sin \left(\pi \tilde{x}_{0}\right) \cosh \left(\pi \tilde{y}_{0}\right)-1 \cos \left(\pi \tilde{x}_{0}\right) \sinh \left(\pi \tilde{y}_{0}\right)
\end{aligned}
$$

The flow distribution functions, $q_{n}$, are in reality not arbitrary, but must be determined by the condition that the pressures as computed from equations (32) and (33) lead to the same flows when the solutions given by these equations are substituted into equation (24) and equation (24) is differentlated to obtain the flow out of each slot. In general, this leads to a system of $\mathrm{N}$ integral equations for the vold pressure at each slot. The solution can be approximated with reasonable accuracy, (i.e enough accuracy to evaluate equation (27)) by noting several points. First, the fact that the total flow issuing from each slot is known implies the constraint given by equation (30) on $q_{n}(y)$. Second, the flow should be greatest at height 
$\tilde{y}=\tilde{y}_{v}$, since that is the level at which the air is drawn out. Third, the flow should ult lmately decay exponentlally with distance away from its maximum, since the integral equations have the Greens functlons for kernels, and the Greens functions all exhlbit this type of decay. Finally, examination of equations (27) and (32) shows that the pressure cannot be sensltive to details of the shape of $q_{n}(\tilde{y})$. Hence, in the spirit of Carrier [11], the following form for $q_{n}(\tilde{y})$ is postulated:

$$
q_{n}(\tilde{y})=\frac{\pi}{\left[2-e^{\left.-\pi \tilde{y}_{v}\right]}\right.} \exp \left\{-\pi\left|\tilde{y}_{-\tilde{y}_{v}}\right|\right\}
$$

Equation (34) is consistent with all the points mentioned above. It also permits the integral in equation (32) to be evaluated in closed form. The result, after some extremely tedlous algebra is:

$$
\begin{aligned}
& \tilde{p}(\tilde{x}, \tilde{y})=\left(1+\sum_{n=1}^{N} \frac{Q_{n}}{Q_{0}}\right) G\left(\tilde{x}, \tilde{y} ; \tilde{x}_{v}, \tilde{y}_{v}\right) \\
& +\sum_{n=1}^{N} \frac{Q_{n}}{Q_{0}} \frac{1}{2 \pi\left(2-e^{\left.-\pi \tilde{y}_{v}\right)}\right.}\left\{\sum_{j=1}^{4} L\left(t_{j}\right)\right. \\
& \left.-\left(\frac{2-e^{-\pi \tilde{y}_{v}}}{2}\right) \log \left[\left(1-a_{j}\right)^{2}+b_{j}^{2}\right]\right\} \\
& L\left(t_{j}\right)=1+e^{\pi \tilde{y}_{v}}\left\{\frac{a_{j}}{2} \log \left[\frac{e^{-\pi \tilde{y}_{v}-a_{j}^{2}+b_{j}^{2}}}{a_{j}^{2}+b_{j}^{2}}\right]\right. \\
& \left.+\left|b_{j}\right|\left[\arctan \left(\frac{a_{j}-e^{-\pi \tilde{y}_{v}}}{\left|b_{j}\right|}\right)-\arctan \left(\frac{a_{j}}{\left|b_{j}\right|}\right)\right]\right\}
\end{aligned}
$$




$$
\begin{aligned}
& +\log \left[\frac{\left(1-a_{j}\right)^{2}+b_{j}^{2}}{\left(e^{-\pi \tilde{y}_{v}}-a_{j}\right)^{2}+b_{j}^{2}}\right] \\
& -\frac{1}{2} a_{j} \frac{e^{-\pi \tilde{y}_{v}}}{\left(a_{j}^{2}+b_{j}^{2}\right)} \log \left[\frac{\left(1-a_{j}\right)^{2}+b_{j}^{2}}{\left(1-a_{j} e^{\left.\pi \tilde{y}_{v}\right)^{2}}+\left(b_{j} e^{\pi \tilde{y}_{v}}\right)^{2}\right.}\right]
\end{aligned}
$$

$$
-\frac{e^{-\pi \tilde{y}_{v}}\left|b_{j}\right|}{\left(a_{j}^{2}+b_{j}^{2}\right)}\left\{\arctan \left(\frac{a_{j}-e^{-\pi \tilde{y}_{v}}}{\left|b_{j}\right|}\right)-\arctan \left(\frac{a_{j}-1}{\left|b_{j}\right|}\right)\right\}
$$

$$
\begin{aligned}
& a_{1}=-e^{\pi \tilde{y}} \cos \left[\pi\left(\tilde{x}+\tilde{x}_{n}\right)\right] \\
& b_{1}=e^{\pi \tilde{y}} \sin \left[\pi\left(\tilde{x}+x_{n}\right)\right] \\
& a_{2}=e^{-\pi \tilde{y}} \cos \left[\pi\left(\tilde{x}-\tilde{x}_{n}\right)\right] \\
& b_{2}=e^{-\pi \tilde{y}} \sin \left[\pi\left(\tilde{x}-\tilde{x}_{n}\right)\right] \\
& a_{3}=-e^{-\pi \tilde{y}} \cos \left[\pi\left(\tilde{x}+\tilde{x}_{n}\right)\right] \\
& b_{3}=e^{-\pi \tilde{y}} \sin \left[\pi\left(\tilde{x}+\tilde{x}_{n}\right)\right] \\
& a_{4}=e^{\pi \tilde{y}} \cos \left[\pi\left(\tilde{x}-\tilde{x}_{n}\right)\right] \\
& b_{4}=e^{\pi \tilde{y}} \sin \left[\pi\left(\tilde{x}-\tilde{x}_{n}\right)\right]
\end{aligned}
$$


When the vertical distance above the hold bottom becomes comparable to the slot width, the flow pattern departs from that calculated in previous sections. While the length $\ell$ of the slot is still long compared with the half-width $d$, the vertical scale is now of order $d$ since the downward flow must terminate at the bottom. The boundary layers at the sides of each slot, which carry the ventllation alr downward, must sp111 out into the bottom across the full width of the slot. The horizontal motion must also adjust so that it can come to rest at the bottom.

To proceed, we consider the dimensional dependent varlables introduced in equation (2). Substituting these into the linearized form of equation (1) (recall that $\operatorname{Re} \sim 0(1)$ ), the equations of motion become:

$$
\begin{aligned}
& \frac{\partial u}{\partial x}+\frac{\partial v}{\partial y}+\frac{\partial w}{\partial z}=0 \\
& \frac{\partial p}{\partial x}=\mu \Delta u \\
& \frac{\partial p}{\partial y}-\frac{\rho g}{T_{0}} \theta=\mu \Delta v \\
& \frac{\partial p}{\partial z}=\mu \Delta w \\
& \frac{T_{1}-T_{0}}{h} v=\frac{\mu}{\rho P r} \Delta \Theta
\end{aligned}
$$


The geometry is shown schematically in figure (7). Equation (36) is to be solved subject to the following boundary conditions:

$$
\begin{aligned}
& u(x, y, \pm d)=u(x, 0, z)=0 \\
& v(x, y, \pm d)=v(x, 0, z)=0 \\
& w(x, y, \pm d)=w(x, 0, z)=0 \\
& \theta(x, y, \pm d)=\theta(x, 0, z)=0
\end{aligned}
$$

Finally, for $y \gg d$, the solutions for $u, v, w$, and $\theta$ must merge smoothly with those obtained in sectlons 2-5. This statement will be made in a more quantitative fashion below.

The solution procedure is based on explicitly recognizing the differences between the four relevant length scales in the problem. These scales are, in decreasing order of magnitude:

1.) The slot length \&

2.) The scale height for large scale motion $(\ell \sqrt{f(\omega)})$

3.) The slot half width $d$

4.) The slot wall boundary layer thickness $(d / \omega)$

The slot bottom region is now divided into two wall boundary layers and an interior region. In the interior region the dependent variables are expanded in an ascending series in the parameter $(d / \ell)$ of the form: 


$$
\begin{aligned}
& p=\frac{3}{2} \frac{\mu Q_{0}}{d^{3} \sqrt{f(\omega)}}\left\{\tilde{p}(\tilde{x}, 0)+\left(\frac{d}{\ell}\right)^{2} p^{*}(\tilde{x}, Y, Z)+\ldots .\right\} \\
& u=\frac{3}{2} \frac{Q_{0}}{\ell d \sqrt{f(\omega)}}\{u *(\tilde{x}, Y, Z)+\ldots .\} \\
& v=\frac{3}{2} \frac{Q_{0}}{\ell d \sqrt{f(\omega)}}\left(\frac{d}{\ell}\right) \quad\{v *(\tilde{x}, Y, Z)+\ldots .\} \\
& w=\frac{3}{2} \frac{Q_{0}}{\ell d \sqrt{f(\omega)}}\left(\frac{d}{\ell}\right) \quad\{w *(\tilde{x}, Y, Z)+\ldots .\} \\
& \theta=\frac{T_{0}}{\rho g d} \frac{3}{2} \frac{\mu Q_{0}}{d^{3} \sqrt{f(\omega)}}\left(\frac{d}{\ell}\right)^{2}\{\theta *(\tilde{x}, Y, Z)+\ldots .\} \\
& \tilde{x}=x / \ell ; Y=y / d ; Z=z / d
\end{aligned}
$$

Note that in equation $(38) ; \tilde{\mathrm{p}}(\tilde{\mathrm{x}}, 0)$ is the pressure obtained from the calculation of the large scale motion in section 4 . The veloctty components and temperature are scaled to ensure consistency with the large scale motion and with each other. Substitution of equation (38) into equation (36) and lgnoring terms of order $(d / \ell)^{2}$ ylelds:

$$
\begin{aligned}
& \frac{\partial u^{*}}{\partial \tilde{x}}+\frac{\partial v^{*}}{\partial Y}+\frac{\partial w^{*}}{\partial Z}=0 \\
& \frac{\partial \tilde{p}}{\partial \tilde{x}}(\tilde{x}, 0)=\frac{\partial^{2} u^{*}}{\partial Y^{2}}+\frac{\partial^{2} u^{*}}{\partial Z^{2}} \\
& \frac{\partial p^{*}}{\partial Y}-\theta *=\frac{\partial^{2} u^{*}}{\partial Y^{2}}+\frac{\partial^{2} w^{*}}{\partial Z^{2}}
\end{aligned}
$$


Since the driving force in equation $(39), \frac{\partial \tilde{p}}{\partial \tilde{x}}(\tilde{x}, 0)$ is known, the velocity component in the direction of the slot, $u^{*}$, can be obtained separately from the other vartables, as the solution of (recall the second of equation ( 8$)$ ):

$$
\begin{aligned}
& \frac{\partial^{2} u^{*}}{\partial Y^{2}}+\frac{\partial^{2} u^{*}}{\partial z^{2}}=\frac{\partial \tilde{p}}{\partial \tilde{x}}(\tilde{x}, 0) \\
& u^{*}(\tilde{x}, 0, Z)=u^{*}(\tilde{x}, Y,-1)=u^{*}(\tilde{x}, Y,+1)=0 \\
& \operatorname{LIm}_{y \rightarrow \infty} u^{*}(\tilde{x}, Y, Z)-\frac{1}{2} \frac{\partial \tilde{p}}{\partial \tilde{x}}(\tilde{x}, 0)\left(1-z^{2}\right)
\end{aligned}
$$

To proceed, $u^{*}$ is written as the sum of the large scale motion near the bottom plus a correction.

$$
\begin{aligned}
& u^{*}=-\frac{1}{2} \frac{\partial \tilde{p}}{\partial \tilde{x}}(\tilde{x}, 0)\left(1-Z^{2}\right)+\bar{u} \\
& \frac{\partial^{2} \bar{u}}{\partial Y^{2}}+\frac{\partial^{2} \bar{u}}{\partial Z^{2}}=0 \\
& \bar{u}(\tilde{x}, Y,-1)=\bar{u}(\tilde{x}, Y,+1)=0 \\
& \bar{u}(\tilde{x}, 0, Z)=\frac{1}{2} \frac{\partial \tilde{p}}{\partial \tilde{x}}(\tilde{x}, 0)\left(1-Z^{2}\right) \\
& \text { Lim } \bar{u}=0 \\
& Y \rightarrow \infty
\end{aligned}
$$

The correction $\bar{u}$ can be expressed in terms of a Green's function $G\left(Y, Z ; Y_{0}, Z_{0}\right)$ in a manner analogous to that described in prevtous sections. The result of the calculation is: 


$$
\begin{aligned}
& \bar{u}(\tilde{x}, Y, Z)=-\frac{1}{2} \frac{\partial \tilde{p}}{\partial \tilde{x}}(\tilde{x}, 0) \int_{-1}^{1} d Z_{0}\left(1-Z_{0}^{2}\right) \frac{\partial G}{\partial Y_{0}}\left(Y, Z ; 0, Z_{0}\right) \\
& G+1 J=\frac{1}{2 \pi}\left\{\log \left(\phi-\phi_{0}\right)-\log \left(\phi-\bar{\phi}_{0}\right)\right\} \\
& \phi=\sin (\pi \lambda) ; \lambda=Z+1 Y \\
& \phi_{0}=\sin \left(\pi \lambda_{0}\right) ; \lambda_{0}=Z_{0}+1 Y_{0} \\
& \bar{\phi}_{0}=\sin \left(\pi \bar{\lambda}_{0}\right) ; \bar{\lambda}_{0}=Z_{0}-1 Y_{0}
\end{aligned}
$$

The final expression for $u^{*}$ can be rewritten in a more convenient form for computation by employing the Cauchy-Riemann equations to eliminate $\frac{\partial G}{\partial Y_{0}}$. The result is:

$$
\begin{aligned}
& u *(\tilde{x}, Y, Z)=-\frac{\partial \tilde{p}}{\partial \tilde{x}}(\tilde{x}, 0)\left\{\frac{1}{2}\left(1-Z^{2}\right)-\int_{-1}^{1} d Z_{0} Z_{0} J\left(Y, Z ; 0, Z_{0}\right)\right\} \\
& J=\frac{1}{\pi} \arctan \left\{\frac{I(Z, Y)}{R(Z, Y)-R(Z, O)}\right\} \\
& \text { if } \mathrm{R}(\mathrm{Z}, \mathrm{Y})>\mathrm{R}\left(\mathrm{Z}_{0}, 0\right) \text {; } \\
& J=\frac{1}{\pi}\left\{\pi-\arctan \left[\frac{I(Z, Y)}{R\left(Z_{0}, 0\right)-R(Z, Y)}\right]\right\} \\
& \text { if } R\left(Z_{0}, 0\right)>R(Z, Y) \text {. }
\end{aligned}
$$

The quantities $I$ and $R$ are given by: 


$$
\begin{aligned}
& R(Z, Y)=\sin \left(\frac{\pi}{2} Z\right) \cosh \left(\frac{\pi}{2} Y\right) \\
& I(Z, Y)=\cos \left(\frac{\pi}{2} Z\right) \sinh \left(\frac{\pi}{2} Y\right)
\end{aligned}
$$

Note that $u^{*}$ as given by equations (43) and (44) has the form:

$$
u^{*}=-\frac{\partial \tilde{p}}{\partial \tilde{x}}(\tilde{x}, 0) U(Y, Z)
$$

Thus, the velocity profile at each axial station $\tilde{x}=$ constant has the same "untversal profile" $U(Y, Z)$. This profile is displayed In figure (8). The $\tilde{\mathbf{x}}$ dependence can be factored out of all the variables in equation (39); the resulting decomposition being given by:

$$
\begin{aligned}
& v^{*}=\frac{\partial^{2 \tilde{p}}}{\partial \tilde{x}^{2}}(\tilde{x}, 0) \quad v(Y, Z) \\
& w^{*}=\frac{\partial^{2 \tilde{p}}}{\partial \tilde{x}^{2}}(\tilde{x}, 0) \quad W(Y, Z) \\
& \theta^{*}=\frac{\partial^{2 \tilde{p}}}{\partial \tilde{x}}(\tilde{x}, 0) \quad \theta(Y, Z) \\
& p^{*}=\frac{\partial^{2 \tilde{p}}}{\partial \tilde{x}}(\tilde{x}, 0) P(Y, Z)
\end{aligned}
$$

The proflle functions $V, W, \Theta$, and $P$ satisfy: 


$$
\begin{aligned}
& \frac{\partial V}{\partial Y}+\frac{\partial W}{\partial Z}=U \\
& \frac{\partial P}{\partial Z}=\frac{\partial^{2} W}{\partial Y^{2}}+\frac{\partial^{2} W}{\partial Z^{2}} \\
& \frac{\partial P}{\partial Y}-\Theta=\frac{\partial^{2} V}{\partial Y^{2}}+\frac{\partial^{2} V}{\partial Z^{2}} \\
& \left(\omega^{4}\right) V=\frac{\partial^{2} \Theta}{\partial Y^{2}}+\frac{\partial^{2} \Theta}{\partial Z^{2}}
\end{aligned}
$$

In order to proceed further, it is necessary to consider the dependence of the solutions on $w$. In particular, the structure of the wall boundary layers (of thickness $(\omega)^{-1}$ on the slot half-width scale) must be determined (see figure 7). The boundary layer structure can be found from equation (47) without loss of generality; since the $\tilde{x}$ dependence factors out in the form glven by equation (47) everywhere in the slot bottom. Symmetry considerations then permit attention to be confined to the wall layer near $Z=-1$, the layer near $\mathrm{Z}=+1$ being identical. In this region:

$$
\begin{aligned}
& V=\omega \hat{V}(\zeta, Y) \\
& W=\hat{W}(\zeta, Y) \\
& \Theta=\omega^{3} \hat{\theta}(\zeta, Y) \\
& P=\omega^{3} \hat{P}(\zeta, Y) \\
& \zeta=\omega(Z+1)
\end{aligned}
$$


Substitution of expressions (48) into equation (47) and keeping the leading order terms in $\omega$ leads to the wall boundary layer equations in the form:

$$
\begin{aligned}
& \frac{\partial \hat{V}}{\partial Y}+\frac{\partial \hat{W}}{\partial \zeta}=0 \\
& \frac{\partial \hat{P}}{\partial \zeta}=0 \\
& \frac{\partial \hat{P}}{\partial Y}-\hat{\theta}=\frac{\partial^{2} \hat{V}}{\partial \zeta^{2}} \\
& \hat{V}=\frac{\partial^{2} \hat{\theta}}{\partial \zeta^{2}}
\end{aligned}
$$

At the wall, $\zeta=0$, the velocity components and the temperature perturbation must vanish (the latter due to the assumed equilibrium between container stacks and hold stratification). As $\zeta \rightarrow \infty$ these solutions must match the expressions for $V, W, \theta$, and $P$ (which have not yet been found) In the Interior of the slot bottom region. For the present, we assume only that all quantities are bounded in the interior, as $\zeta+\infty$.

Equation (49) may be readily solved by noting that, from the second of these equations:

$$
\hat{P}=\hat{P}(Y)
$$

\footnotetext{
Although $\hat{P}(Y)$ is as yet unknown, $\hat{V}$ and $\hat{\theta}$ may then be found in terms of $\hat{P}(Y)$ as:
} 


$$
\begin{aligned}
& \hat{\theta}=\frac{\partial P}{\partial Y} \quad\{1-\exp (-\zeta / \sqrt{2}) \cos (\zeta / \sqrt{2})\} \\
& \hat{V}=-\frac{\partial P}{\partial Y} \exp (-\zeta / \sqrt{2}) \cos (\zeta / \sqrt{2})
\end{aligned}
$$

Note that as $\zeta \rightarrow \infty$ (1.e. as the interior of the bottom region $\theta$ is approached)

$$
\begin{aligned}
& \hat{\theta}+\frac{d \hat{P}}{d Y} \\
& \hat{W}+(2)^{-1 / 2} \frac{d^{2} \hat{P}}{2 Y^{2}} \\
& \hat{V}+0
\end{aligned}
$$

In order for the interior functions (the solutions to equation (47)) to have proper scaling with respect to $\omega$, they must be consistent with equation (52) as $Z \rightarrow \pm 1$. This can be achieved by rescaling as follows:

$$
\begin{aligned}
& V(Y, Z)=(\omega)^{-1} V_{I}(Y, Z) \\
& \Theta(Y, Z)=(\omega)^{3} \theta_{I}(Y, Z) \\
& P(Y, Z)=(\omega)^{2} P_{I}(Y, Z)
\end{aligned}
$$

The leading terms in the interior equations then become: 


$$
\begin{aligned}
& \frac{\partial W}{\partial Z}=U \\
& \frac{\partial P}{\partial Z}=0 \\
& \frac{\partial P I}{\partial Y}-\theta_{I}=0
\end{aligned}
$$

From the second of equation (54) and equation (50):

$$
P_{I}=\hat{P}(Y)
$$

The last of equation (54) is now consistent with the first limit in equation (52), yielding the result:

$$
\theta_{I}=\frac{\hat{d P}}{d Y}(Y)
$$

Finally, the first of equation (54) yields:

$$
W=\int_{0}^{Z} U d Z
$$

where

$$
U=\frac{1}{2}\left(1-Z^{2}\right)-\int_{-1}^{1} d Z_{0} Z_{o} J\left(Y, Z ; 0, Z_{0}\right)
$$

(see equation (43)).

The transverse profile $W$ is displayed in figure 9. Note that $U$ is symmetric in $Z$, so $W$ is anti-symmetric. The remaining unknown $\hat{P}(Y)$ is 
determined by requiring that $W( \pm 1, Y)$ be cosistent with the matching condition glven the second of equation (52). Thus:

$$
\frac{d^{2} \hat{P}}{d Y^{2}}=-\sqrt{2} \int_{0}^{1} U(Z, Y) d Z
$$

This equation can be integrated once with respect to $Y$, using the value $\frac{d \hat{P}}{d Y}(0)=0$ to ensure that the vertical velocity in the wall layer vantshes at $Y=0$ (see equation $(51))$.

The most important results of this section are equations (43) and (57), which yleld the profiles for the two principal velocity components in the bottom region. These profiles will now be used in the calculation of the vapor plckup in this reglon.

\section{THE VAPOR PICKUP}

The calculation of the vapor plckup requires a solution for the vapor concentration gradient at the bottom of the hold. In order to proceed, it is necessary to recall the spill scenario postulated in section 2 . It is now further assumed that the bulk of the pickup takes place along the bottom, but outside the wall boundary layers. The concentration $c(x, y, z)$ then obeys the equat Lon:

$$
u \frac{\partial C}{\partial X}+w \frac{\partial C}{\partial z}=D \Delta C
$$

Here $D$ is the diffusivity of the spill vapor in air, $\Delta$ is again the Laplacian operator; and $u$ and $w$ are the veloclty components determined in the previous 
section. At $y=0$, the concentration is assumed to be $C_{0}$, the equilibrium vapor pressure at the temperature corresponding to the hold bottom. Outside the layer, there is no vapor; $C=0$.

We now non-dimensionalize the velocitles and coordinates as in equation (38). The concentration equation (59) then takes the form:

$$
\begin{aligned}
& u * \frac{\partial C}{\partial \tilde{x}}(\tilde{x}, Y, Z)+w * \frac{\partial C}{\partial Z}(\tilde{x}, Y, Z)=\frac{1}{R_{e}^{*} S_{C}} \Delta_{2} C \\
& \Delta_{2} C \equiv \frac{\partial^{2} C}{\partial Y^{2}}+\frac{\partial^{2} C}{\partial Z^{2}} \\
& R_{e}^{*}=\frac{3 Q_{o}}{2 \ell d \sqrt{f(\omega)}}\left(\frac{d}{v}\right)\left(\frac{d}{\ell}\right) \\
& S_{C}=v / D
\end{aligned}
$$

Equation (60) must be solved subject to the boundary conditions:

$$
\begin{aligned}
& C(\tilde{x}, 0, Z)=c_{0} \\
& \operatorname{Lim}_{Y \rightarrow \infty} C(\tilde{x}, Y, Z)=0
\end{aligned}
$$

The solution procedure employed is a generalization to three dimensions of that used by Lighthill [12] In obtaining his heat transfer formula. Recall that equations (45), (46) and (57) allow $u^{*}$ and $w^{*}$ to be expressed as: 


$$
\begin{aligned}
& u^{*}=-\frac{\partial \tilde{P}}{\partial \tilde{x}}(\tilde{x}, 0) \frac{\partial W}{\partial Z}(Y, Z) \\
& w^{*}=\frac{\partial^{2} \tilde{p}}{\partial \tilde{x}^{2}}(\tilde{x}, 0) W(Y, Z)
\end{aligned}
$$

Following Lighthill, the vertical dependence of velocity proflles ls approximated by a linear function.

$$
W(Y, Z) \cong W_{0}(Z) Y, W_{0} \equiv\left(\frac{\partial W}{\partial Y}\right) Y_{Y=0}
$$

This approximation may be justified in several ways. First, when the Schmidt number $S_{c} \gg 1$, it is rigorously true that this simplification yields the asymptotic solution for the concentration profile. Lighthill has shown that In the case of heat transfer, the approximation works quite well for Prandt 1 numbers of 0.7 , corresponding to air. In the present application, $S_{c}$ is usually in the range $1.5<s_{c}<2$. For this range of Schmidt numbers, the concentration field is largely controlled by the velocity proflles near the bottom. Inspection of figures (8) and (9) shows that the velocity profiles are fairly linear in this region. Finally, it should be noted that only the wall concentration gradient is required, not the whole concentration profile. Such information can be (and of ten is) obtained using much cruder profile information than will emerge from this calculation.

It is convenient to express the velocity components in terms of a stream function $\psi(\tilde{x}, z)$ defined as:

$$
\psi(\tilde{x}, z)=-\frac{\partial \tilde{p}}{\partial \tilde{x}}(\tilde{x}, 0) w_{0}(z)
$$


The velocity components are given by:

$$
\begin{aligned}
& u^{*}=Y \frac{\partial \psi}{\partial Z} ; \\
& w^{*}=-Y \frac{\partial \psi}{\partial \tilde{x}}
\end{aligned}
$$

The vertical coordinate is now rescaled as follows:

$$
\lambda=\left(\mathrm{R}_{\mathrm{e}} \mathrm{S}_{\mathrm{c}}\right)^{1 / 3} \mathrm{Y}
$$

The concentration equation now becomes:

$$
\eta\left\{\frac{\partial \psi}{\partial z} \frac{\partial C}{\partial \tilde{x}}-\frac{\partial \psi}{\partial \tilde{x}} \frac{\partial C}{\partial z}\right\}=\frac{\partial^{2} C}{\partial \lambda^{2}}
$$

The solution of equation (67) depends cruclally on the observation that curves of constant $\psi$ represent the trace of the streamlines calculated in section 6 on the bottom. These streamlines originate in the wall layer at the side of each container stack. Let s denote distance along each streamline with the origin at the point where the streamline emerges from the wall (see figure 10). Using $s, \psi$ as independent variables in place of $\tilde{x}, z$; equation (67) becomes:

$$
\begin{aligned}
& q(s, \psi) \lambda \frac{\partial C}{\partial s}=\frac{\partial^{2} C}{\partial \lambda^{2}} \\
& q^{2}=\left(\frac{\partial \psi}{\partial z}\right)^{2}+\left(\frac{\partial \psi}{\partial \tilde{x}}\right)^{2}
\end{aligned}
$$


At $s=0$; the ventilation air has just entered the bottom region; hence $C=0$. At $\lambda=0 ; C=C_{0}$ and $C+0$ and as $\lambda \rightarrow \infty$ from equation (61). This is a relatively stralghtforward problem. To proceed, we introduce a modified streamwlse varlable $\xi$ defined as:

$$
\xi=\int_{0}^{s} \mathrm{ds} / \mathrm{q}(\mathrm{s}, \psi)
$$

then

$$
\eta \frac{\partial C}{\partial \xi}=\frac{\partial^{2} C}{\partial \lambda^{2}}
$$

Introducing laplace transforms with respect to $\xi$; equation becomes:

$$
\begin{aligned}
& \mathrm{p} \lambda \overline{\mathrm{C}}=\frac{\partial^{2} \overline{\mathrm{C}}}{\partial \lambda^{2}} \\
& \overline{\mathrm{C}}=\int_{0}^{\infty} \mathrm{e}^{-\mathrm{p} \xi} \mathrm{C}(\xi, \lambda) \mathrm{d} \xi \\
& \overline{\mathrm{C}}(\xi, 0)=\frac{\mathrm{C}_{0}}{\mathrm{p}} ; \overline{\mathrm{C}}+0 \text { as } \eta+\infty
\end{aligned}
$$

The solution for $\bar{C}$ satisfying equation (71) is readily found [13] to be:

$$
\bar{C}=\frac{C_{0}}{p} \Gamma(2 / 3)(3)^{2 / 3} \mathrm{Ai}\left((p)^{1 / 3} \lambda\right)
$$

Here Ai is the Airy function, and $\Gamma$ the Gamma function as defined in reference [13] 
Although Inversion of $\bar{C}$ to obtain the concentration profile would be a formidable undertaking, the problem becomes tractable if only the wall concentration gradients are required. The mass flux plcked up at each point by the ventilation system, $\dot{\mathrm{m}}$, is given by:

$$
\begin{aligned}
\dot{\mathrm{m}} & =-D \frac{\partial C}{\partial y} \\
& =-\frac{D}{d}\left(R_{e}^{*} S_{c}\right)^{1 / 3} \frac{\partial C}{\partial \lambda}
\end{aligned}
$$

From equation (72), the laplace transform in is readily computed as:

$$
\overline{\mathrm{m}}=\frac{\mathrm{D}}{\mathrm{P}}\left(\mathrm{R}_{\mathrm{e}}^{* \mathrm{~S}_{\mathrm{c}}}\right)^{1 / 3} \mathrm{C}_{\mathrm{o}}(3)^{1 / 3} \frac{\Gamma(2 / 3)}{\Gamma(1 / 3)}(\mathrm{p})^{-2 / 3}
$$

Inverting equation (74) and recalling the definition of $\xi$ from equation (69), the mass flux becomes:

$$
\begin{array}{r}
\dot{\mathrm{m}}=\frac{\mathrm{D}}{\mathrm{d}} \mathrm{c}_{0} \frac{3 \mathrm{R} \mathrm{e}_{\mathrm{c}}}{\Gamma(1 / 3)}\left\{\int_{0}^{\mathrm{S}} \mathrm{ds} / \mathrm{q}(\mathrm{s}, \psi)\right\}^{-1 / 3} \\
\Gamma(1 / 3)=2.67894 \ldots
\end{array}
$$

Equation (75) ylelds the pickup at each point in a given slot. The quantity actually desired is the total mass pickup. The total mass pickup in a slot $\dot{M}$ is given by:

$$
\begin{aligned}
\dot{M} & =\int_{-d}^{d} d z \int_{0}^{\ell} d x \dot{m} \\
& =2 d \ell \int_{0}^{1} d z \int_{0}^{1} d \tilde{x} \dot{m}(\tilde{x}, z)
\end{aligned}
$$


Now let $s$ and $n$ be coordinates along and normal to a streamline $\psi=$ constant. Then, from equations (75) and (76):

$$
\dot{M}=d D \& c_{0} \frac{\left(3 R_{e}^{*} c_{c}\right)^{1 / 3}}{\Gamma(1 / 3)} \iint \operatorname{dsdn}\left\{\int_{0}^{s} d s / q(s, \psi)\right\}^{-1 / 3}
$$

Using the fact that $d n=d \psi / q$, and $d \xi=d s / q$, it is possible to carry out the integral along streamlines to obtain:

$$
\begin{aligned}
& \dot{M}=\frac{2 D \ell C_{0}\left(3 R * e_{c}\right)^{1 / 3}}{\Gamma(1 / 3)} \int_{0}^{M} d \psi \frac{3}{2}[\xi(\psi)]^{2 / 3} \\
& \xi_{M}(\psi)=\int_{0}^{s_{M}(\psi)} \mathrm{d} s / q
\end{aligned}
$$

Here $s_{M}(\psi)$ denotes integration over the entire distance along each streamline from the point it enters the bottom until the time it exits into the end vold (see figure 10). Similarily, $\psi_{M}$ denotes the maximum value of the stream function, so that the integration covers all streamlines originating in the wall layer.

At this point it is convenlent to recapitulate the overall calculation procedure. The first step is the determination of the flow assigned to each slot and to the end vold. This is given by equation (19), which ylelds the total flow in each slot, $Q_{n}$, as a function of the total flow drawn through the hold, the hold geometry, and the degree of stratification. The next step is the computation of the pressure gradlent along the bottom of each slot 
containing spill material. This pressure gradlent controls the development of the spill material boundary layer, and hence the rate at which spill material is picked up by the ventilation system. The necessary result is given in equation (27). Note that this formula, In turn, requires a knowledge of the vartation of the void pressure $\tilde{p}_{v}$ with height at the open end of each slot in question. The void pressure at any point is given by equation (35), which requires only the information already obtained from equation (19). With the pressure gradient along the slot bottom now determined, the velocity distribution near the slot bottom are given by equations (43-46) and (57). These results are then used to get approximate simplified formulae, equations (63) and (64), which are actually used in the calculation of the rate of plckup of spill material. These latter formulae express the velocities near the bottom of each slot in terms of a "bottom stream function" $\psi$. Given the quantity $\psi$, the magnitude of the velocity gradient at each slot bottom, $q$, can be determined from equation (68). Finally, given $q$ and $\psi$, equation (77) yields the total mass pickup in each slot $\dot{M}$. These results, summed over all the slots containing spill material, yield the total mass per unit time extracted from the hold by the ventilation system. The computer program which executes these calculations is of necessity quite elaborate. The following sections describe the overall program layout, the princlpal subroutines, sample results and a complete listing. 


\section{NUMERICAL PROGRAMS}

Two main programs were written. The larger one carries out the numerical calculations of the contalnership hold ventllation model; whlle the other plots selected pressures and streamlines. Although the plot progran uses CALCOMP emulation subroutines, the program is sufficiently speciallzed to our computer that 1 t would have 1 imited interest. It will not be described.

\subsection{Main Numerical Program}

The main numerical program controls the entire calculation, i.e., all subroutines are called from the main program. There are eleven of these. In addition, there are two external function routines. These are called from subroutines. A simple block dlagram of the program is shown In figure 11.

The first two subroutines, INTEG1 and INTEG2, carry out numerical Integrations related to the flow at the bottom of a slot. In the dimensionless variables used, these are geometry independent. PRINT then tabulates the geometry independent dimenstonless slot bottom quantities. Since they do not depend on input data they are carried out once and the results saved for use in all variable geometrles to be calculated.

The program is arranged to calculate multiple geometric or thermal cases. The number of these is read (NGEOMS) and a loop entered between CALL INPUT and the end of the main program. INPUT reads, from the input file or device, logical unit 5, the geometric and temperature values to be used. At this point the main program performs two scaling operations, one for the main 
transverse space (which will be referred to as the "main vold" or simply the "void") and the second for the gaps extending fore and aft between stacks of containers (referred to as "intercontainer slots" or simply "slots"). These operations correspond to the quantities $\omega$ and $f(\omega)$, defined in equations (6) and (10). The void and the intercontainer slot volumes are assumed to be the only unoccupied space in the hold. For ships with wing tanks, the maln void is the volume on the framed side of the transverse bulkhead between the bulkhead and the contalner stacks. Where there are no wing tanks, the main void is increased in length to account for the volumes between the outermost container stack and the side of the ship. The scaled lengths of the void and slots are then compared to their respective widths to see if the assumptions of the model are satisfied, namely that the scaled widths are less than their lengths. Actually, the widths should be much less than the lengths. If either of these scaled lengths is less than the respective widths, program execution stops with an appropriate message.

The air issuing from the slots into the main void could be a problem to the model if the flow were strong enough to have a jet-like character. In addition, if the slots were spaced close enough together, after scaling, compared to the width of the void they might interact violating another assumption of the model--that the slots are widely spaced. For some actual ship hold geometrles this condition may, in fact, be violated. However, the vold is not a simple, smooth sided space as assumed by the model but, rather, a complex of interconnected volumes formed by the framing of the bulkhead. It is further broken up by supports for the containers. The structure provides considerable surface for heat exchange and can break up and separate any jets. For practical purposes there seems no way to treat the vold correctly 
in any detall. Accordingly, it was decided to treat it as a slinple smooth space as per this model, recognizing that this was questionable. Having made this decision, the scaled slot spacing to vold width ratio is computed and printed. If this ratio is not small a warning is also printed.

If the transverse location of the suction aligns with one of the slots there will be numerical problems. Should this occur, the suction is arbitrarily moved away from the slot $1 / 2 \%$ of the vold length. This is a distance less than the resolution scale of the overall calculation. Another check looks at the location of the (single) suction to see if it is very near the tank top, $Y=0$. The calculation assumed it is not. If it is, it is arbitrarily moved up $5 \mathrm{~cm}$. Next, the slots numbers, for the slots furthest and closest to the suction, are determined for later use in plotting pressures and streamlines. It turns out that, even for very small stable stratification temperature differences, the differences in the flow in the several slots is very small, hence only selected results need be displayed to adequately show the flows.

Having completed these housekeeping detalls, the calculation proper begins. The matn calculation is a large loop, passing once around for each slot. Within the loop the slot bottom flow is calculated, SLOTl, and streamlines traced, STRMl. The mass plck-up is then obtained for the separate stream tubes by integrating along the streamlines, PICUPl. Finally, the total mass evaporated from the slot is obtained by Integration over all the streain tubes, also PICUPl. This is repeated for each slot and the total mass evaporated obtained by summing the contributlons from each slot. In tracing the streamlines, a matrix, ZPSI, glving the transverse location, $z(x)$, for 
various constant values of slot bottom strean function is formed. This is used in calculating the stream tube integrals and is unique to any given slot. Since the matrix is over-written with each pass through the loop, the ZPSI matrix for two slots--the one closest to the suction and the one furthest from 1t--are saved as a convenience for later plotting. Upon completion of this calculation for all the slots, results are printed. PRNTl tabulates the dimensionless slot velocity and stream functions. The axial velocity near the bottom of the slot, USLOT (u of equation (43)), is a function of axlal distance along the slot and differs for each slot. This is the axial velocity in the slot just above the boundary layer at the slot bottom. The slot bottom boundary layer velocity approaches USLOT asymptotically with helght. The slot bottom stream function defines the track of the air as it passes over and evaporates the spilled 1iquid assumed to be spread over the hold bottom. Stream function values are tabulated for each slot--the value of the stream function, PSI, for fixed locations along the length of the slot (rows) and fixed locations across the width of the slot (columns). Next the dimensionless mass pick-up for each slot is printed together with the corresponding dimensionless slot location.

The intent in developing this program was to be able to apply the results of the calculation to specific chemicals. Calls are made to INPUTl where vapor pressure, temperature and diffusivity data are read for the number of chemicals specified in INPUT and NCHEMS. The total mass pick-up, in dimensional form, is computed for the hold ventilation rates read by INPUT2. Note that the mass pick-up varies in an almost trivial way with ventilation rate, the $1 / 3$ rd power, so that an elght fold increase in ventilation doubles the mass pick-up. The vapor concentration in the exhaust air is also computed for 
SLOTl is a very short, simple subroutine but, through it use of the external function GRAD, which in turn employs the external function PRESS, Lnvolves a falrly complex program structure. The axial flow in a slot depends on the axlal pressure gradlent. SLOTI determines the characteristic magnltude of the velocity USLOT, which is the same as $\frac{\partial \tilde{p}}{\partial \tilde{x}}$, near, but not quite at the slot bottom, the first term on the right of equation (45). This term Ls determined by equation (27). The boundary layer-like analysis of the local flow at the very bottom of the slot detailed in INTEGI and INTEG2 is scaled to approach asymptotically the velocity USLOT as height increases away from the slot bottom.

GRAD

Subroutine GRAD carries out the integral, equation (27), which gives the pressure gradient just above the hold bottom, $\partial \tilde{\mathrm{p}} / \partial \tilde{\mathrm{x}}(\tilde{\mathrm{x}}, 0)$, for each slot (needed by subroutine SLOTI as discussed above). This integral requires the vertical pressure gradient in the end vold at the location of the slot, for each slot. This is found by a call to subroutine PRESS. There are two noteworthy aspects of this calculation:

(1) The integrand of the integral carried out in GRAD has an integrable singularity for $x=-1 / 2$ (the slot vold intersection) and $y=0$. Rather than carry out the rather messy algebra to Integrate this formally and provide a program opt ion 
subtracting the value of $U B$ at $Y=0$, which is 0 , and multiplying, the result by 20. Figure 12 shows $U B$ for $Z=0$ as a function of $Y$. It is seen to be quite smooth indicating that this approximation should be quite good. Examination of figure 8 shows that this is also true for other values of $Z$.

INTEG2

INTEG2 forms the indefinite integrals with respect to $Z$ of the quantity UB which yields $W$, equation (57) and of UBO which yields $W_{0}$ again using the trapezodial method. $W$ is shown in figure 9.

PRINT

This is a fairly straightforward tabulation.

INPUT

For each geometry, temperature difference (stratification) data is read. Then hold geometry, as reflected by the main void and slot geometries, is read. Several consistency checks are made: the number of slots must be no more than 11 (dimenston statement and format 1 lmit) and the number of $x$ values along the slot, NXSLOT, for which values will be computed must not exceed 30 (dimension statement limit). Also the spacing between slots times the number of slots must not exceed the length given for the main vold. Fallure of any of these tests results in termination of execution with an appropriate message printed. The slot-vold intersection locations are calculated placing the slots symmetrically about the centerline of the void. The suction location is then read. 
SLOTl is a very short, simple subroutine but, through it use of the external function GRAD, which in turn employs the external function PRESS, Involves a falrly complex program structure. The axial flow in a slot depends on the axlal pressure gradlent. SLOTl determines the characteristic magnitude of the veloclty USLOT, which is the same as $\frac{\partial \tilde{p}}{\partial \tilde{x}}$, near, but not quite at the slot bottom, the first term on the right of equation (45). This term is determined by equation (27). The boundary layer-like analys is of the local flow at the very bottom of the slot detalled In INTEG1 and INTEG2 is scaled to approach asymptotically the velocity USLOT as helght increases away from the slot bottom.

GRAD

Subroutlne GRAD carrles out the integral, equation (27), which gives the pressure gradient just above the hold bottom, $\partial \tilde{p} / \partial \tilde{x}(\tilde{x}, 0)$, for each slot (needed by subroutine SLOT1 as discussed above). This integral requires the vertical pressure gradient in the end vold at the location of the slot, for each slot. This is found by a call to subroutine PRESS. There are two noteworthy aspects of this calculation:

(1) The integrand of the integral carried out in GRAD has an integrable singularity for $x=-1 / 2$ (the slot void intersection) and $y=0$. Rather than carry out the rather messy algebra to Integrate this formally and provide a program opt ion 
to use the alternatlve algebra, use was made of the fact that

the result is smooth as $x=-1 / 2$ is approached. Numerical

experiments for a series of values of $x$ approaching $-1 / 2$ showed

that using $x=-0.498$ gave a result very close to the extra-

polated value without encountering numerical problems. $\mathrm{x}=$

-0.499 gave a value fairly close to the extrapolated one but was

suggestive of an approaching numerical problem, see figure 13.

(2) The integral is over an infinite range. The infinite integral

is completed by adding an analytically determined piece for

argument three to infinity to the trapezodial rule computation

from zero to three.

PRESS

The function PRESS is called from GRAD (and also from PPLOT). It computes the pressure at the intersection of the slot at transverse location $X S(N)$ with the main void using equation (35). This pressure depends on the flows from all the other slots.

The calculation involves two pairs of two terms each and, as will be discussed later, has some numerical problems since these terms involve small differences of not very small terms. These problems appear to be large enough to require the use of double precision on 32 bit computers. Figure 14 shows the result of calculating pressure in single precision. A double preciston version of PRESS produced smooth plots, compare figure 14 with 20a. Numerical values of the mass pick-up were about $4 \%$ lower when using the double prectston 
pressure rout lne as compared to single preclsion. Subrout Ines GRAD and PRESS were originally written by Dr. D. Corley of Montgomery College and NBS.

STRMI

The value of the stream function in the Nth slot at a polnt $X(I)$ axially along the slot length and $z(k)$ transverse to the slot center ilne is given by (see equation (64)):

$$
\operatorname{PSI}(I, K, N)=\operatorname{USLOT}(I, N) * W O(K)
$$

where, as already discussed, USLOT is the characteristic velocity magnitude at this axlal position in this slot as tabulated in SLOTl and wo is the indefinite $z$ integral determined in INTEG2, of UBO, the gradient of the slot bottom velocity determined in INTEGl. The task of STRMl is to produce, from values of the stream function at flxed geometric points, a table of coordinate patrs $(x, z)$ which correspond to flxed values of stream function. Thus, it is rather analogous to a contour plot routine. The routine chooses an $x$ from the equally spaced ones for which USLOT and wo are known. It determines the PSI value at this $x$ and at the slot edge, $z=1$. Since flow descends along the slot walls and flows out onto the slot bottom, streamlines originate at the slot edge. The streamline originating at this $x$ is then followed toward $x=-1 / 2$. At each fixed $x$ between the inttial one and the far end of the streamline a is determined, by Iinear Interpolation between the flxed $z^{\prime}$ s for which wo is avallable, where the required stream function value is found. The result is a table of $z(x)$ for flxed PSI, ZPSI. Most streamlines terminate at $z=-1 / 2$ whth a $z$ between 0 and 1 . However, espectally for slots near the suctlon and 
suctions raised above the slot bottom, not all the flow goes directly out the end of the slot. Some of it may return to the slot side wall and flow up the wall to near the helght of the suction where it finally leaves the slot. Streamlines for this flow are shown schematically in figure 10. This flow behavior is associated with a maximum in PSI for an $x$ greater than $-1 / 2$. To Identify the location of the end of a streamline th is useful to record the $x$ location of 1 ts end, either $-1 / 2$ or the $x$ along the slot sidewall to the left of the maximum PSI where the required stream function value occurs. This is obtalned by linear interpolation and recorded in XPSI(N). The matrix of values of ZPSI is returned to the main program and passed forward to PICUPI but is not retained as successive slots are treated.

PICUP 1

The mass evaporated from the spill pool at the bottom depends on the velocity and path over the pool. The pick-up integral is given by equation (77). The limits of the Integral are set by the extent of the spill. It has been assumed that the spill covers the entire hold bottom so the limits have been made on the wall where the flow enters the slot bottom and elther the slot-void junction or the wall, if the flow returns there as described above. It would have been a simple extension of the program to input the extent of the spill pool, presumably less than the full length of the slots and different for each slot, but this seemed to offer little advantage since there is no information on the expected stze or extent of a spill. As is done throughout the program, the trapezodial algorlthm is used for the integration. Once the separate stream tube integrals have been formed the total mass pick-up for the slot is formed by integrating over the stream tubes. 
After all the slot quantlties have been calculated the results are tabulated. The values of USLOT are printed in columns for each slot with rows corresponding to axial position $\mathrm{X}$, along the slots. The columns are headed by the dimensionless slot location. The stream function is then tabulated for each slot with columns giving the transverse, $\mathrm{Z}$, location and rows the axlal posttlon, $X$. In this case, slot location is given in dimensional unlts. This is followed by a short table pairing the dimensionless slot locat lon with the total, dimensionless pick-up for that slot.

INPUT1

In INPUT the counter NCHEMS was set. The main program now loops through INPUTl reading chemical data for as many materials as requested by NCHEMS. The chemical data entered is the mass diffusivity and partial pressure data using the "Antoine Formula" [14]. The data is then corrected for the case temperature to give the saturation concentration and corrected diffuslvity. For each chemical, several flows can be used. The effect of flow is very simple but this feature was included as a convenience. The number of flows to be considered for each chemical is read, NFLOWS.

INPUT2

This simply reads the flow and returns. It is called as many times as requested by NFLOWS. 
PPLOT

The pressure at the slut-void intersection for the same pair of slots for which streamline data was saved in STRMl is nuw calculated using the external function PRESS. This is dune separately rather than saving values cumputed during the slot calculation to provide some additional flexibility in the range of values computed. The cust in cumputing time is nut great.

\subsection{Input Data}

A sample input data file is given in appendix 1. The example is for a single case with a $\Delta \mathrm{T}$ of $0.1^{\circ} \mathrm{C}$. The length of the main vuid (in this case the width of the hold plus twice the container length to simulate a ship without wing tanks) is $51 \mathrm{~m}$, its width (fore and aft dimension is $0.8 \mathrm{~m}$ and its height $20 \mathrm{~m}$. The intercuntainer slots are $12 \mathrm{~m}$ long (fore and aft), $0.1 \mathrm{~m}$ wide spaced $2.46 \mathrm{~m}$ along the length of the main void. Since the sluts are the same height as the main void their height need not be input. Twenty points are calculated alung the length of the sluts and there are 11 slots. The suction is placed at and a numinal height $=0.6 \mathrm{~m}$ and transverse location relative to the center line of the main void of 0.0 . The huld empty volume is $2407 \mathrm{~m}^{3}$ and the vold volume is $1920 \mathrm{~m}^{3}$. One chemical is cunsidered. The captiun is fur this chemical; the caption is limited to one line of 80 characters, maximum. Chemical data entered is: 
Mass diffusivity of spill vapor at $0^{\circ} \mathrm{C} \mathrm{cm}^{2} / \mathrm{sec}$

Molecular weight of spill chemical

Materlal cunstant, $B$ of Antulne's furmula, ${ }^{\mathrm{K}}$

Temperature at which spill chemical has a vapor pressure of 1 atm ${ }^{3} \mathrm{C}$

Reference temperature, $\mathrm{C}$ of Antoine's furmula, ${ }^{\mathrm{K}}$

Ambient temperature at spill liquid, ${ }^{\circ} \mathrm{C}$

One flow is considered and the flow is $1.0 \mathrm{~m}^{3} / \mathrm{sec}$. The result of executing, the program (in double precision) whth this input is reproduced in appendix 2.

\section{NUMERICAL RESULTS}

The purpose of this study was to predict the mass evaporation rate for a hazardous liquid spill in a containership hold. Since no information was available about the extent of such a spill, it was assumed that the liquid would spread unffurmly over the buttum of the hold (tank top). In practice, there is almust always sume trim to the ship so that liquid would tend to drain to the aft end of the hold. A low point sump could cullect sume of the liquid which might be advantageously pumped to a safe place thus reducing the amount of liquid that would have to be removed by the rather slow evapuration process. Rulling of the ship wuld tend to spread the spill across the entire width of the hold. As discussed in the section of this report describing the numerical programs, the spill was assumed to extend fore and aft alung the entire length of the intercuntainer sluts and athwart ships across all the slots. However, no evapuration was cumputed for the main void cumprising the transverse space between the bulkhead and the end of the cuntainer stacks. Unless otherwise nuted the calculations were done for a hold cuntaining twelve 
stacks of $12 \mathrm{~m}$ (40 foot) long contalners and with eleven intercontainer slots $0.1 \mathrm{~m}$ wide. The container width was $2.36 \mathrm{~m}$, glving slot spacing of $2.46 \mathrm{~m}$. The alr temperature near the bottom of the hold was taken as $10^{\circ} \mathrm{C}$. Dimenstonal mass evaporation rates are based on vapor pressure and diffustvity data for heptane. Calculations for numerous other fuels have been made by Sealand Corp. (using a slightly less general model) and are reported elsewhere [1].

Calculations were made for various locations of a single suction pipe, for several air flow rates and several stable stratification temperatures. The effect of varying the helght of the suction above the tank top is shown in figure 15 for a suction on the centerline of an idealized ship. Ralsing the suction from $.05 \mathrm{~m}$ above the tank top to 1.5 meters is seen to decrease the evaporation rate by a factor of $3-1 / 4$ for a stable stratification of $0.1^{\circ} \mathrm{C}$ over the hold helght of $20 \mathrm{~m}$. Since the evaporation rate varies as flow to the third power, to remove liquid with the suction at 1.5 meters at the same rate as with it at $.05 \mathrm{~m}$ the flow would have to be somewhat more than 34 times as great for the 1.5 meter height $\left(3.25\right.$ cubed). For a $1^{\circ} \mathrm{C}$ stable stratificaton this effect of suction height is seen, from figure 17, to be very much more pronounced.

Moving the suction laterally at constant height has comparatively little effect. This is illustrated in table 2 which lists the dimensionless mass pick-up for two suction locations, one on the centerline and the other near one side of the ship. Figure 16 presents the same information graphically. However, since this calculation falls to account for the interference to transverse flow occasloned by the vertical framing of the bulkhead, these results should be viewed with cautlon. Figure 17-a shows the calculated 
pressure at the open end of a palr of sots, one on the hold centerilne (sol1d 11ne), the other the last lot outboard (dots). Pressures for two suction helght are hown, $.05 \mathrm{~m}, 11$ gure 17-a and $0.6 \mathrm{~m}, 11$ gure 17-b. Note that, except for a region of about 0.2 dimensionless units around the helght of the suction, the preseures are essentlally the same for the two alot locations at a glven suction helght. Since the slot flow do determined primarlly by the gradlent of the pressure at $y=0$, little difference in the slot flows should be expected. Thls 18 reflected in the data presented in table 2. Note also the effect on the pressures below the suction of ralsing 1t, L.e., compare, In figures 17-a and 17-b, the pressure behavlor below the pressure "spike". In flgure 17-b, the pressure gradlent lo small between the tank top, $y=0$, and a dimenslonless helght of about 0.1 (dimenslonal helght $0.2 \mathrm{~m})$. The very small pressure gradlent at $y=0$ results in little flow adfacent to the tank top and little scavanging of the flammable vapors. Thlo accounts for the behavior shown In flgure 15 of mass removal rate with suction helght.

Streamlines corresponding to the two sets of palred pressure dletrlbut lons, flgure $17 \mathrm{a}$ and $17 \mathrm{~b}$, are shown In flgures $18-\mathrm{a}, \mathrm{b}$ and flgures 19-a,b. In these, the transverse scale has been expanded about 100 times relative to the longltudinal scale. The drawings should be very attenuated in wldth to properly represent the geometry but, if so presented, would be unreadable. The flrot palr, flgure 18, show the streamlines for the boundary layer flow at the bottom of the slots for the suction only $.05 \mathrm{~m}$ above the tank top. A thin layer of gas flows down the sides of the contalners and spreads out over the slot bottom--streamlines orlginating at the sides. It turns and flows along the slot bottom toward the open end of the slot. For 
the slut clusest to the suction the streamlines are strongly bunched in the center of the slot. Fur the slut farthest away from the suction the hehavise Ls similar but the bunching of the streamlines near the centerline of the slut is less pronounced. As the suction is raised there is quite a noticeable change in the flow which becumes more marked as the suction is raised. This change is seen by comparing figures 18-a and 19-a. With the suction raised, not all the flow leaves the slot alung its buttom surface. Sume returns to the container sides and flows up, turning toward the main void as it approaches the height of the suction. By the same score, not all the flow descends in the thermal boundary layer next to the container sides to the slot buttum although it does toward the rear of the slot. Some of the flow near the opening into the void turns as it approaches the height of the suction and exits directly. This flow is shown schematically in figure 10 . Note that flow descending all the way to the tank tup has actually been uver couled. In the stably stratified situation pertaining, it must be warmed again in order to rise to the height of the suction. To gain heat it must pass close to either the walls of the main void or of the slot. Obviously, for the suction raised well abuve the tank top, sume of the air finds it easier to seek the slut side wall rather than the main void walls. This flow behaviur was fuund through the numerical calculation. Although it is completely plausible, it was not anticipated. As the suction is further raised the flow along the slot buttum becumes still weaker and the tendency to return to the wall decreases. It has almost completely dissappeared with the suction at $1 \mathrm{~m}$, figures $20 a, b$, and $c$.

The effect of increasing the stable thermal stratification is seen by comparing figures $17-a$ and 21 . Note the different ordinate scales of the 
pressure plots. In figures 17 -a the temperature difference over the $20 \mathrm{~m}$ hold height is $0.1^{\circ} \mathrm{C}$ while it is $1.0^{\circ} \mathrm{C}$ in figure 21 . The dimenstonal suction helghts are the same but, due to the greater thermal stratification, the dimensionless helght at $\Delta \mathrm{T}=1.0^{\circ} \mathrm{C}$ is greater. In general, the effect of Increasing $\Delta T$ is to compress the vertical scale of the flow. With a higher $\Delta T$ the same vertical suction helght appears to the flow as further from the tank top.

Increasing the stable temperature stratification acentuates the flow effects as shown in figures 18, 19, and 20. The flow in the slot closest to the suction bunches strongly but then spreads rapldly as the mouth of the slot is approached, figure 21-b. Even with this low suction location some flow, driven by the stronger stratfication, returns to the wall. The flow in the slot furthest from the suction is less strongly affected, figure $21-c$.

The main computed results for a glven hold configuration and temperature stratification are expressed in dimensionless form for a nominal temperature of $10^{\circ} \mathrm{C}$. To obtain dimensional output the ventilation flow and spill liquid partial pressure and diffusivity are needed. Some vapor pressure data as a function of temperature can be found in the 1iterature [2] and, typically, the $\log$ of the vapor pressure is nearly linear with $1 / T$ as shown for heptane in figure 2. Although the theory for vapor pressure is very well developed [15], a much stmpler semi-empirical approach, Antolne's formula, is found in HLrata, Oke and Nagahame [14]:

$\log p=A=B /(C+T)$ 
where $\mathrm{p}$ is the partlal pressure, $\mathrm{T}$ temperature and $\mathrm{A}, \mathrm{B}, \mathrm{C}$ constants unique to the particular chemical. Further, since Hirata et al give values for these constants for a large number of chemicals their approach was used. Diffusivity data was corrected for temperature using the empirical relation given in [16].

It is clear from figure 2 that the equilibrium vapor concentration is a strong function of temperature. The numerical calculation obtains the concentration for the input value of slot bottom temperature. However, the flow, which depends strongly on the differential stratification temperature, but only weakly on average ambient temperature, is computed using a nominal ambient.

\section{EXPERIMENTAL PROGRAM}

An approximately $1 / 12$ scale model of a much simplified containership hold was built. It consisted of a box with inside dimenstons $1.22 \mathrm{~m}$ long $\mathrm{x} 2.66 \mathrm{~m}$ wide $\times 1.68 \mathrm{~m} \mathrm{high} \mathrm{built} \mathrm{of} 0.65 \mathrm{~cm}$ fir plywood and $0.6 \mathrm{~mm}$ galvanized steel. To simulate the cooling effect of seawater on the hull, the bottom and lower $74 \mathrm{~cm}$ of the two ends were steel, maintained at constant temperature by circulating temperature controlled water through copper tubes soldered to the steel. The remainder of the apparatus was of wood, and allowed to seek room temperature. The apparatus was in a large temperature controlled room where typically the temperature varied between 18 and $25^{\circ} \mathrm{C}$ with an average value of $23^{\circ} \mathrm{C}$ during the course of a day. Inside this "hold" were three plywood boxes $1.51 \mathrm{~m} \mathrm{high} \times 1.02 \mathrm{~m}$ long. The center box was $0.81 \mathrm{~m}$ wide and the two outer boxes $0.61 \mathrm{~m}$ wide. These simulated stacks of containers. These three boxes 
were positloned to glve two slots $4 \mathrm{~cm}$ wide between them and $2 \mathrm{~cm}$ wide slots between them and the sides of the hold. All three were centered between the long sides of the hold leaving two transverse volds $10 \mathrm{~cm}$ wide (fore and aft). All the plywood surfaces were coated with epoxy base palnt to prevent take-up of the splil vapors. A s.mplified cross section of the apparatus ts shown in flgure 22 .

The flammable spill was represented by a shallow pan filled with an ethyl alcohol-water mixture. The pan was $1.16 \times 2.39 \times 0.025 \mathrm{~m}$ and held about 40 liters of mixture. The pan was placed in the "hold" and the simulated contalner stacks set in on pads $0.031 \mathrm{~m}$ high to allow the liquid to pass freely under them. The choice of a water alcohol mixture as the splil liquid was unfortunate. It was made for safety reasons. The flammable gas detector to be used could detect the alcohol vapors at concentrations well below the $\mathrm{lr}$ flammable 1 imit and mixtures and temperatures were chosen so that only nonflammable mixtures would exist. The mixtures themselves were too dilute to support combustion. However, the concentration of the mixture was difflcult to control and changed substantially during the course of a test. Thus, there was constant uncertainty about the equilibrium vapor pressure of the spill Iiquid.

Reduclng the physlcal scale requires that the initial temperature difference be increased if similar flow conditions are to prevail. The dimensionless Grashof Number, $G R=\left(\mathrm{gd}^{3} / \nu^{2}\right)(\Delta T / T o)(d / h) P r$, must be kept constant. With a $1 / 12$ reduction in physical size the ratio $d / h$ was increased but, In the model, the temperature difference top to bottom for similar stable stratification should be increased by a factor of 90 . In practice a tempera- 
ture difference of about $15^{\circ} \mathrm{C}$ could be achieved, equivalent to a full-scale temperature difference, $\Delta \mathrm{T}$, of only $15 / 90=0.17^{\circ} \mathrm{C}$. Calculations in the previous section were for $\Delta T^{\prime}$ s of 0.1 and $1.0^{\circ} \mathrm{C}$. The stable situations tested are for weak stratification compared to full scale. For the unstable case, model temperature difference of only $5^{\circ} \mathrm{C}$ was achieved. Thus the full scale instability simulated was quite weak.

Due to the limited budget and time, no air flow measurements inside the "hold" were attempted so it was never established if the actual flows resembled those predicted by the calculations nor if there were significant circulating flows, as might arise from a transverse temperature gradient. Some tests were run in the configuration shown in figure 22 and some with the inlet and exhaust connections reversed. For all tests the cooling water was turned on and adjusted to the test conditions the day before the spill 1 iquid was to be loaded and data taken.

Results for a stably stratified condition are shown in figure 23 for several air change rates. Note, however that, again a scaling factor enters, model air changes per hour are not the same as full-scale. The behavior during the first 15-30 minutes is erratic because of the transients associated with loading the liquid in the pan, achieving steady liquid temperature and ventilation conditions. The qualitative trend after 30 minutes, for both suction locations, is to reduce the combustible vapor concentration in the exhaust as air flow is increased. With the exhaust at the bottom, significantly more vapor is removed than with it at the top for the same air change rate. 
When the behavior with a stable temperature gradient is compared to that with an unstable gradlent, it is necessary to recall that, in this apparatus, the upper portion was always nominaly at room temperature. When a stable temperature gradient was called for, the lower portlon and the Ilquid pan were cooled; when an unstable gradient was desired they were warmed. Thus, with the same splil liquid, the equilibrium vapor concentration in the stable case (cool liquid) was considerably less than for the unstable case (warm liquid). At zero alr changes per hour a survey of vapor concentration versus helght showed little varlation. At 1 air change per hour with a bottom exhaust for the unstable case the vapor concentration, except very close to the surface of the pan, was quite uniform and about $40 \%$ of its equilibrium value. For the stably stratifled case the vapor concentration decreased near the pan more slowly with helght than in the unstable case but leveled out at about $30 \%$ of its equilibrium value about $10 \mathrm{~cm}$ above the bottom and decreased slowly with height above that, figure 24. Shifting the exhaust from the center to one end had no effect to the accuracy of these tests. The behavior In the stably stratifled case suggest that a significant secondary mixing flow was present, but that a mild degree of stability was achieved.

Overall the experimental results were ambiguous to mildly encouraging. They also illustrate the inadvisability of conducting convection experiments hastily and with a tight budget. The experimental apparatus was built by Mr. W. Balley and the data taken by Mr. S. Steel, both of NBS. 


\section{CONCLUSIONS}

One of the nore interesting aspects of this study of a significant hazard to shlpping was the almost total lack of previous scientific research at the time the initial decision of the International Maritime Consultative Organization relative to containership ventilation was made. Our limited study revealed many unanswered questions about fluid flow and heat and mass transfer in the context of maritime safety. It shed some light on one particular situation -- the ventilation of a stably stratified containership hold. Many assumptions had to be made -- when a surface temperature was needed, we assumed it was known, when geometric simplifications had to be made, it was assumed that associated complicated flow phenomena were not present. Despite these simplifications and Idealizations, the work reported here is, to the best of our knowledge, the only analysis in existence that attempts to study the efficiency of ventilation in a realistic hold geometry and thermal environment.

Although much more detalled research should be done on a variety of specific points, we belleve that some important conclusions can be drawn from our study and that these conclusions will stand the test of time.

(1) In a stably stratifled containership hold, almost all the extracting capability of a ventilation system will be concentrated at the vertical level of the suction.

(2) In order to extract any significant amount of spilled material, it is essential to place the suction as close to the hold bottom as is feastble. 
(3) With few exceptions, the natural tendency of vapors from spllled liquids will be to concentrate near the hold bottom. Therefore it is not efficient to try to design the ventilation system so as to $\mathrm{mix}$ the gas throughout the hold.

(4) Ventllation expressed simply as alr changes per hour (for some arbltrary hold loading condition -- empty or full) is a poor measure of performance. The performance will be sensitive to the thermal environment, degree of stratification and spacing between containers.

(5) The lack of the ability to analyze the thermal environment of a containership hold is a major impediment to systematic study of hold ventilation. There is important need for research in this area.

\section{REFERENCES}

[1] von Iperen, Willem, H.P., A Study of Ventilation of Containership Holds for Carrlage of Flammable Liquids, unpublished, June 18, 1979, Sea-Land Service, Inc. P.0. Box 1050, Elizabeth, NJ 07207.

[2] Hodgman, C.D., Handbook of Chemistry and Physics, 27th Edition, Chemical Rubber Publishing Co., Cleveland, OH, 1943.

[3] Lewis, B. and von Elbe, G., Combustion, Flames and Explosion of Gases, Academic Press, New York, 1961.

[4] Turner, J.S., Buoyancy Effects in Flulds, Cambridge University Press, Cambridge, MA, 1973.

[5] Birikh, R.V., Gershuni, G.Z., Zhukhovitskil, E.M. and Rudakov, R.N., Stability of the Steady Convective Motion of a Fluid with a Longitudinal Temperature Gradient, Journal of Applied Mathematics and Mechanics, Vol. 33, No. 6, 1969, Pp. 937-947, Pergammon Press, Elmsford, NY (translated from the Russian version). 
[6] Schlichting, H., Bcundary Layer Theory, McGraw-Hill, New York, 1955.

[7] Batchelor, G.K., An Introduction to Fluid Dynainlcs, Cambridge University Press, Cambridge, MA, 1967.

[8] Prandt1, L., Essentials of Fluid Dynamics, Blackie, London, 1952.

[9] Gi11, A.E., The Boundary Layer Regime for Convection in a Rectangular Cavity, J. Fluid Mech., 26, P. 513, 1966.

[10] Elder, J. W., Lamtnar Free Convection in a Vertical Slot, J. Fluid Mech. 23, p. 77, 1965.

[11] Carrier, G.F., Analytical Approximation Techniques in Applied Mathematics, J. Soc., Indust. Appl. Math., 13, p. 68, 1965.

[12] Lighth111, M.J., Contributions to the Theory of Heat Transfer Through a Laminar Boundary Layer, Proc. Roy. Soc. A, 202, p. 359, 1950.

[13] Abramowitz, M. and Stegun, I.A., Handbook of Mathematical Functlons, National Bureau of Standards AMS 55, U.S. Govt. Printing office, Washington, DC, 1964.

[14] Hirata, H., Oke, S. and Nagahame, K., Computer Alded Data Book of VaporLiquid Equilibrium, Kodanska Limited, Elsevier Scientific Publishing Co., Tokyo/New York, 1975.

[15] Summerfield, A., Thermodynamics and Statistical Mechanics, Academic Press, New York, 1956.

[16] Eckart, H.R.G., Introduction to Heat and Mass Transfer, McCraw-Hill, New York, 1963. 


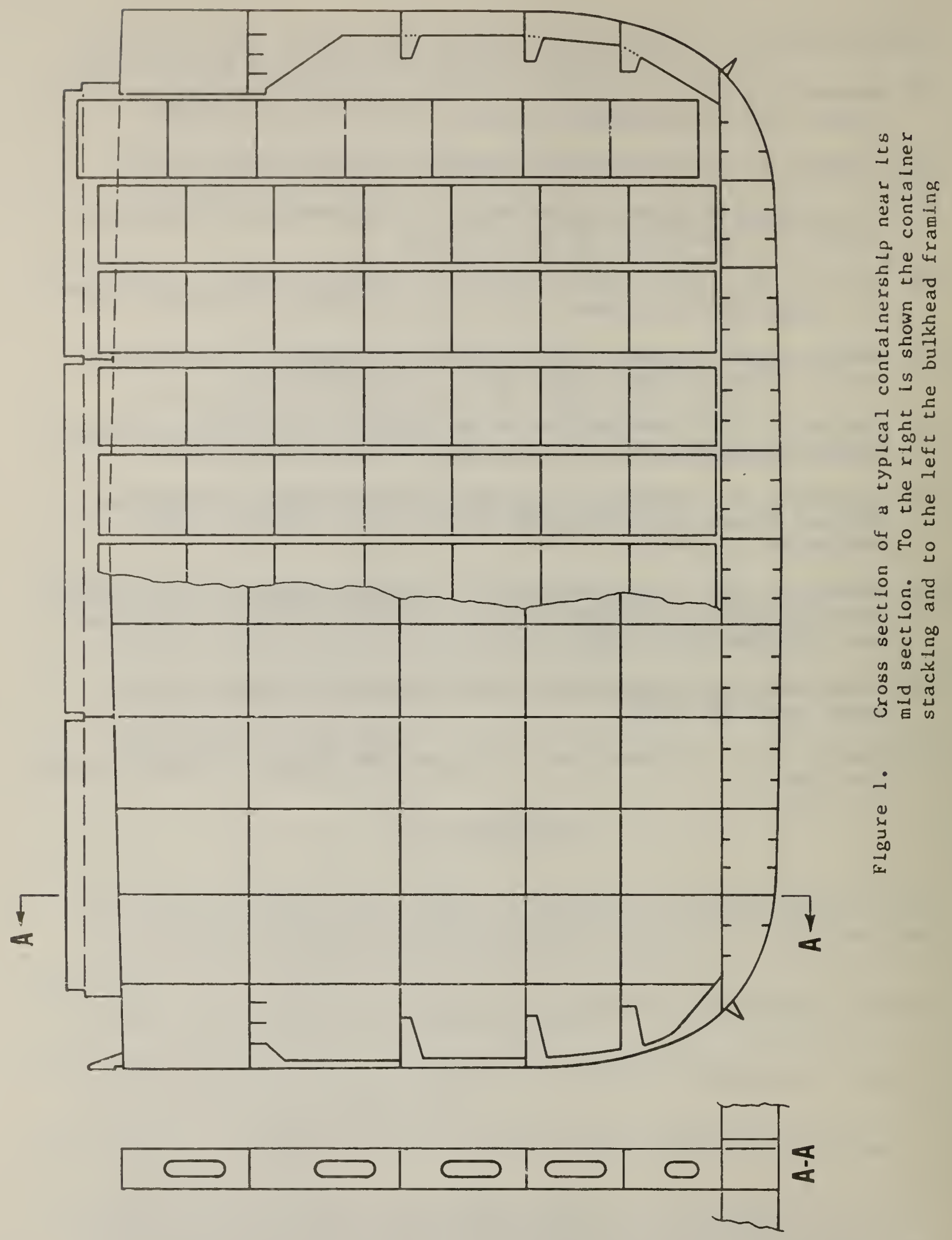




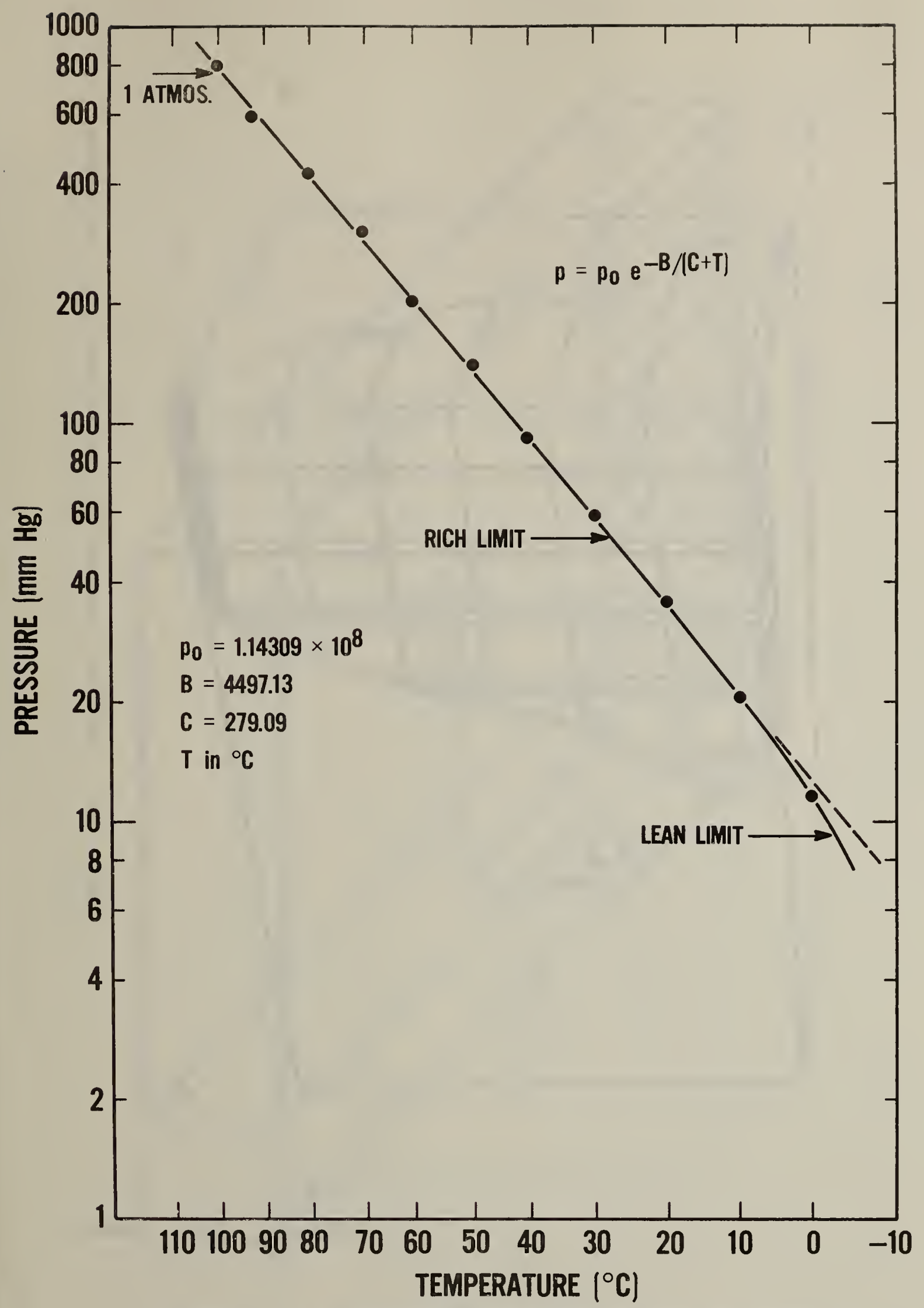

Figure 2. Vapor pressure versus temperature for heptane. Rich and lean Ilmits are for an alr environment 


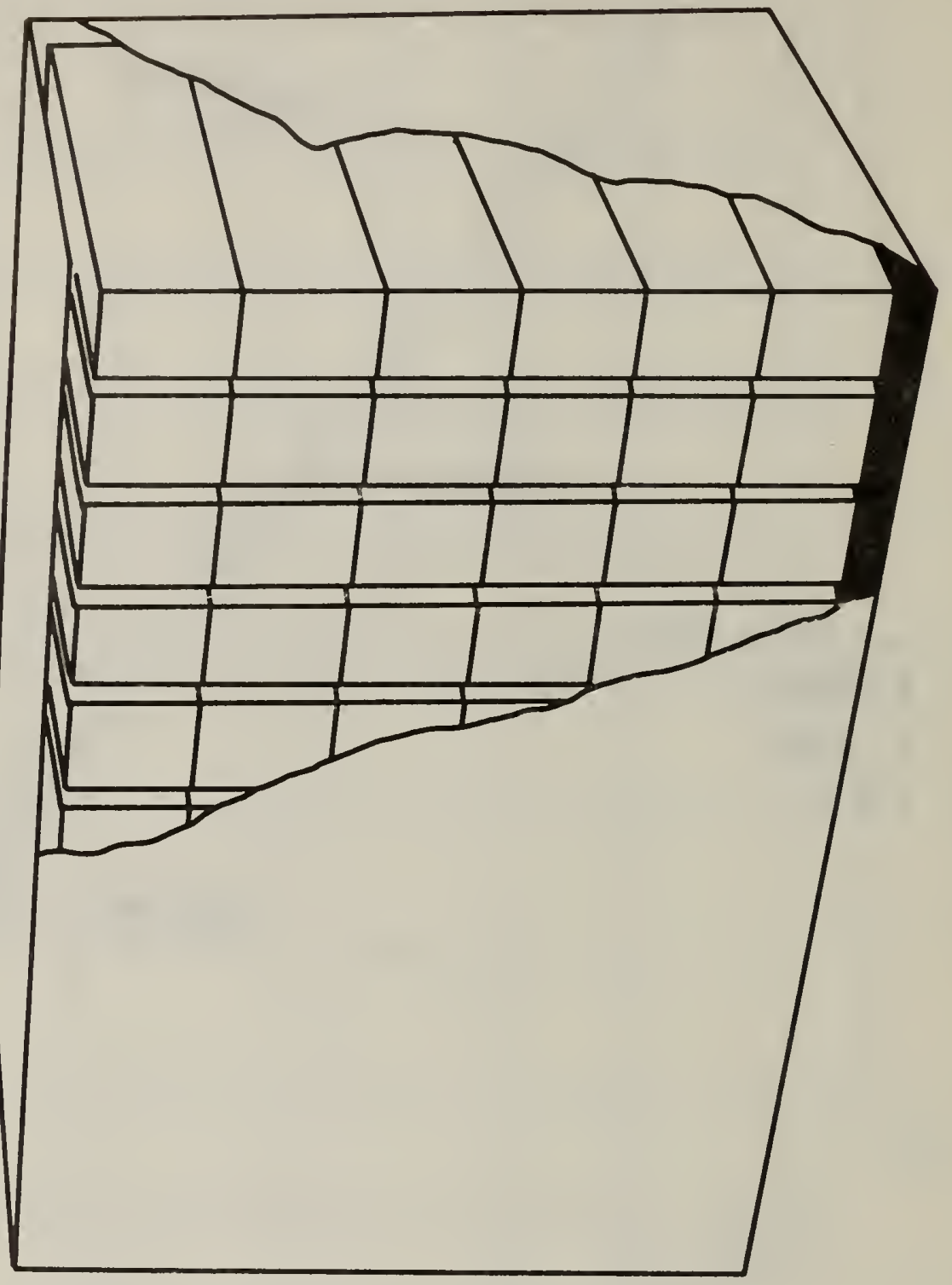

D 


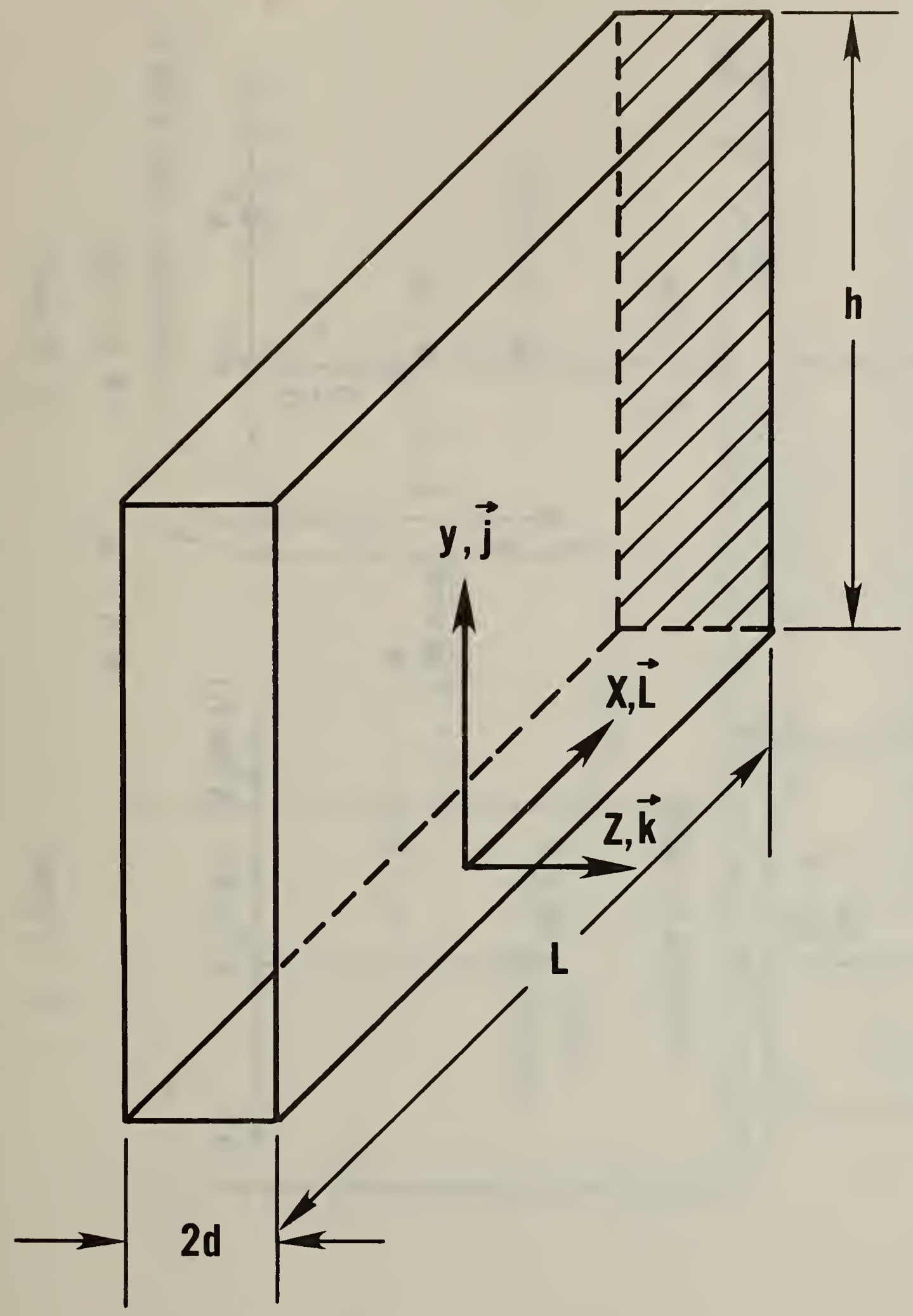

Figure 4. Geometry of the space between two stacks of contalners (inter-container slot) 


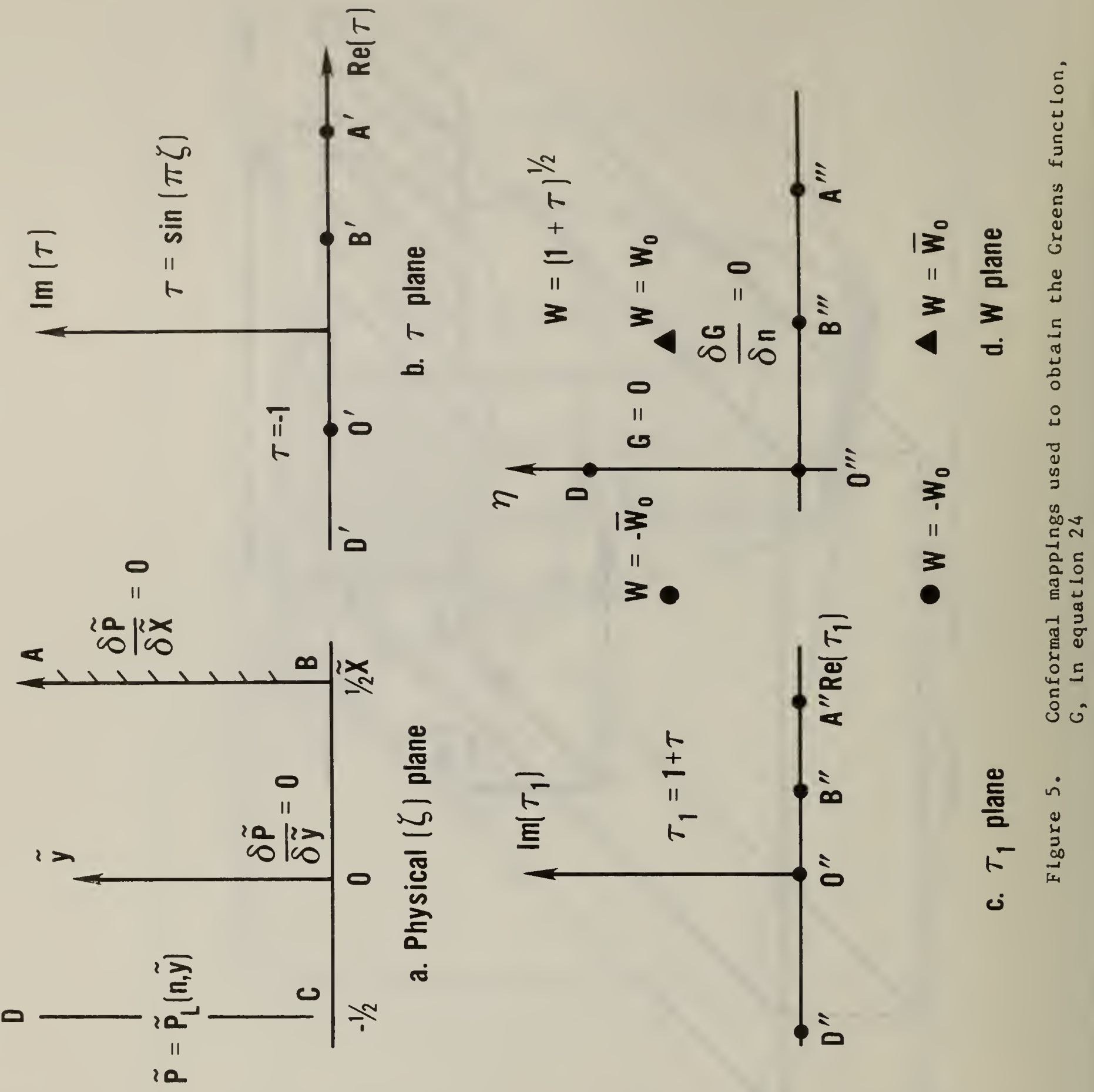




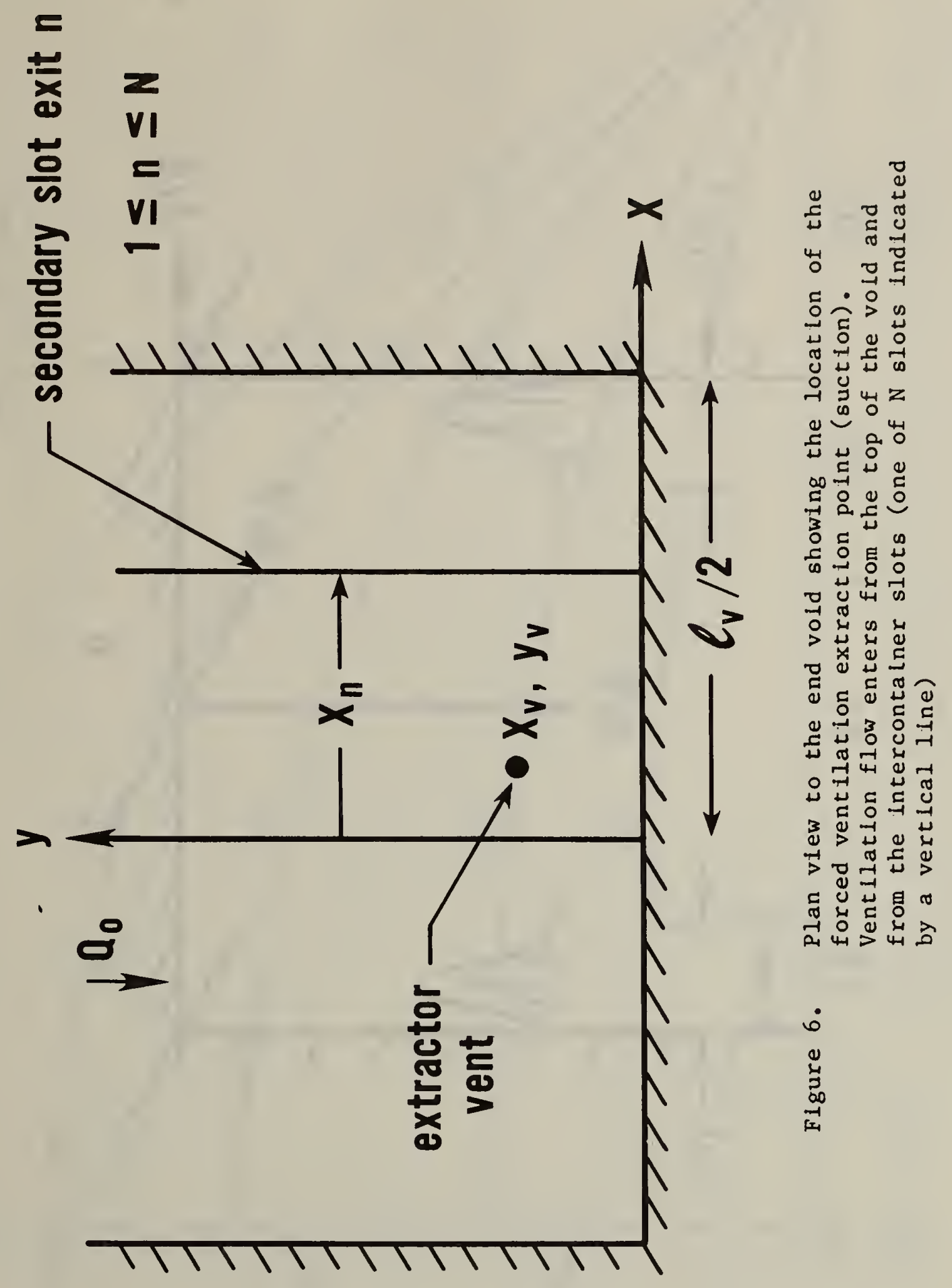




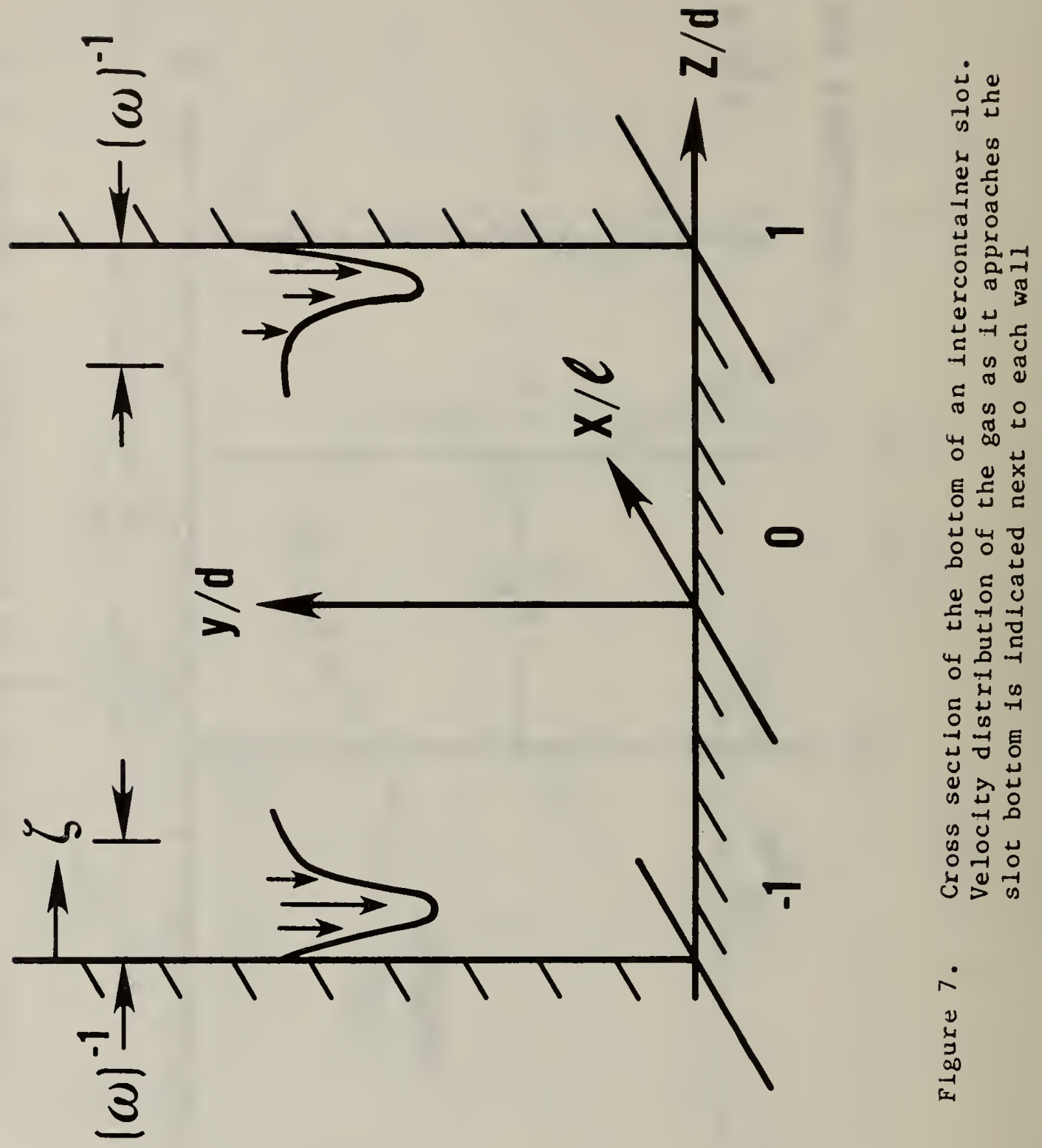




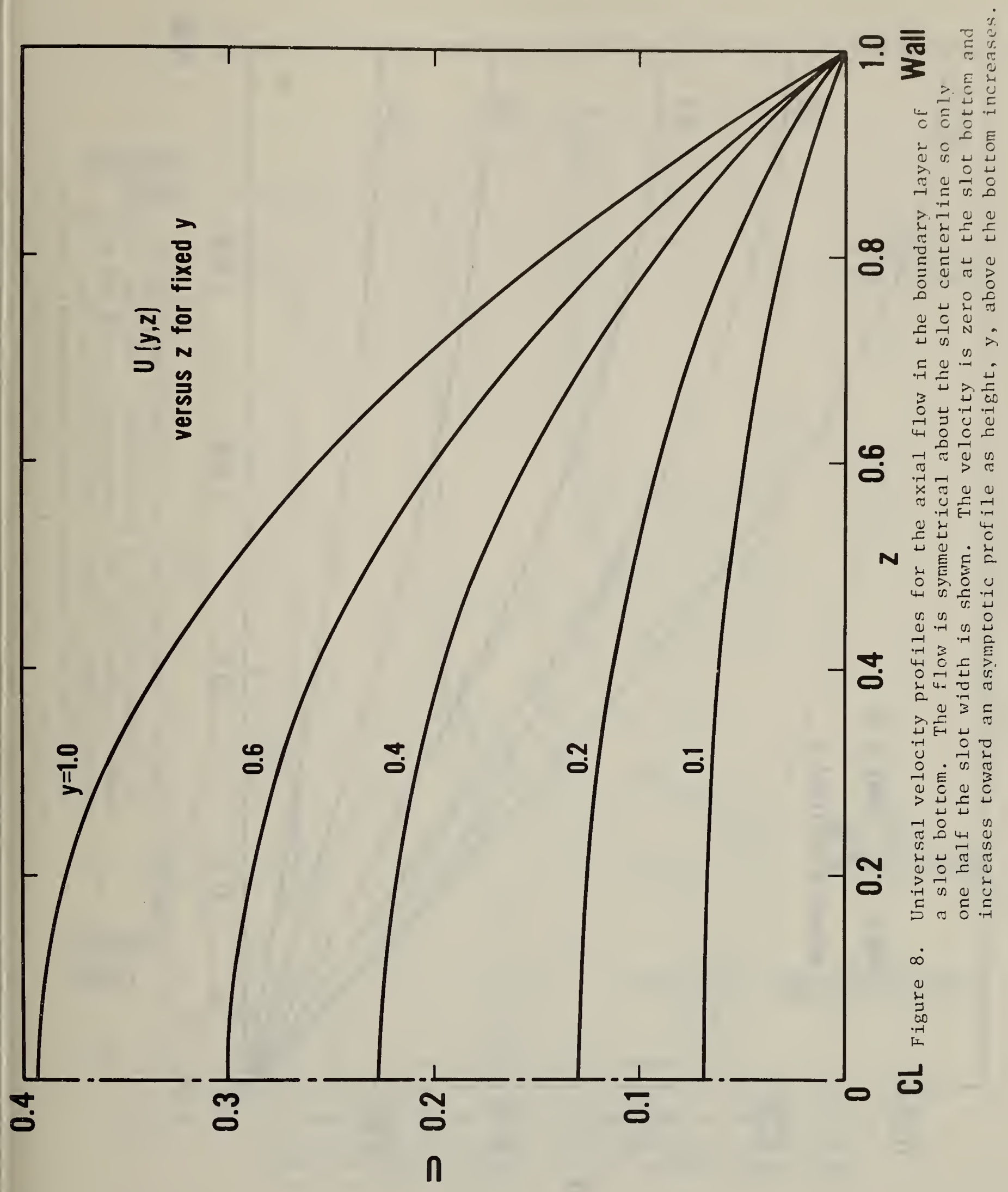




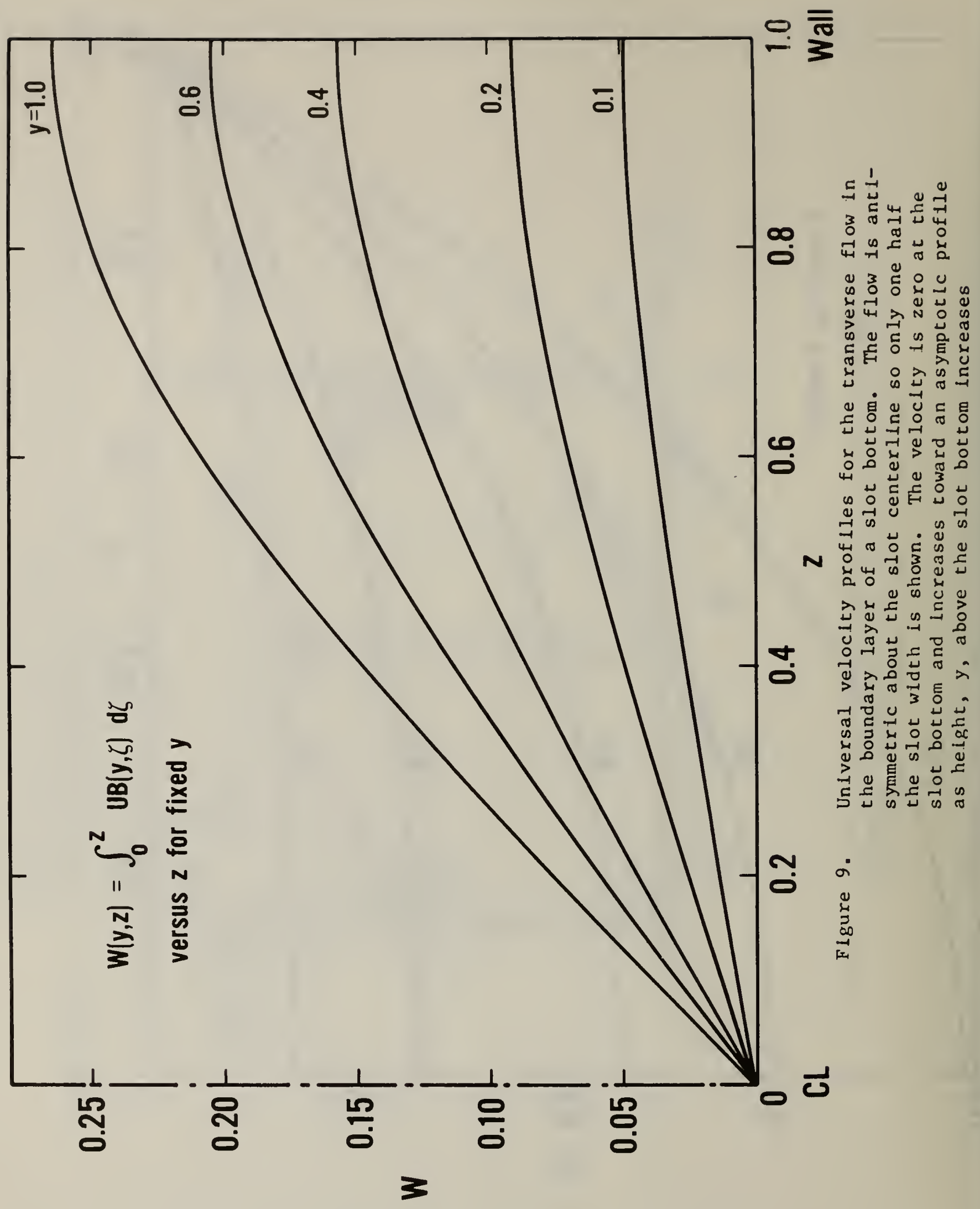




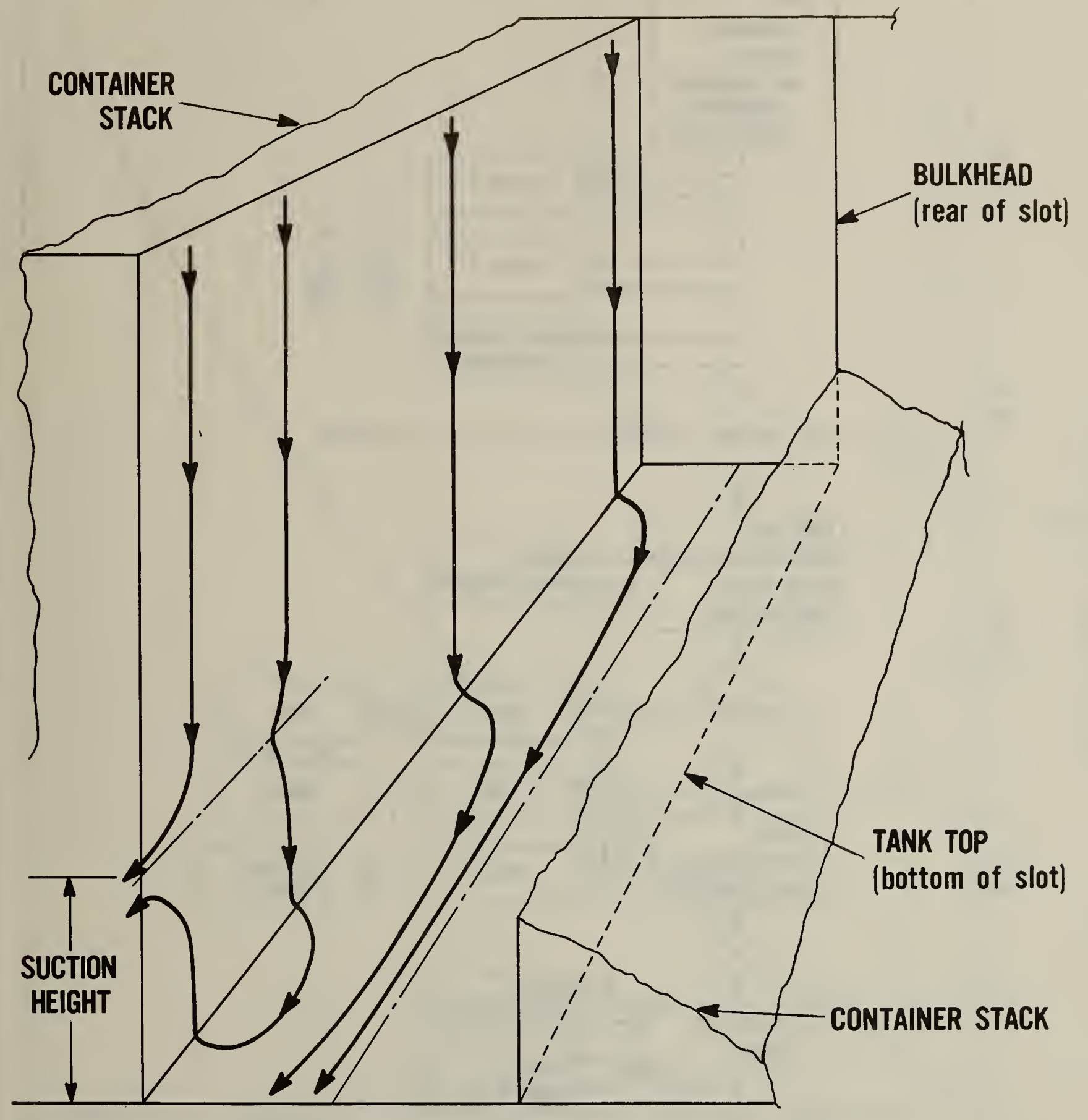

Figure 10. Perspective sketch of an intercontainer slot showing air flow streamlines. The air plcks up evaporated spill vapor as it moves in the boundary layer along the bottom of the slot 


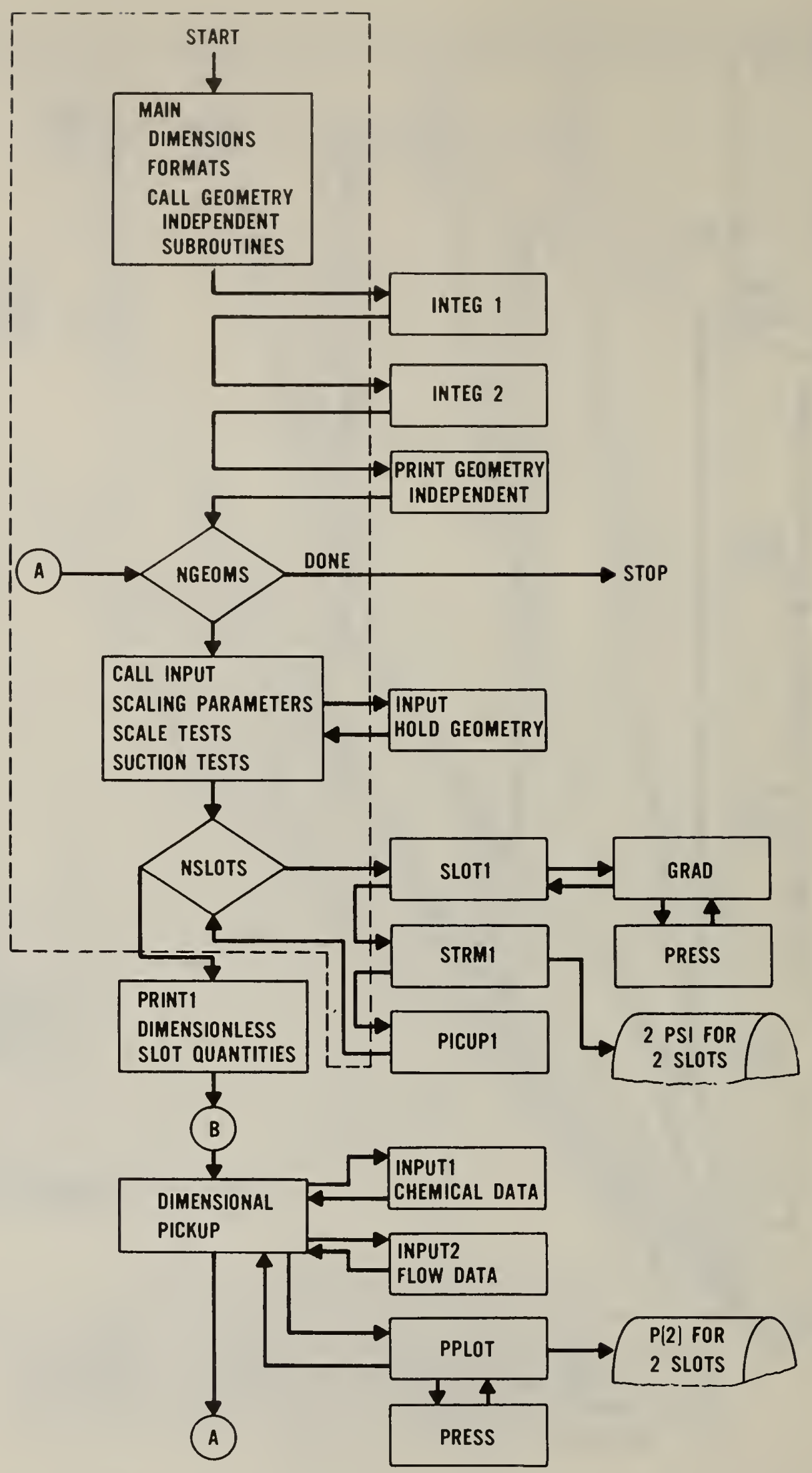

Figure 11. Simplifled flow diagram for the computer program 


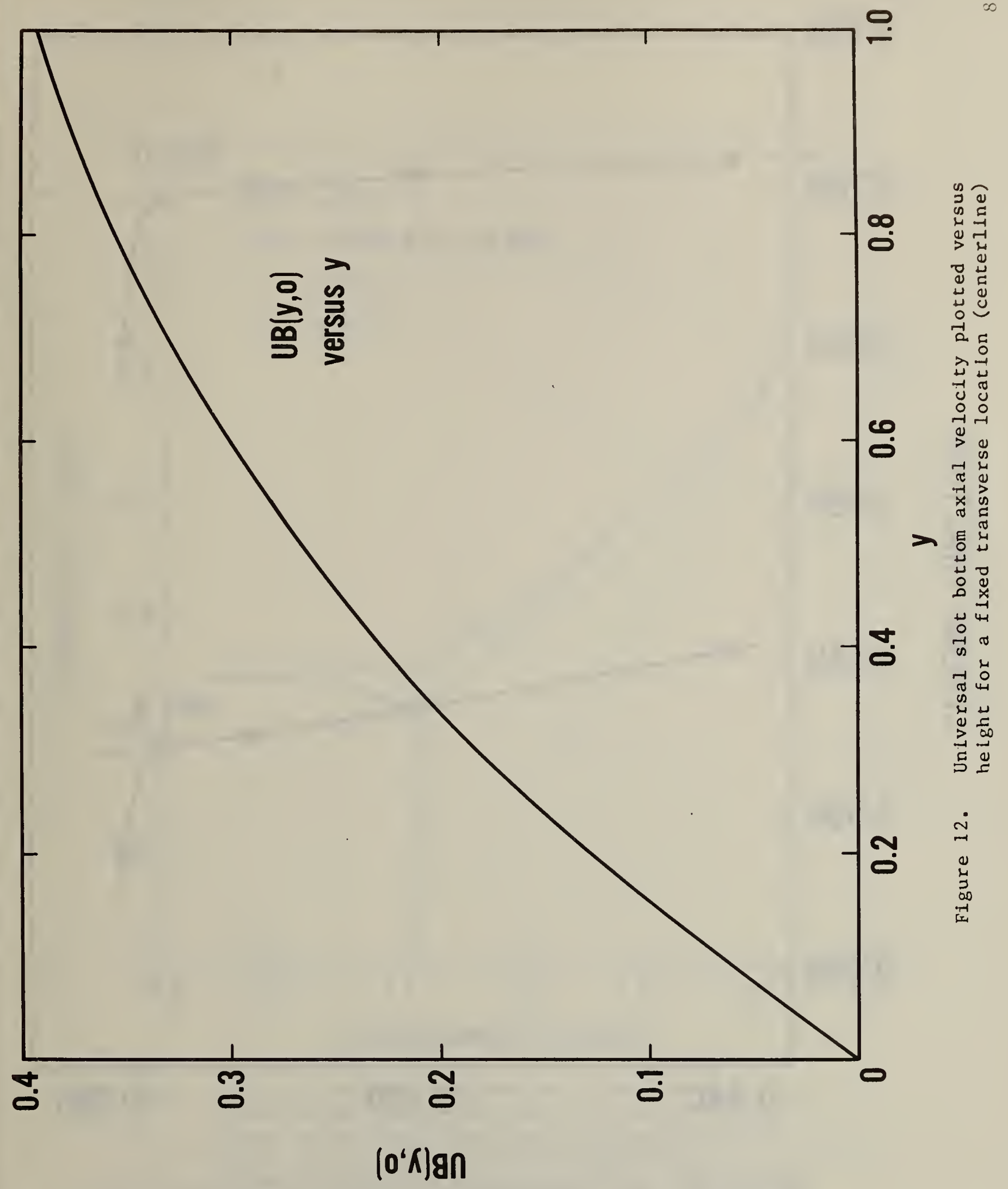




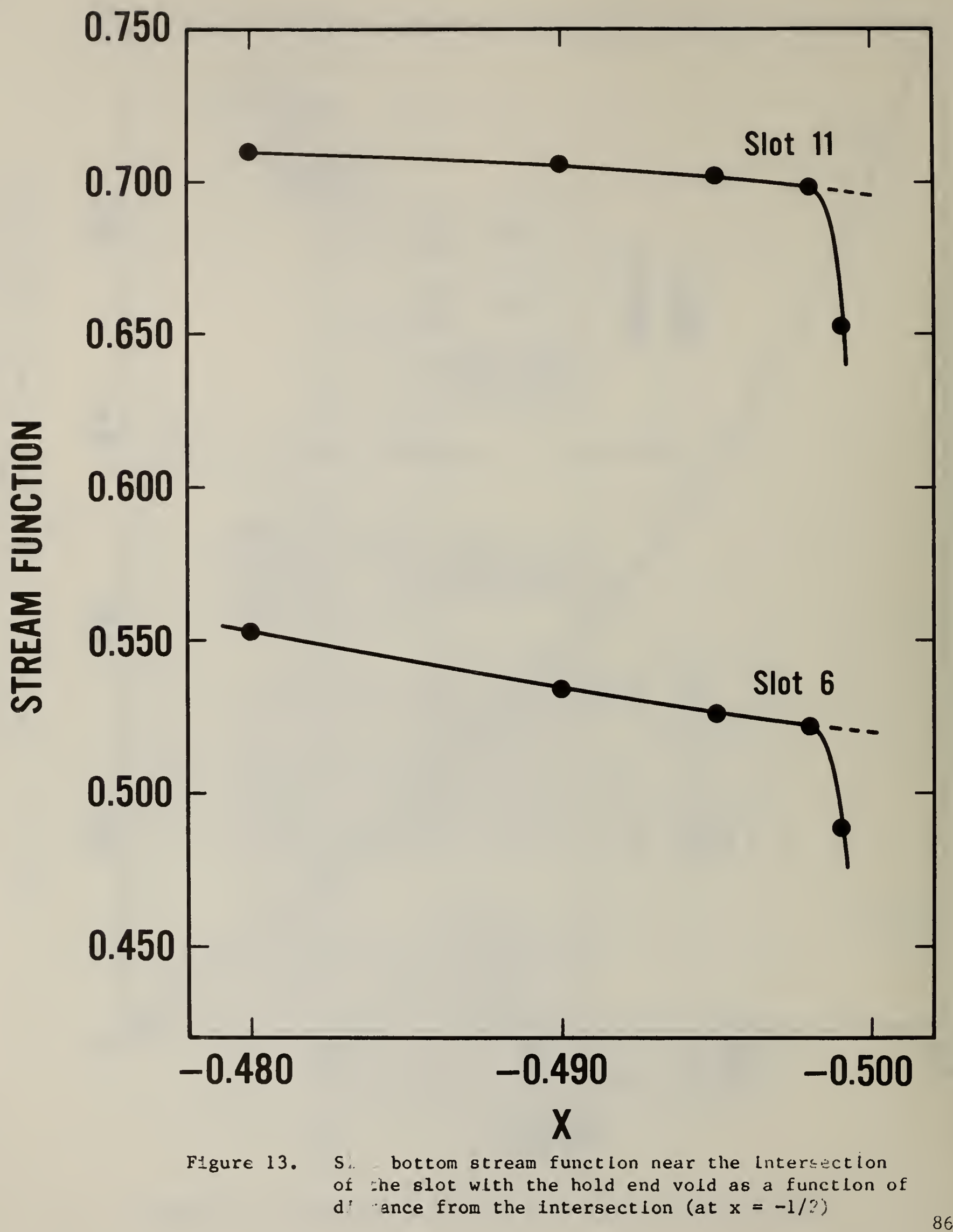




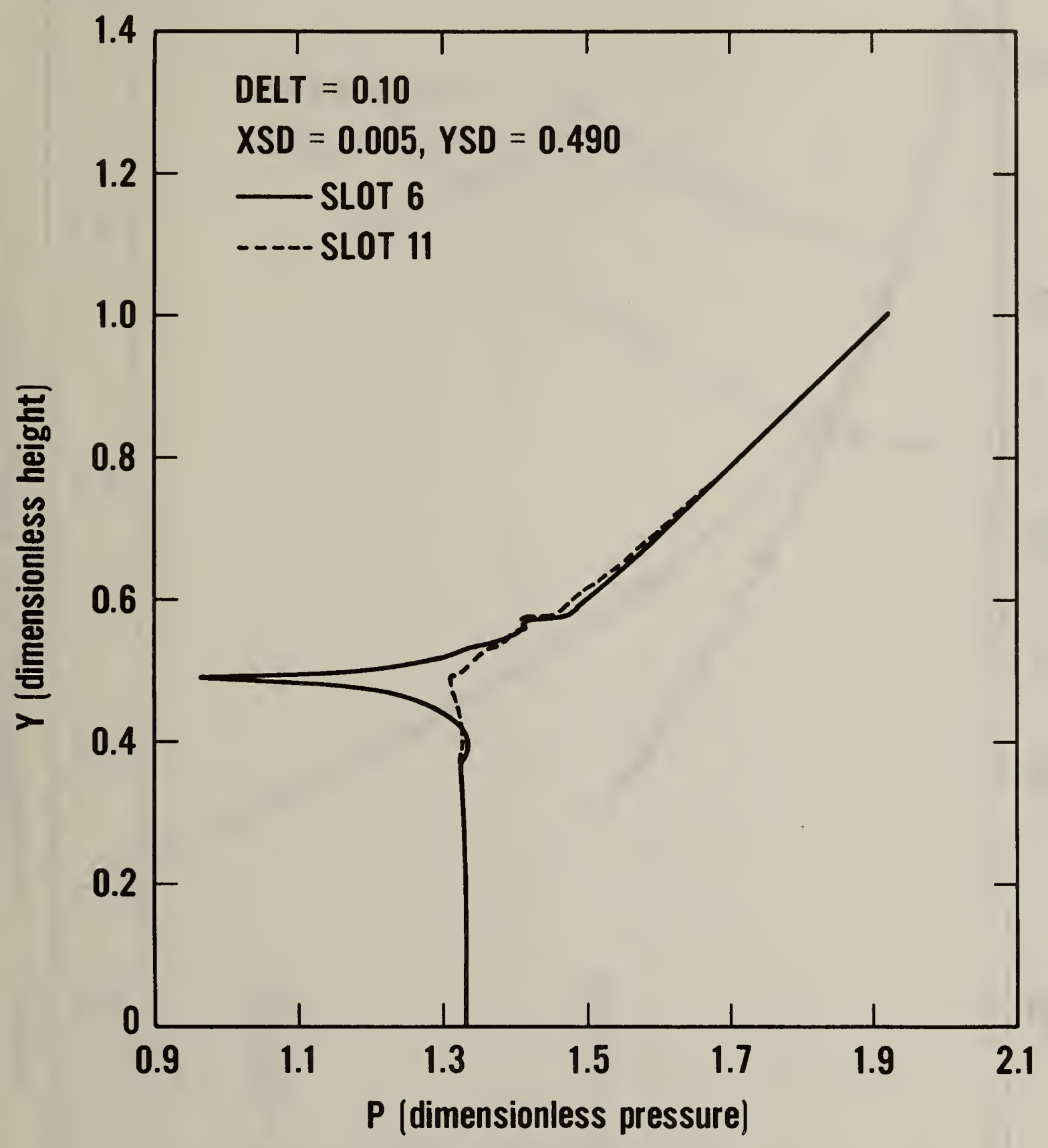

Figure 14. Dimensionless slot pressure as a function of dimensionless helght above the slot bottom for two slots: solid line, slot nearest the suction and dotted line, slot furthest from the suction. Pressures calculated single prectsion. Compare with flgure 20-a which is the same case calculated in double-precision 


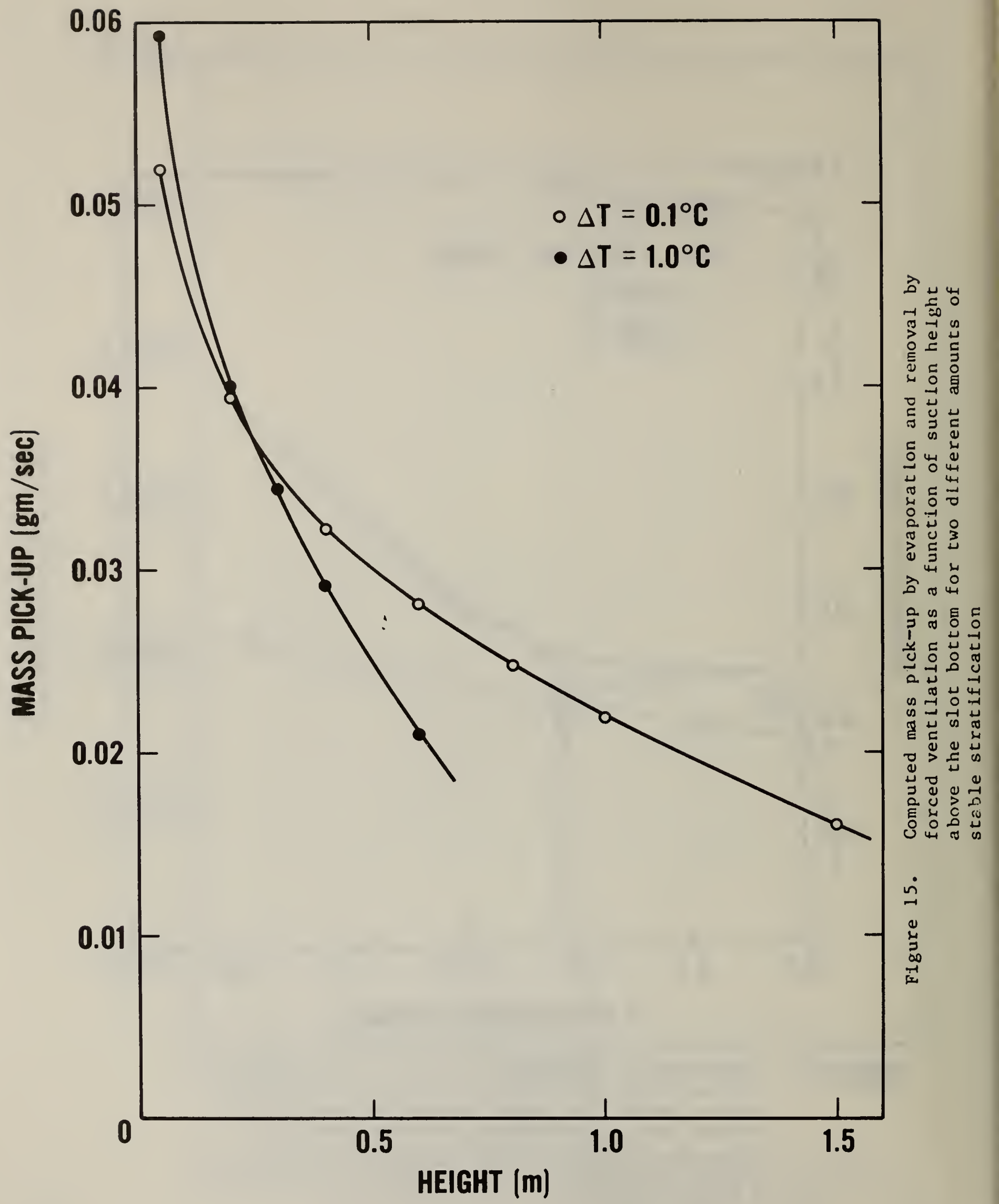




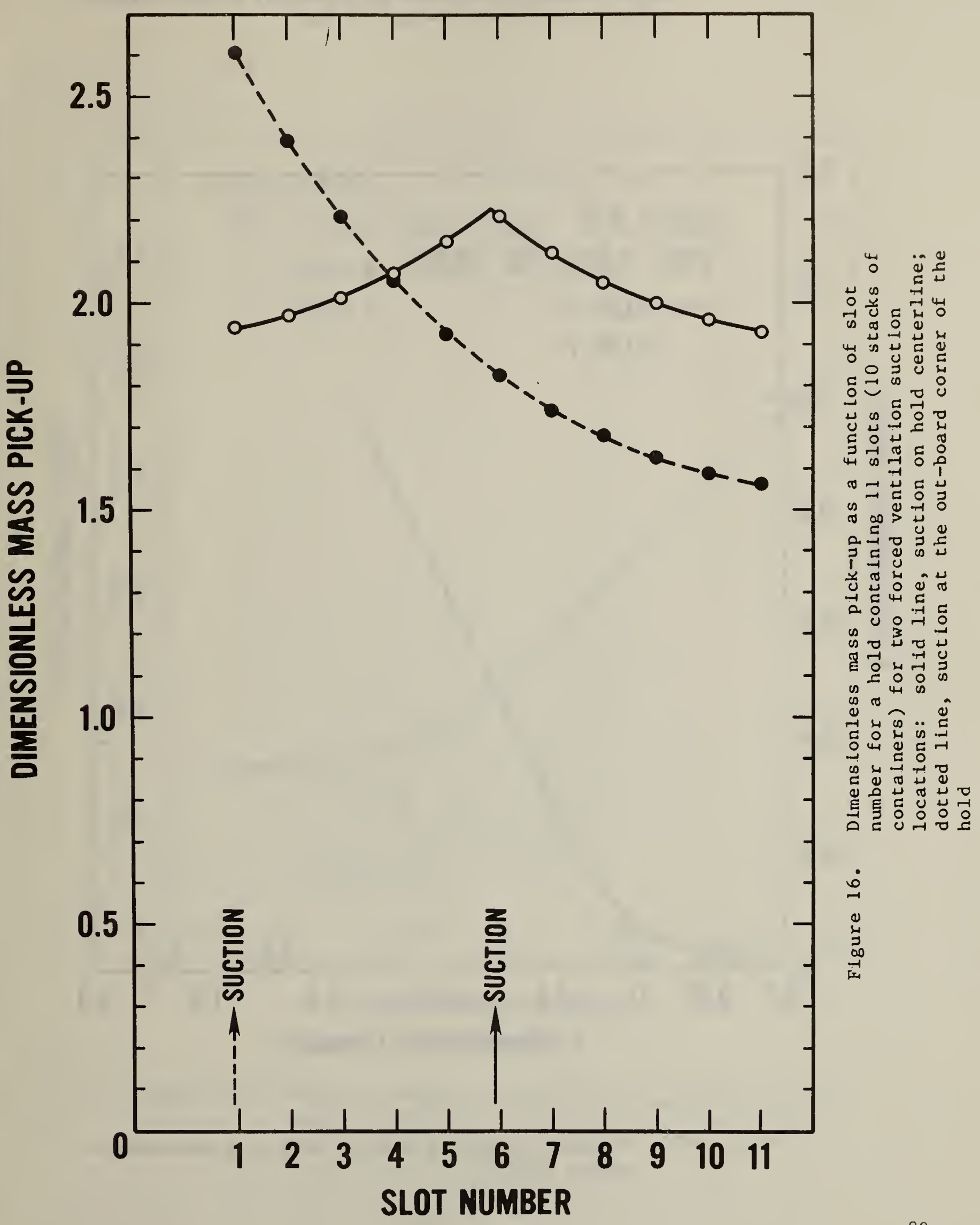


Flgure 17. Dimensionless pressure as a function of dimensionless helght (double precision calculation) stable stratiflcation $0.1^{\circ} \mathrm{C}$ over helght of hold

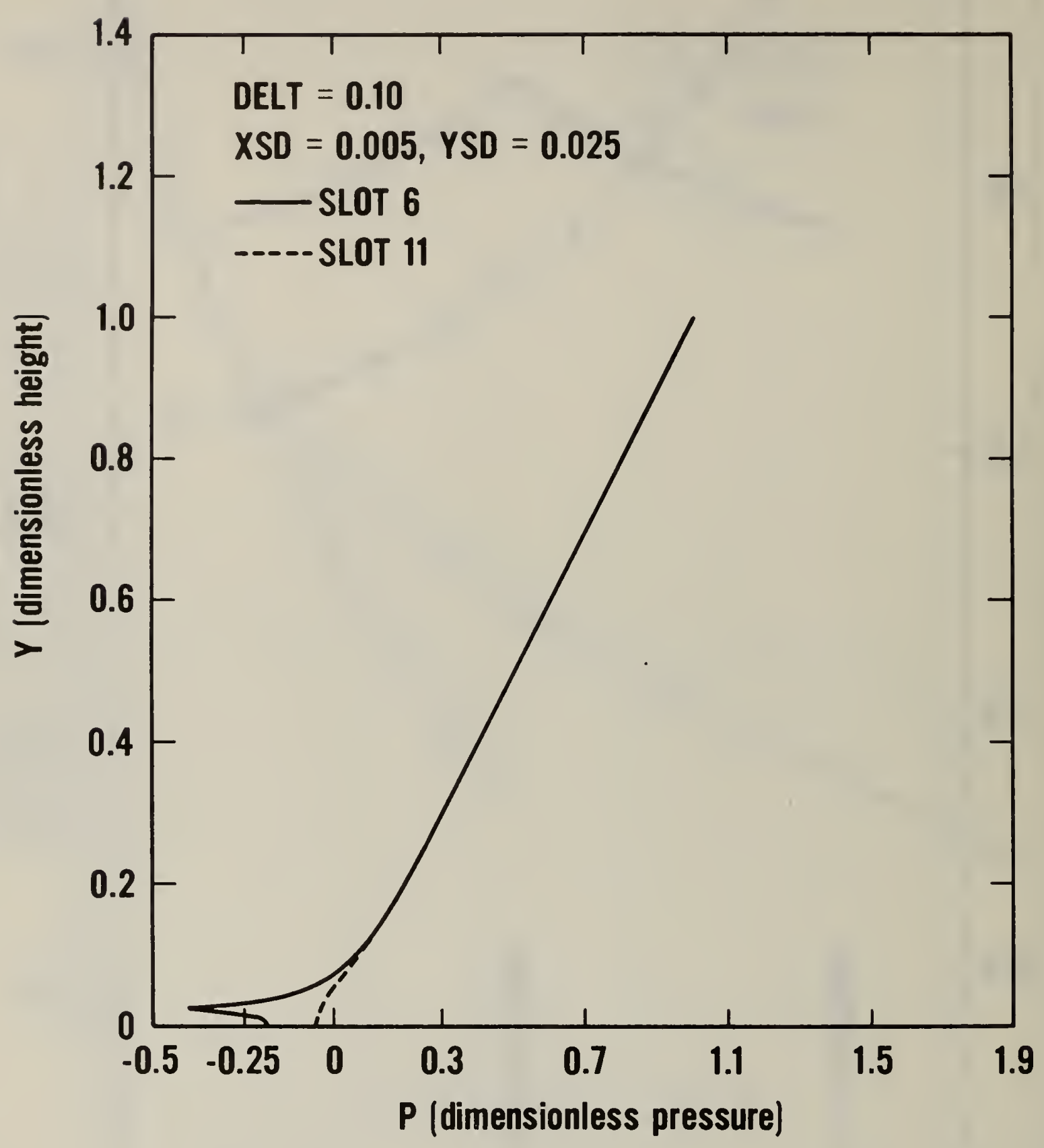

Figure 17a. Physlcal height of suction $0.05 \mathrm{~m}$, dimensionless helght 0.025 


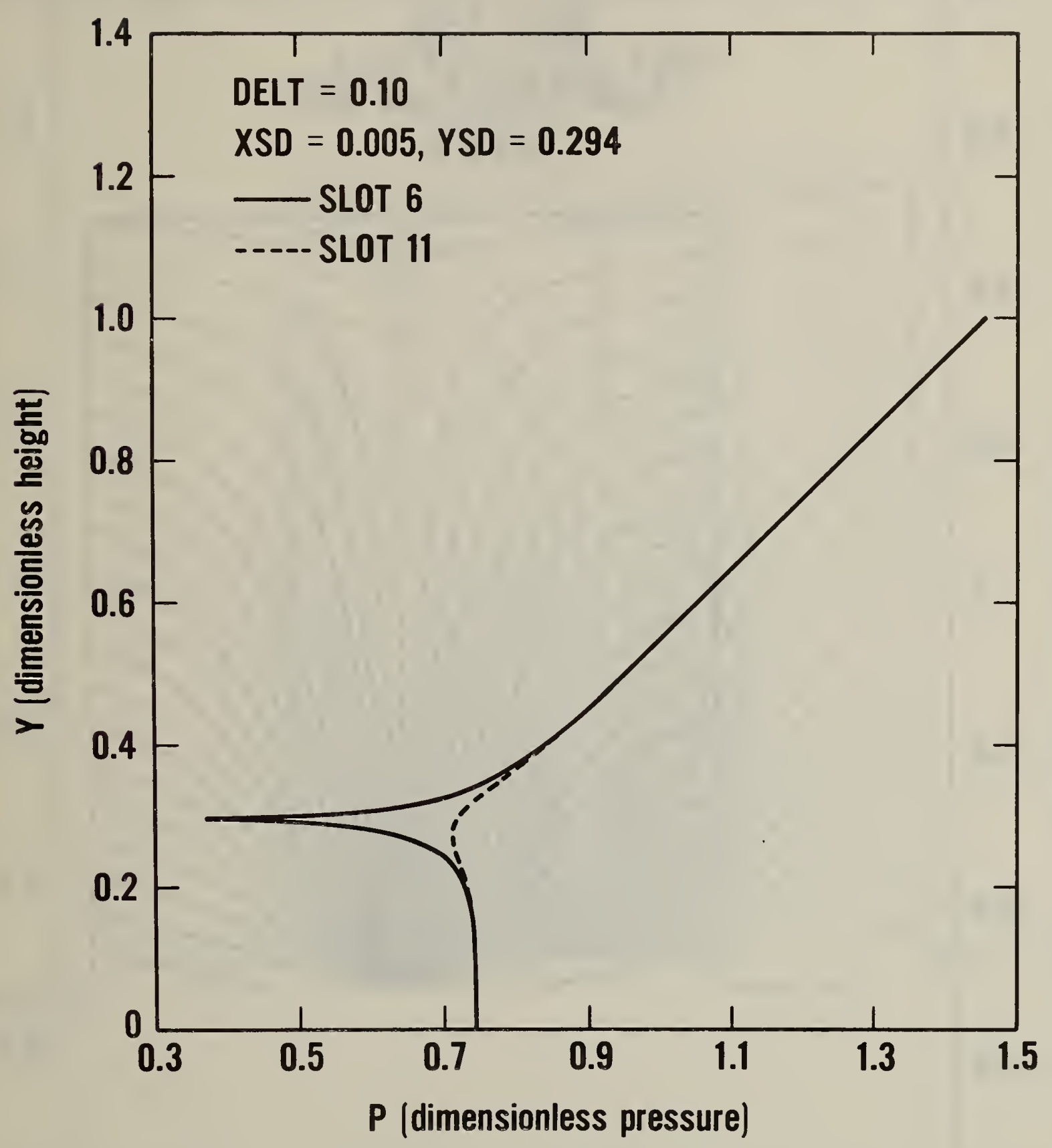

Figure 17b. Physical helght of suction $0.60 \mathrm{~m}$, dimensionless helght 0.294 
Flgure 18. Slot bottom boundary layer streamlines corresponding to ihe pressures shown in figure 17a

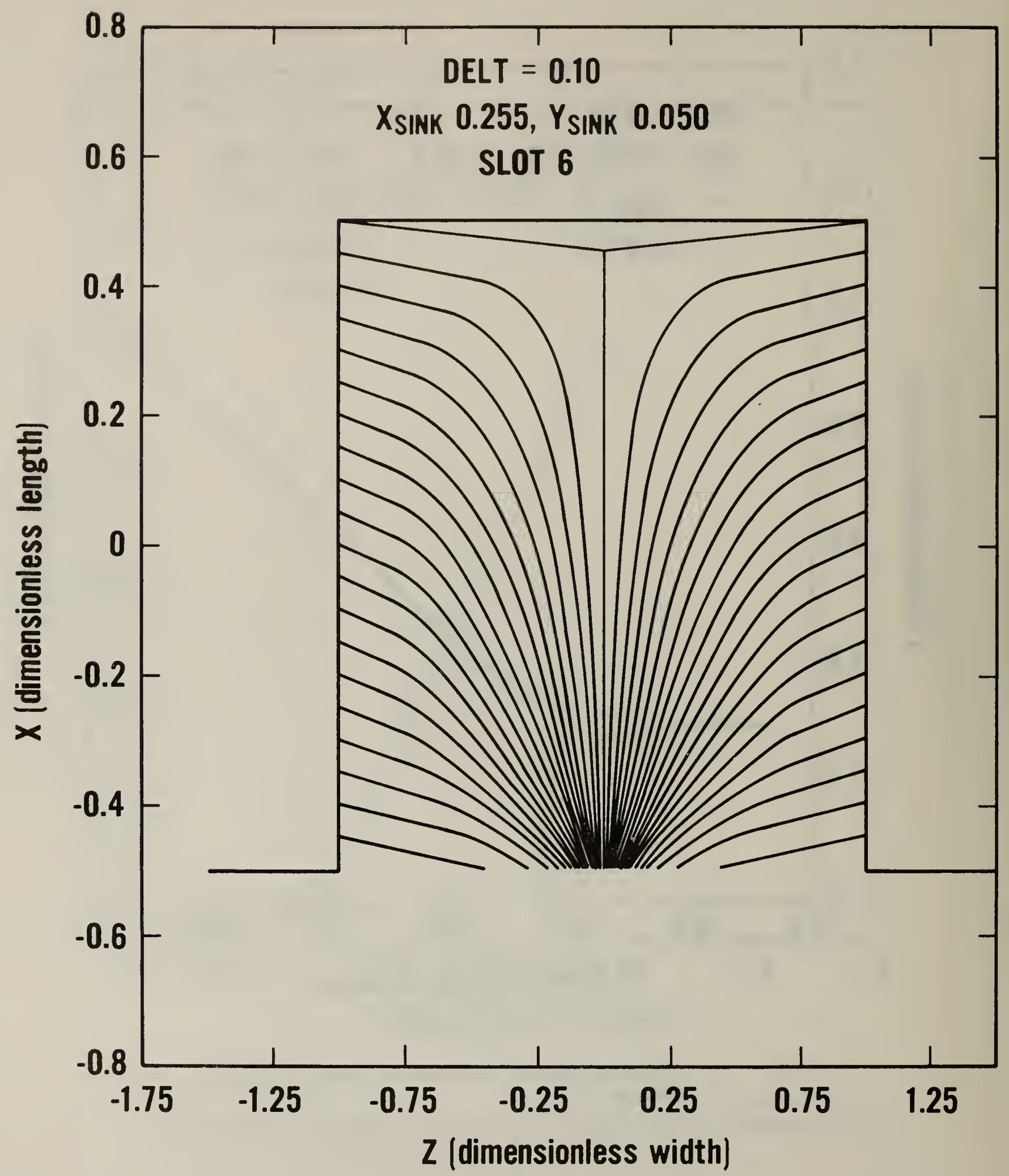

Flgure 18a. Streamlines for slot at center (nearest suction) 


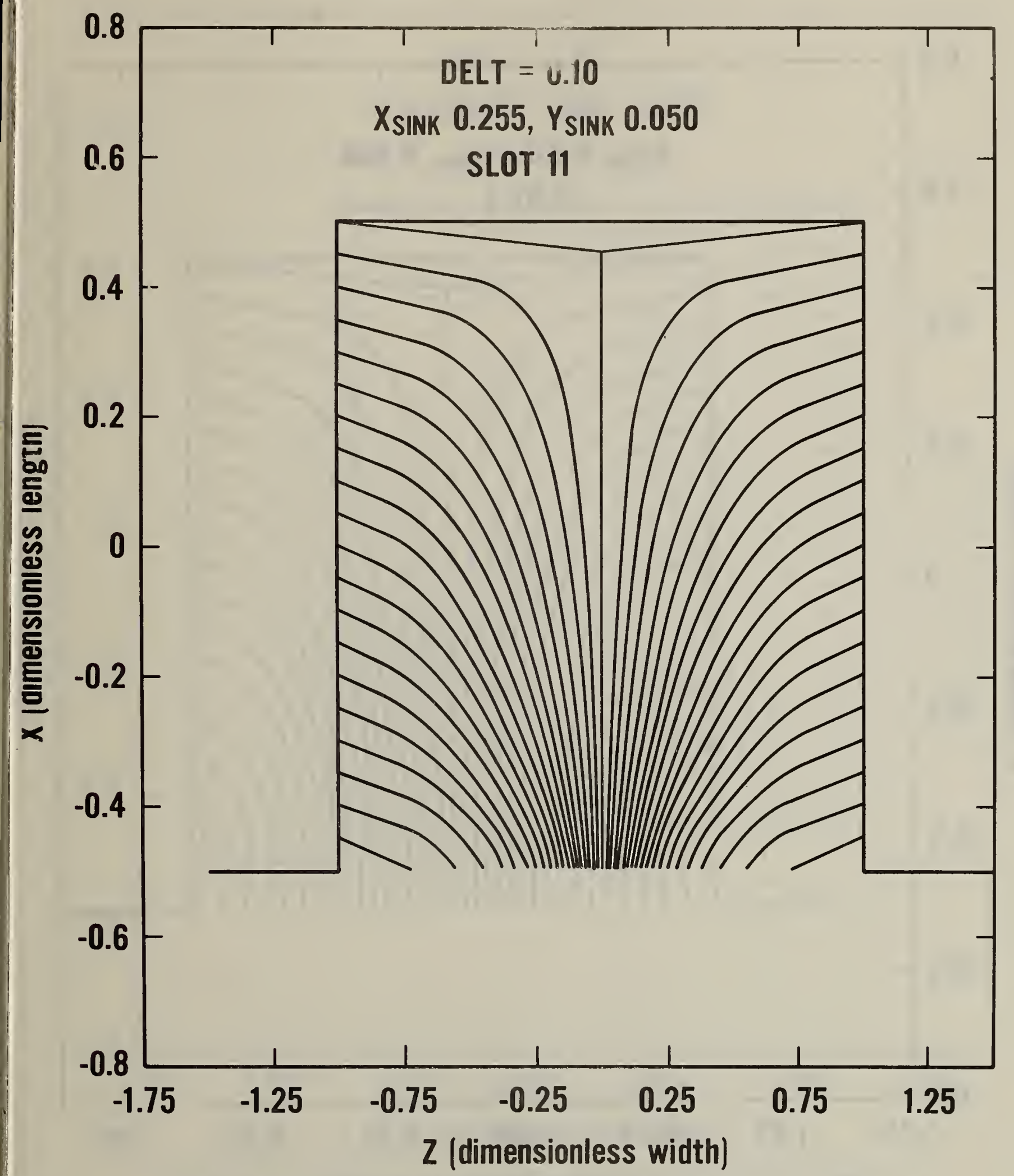

Figure 18b. Streamlines for slot at hold side (furthest from suction) 
Flgure 19. Slot bottom boundary layer steamlines corresponding to the pressures shown in $f$ igure $17 \mathrm{~b}$

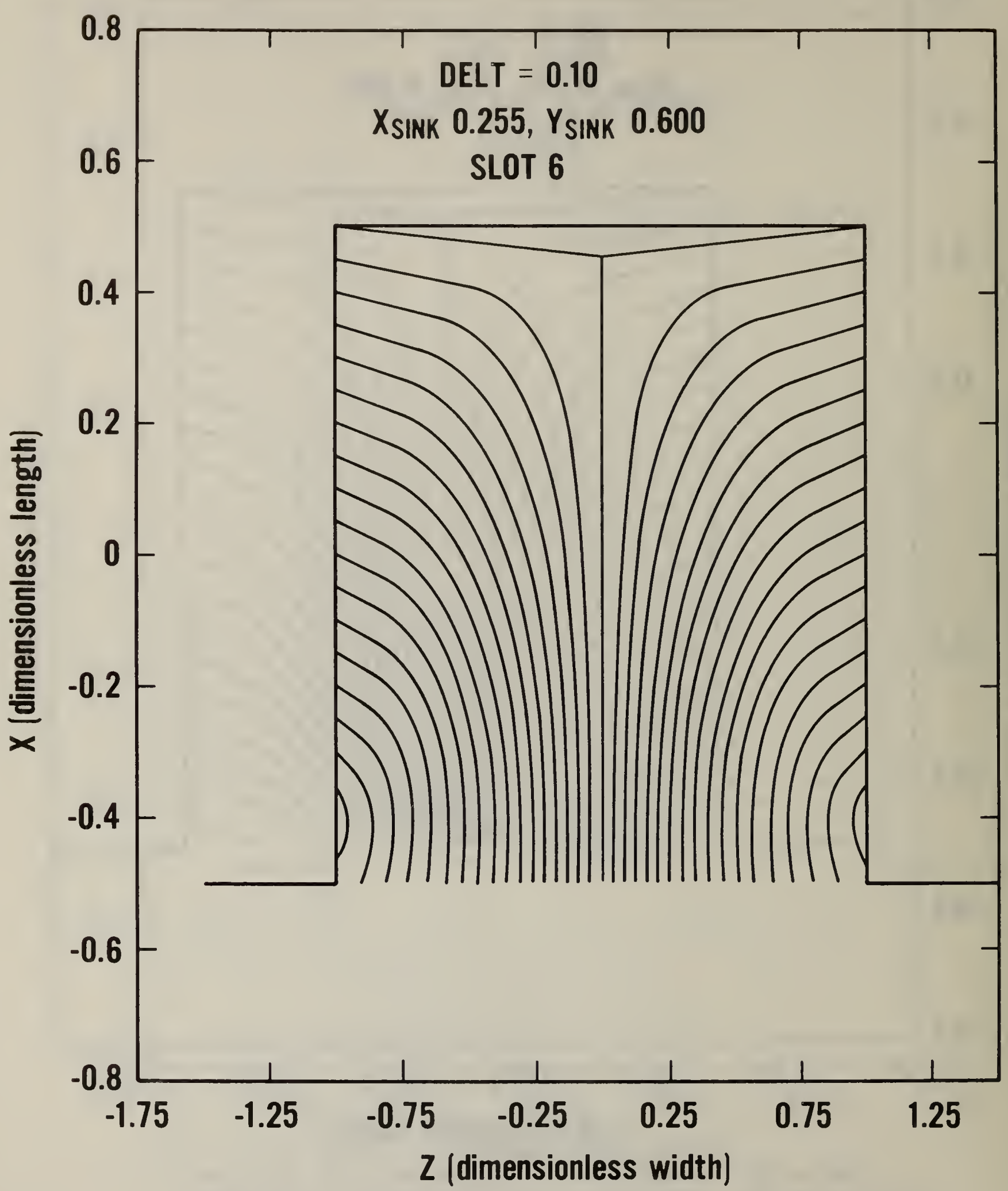

Flgure 19a. Streamlines for slot at centerline (nearest suction) 


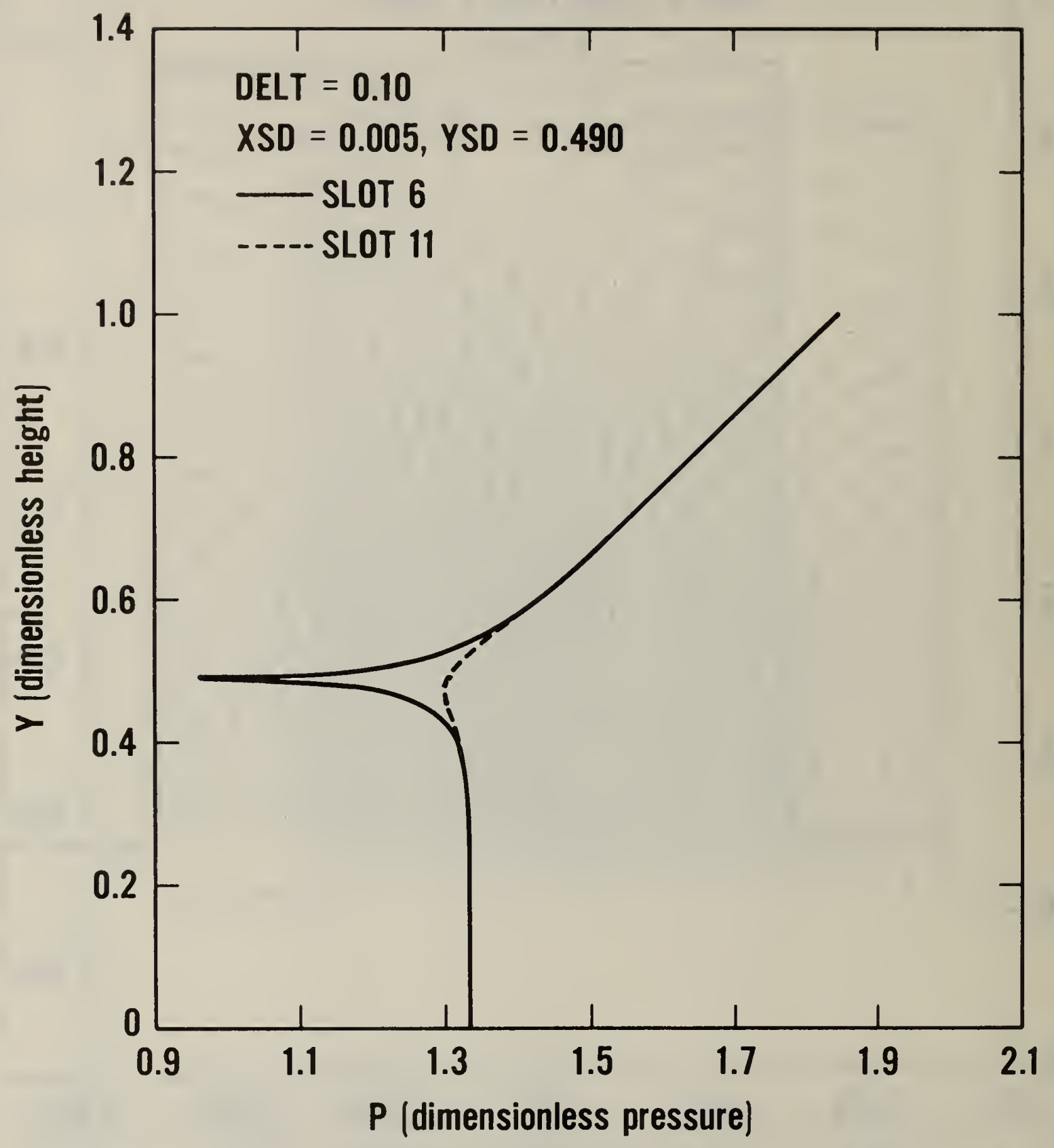

Figure 20a. Dimisionless pressure as a function of dimersionless helgint (double preciston calculation, compare with figine 14). Suction $1 \mathrm{~m}$ above hold bottom 


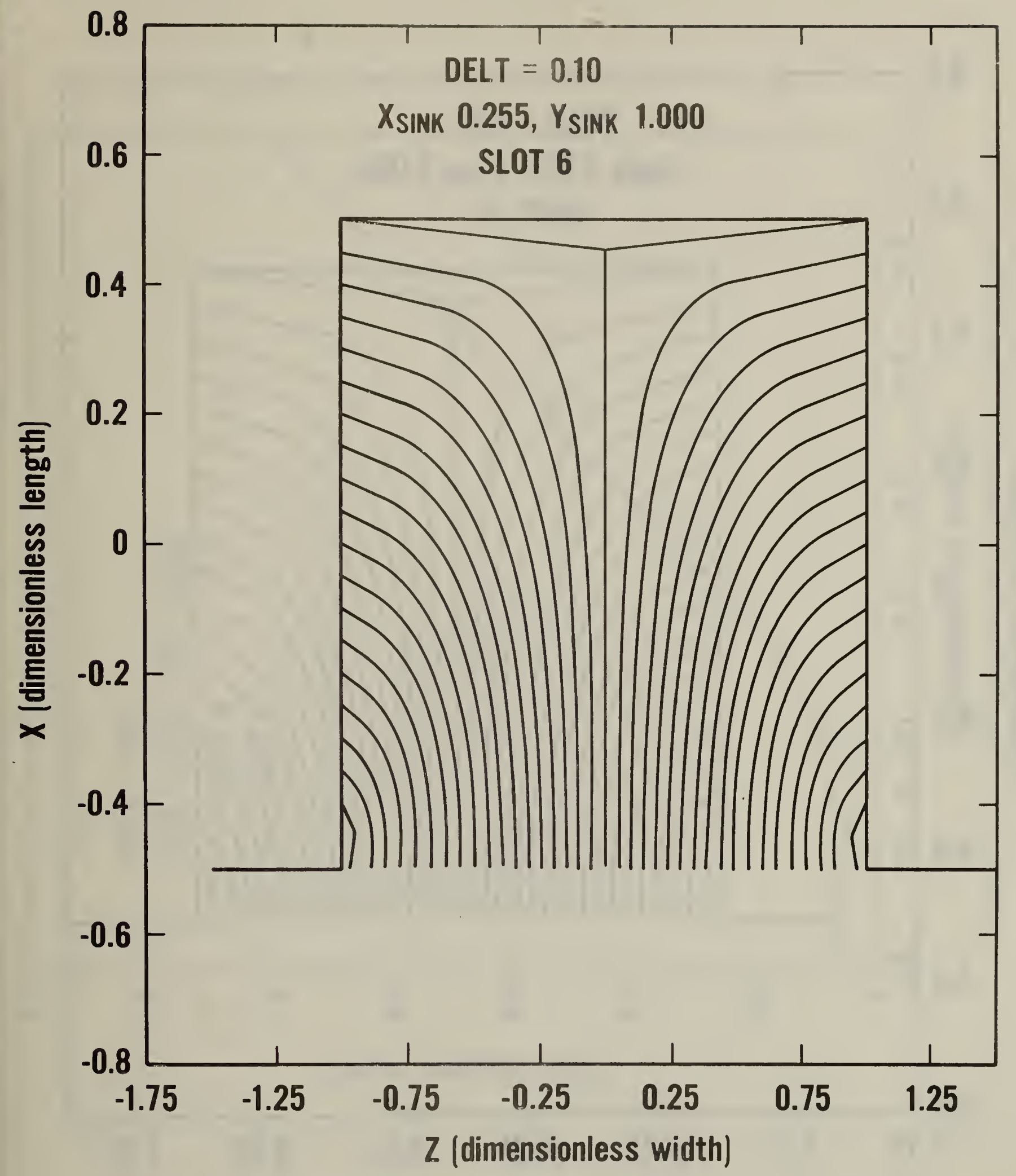

Figure 20b. Slot bottom boundary layer streamlines cor.esponding to the pressure shown in figure $20 \mathrm{a}$. Centerline slot (nearest suction) 


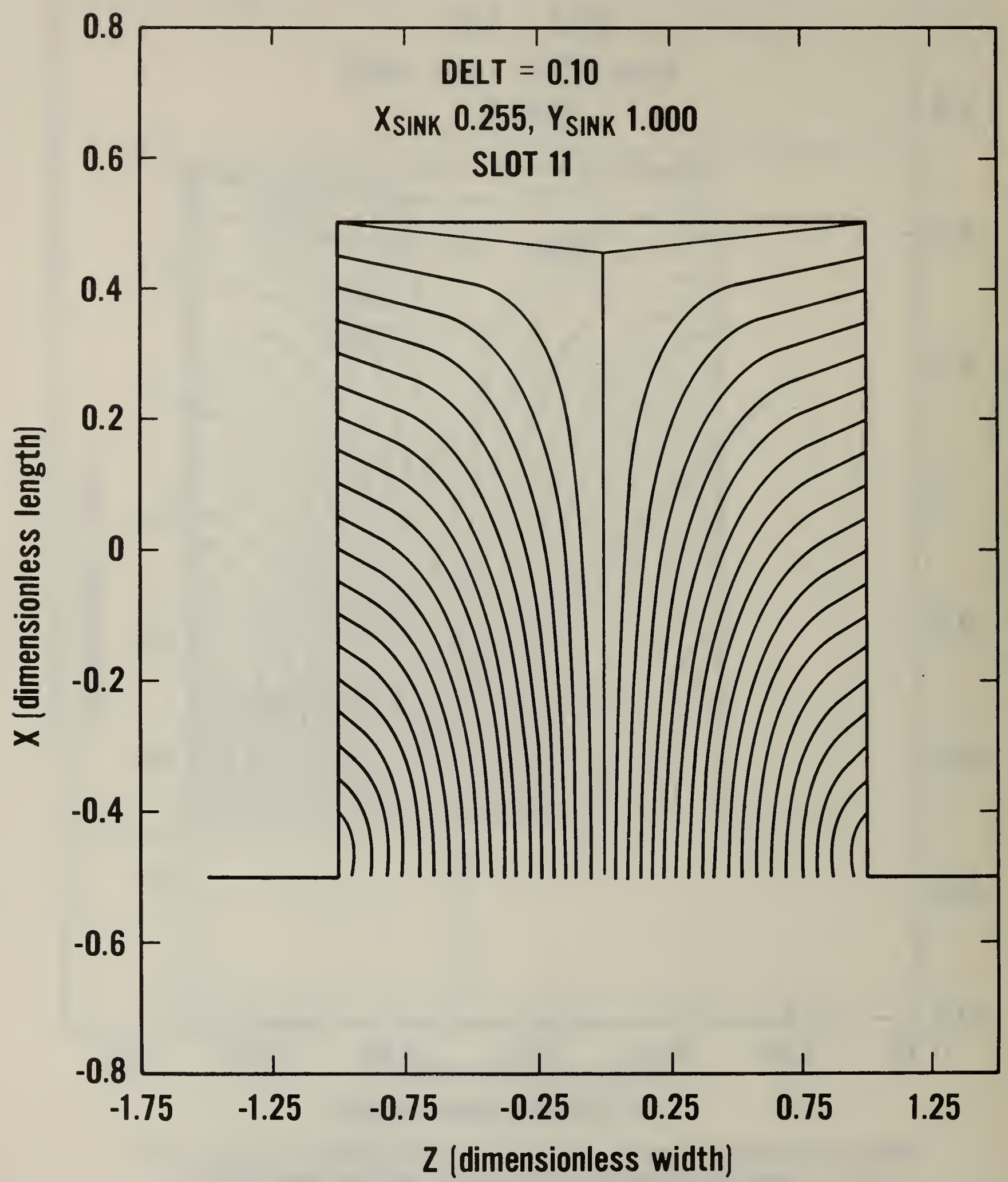

Figure 20c. Slot bottom boundary layer streamlines corresponding to the pressures shown in figure 20a. Side slot (furthest from suction) 


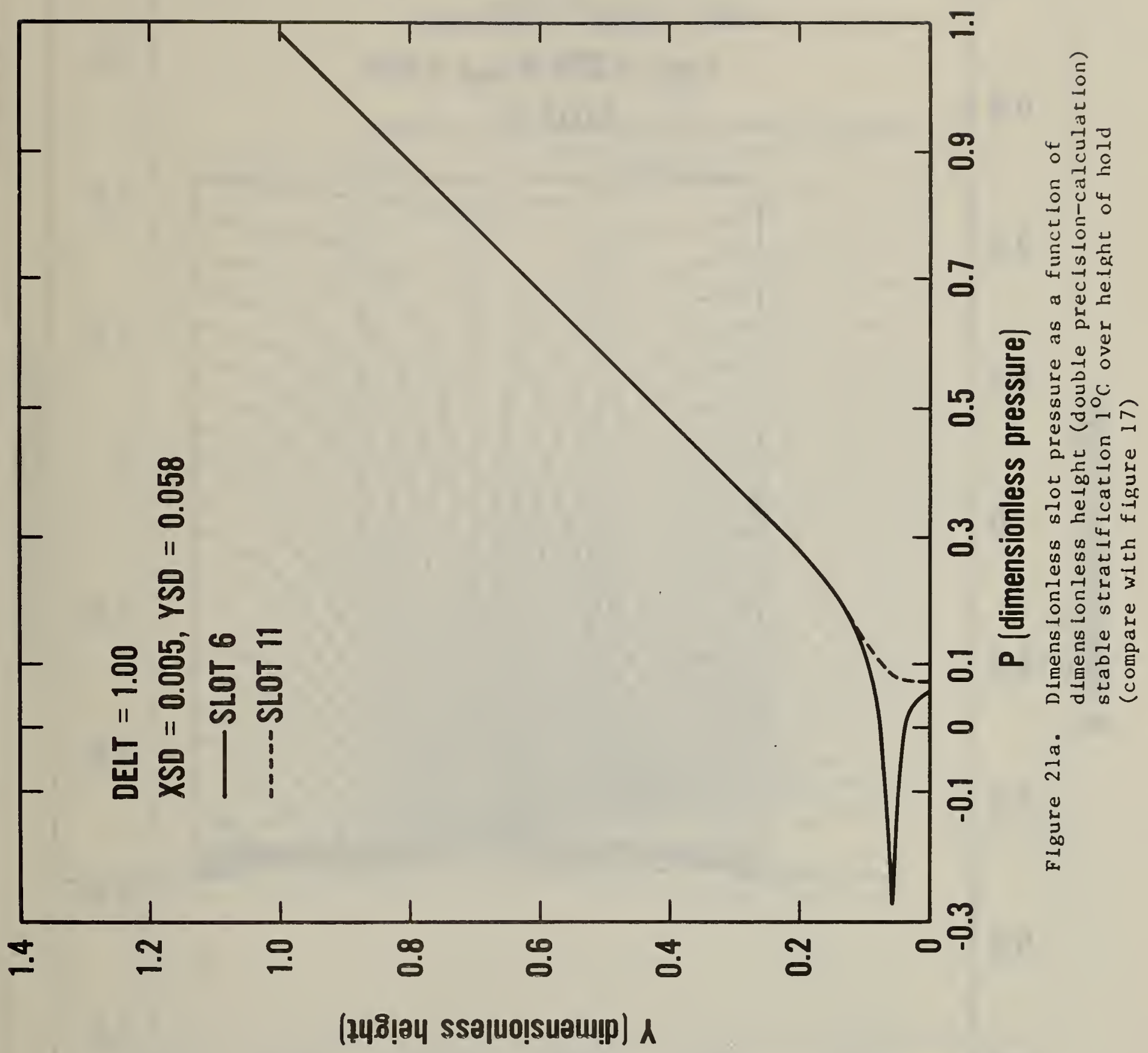




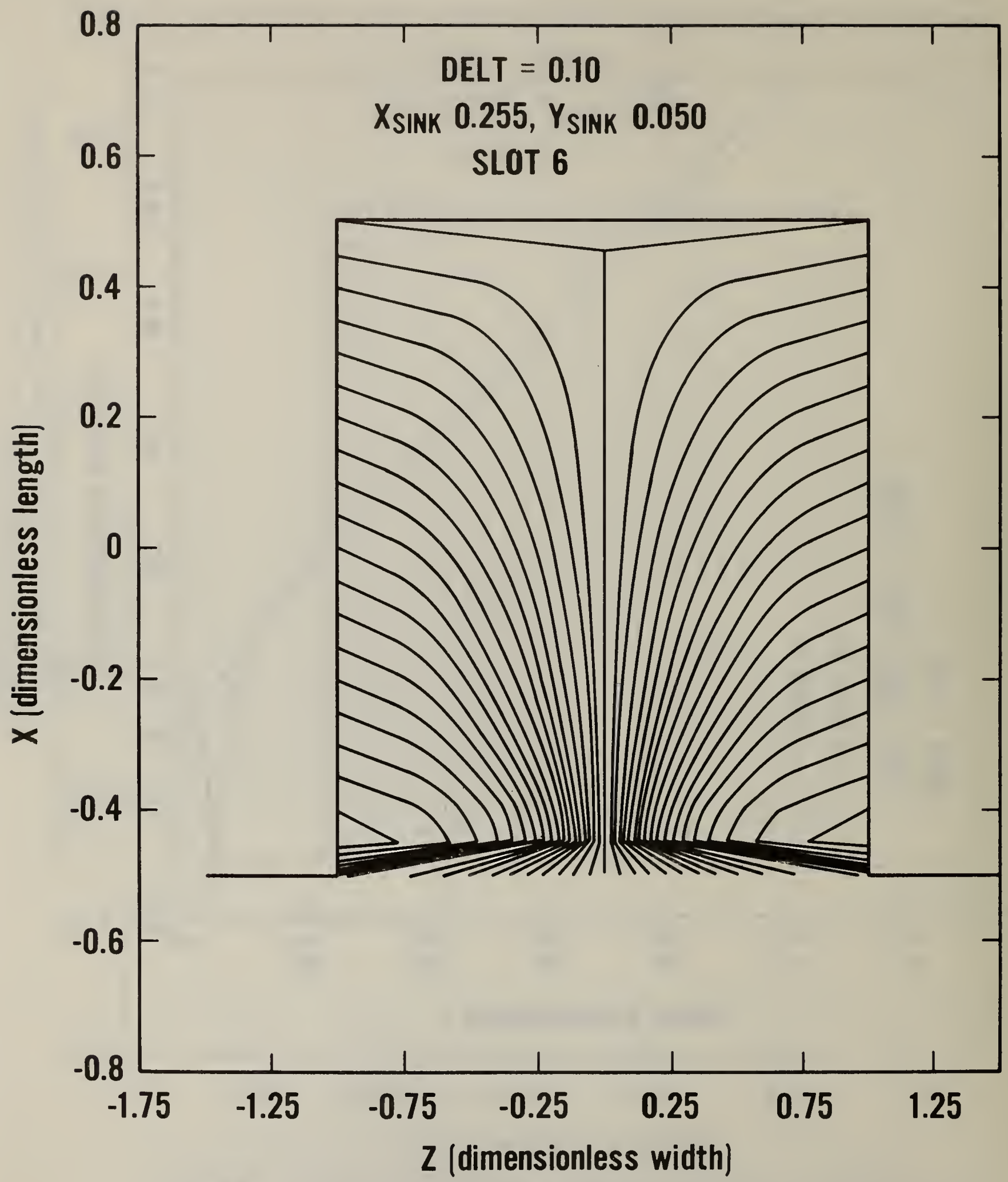

Figure 21b. Slot bottom boundary layer streamlines corresponding to the pressures shown in figure 2la. Centerline slot (nearest suction) 


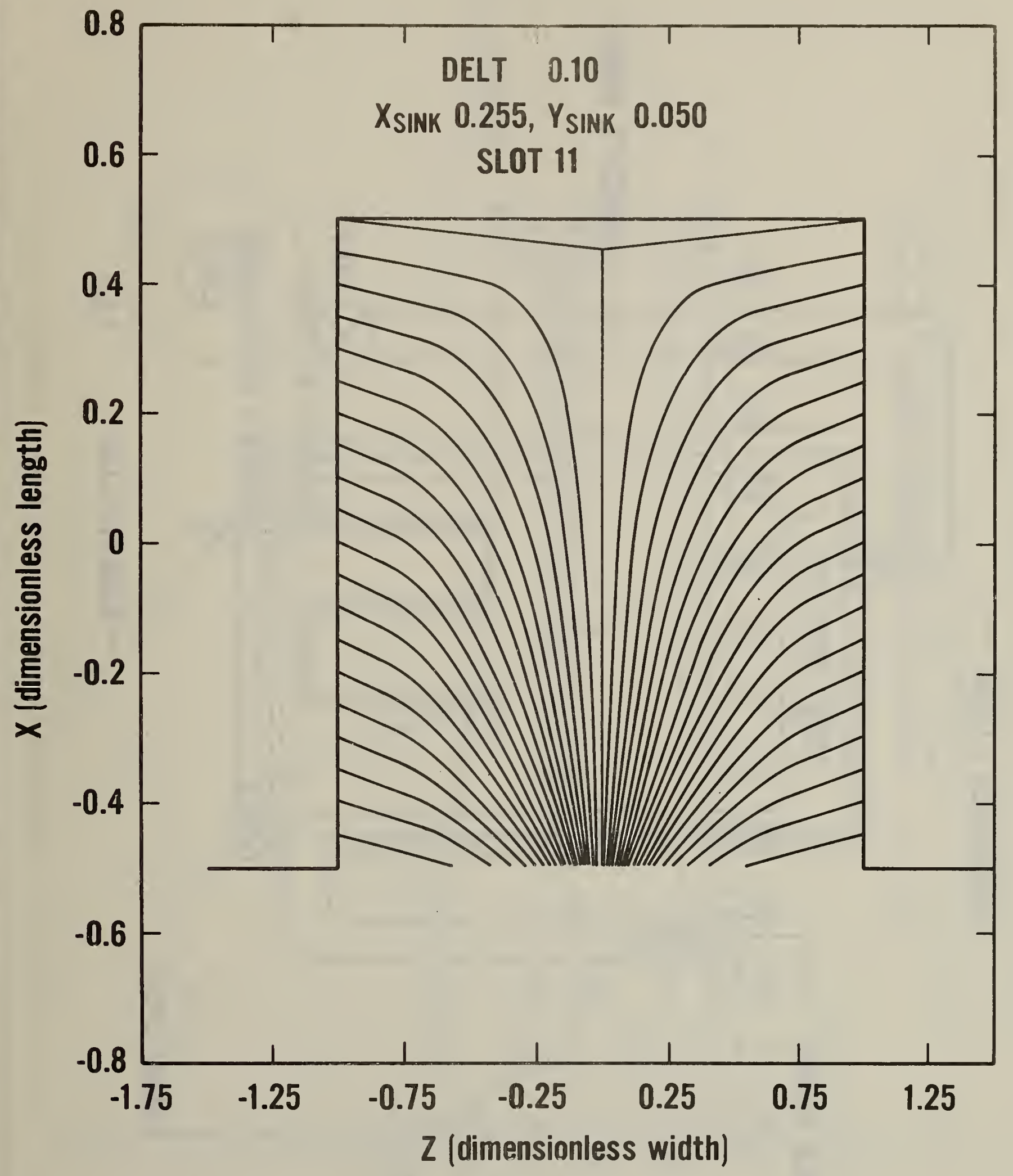

Figure 21c. Slot bottom boundary layer streamlines corresponding to the pressures shown in figure 2la. Side slot (furthest from suction) 


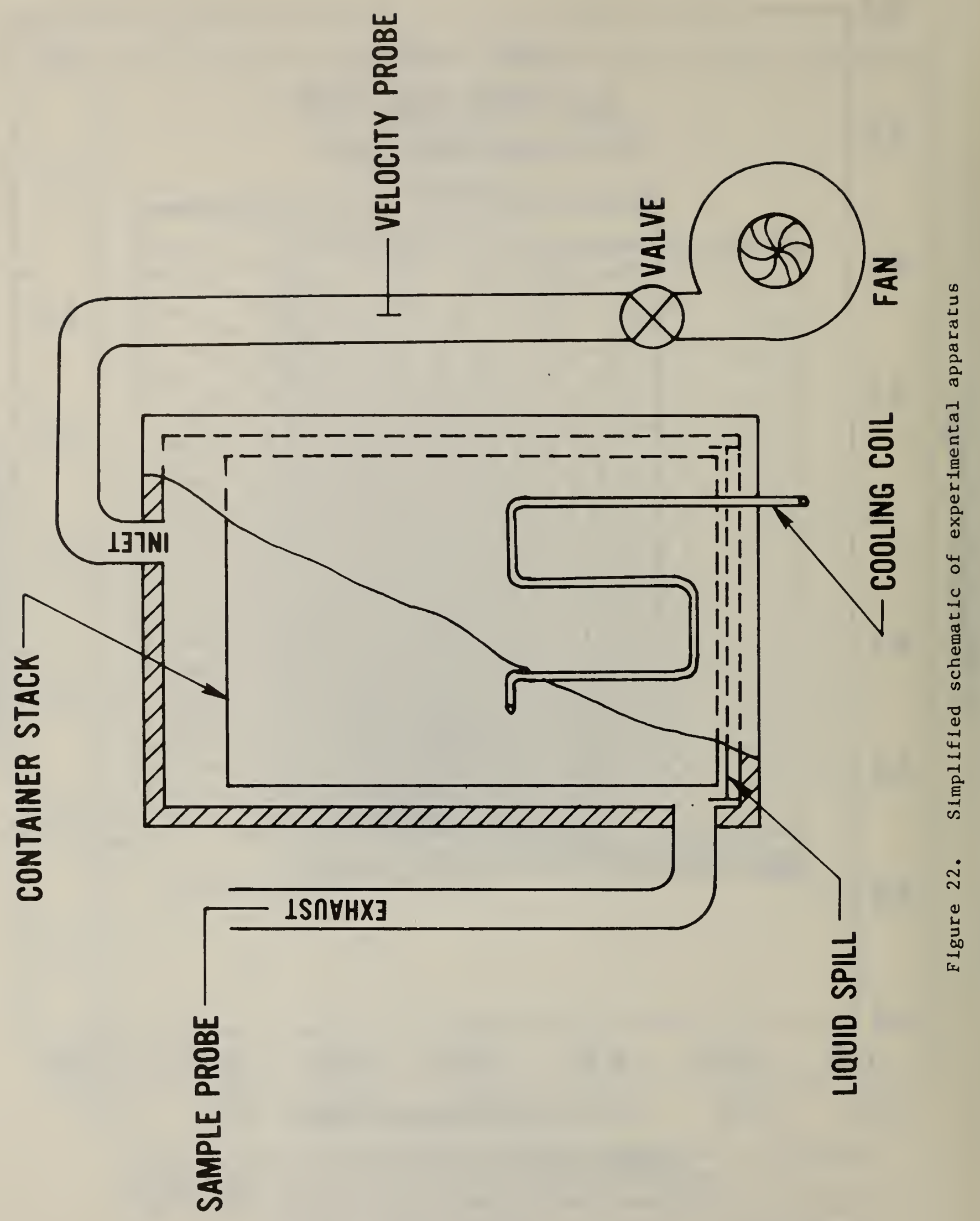




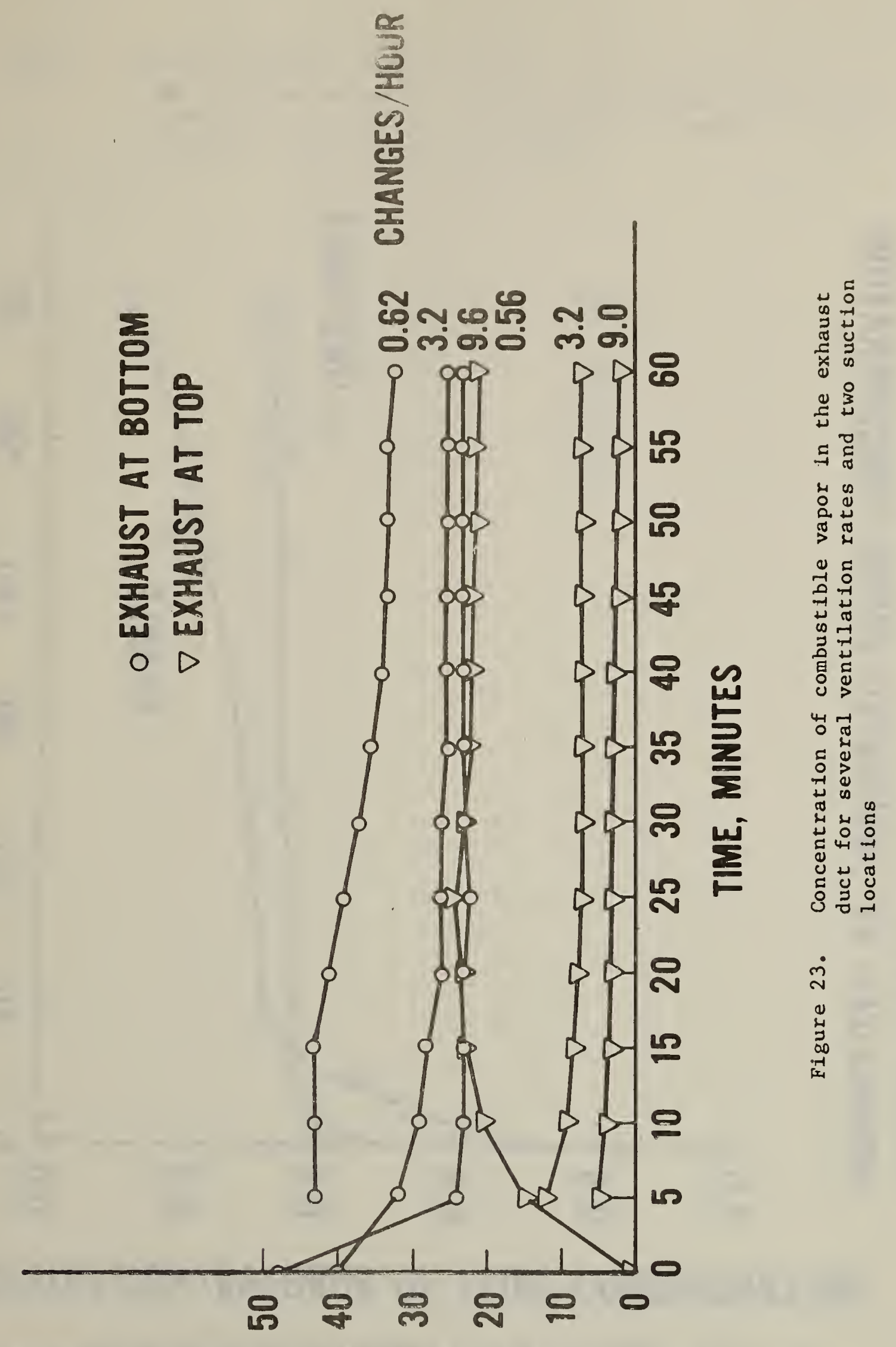

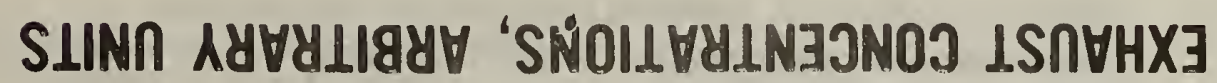




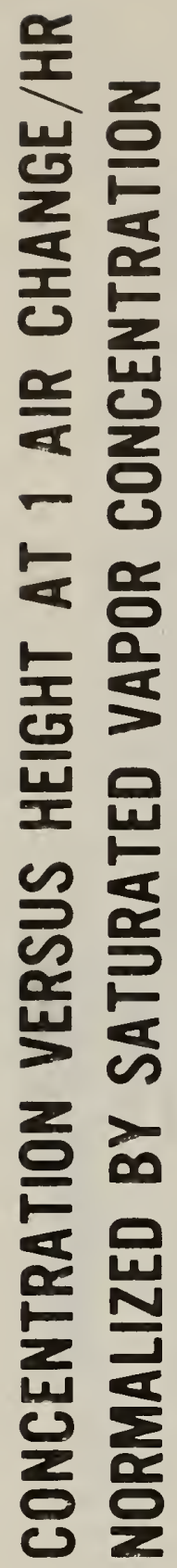

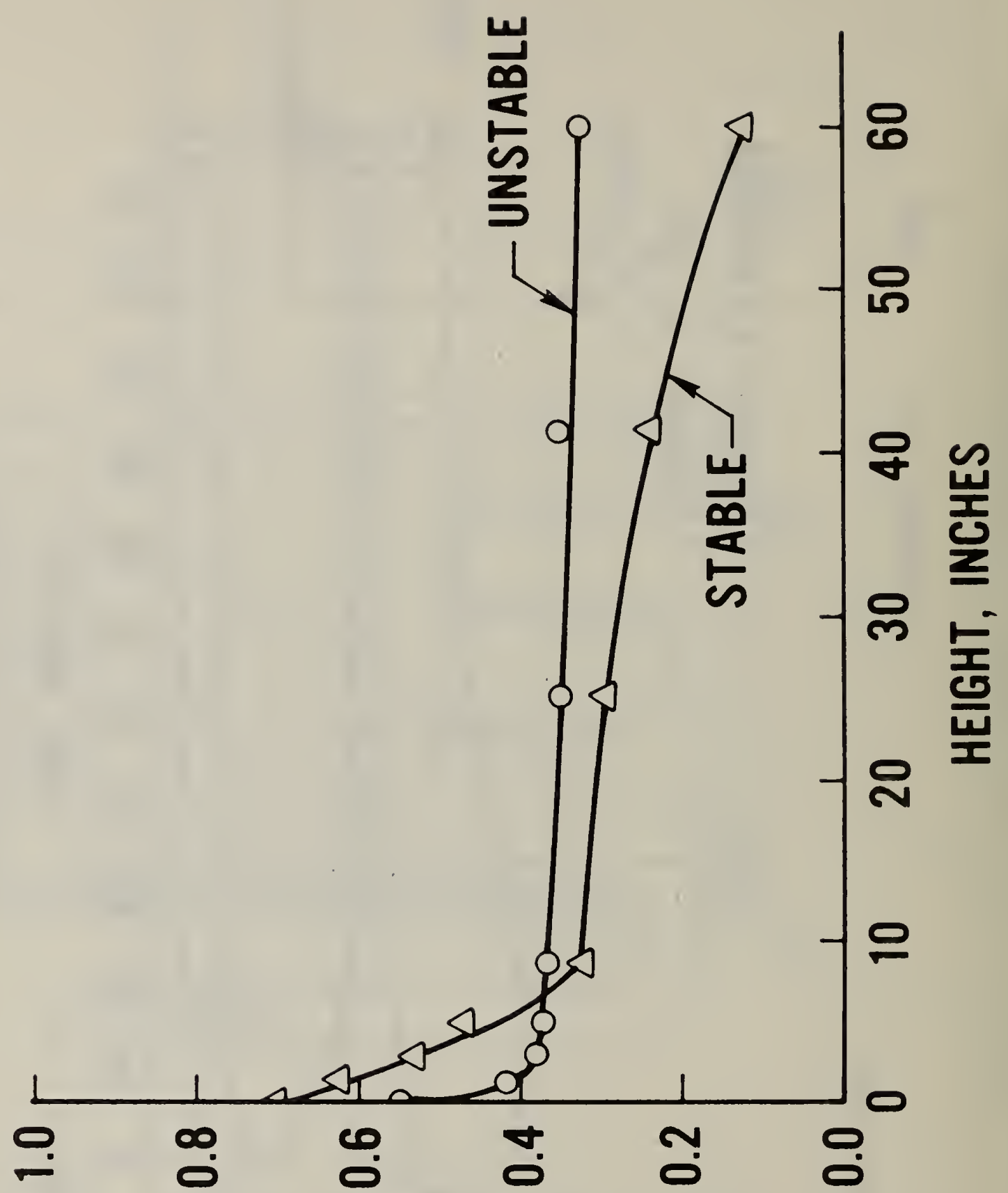

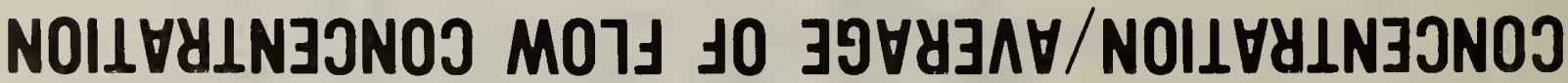

Figure 24. Concentration to combustible vapor inside the experimental enclosures versus height of the sampling point. One air change per hour forced ventilation flow, low suction 
Table 1. Vertical pressure gradient effectlveness $f(\omega)$ dependence upon stratification parameter $\omega$ defined $\ln E q .(10)$ of text. $f(\omega)$ is the ratio of vertical to horizontal flow capable of being produced by a given pressure gradient. 
Table 2. Dimensionless Mass Pick-Up

Suction Helght $5 \mathrm{~cm}$ Mass Plck-Up

S1ot 非

1

2

3

4

5

6

7

8

9

10

11
Centerline Suction

2.01

2.05

2.12

2.25

2.37

2.51

2.34

2.18

2.12

2.03

1.95
Side Suction

2.72

2.49

2.29

2.16

2.00

1.91

1.82

1.74

1.74

1.70

1.66 
APPENDIX 1.

Example of Input Data 
웅

$a$
$\vdots$
$i v$

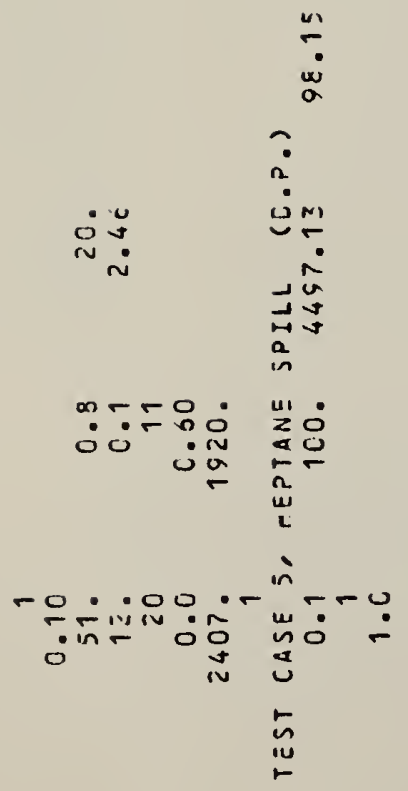


APPENDIX 2.

Output for the Input Data of Appendix 1 


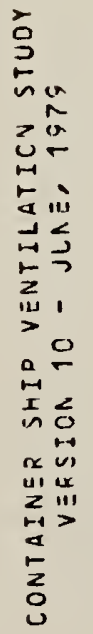




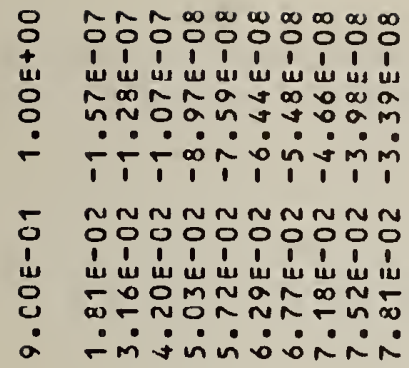

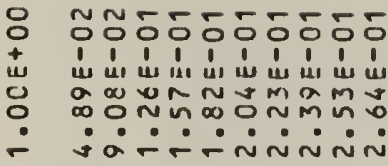

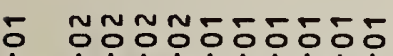

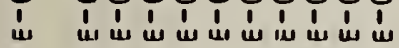

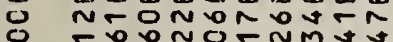

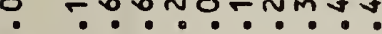

- Nกำ-

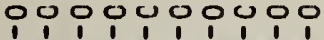

(u) w w w w w w w w

min

?ำ?

5

n $2.0-2-2 .-2$.

$\begin{array}{ll}5 & \vdots \\ 0 & 1 \\ 1 & u \\ 0 & \cdots \\ 0 & \vdots \\ 0 & -\end{array}$

잉ㅇㅇ엉ㅇㅇㅇㅇㅇ

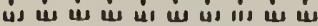

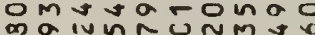

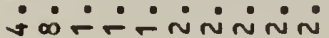

$\begin{array}{ll}5 & 5 \\ 1 & 1 \\ u & u \\ 0 & \sim \\ 0 & m\end{array}$

5
1
1
0
0

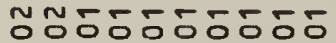

i 1 11 i i

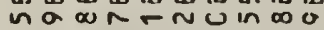
n?

a

$\begin{array}{ll}5 & 0 \\ 1 & 1 \\ u & 4 \\ 0 & 0 \\ 0 & \vdots \\ & \vdots\end{array}$

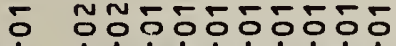

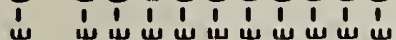

ч

o $0 \div \div n \infty 0 \div m \div$ ?

- N 055050550

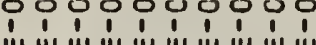

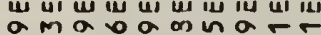
amơñ

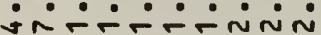

$\begin{array}{ll}5 & 5 \\ 1 & 1 \\ w & u \\ 0 & 0 \\ 0 & 0\end{array}$

- Nㅜㅇㄷㅇㄷㅇㄷㅇ

1 11111111

岁

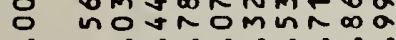

i ír-inininin

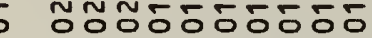

:

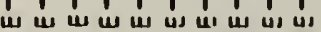

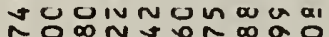

min-

$\begin{array}{ll}5 & 5 \\ 0 & 1 \\ 1 & w \\ 0 & N \\ 0 & \vdots \\ \text { n } & \text { n }\end{array}$

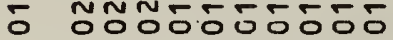

'́n

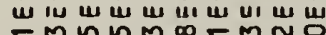

NOYONmEDN

mix $\dot{0} \div \div \div \div \div$

웅 눙두웅ㄷㅇㅇㅜ

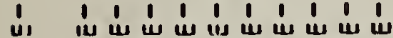

ப ปm

-

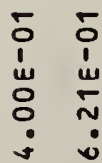

0000

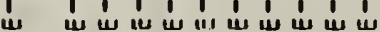

는

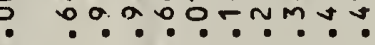

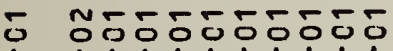

1 1 11111111

능ำ

ن

- 우융ㅇㅇㅇㅇㅇㅇ

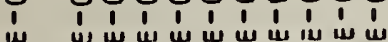

w 쓴ㅆㅆ

ப ถิ

i $\dot{-r n v i n m i m i m}$

$\begin{array}{ll}5 & 0 \\ 1 & 1 \\ 1 & u \\ 0 & \infty \\ 0 & n \\ m & 0\end{array}$

- nnnnnnn-tron

- 00บ00000

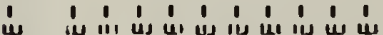

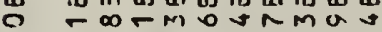

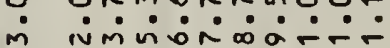

$\begin{array}{ll}5 & 5 \\ 1 & 1 \\ u & u \\ 0 & 0 \\ 0 & 0\end{array}$

- munnnnanna

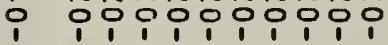

u

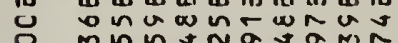

i

๘

1. 1

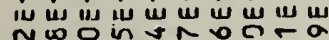

넝요

-

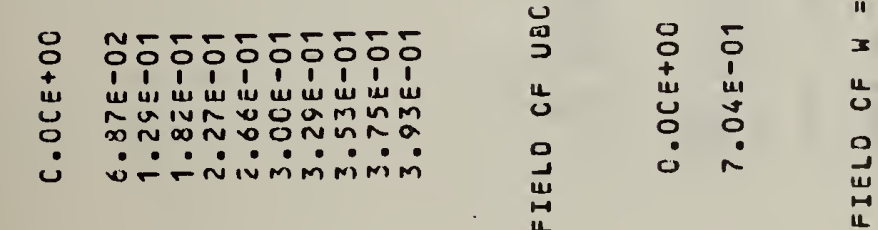

monumunindund

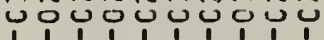

м ш

a

$\therefore-\dot{n} \sim \dot{m i m}$

$\begin{array}{ll}11 & 0 \\ \sim & 0 \\ 2 & 0\end{array}$

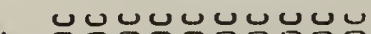

응응응응응응응응

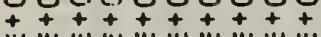

بئن

ن



نبن

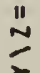

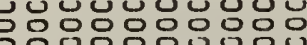

ㄴ.? ن் 


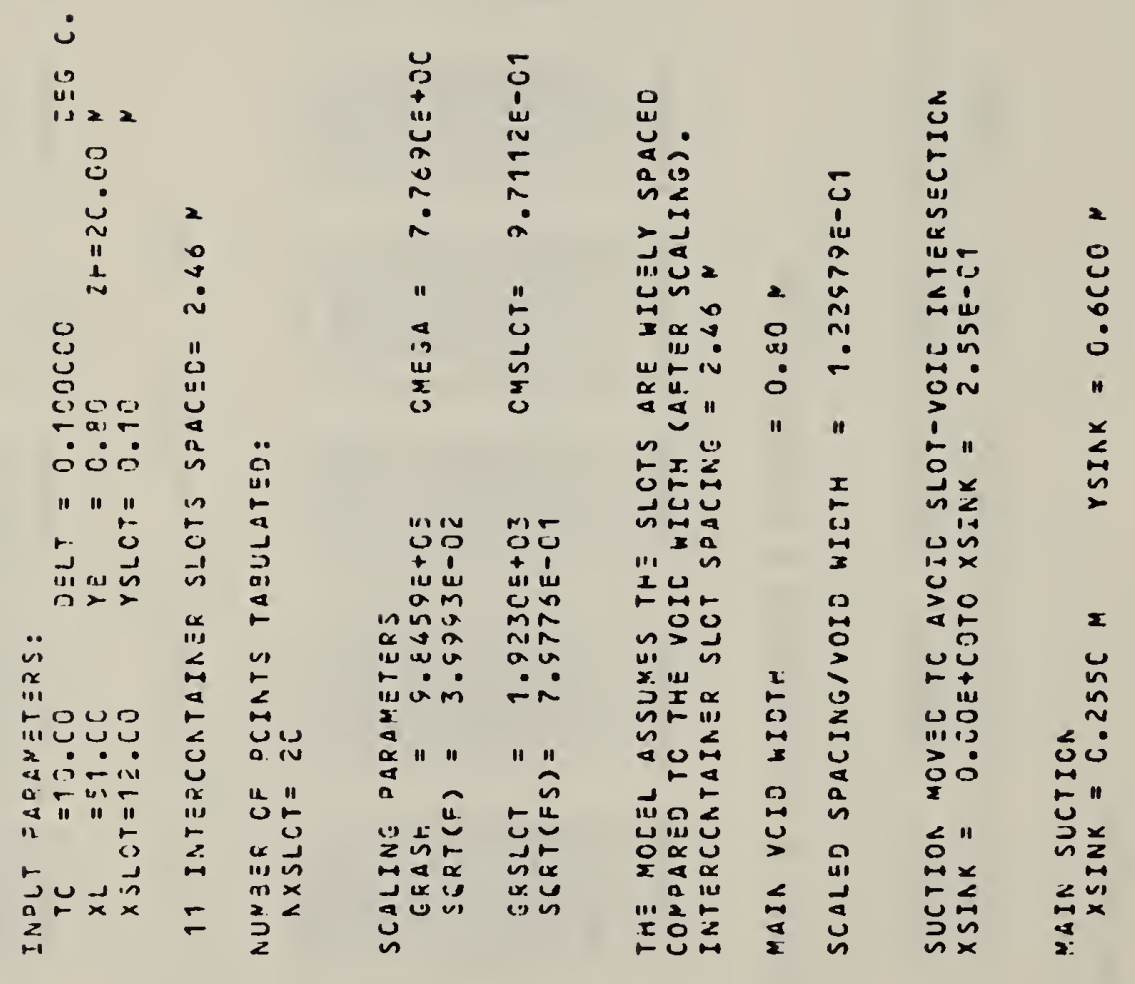


5 555555555555555555N t

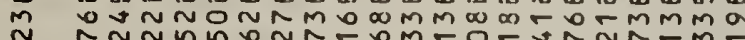

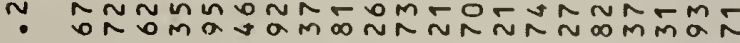
ó

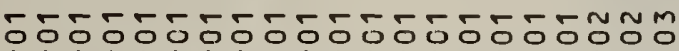

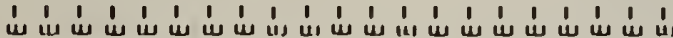

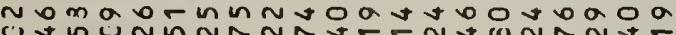

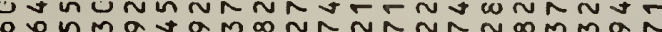
க́

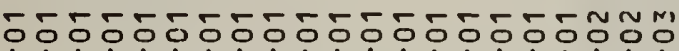

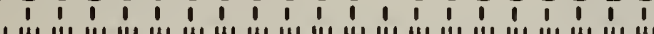
ON

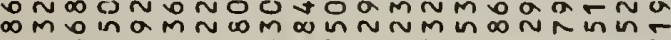
un $u \propto \alpha+a m \infty \sim \sim \sim \sim \sim \sim \sim \infty m m \alpha \pi$ w w o o

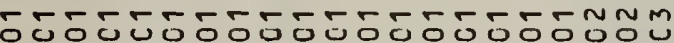

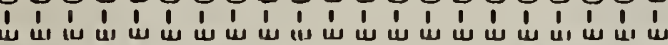

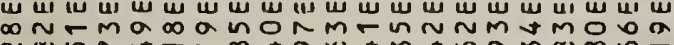
mmm

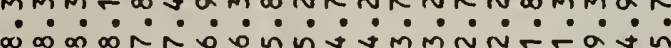
555555555555555555 №

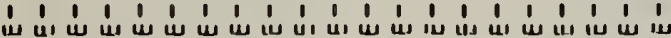
w móñ

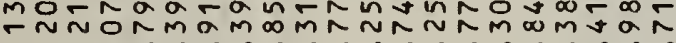
क

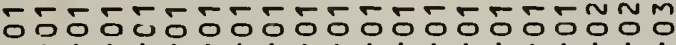

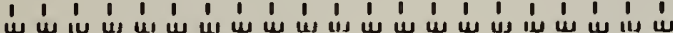

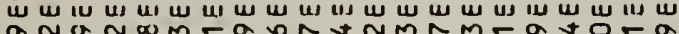
a $N$ a «U.?

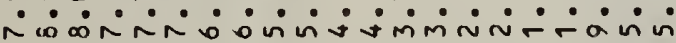

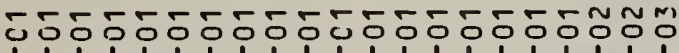

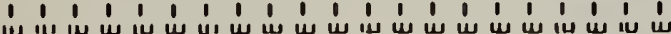

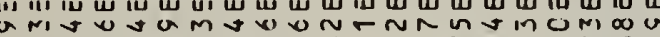
ำกำ क्ष

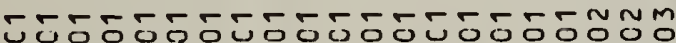

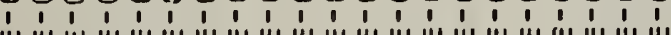
11. Г⿴囗十

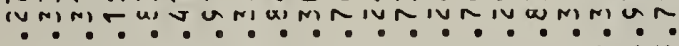

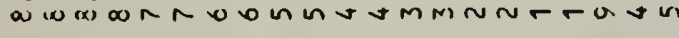

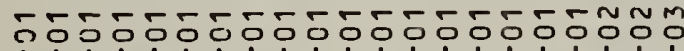
wis

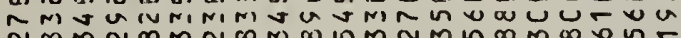

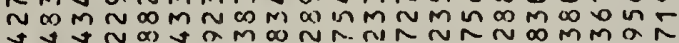

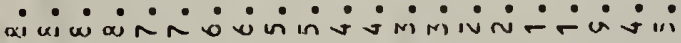
- 2-7إب "11

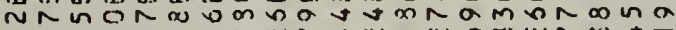

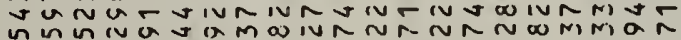

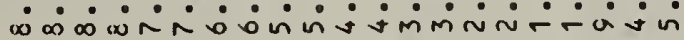

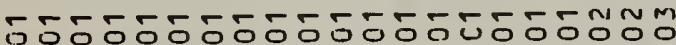

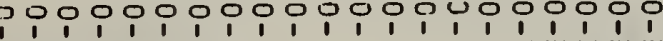

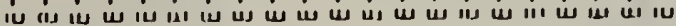

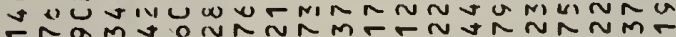
o m ovm

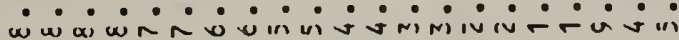

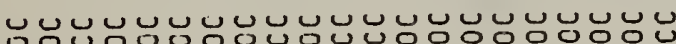
ن u

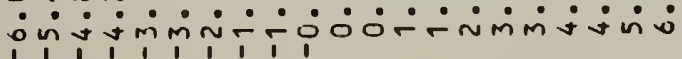

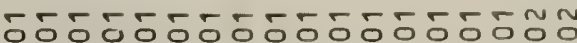
$1,1,1,1,1,1,1,1,1,1,1,1$

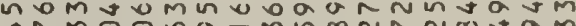

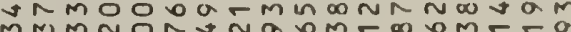

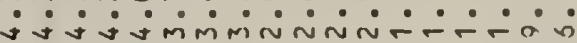

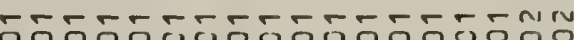
CO000000000 س - Noma

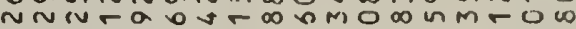

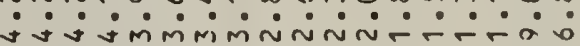

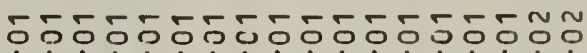
cu w

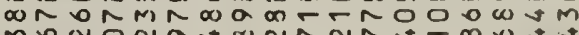
mornonasannanatrom oo oon? tet-tet-tet-tetinnn

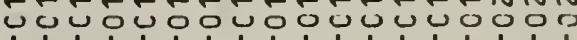

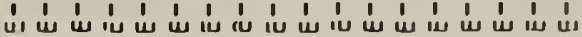

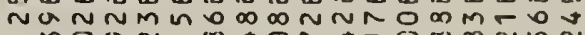

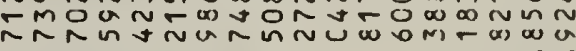

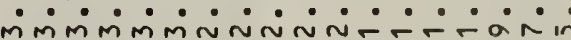

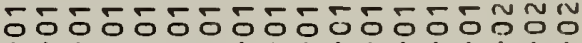

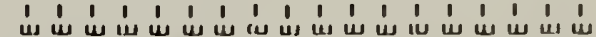

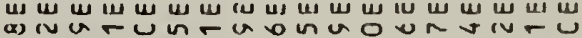
d)

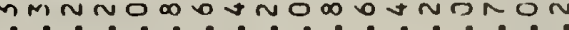
mMimm nivivant-R-R

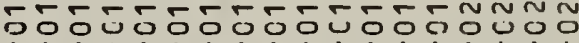

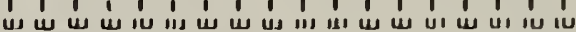
mon

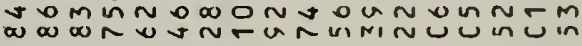

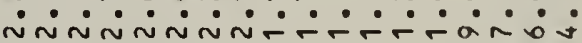

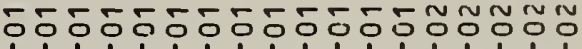
'́

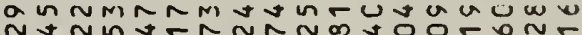
mmmñ

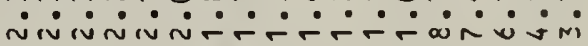
T-

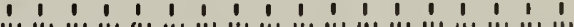

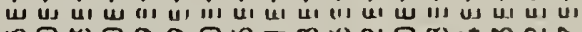

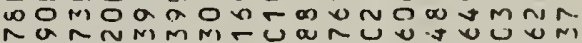

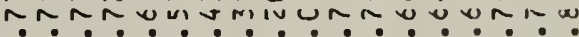

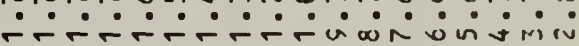

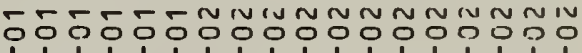
if '

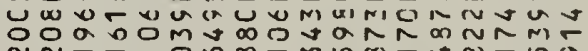

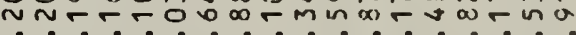

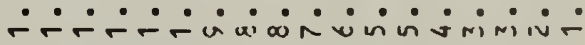

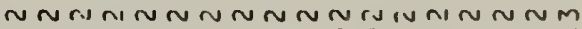
1

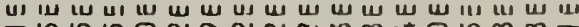
$\sigma$ in $n$ in $0 N a \sim N \alpha, m$ oo 0 in $m m-$

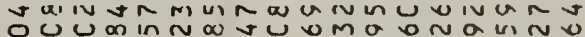

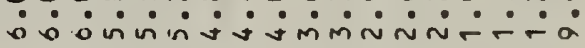
엉엉엉엉ㅇㅇㅇㅇㅇㅇㅇㅇㅇㅇㅇㅇㅇㅇㅇㅇㅇㅇㅇㅇㅇㅇㅇ +4 +

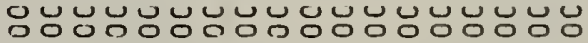

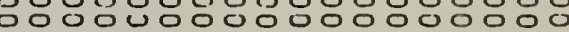
ن ن ن ن ن ن ن ن ن ن ن ن ن ن ن

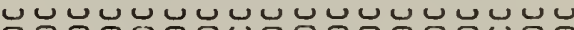
"

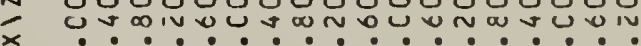

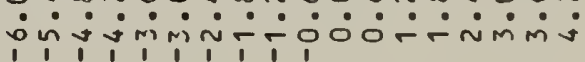


Nㅣㅇ

ú

○ు

$\because \because \infty$

กับ

000

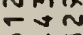

inin

No

is ú

$0 \pm-$

$m m ?$

in

○บ

a) as un

ธก

iniv

1uㅗ

سُ سُ

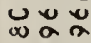

!

ح

1

이

ب.

웜

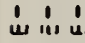

iv

in $m$ "

N Nm

?

"ו"

iv 5 a

$\therefore \because$

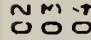

is

(2)

ئ

促

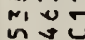

:

응요

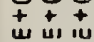

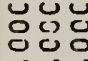

ن

4'

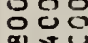

iñ.

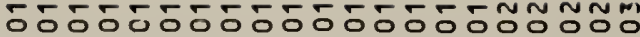

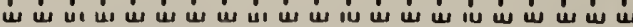

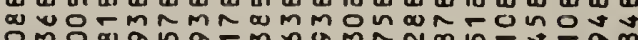

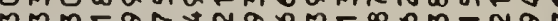

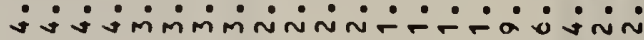
-50.5-50-5.5-5.- n n nNm 11011 1 шш ш ш ш ш 前

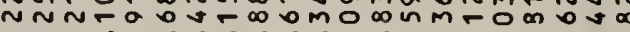

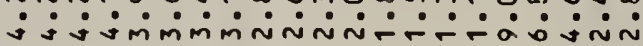

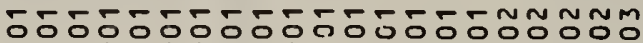

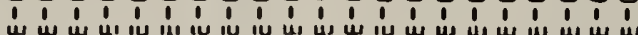

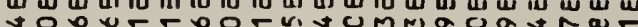

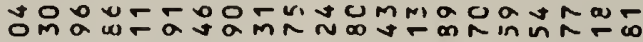

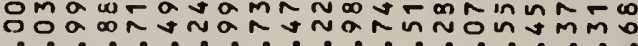

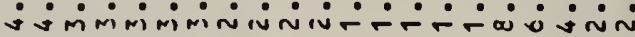

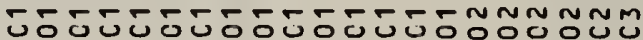

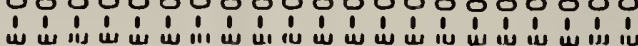

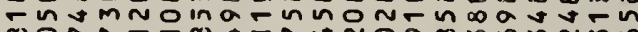

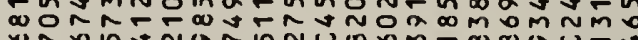

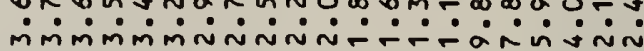

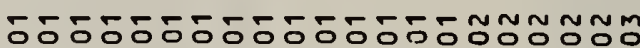

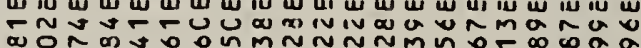

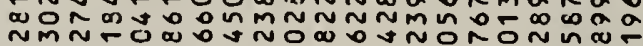

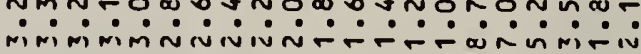

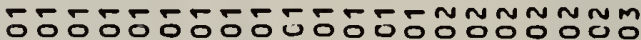
íd ' wू ut

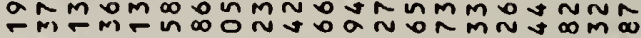
wown w y o on mivu un un una

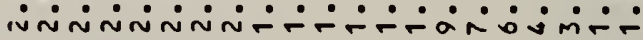

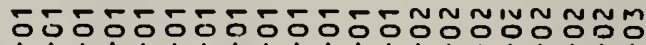

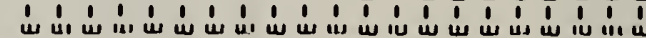

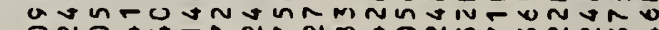

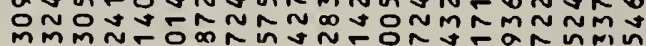

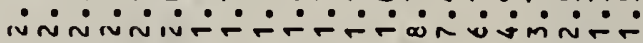
-5-5-5.5-

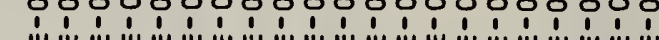
w

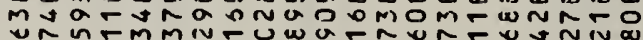

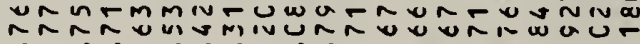

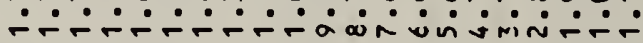

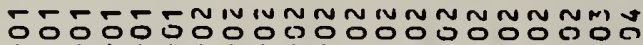
ú Ua

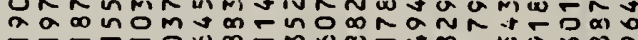

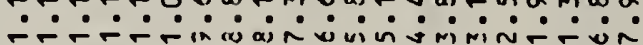
M N بي بوب ш

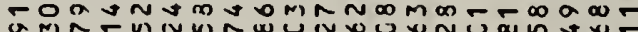

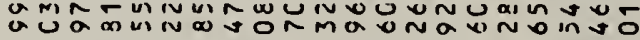

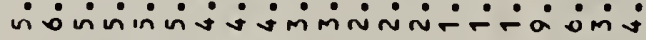

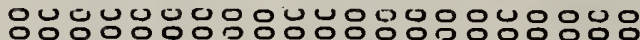

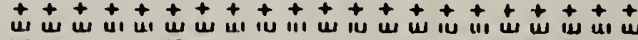
بون

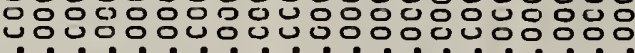

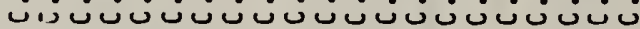

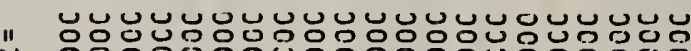

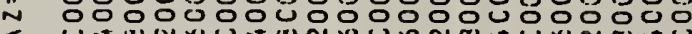

$\bar{x}$

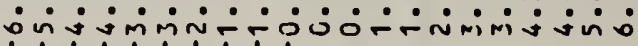

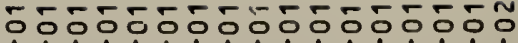

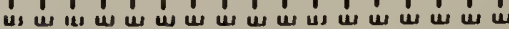

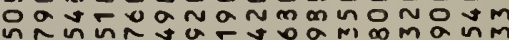

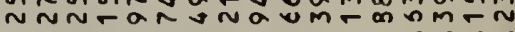

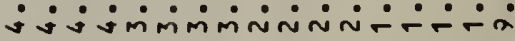

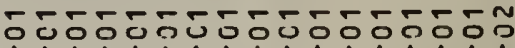
w

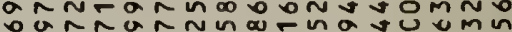

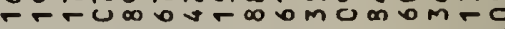

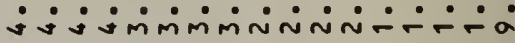
5.505050-5050505550

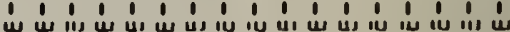
omnusunua ou $\operatorname{man} \pi=\pi \pi \infty$ a a a w o s Nan? Narman

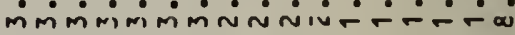

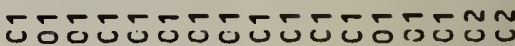
1 1 muñ U 0 on mimmimininini-:-

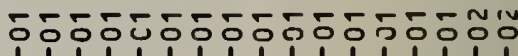
ñus

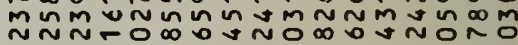

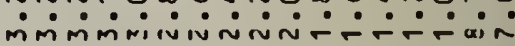

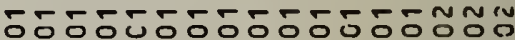

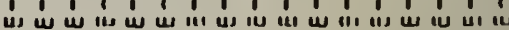

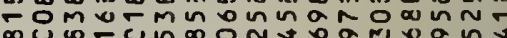
oun

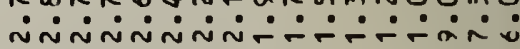

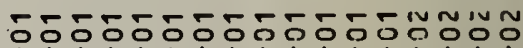

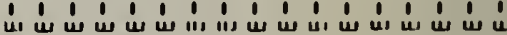
wmo in

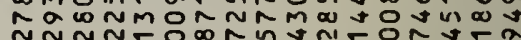
innivinirarámín

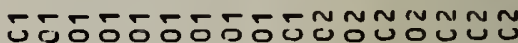

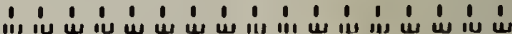
aroa) a wastrutun

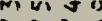

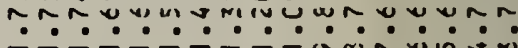

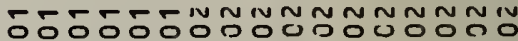

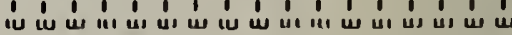

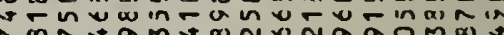

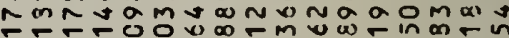

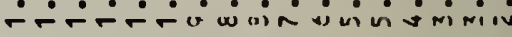

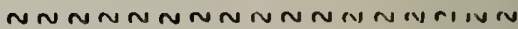
ب ע

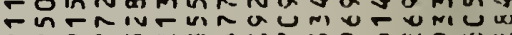

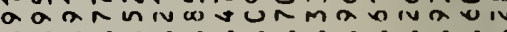

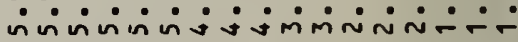

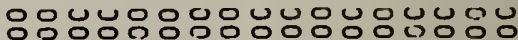

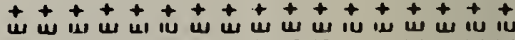
بئئن

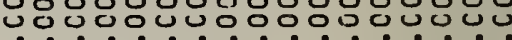
نuن

$\stackrel{n}{x}$

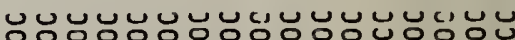

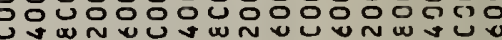
on

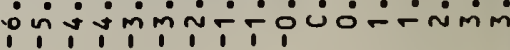




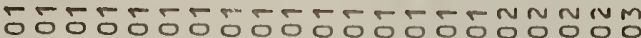

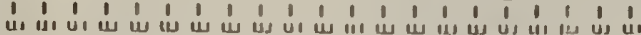

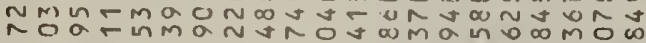

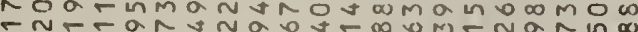

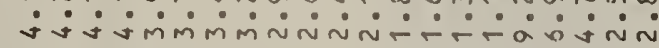

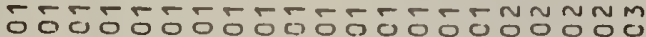
س $\sim M \sim \sim ⿻ 上 丨$ an Mn

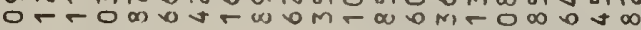

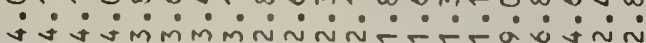

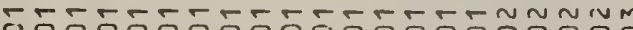

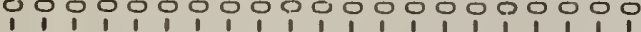
س

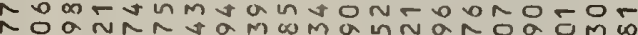

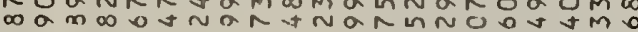

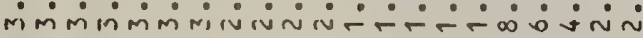

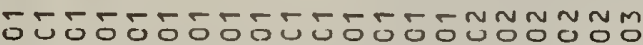

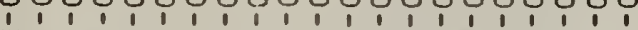

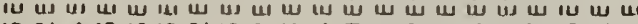

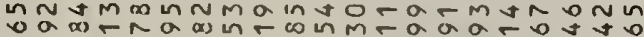
in in in in

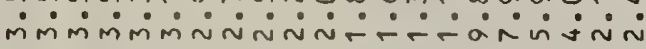

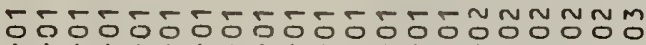

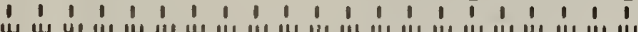

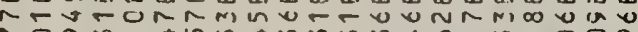
\{ mmiminanantrránimán

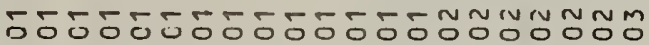

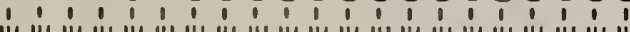

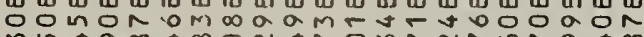

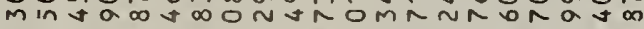

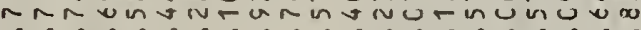

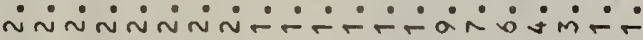

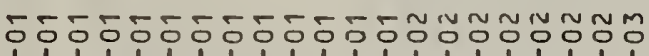

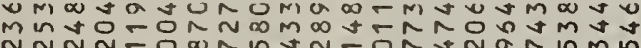
nก ก n

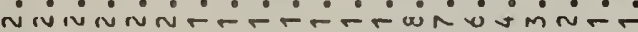

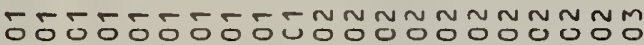
1 '

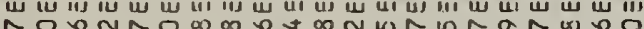
然

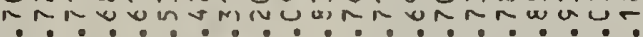

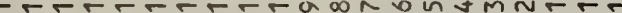

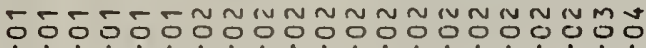
III

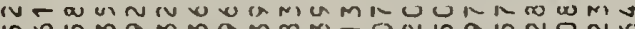

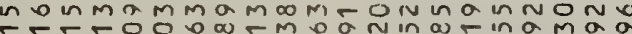
$\because \because \because \because-\dot{0}$ a

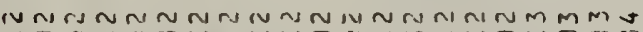
ب0 ш 11

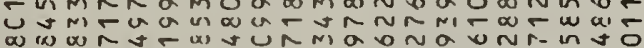
w w w

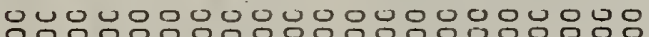

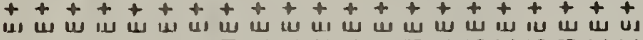

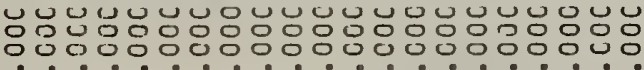
نuvن

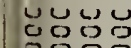

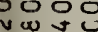
is is $\stackrel{11}{x}$

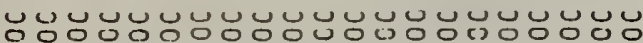
.

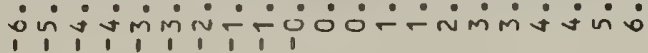

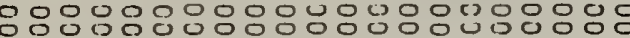

0 050555055505555

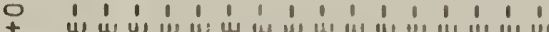
แ - 0 -

- i i imimini

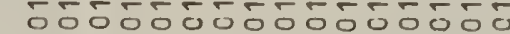

0

III

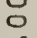

5

0
1
0
0

5

is

0

r-

5

岁

i

ज

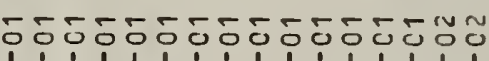

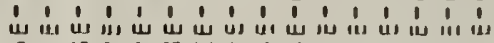

ơ

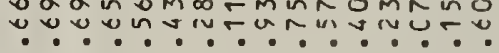

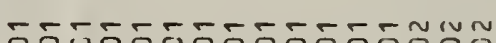

5

1

잉

u

"

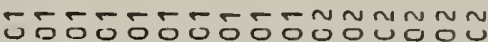
is

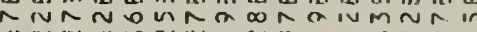
w w w w w w w w w 눈

\section{5.}

11190

号

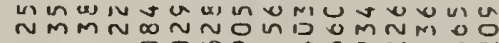
nmm

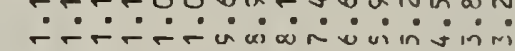

(

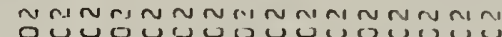

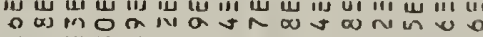

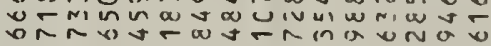

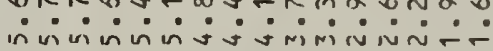

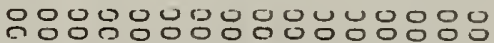

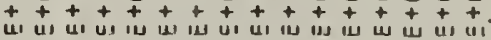

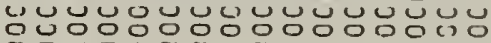

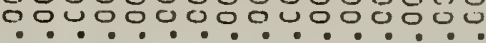

" "

× oij 
ํㅜㅇㅁํำ w Nomw ㄷำแ anjin กำM 111 แ

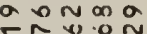
$-\infty$ w ájin กำกำ i i

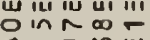
屯ี åjin N N NM מי moro in

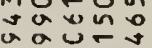
iniñ ก๊กับั í

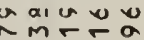

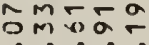
ninmi-n

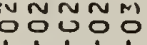
14 س un ○ंi்:

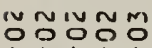
us min ar.? in ? N N NM Oบㅡㅇ iud w oma

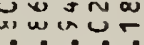
miñ-:

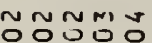
이난

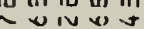

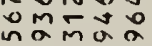
$\dot{i-\dot{r}} \dot{i}$

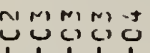
惢出装㟧出 ปก⿻上丨 -0iri: 옹응음응 廿 능워웡 ن ن ن ن

낭웡ㅁㅇ unw ijisi

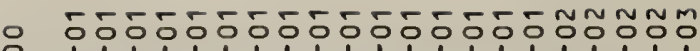

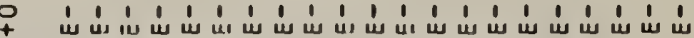

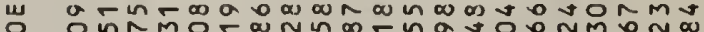

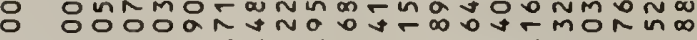

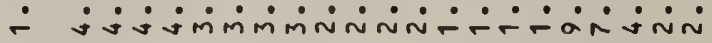

1 س

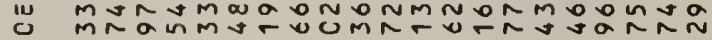

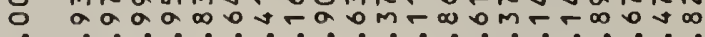

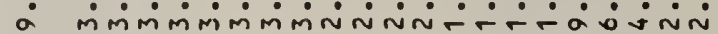

- 000000000000000000000 1

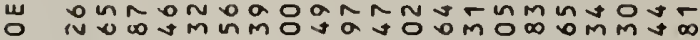

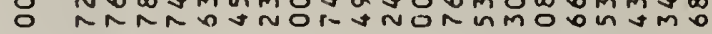

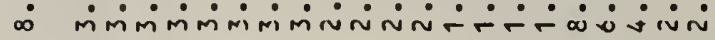

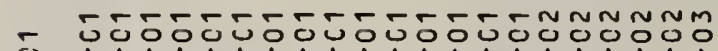

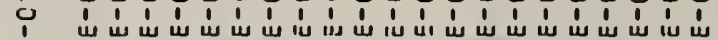

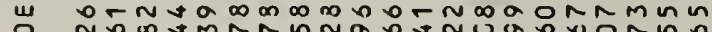
ㅇำ

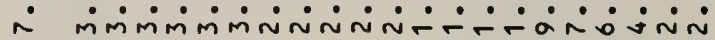

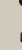

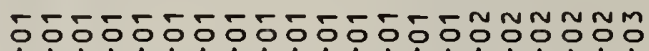
111111111111111111111 ш иш س

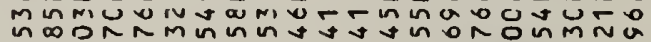

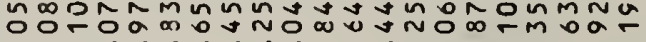

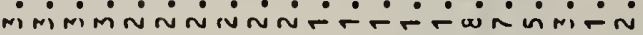

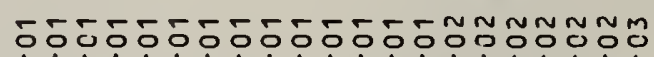
$\Xi$ i 1.

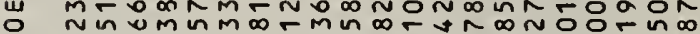

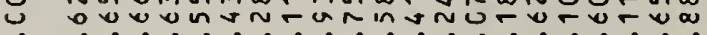

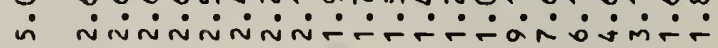

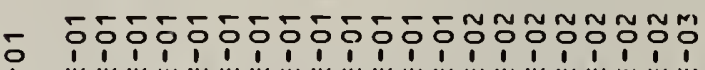

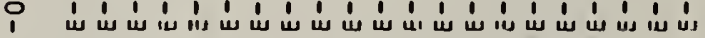
ư

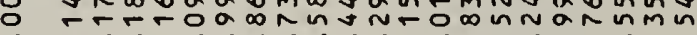

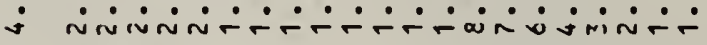

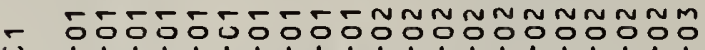

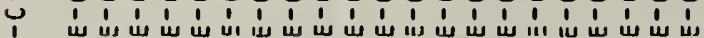
山 马 v i

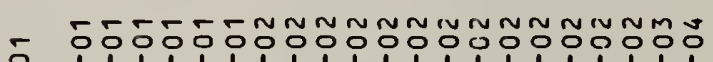

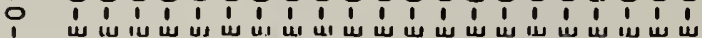

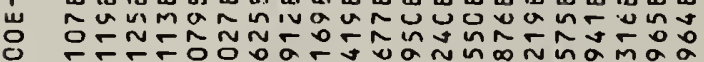

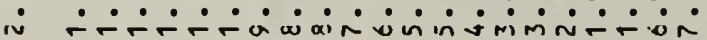

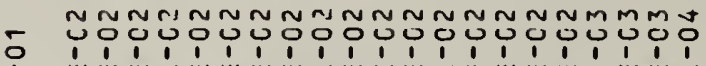

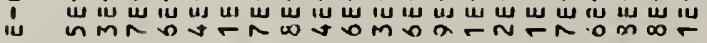

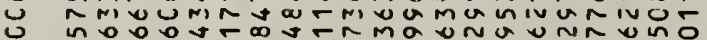

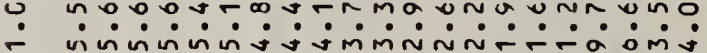
- 응ㅇㅇㅇㅇㅇㅇㅇㅇㅇㅇㅇㅇㅇㅇㅇㅇㅇㅇㅇㅇㅇㅇㅇㅇㅇㅇㅇㅇㅇㅇㅇㅇ영

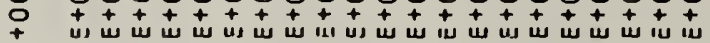

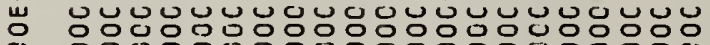

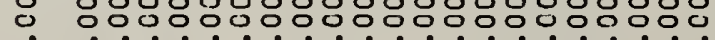

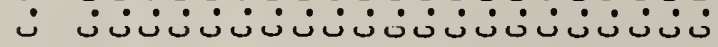

"

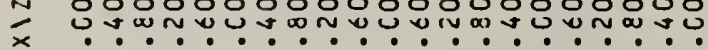

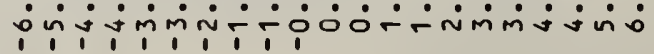

安

ư

m.

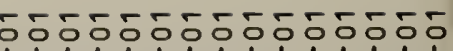
س N ำง

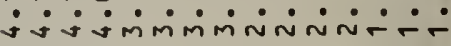

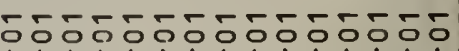
11 1 in 1111

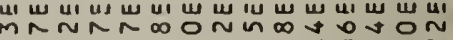

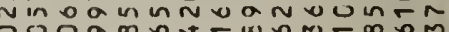
O००0\% immimmannatr-

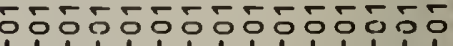
u

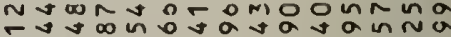

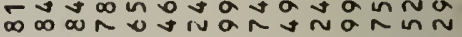

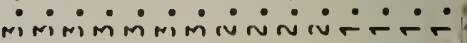

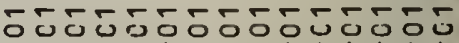
شُ

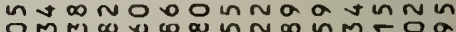

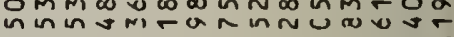
mimmiminininí:-

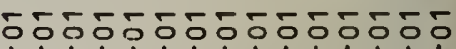
1 ' 出

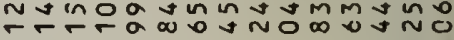

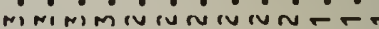
등ㄷㅇㅇㅇㅇ드응유

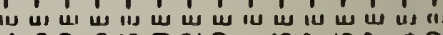

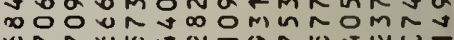
ininininirirாட்ட

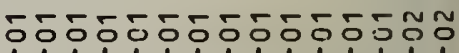
ш

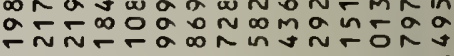

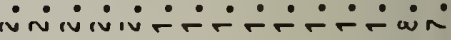

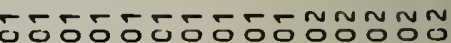
 N N N

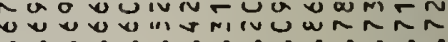

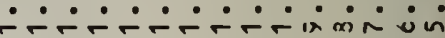

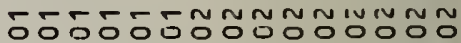

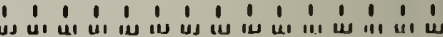

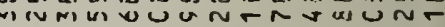

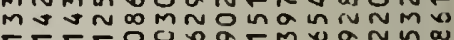

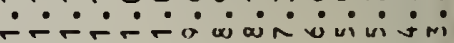

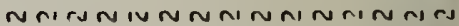
ب

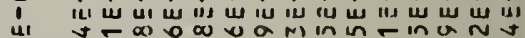

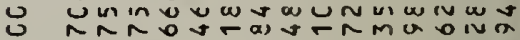

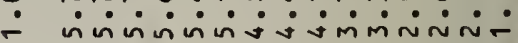

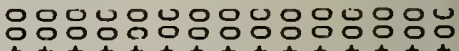

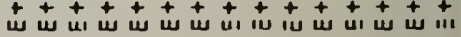

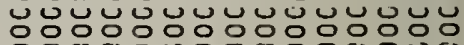
○.000 ن ن ن ن ن ن ن ن ن ن ن ن

$\stackrel{n}{x}$

نטים 영영영ㅇㅇㅇㅇㅇㅇㅇㅇㅇㅇㅇㅇㅇㅇㅇㅇㅇㅇㅇㅇㅇ

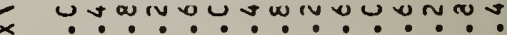

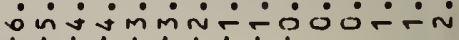


โกับำกั 일 б 이ㅇㅠㅛ -ásiñ

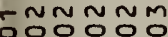
س

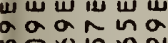
舟

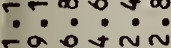
-ñNam 잉이

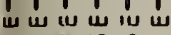

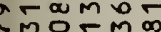
omoำ NNN N

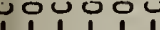
ш Nmwin acuurs oninin NกNกNm ! แ出出出出

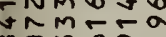
ด.? ?.? NMNNNM 200000 i N N a

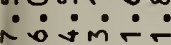
กับกับ i ш $m \infty m i n$ Naññ - $\dot{0}$ iñ ÑÑ ' o on $m$ 的。

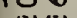
wwu

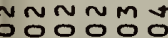

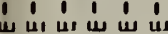
嵌嵌

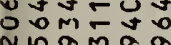
mírin INMmM 100900 uा س س س 正舟 or -rám 응웅엉ㅇㅇㅇㅇㅇㅇㅇㅣ $+++++t$ س ل

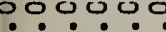

넝붕ㅂㅁㅇㅇㅛ 영엉엉영용

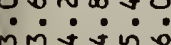

-5055-55-55

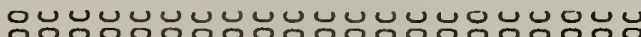
응응ㅇㅇㅇㅇㅇㅇㅇㅇㅇㅇㅇㅇㅇㅇㅇㅇㅇㅇㅇㅇㅇㅇㅇㅇㅇㅇㅇㅇㅇㅇㅇㅇㅇㅇㅇㅇ O.n.

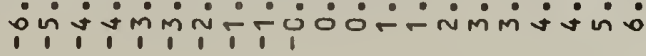

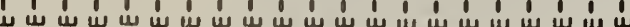

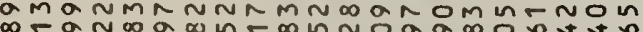

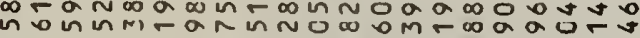

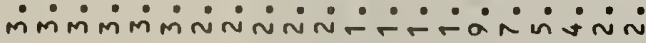

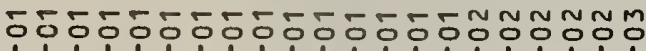

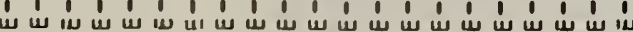

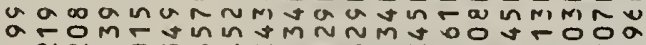

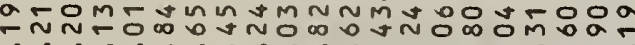
mimnNanNe-t-

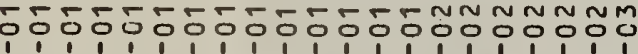

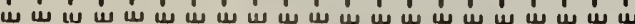

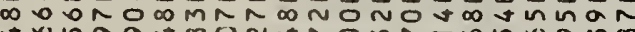

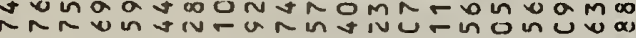

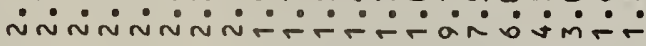

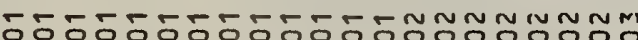

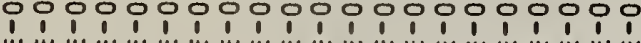
שш

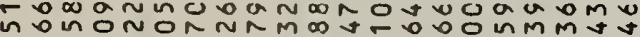

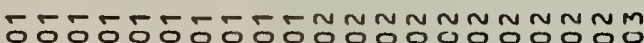

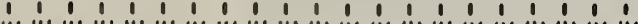

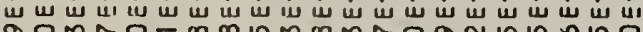

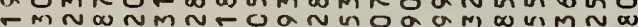

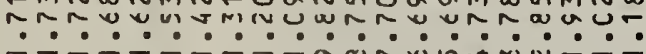

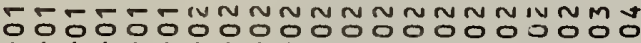
in

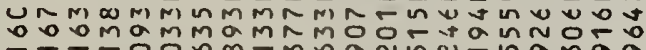

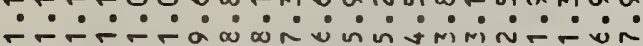
NNNNNNNNNNNNNNNNNMMMN

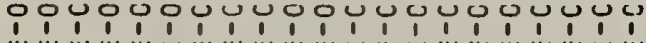
此

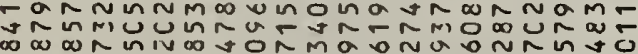
vivininis jmiñ

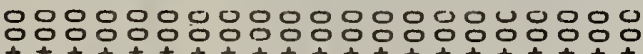

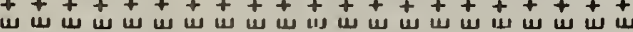

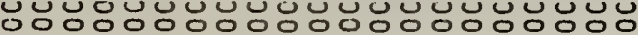

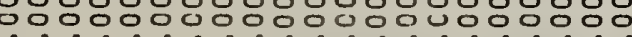

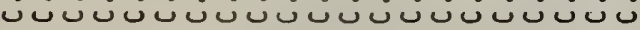

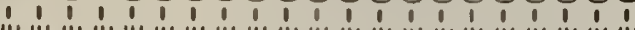

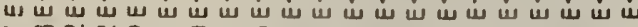

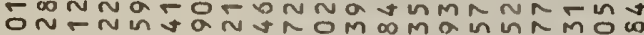

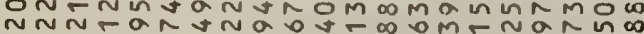

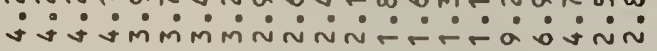

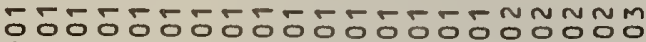

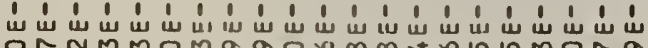

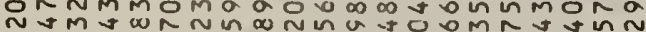

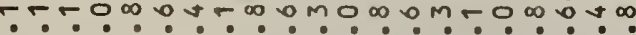
a a ammmmnnNmtrtrabann

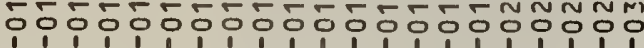
w oñma mimmimminivír-ேோT5.5-5.5-5.-5- -

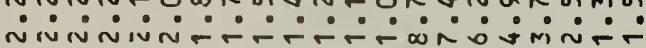

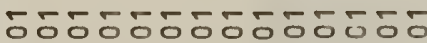
10 品穴nar j-jmimininini-

550555555555555 úch

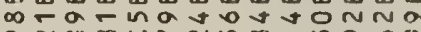

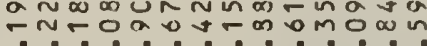
- jommiñuñ--

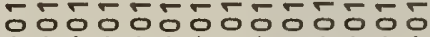

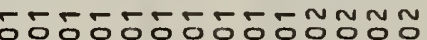

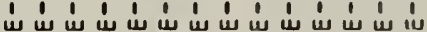

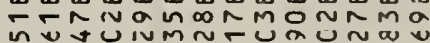
r?

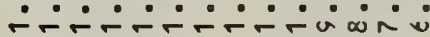

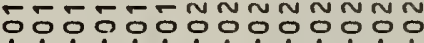

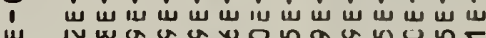
แ

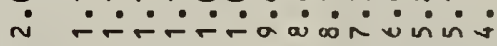
nNmNnNmNnNanivn 5 Y

1

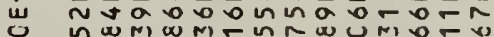

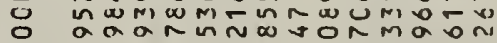
$\because$ vinivininisimiñ

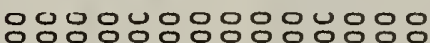

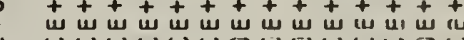

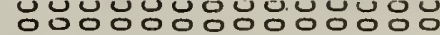
응응ㅇㅇㅇㅇㅇㅇㅇㅇㅇㅇㅇㅇㅇㅇㅇㅇㅇㅇㅇㅇㅇㅇㅇㅇ

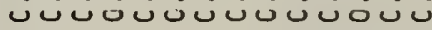

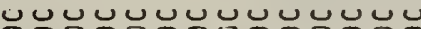

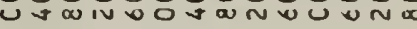
눈 1 in 
- $00 \mathrm{nN}$ 1,1111 us us a m $N \backsim \sim \infty$ - $-\dot{a} \dot{i} \mathbf{n}$ 1 ' I ' I ' ' ' м ш ш ш N M $-0 \infty \cup \checkmark \infty$ - - $\dot{0} \dot{0}$ 1 11 on a n Nonsmmo $\because-\dot{\omega} \dot{\sim} \dot{\sim}$ - NNNNMm 1 1 1 ш ш ш ш №mosn - irinini

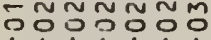

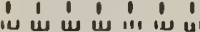
nUw山

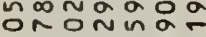
- $\dot{x} \dot{\sim} \dot{m} \dot{\sim}$ wNMNNNm : 1000000 w u 年 on

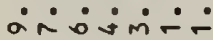

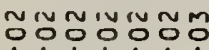
年 等

risini-:

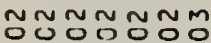
ouo잉

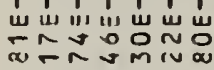

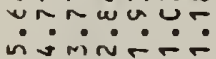

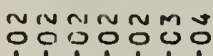
等 mã or N N rummms ט

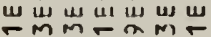

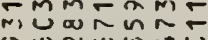

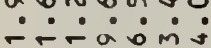
0000000 it $t+t+t+t+t$ -

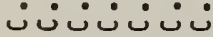

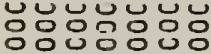

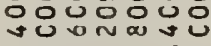
imí; is

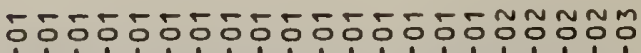
แ แ m mmmran

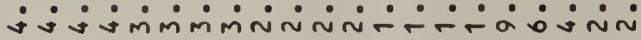

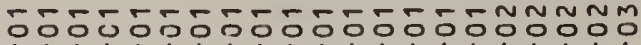

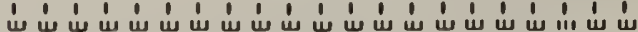
or

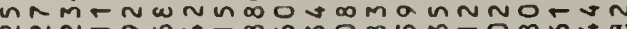

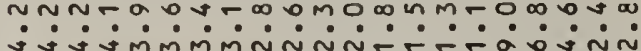
5555555555555555№n N N

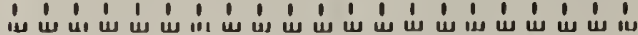

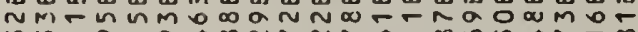

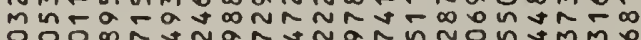

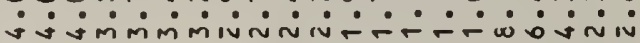
-555

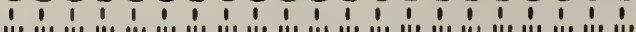

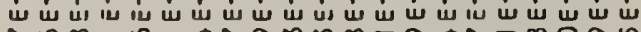

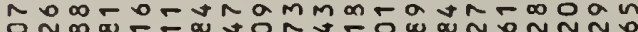

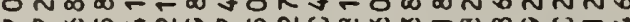
ก MmMmmMnNNNNFR-ROR

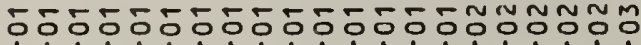
w' ơ mmn $55555555555555 N \tilde{0} 0$ N

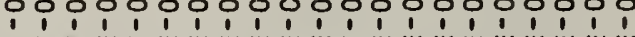
ш

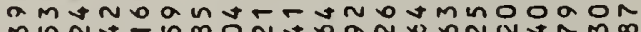
m n w w

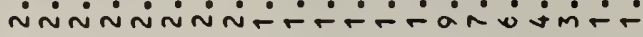

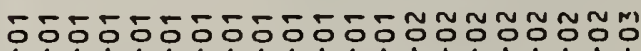
' Un

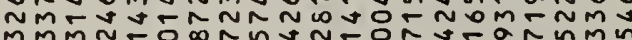

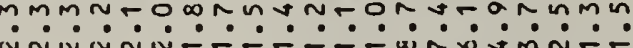

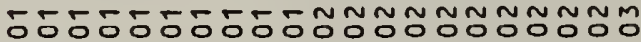

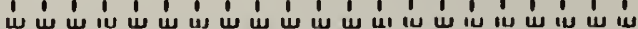
ผ

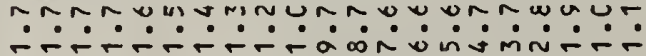
! ш

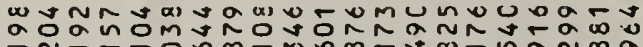
?

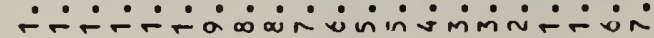

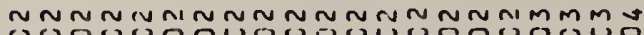
ن щ

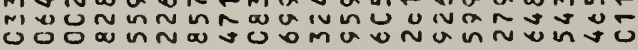

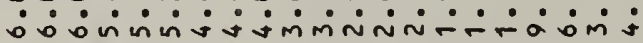

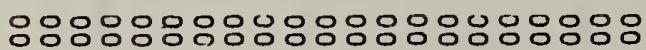
$++t+t+t+t+t+t+t+t+t+t$

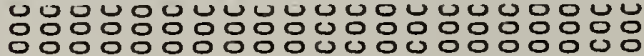

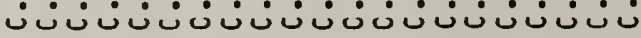

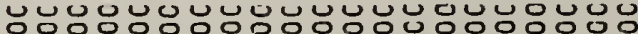

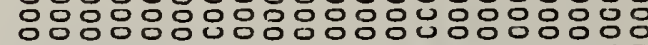
? inj
550555555రํำ ش

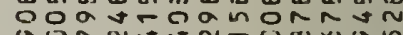
rwarumumisum

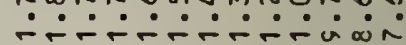

m iv zo

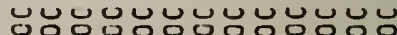

$\bar{x}$

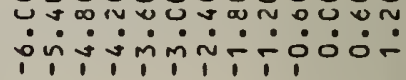


5.

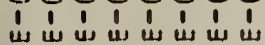
$m m \infty+0 \pi \infty$ $\because \div \div 0 . \div+\infty$

- -a a ivn

임ำ w NOODMNOO a in nom on inm $\because \because \therefore$ ini

- - runnam io س $\infty$ in $N$ in $N$ in $N$

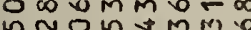
$\ddot{-}-\dot{0} \dot{0} \dot{i}$

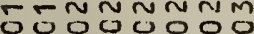

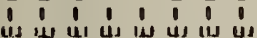
a. a M) - o w a w $\therefore \dot{0} \dot{0} \dot{0}$

-

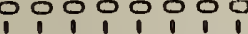
шы ш

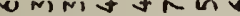
m的机爪 norarvin on $\because \therefore \dot{0} \dot{0} \dot{0}$

- nNannNm 00000000 w w 证 $N$ in otrom n प4w -ávimiே

nominnum

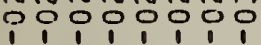
w 으문 드는 in் $\dot{0} \dot{0}$

NNNNNMNM U0000000 in ' ' ' ' ' ' '

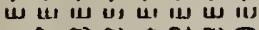
$-\pi \infty$ a) $N$ wo पnammir

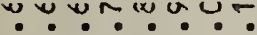
的 nunnammat

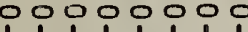
"1.. แ แ (v) U v

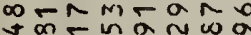
जima-ín

UAN UMMMU ש.

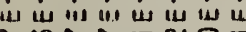
NmR iv a in $n$ o ing $\dot{0} \div \dot{0} \dot{0} \dot{0}$

응벙ㅇㅇㅇ영영응

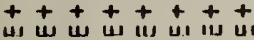
山س

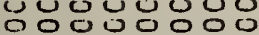

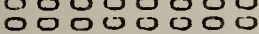
:ن: ن ن ن

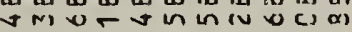
NoOD. in

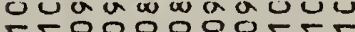

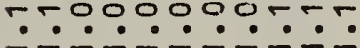

ง -0000000000

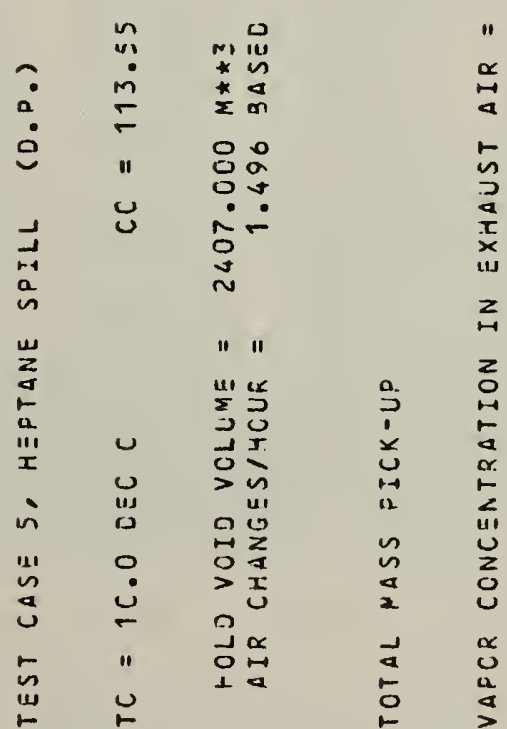

טưưuo

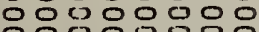

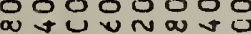
- imíiví 
APPENDIX 3.

Computer Code Listing 
- Nm $\forall$ m
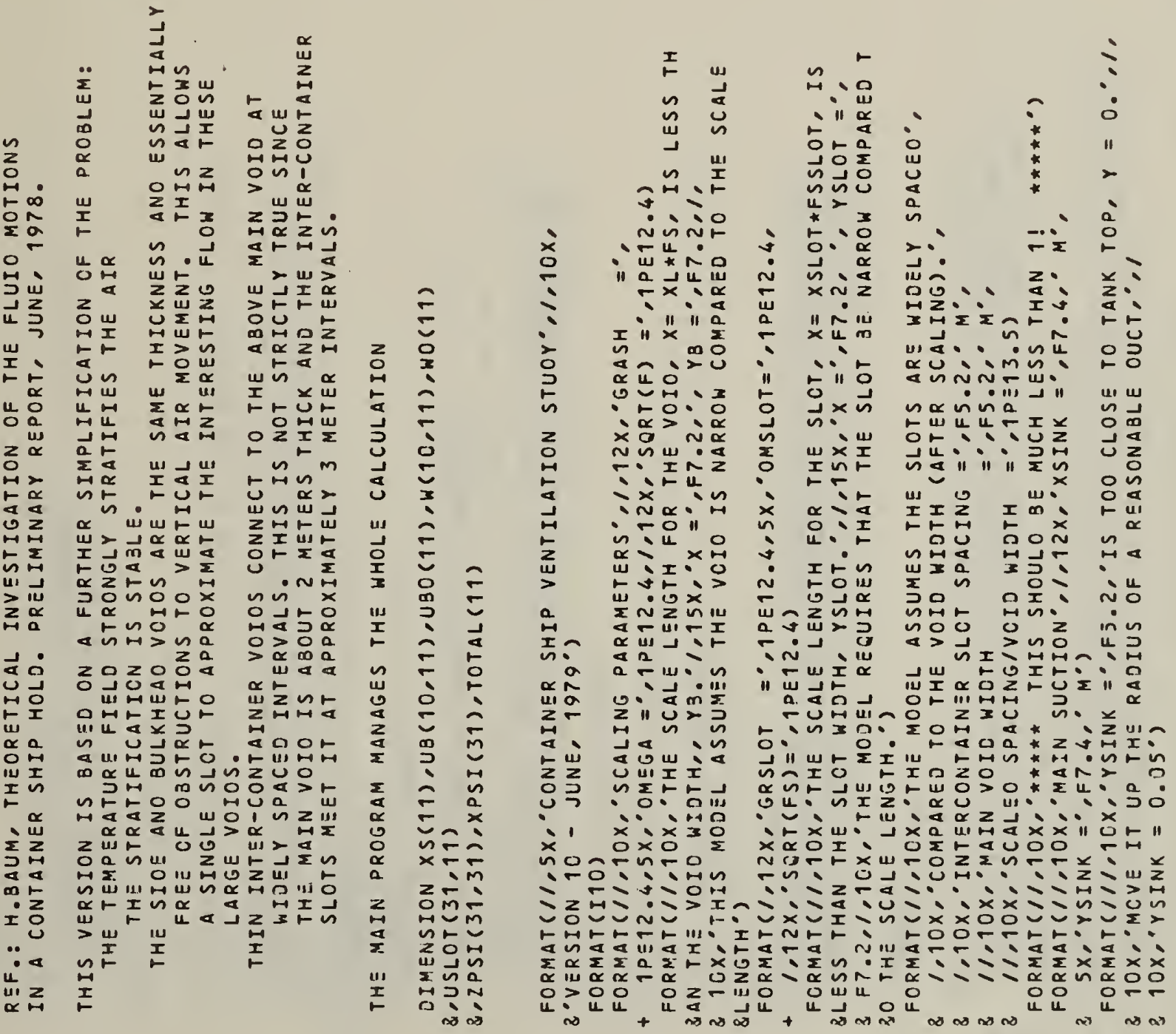

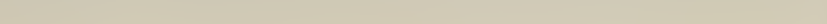




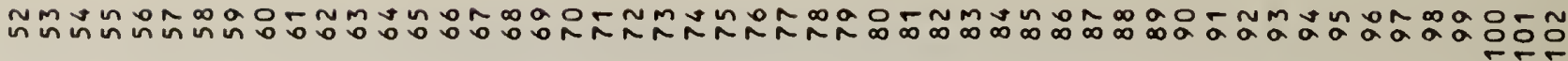

is:

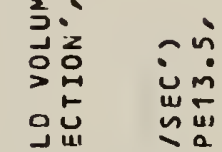

卉崖

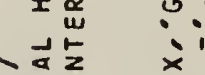

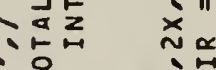

的央。 in

* żั๋

- of: ũ

诘西正

뜸ำ

$\because 0 \div 2$

붕

i往远

س월

x난다

굴

ㅇ " wo

垴

옥

䑻放

>İzo

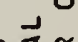

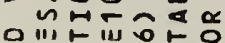

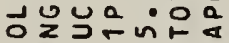

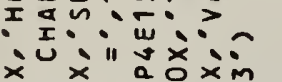

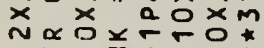

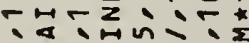

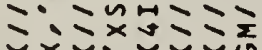

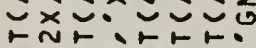

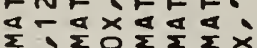

u
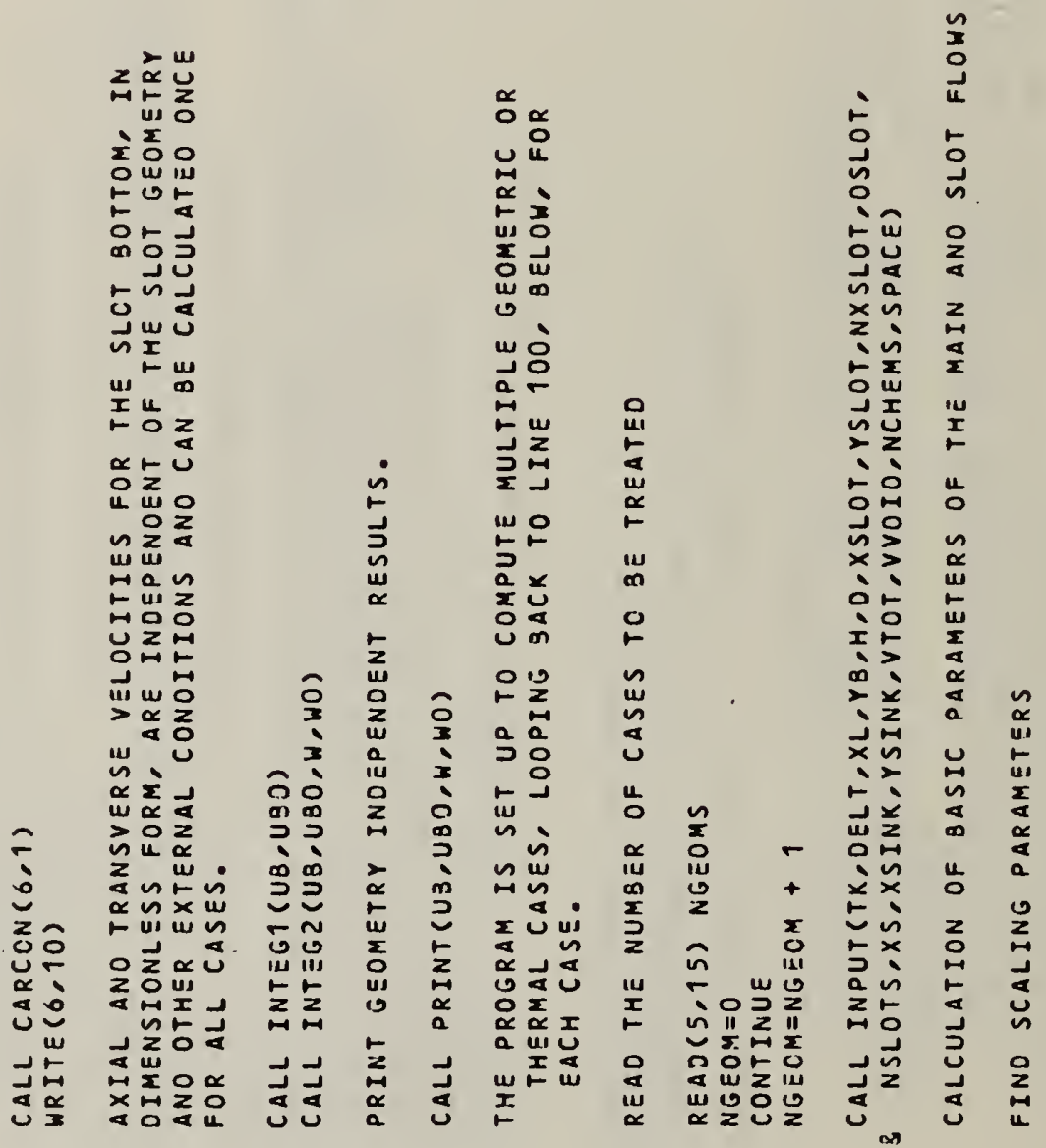

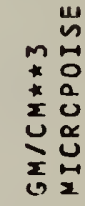

웃 응

ט

웅

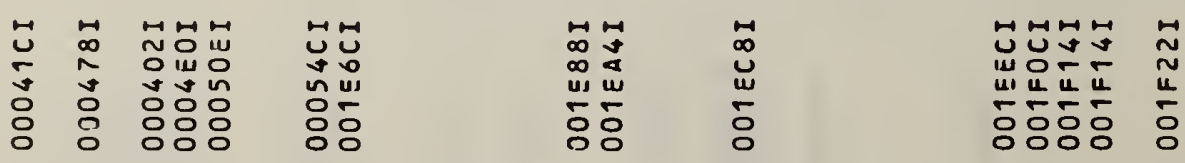

보윯ำ

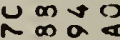

ü uuㅡ

흥흥ㅎㅇ

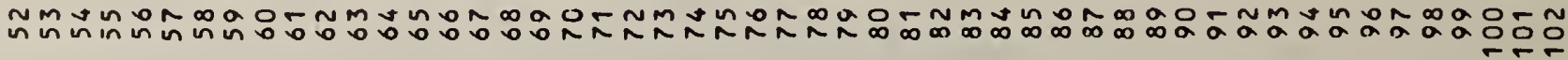


mUVIO

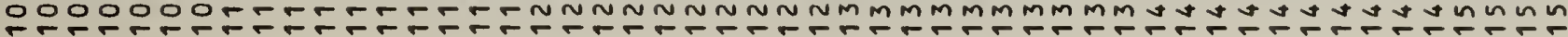
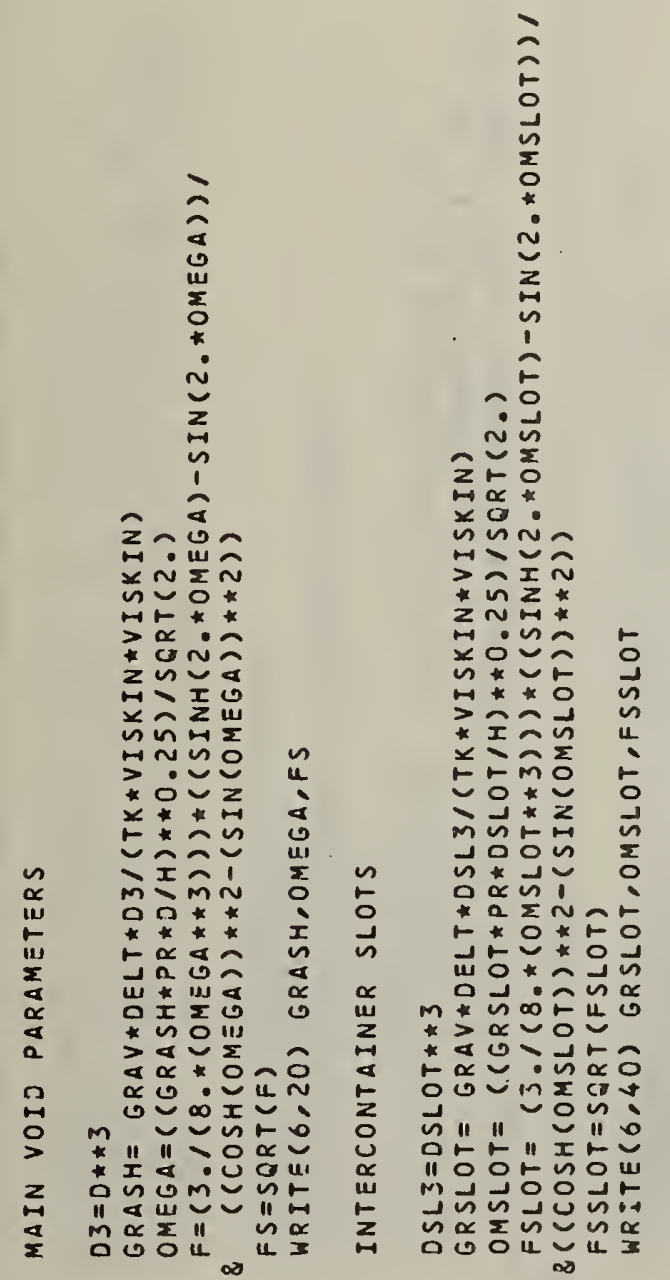

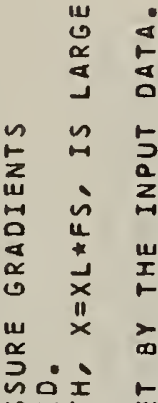

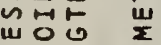

$\alpha>2$

a

이눈

u

$\propto 0$

w $z_{0} \dot{\sim}$

$\alpha+x$

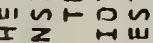

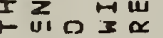

I

x

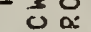

แั

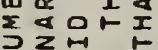

至 2 ज。

«I

$\Delta I>0$ U

แே๊ $\backsim$ แ

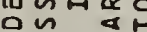

인 눈 45

牙资品

玍

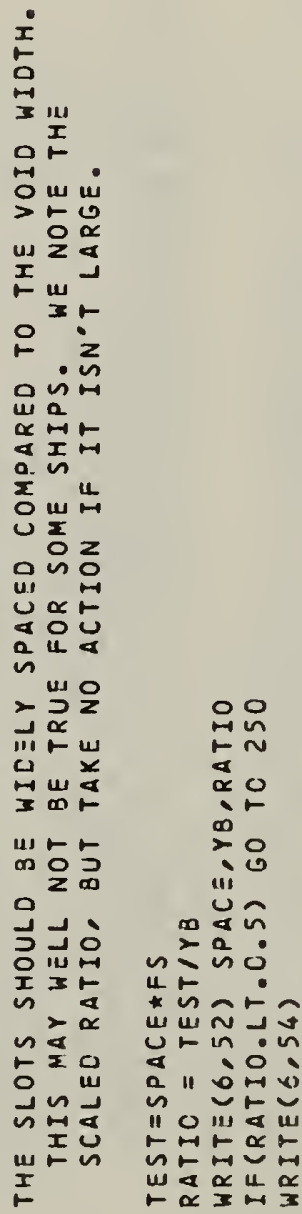

\begin{tabular}{|c|c|c|c|c|c|c|c|}
\hline 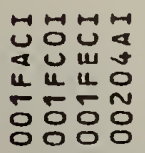 & 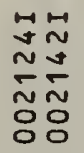 & 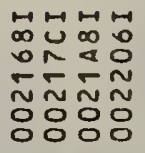 & 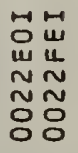 & 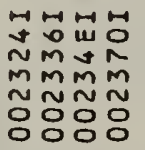 & 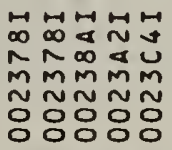 & \begin{tabular}{l}
\multirow{U}{U}{} \\
m̃ \\
$\tilde{O}$
\end{tabular} & 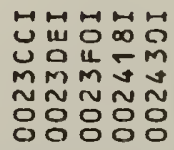 \\
\hline
\end{tabular}

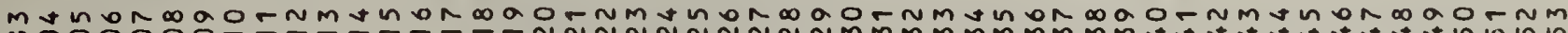
UOOOOOOOOOFFF 


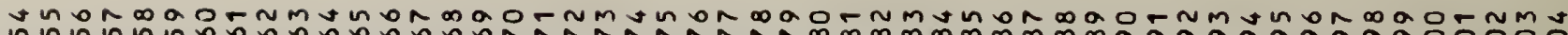

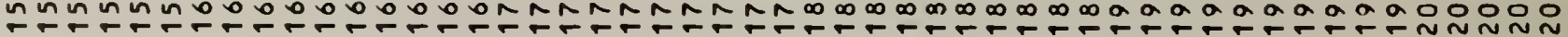

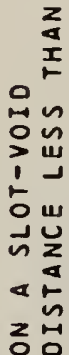

$m a$

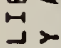

는응

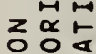

언옹

놇

in

$z_{\substack{11 \\ 0}}$

불올

แ赔

I㟧

응정

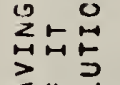

离出可

욜

울

$\geq$ 운

돈

uㅕㅇ

य ${ }_{z}^{2}$ a

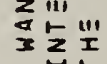

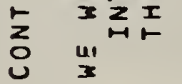

음ํำ

온응

츠

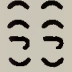

นิ

กั.

पु

$\dot{x} \dot{x}$

$2 \frac{2}{m}$

뜬

주

울

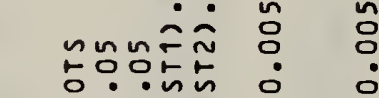

矛过哭出

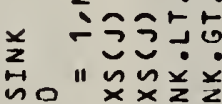

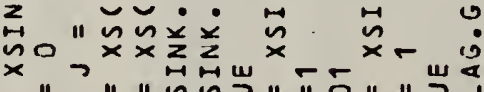

" "이 "

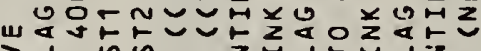

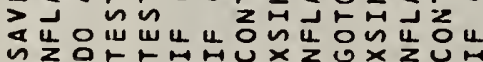

$\therefore$

운 晒

比

준다

แ쏙

I

†

웅

땅하

«

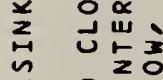

엄더

언

n工

$\rightarrow$

$2 \geq$

各徣 品

Ł世

光它。

폰

แ

4 n

㟧出崖

안도응

논현
紝

ư

幽出

计

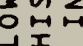

UI

겨온원

동잉

아옹

동?

วิน

zon

분

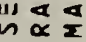

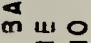

푼

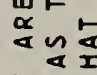

단

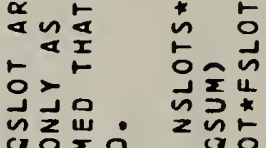

음웅

운도

z出约

$4 * \tilde{x}$

$4^{*} x^{*}$

x.m

*man

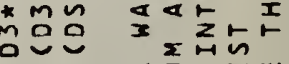

"II"

곰ํํำ

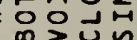

西

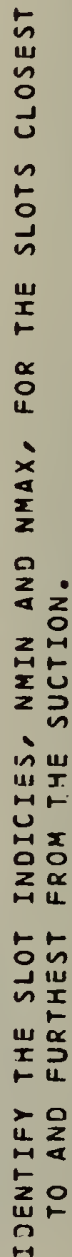

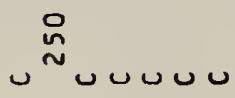

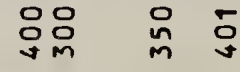

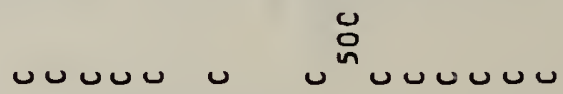

טنט

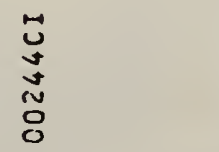

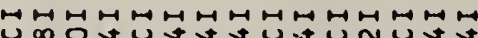

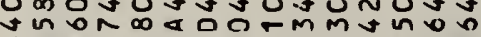

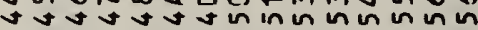

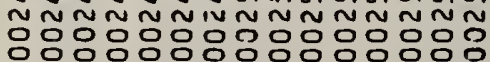

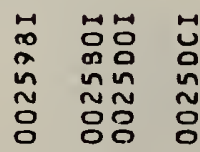

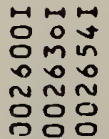

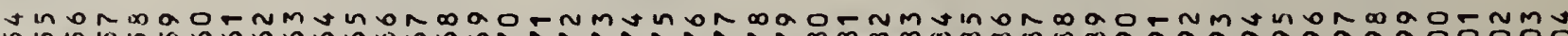
느는 
in

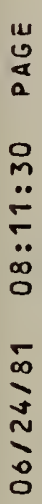

moN

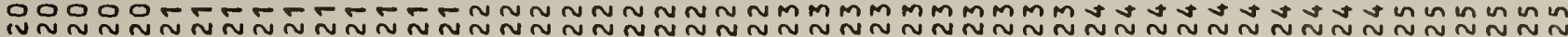

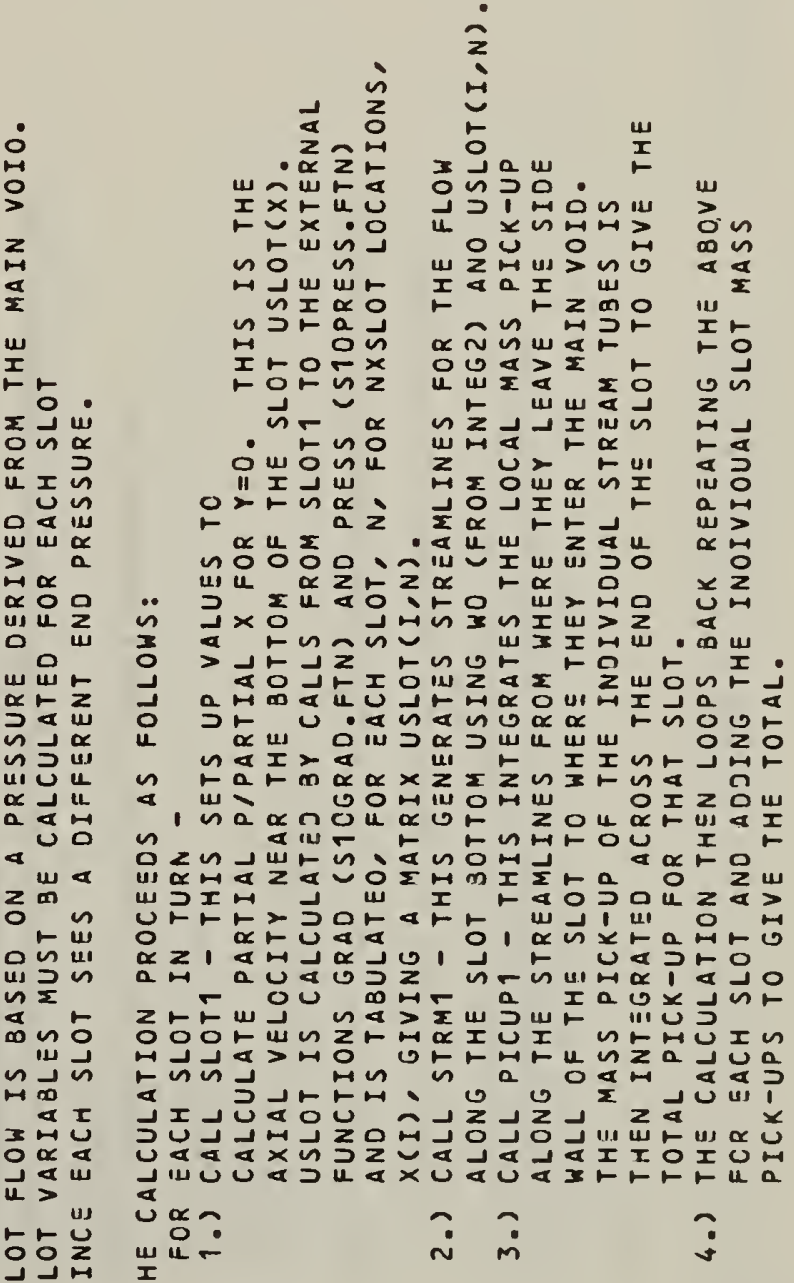
$u$

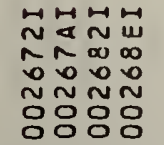

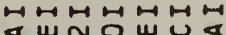
a DOONR̃

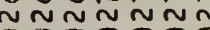
잉ㅇㅇㅇㅇㅇㅇㅇ

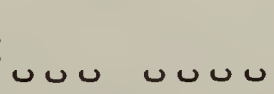

:

MON

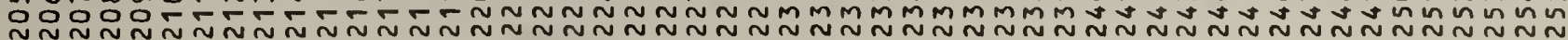



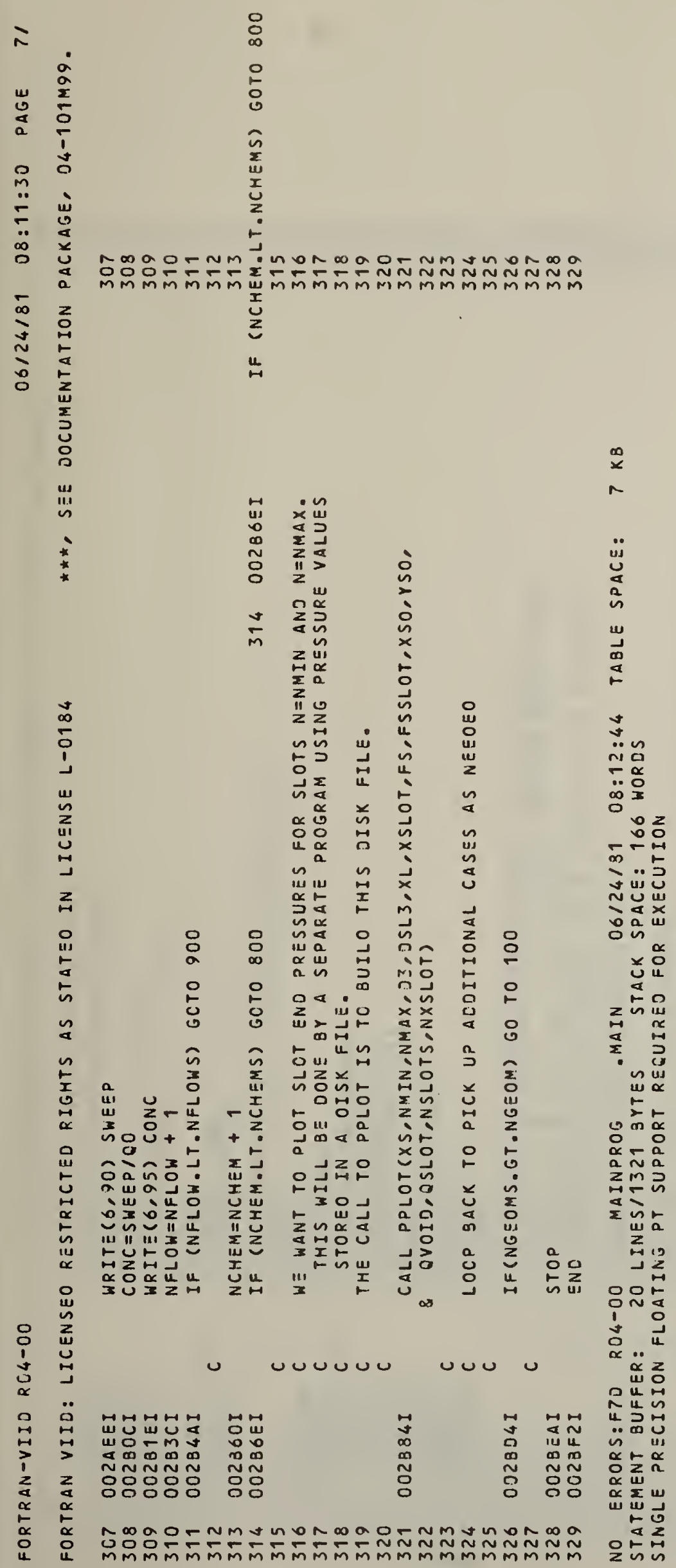


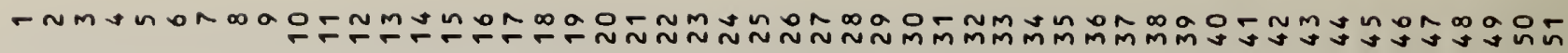

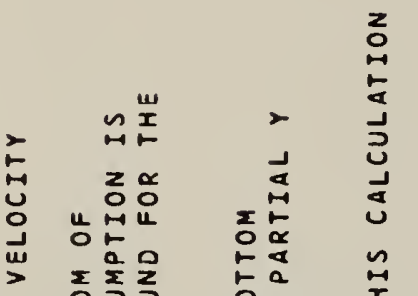

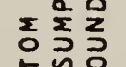

는

un

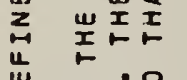

ב

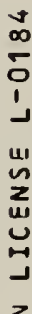

$z_{1}$ 능 종은

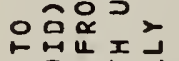
ㅇํㅇㄷㅗ

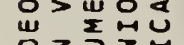
에는

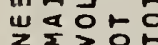

证的空 告王的公

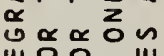

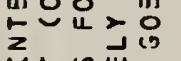
斻的

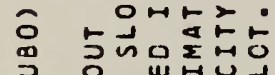

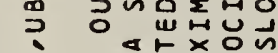

i n क्षog

ว

엉

in a a

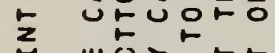

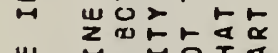

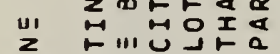

a 5 x

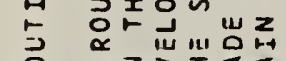

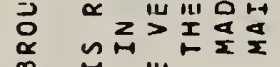

离 $\stackrel{M}{I} \stackrel{11}{r}$

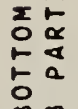

m

홈

w出

I

å."

品

in

皆

$>$ 王贺

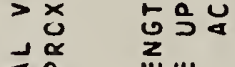

i

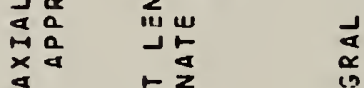

w

고일

i.

$\approx$

Nij

¿๊

D*

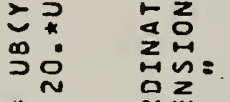

" "이욜

ำ

żo

a $\tilde{n}$

$\omega \stackrel{\text { "u }}{2}$

产客

$\sum_{0}^{m}$

咲尔

要品

"1" 1

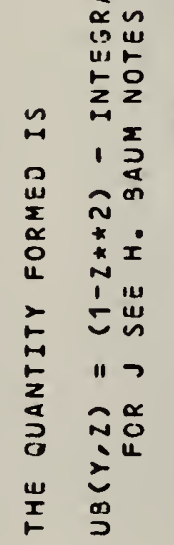

옴

0

点

ì

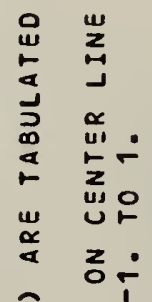

ร

안

ڤิ

옹

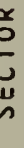

U⿺辶寸

$\stackrel{\text { ș }}{\alpha}$

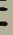

i NOOO

క

zu․ㄴ

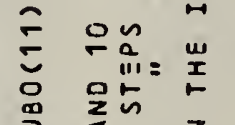

$z_{a}=$

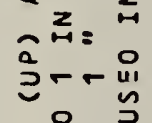

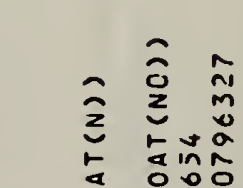

$2+=11$
$200 \%$

$200 \frac{x}{\alpha}$

a 웅.

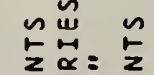

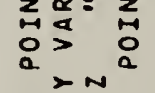

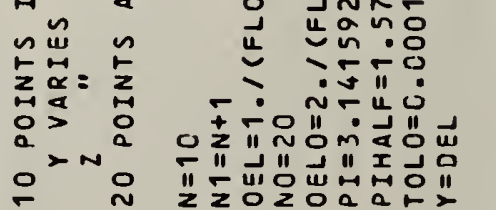

$\vec{a}$
a
0
0
0
0
$\vdots$
$a$
0
0

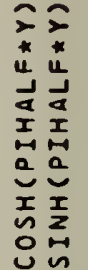

ż

$\sum \quad \sum \quad$ 苔

II

우을

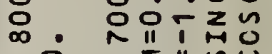

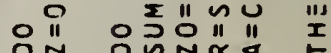

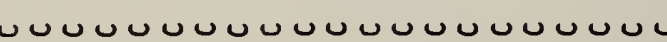

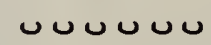

$\cup \cup \cup$

$\cup$

$\bullet \cup$

0
0
0
1
2
$a$

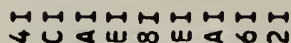

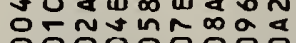
ㅇํㅇㅇํㅇํㅇํํ

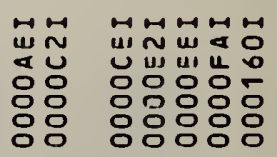

- NMง 


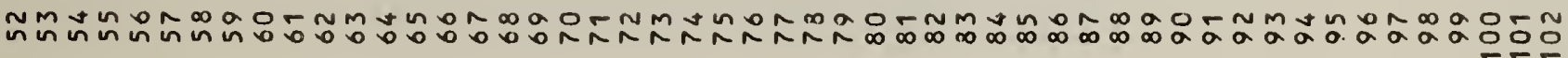

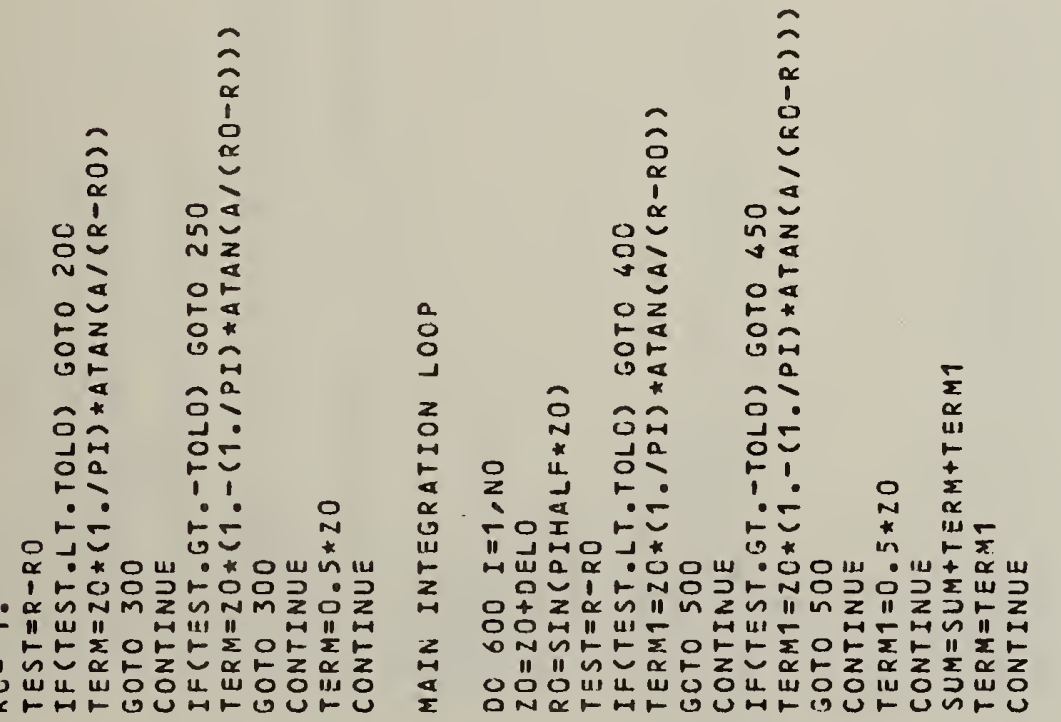

总 品 8 品

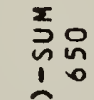

$\underset{i}{\sim} \neq 0$

눙요

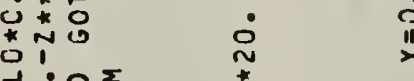

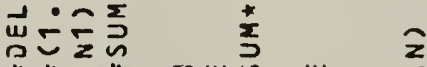

* *

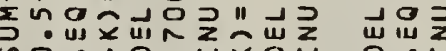

no

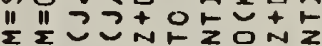

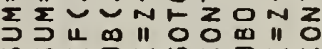
文证

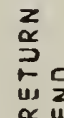
员吕吕, 㽞 $\omega$

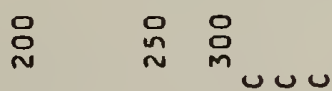

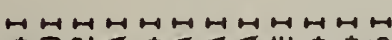

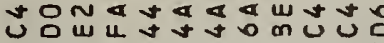

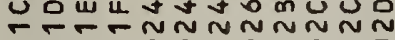

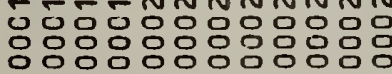

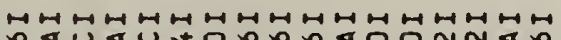

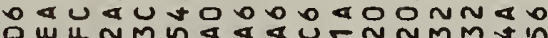
N NN Nóm

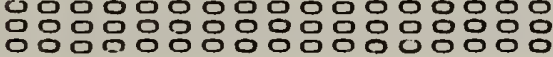

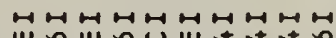

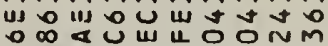
y

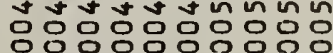

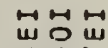
w 000 응ㅇㅇㅇㅇㅇㅇ

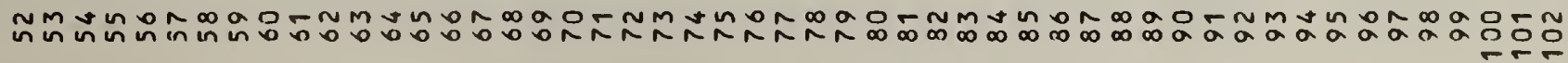




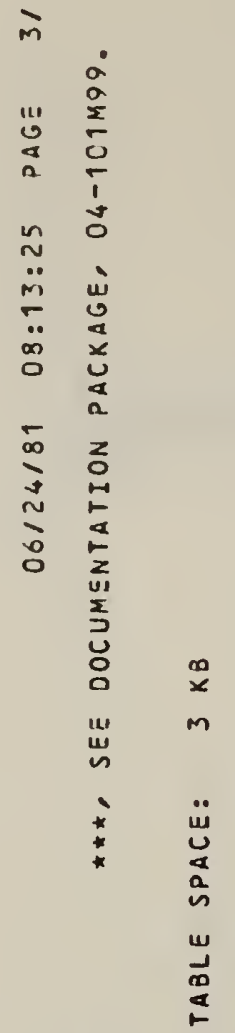

$\stackrel{\infty}{\infty}$

j)

u $\ddot{\infty} \equiv$

$\sum_{i}^{n} \quad-z$

品 $\quad$ -

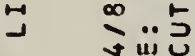

2 Nư

-

o 0 的

남

乞 万占品

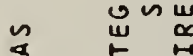

$\approx \sum_{n} D_{0}^{5}$

I

난

- 5

uा

5 ๔mว

品 䟲。

点 nัน

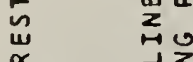

웅 웅둥

욜 范

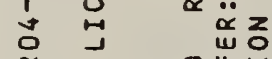

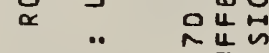

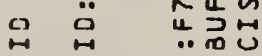

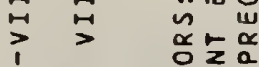

z $z$ o

๙

告 $\frac{\alpha}{0}$ o 


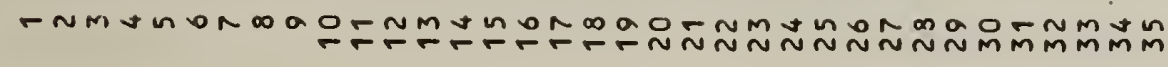

$\stackrel{\infty}{\vdots}$

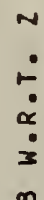

$\stackrel{3}{3}$

존

m...

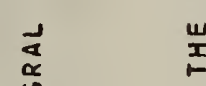

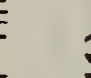

5
$\vdots$
0
$\vdots$
$\vdots$
$\vdots$
0
0
$\vdots$
$\vdots$
$\vdots$
$\vdots$
$\vdots$
$\vdots$

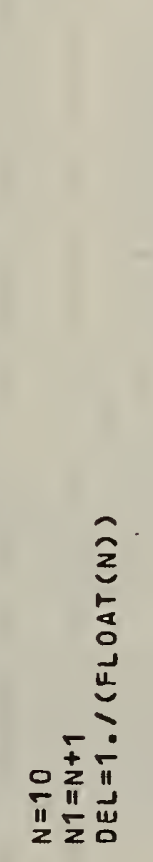

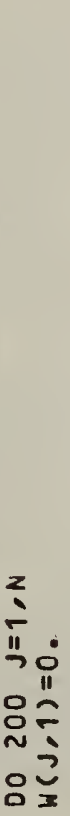

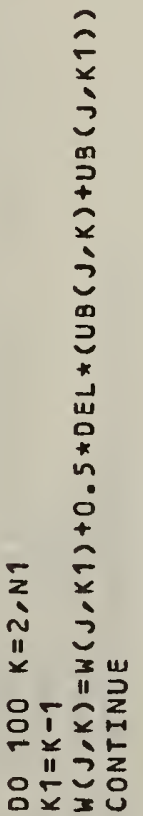

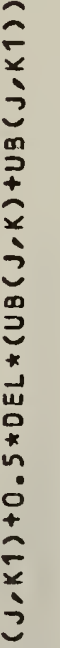

요

$\ddot{\infty} \div$

象

$-\infty$

$\infty$

uㅓㅆ

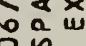

운

N要

约

$\underset{5}{2} \stackrel{x}{\exists}$

nuा

$\omega \propto$

$\sum_{i=1}^{\infty}$

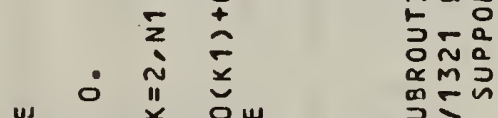

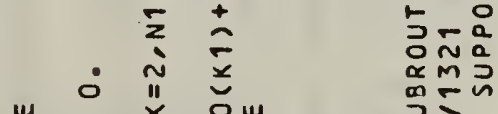

政

ว

$\propto \alpha$

$\approx \approx+u$

I
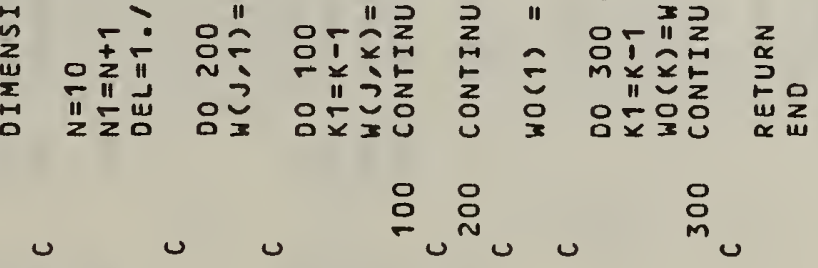

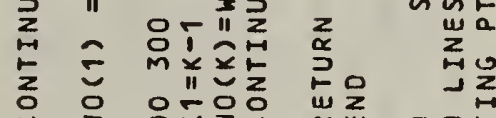

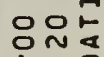
! N वे $\ddot{\alpha} z$

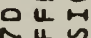
出

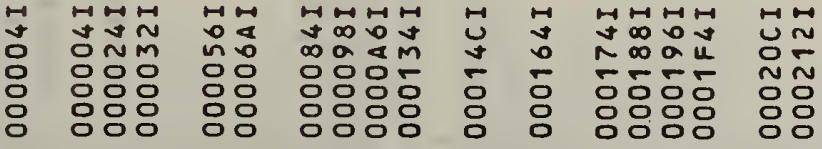
…넌 叶 更品 $\stackrel{\alpha}{\alpha} \omega$

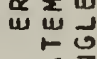
울돈 


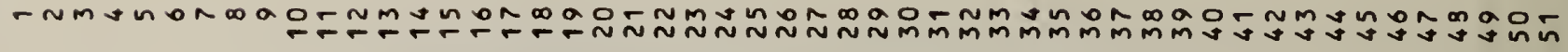

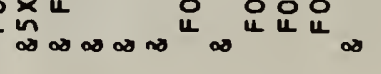



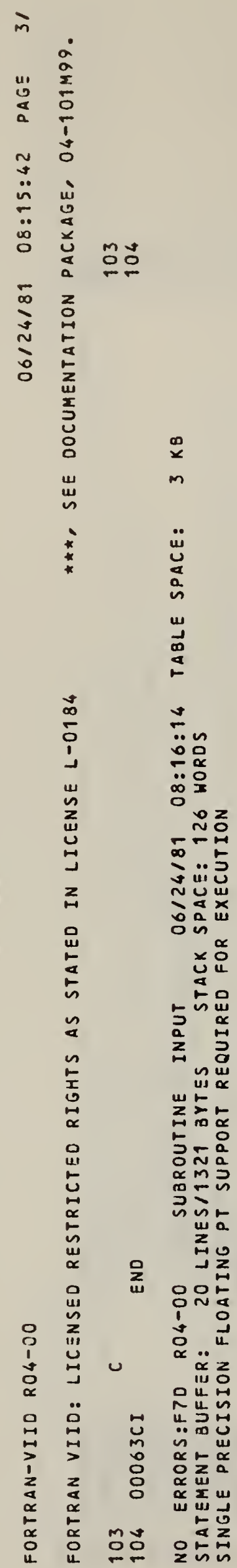
rNmง

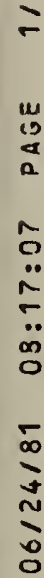

$\frac{2}{2}$

n

*

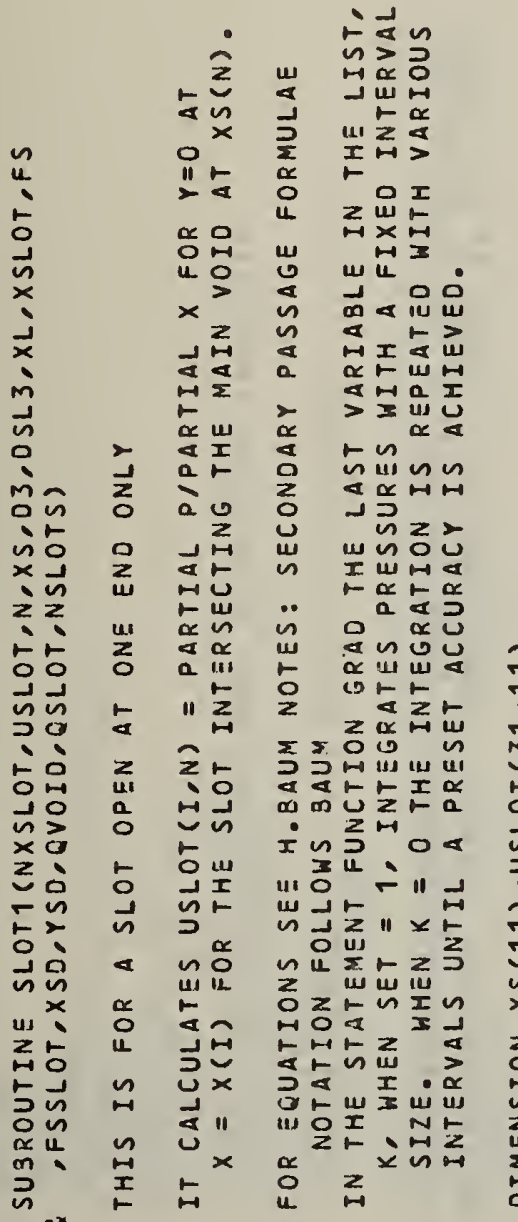

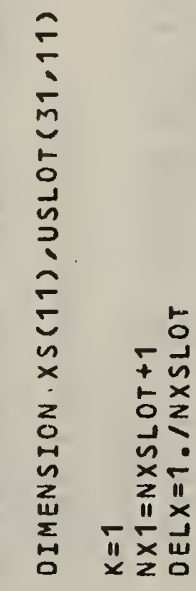

uj
us
in
$u$
un

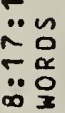

○

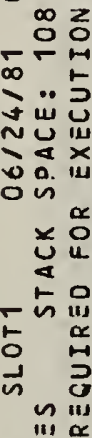

난

的

$\times \times 0 z$

$\sum_{i=0}^{\infty}$

S-

ON

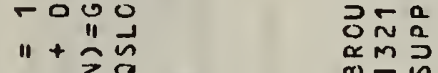

$m$ m $29 \quad m$ 政

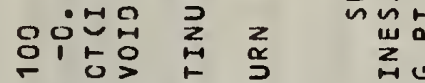

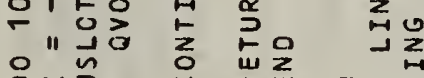
응

웅

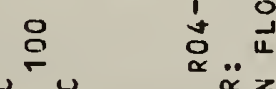

萂

은

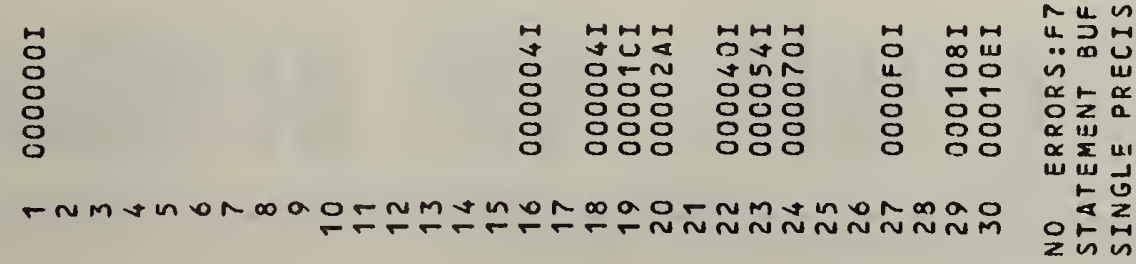


-NMง
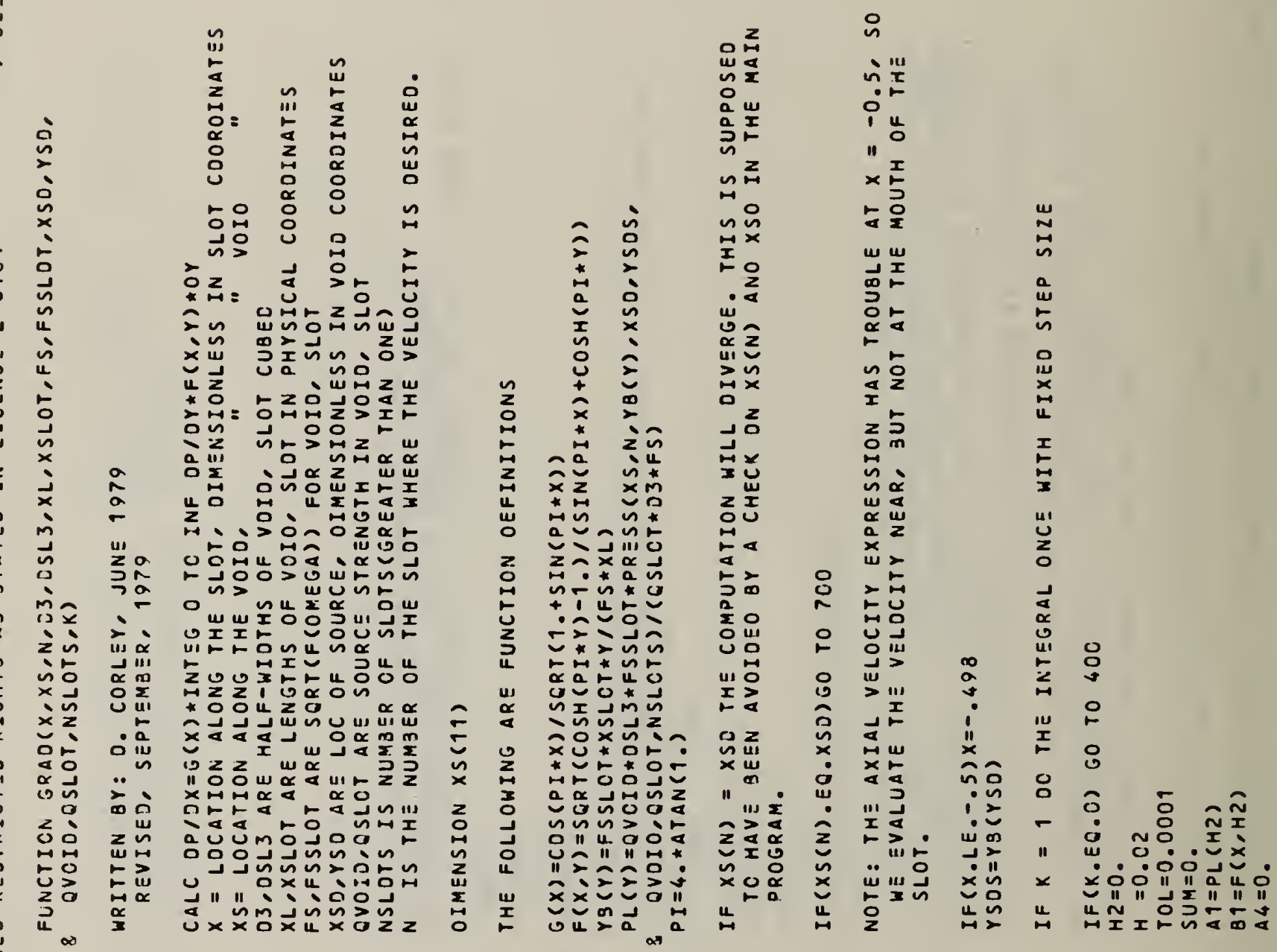

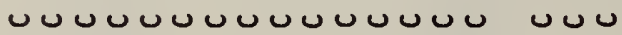

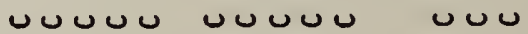
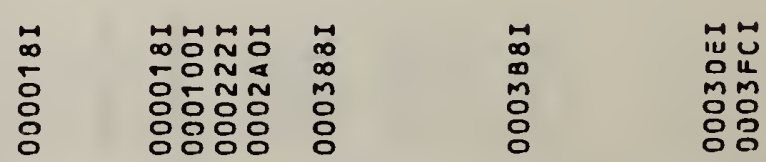

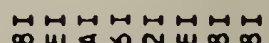
$\begin{array}{lc}-1 & -1 \\ 0 & 5 \\ 0 & 0 \\ 0 & 8\end{array}$

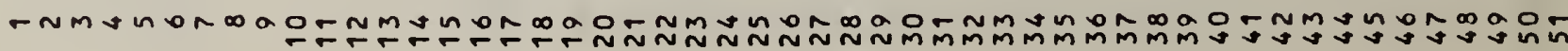




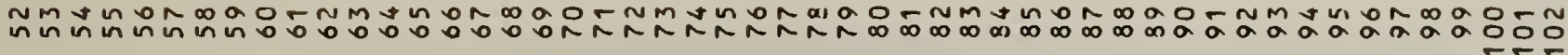

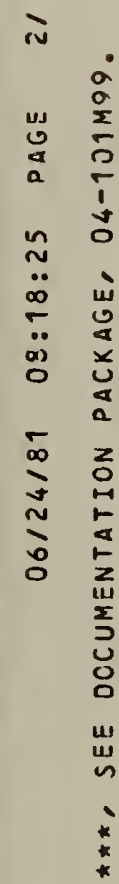

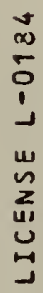

$\sum$

온

I4

岁

学

옹

운

온

존

웅

5 
$m \Xi n$ on

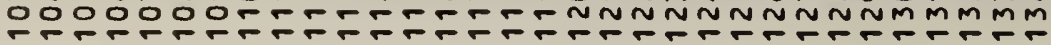

ǔu ü"

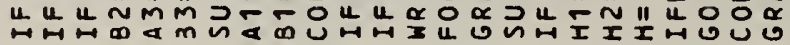
뚬 wa

żi

แัต

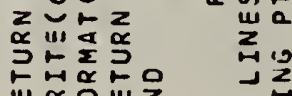

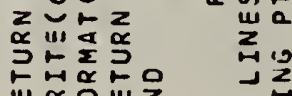

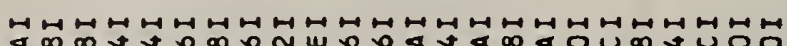
aUom in

봄બำ 우요 $\ddot{n}$ $\propto$ 임

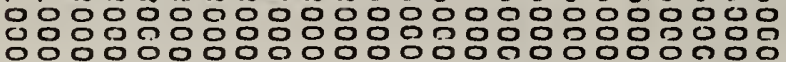


- Nm
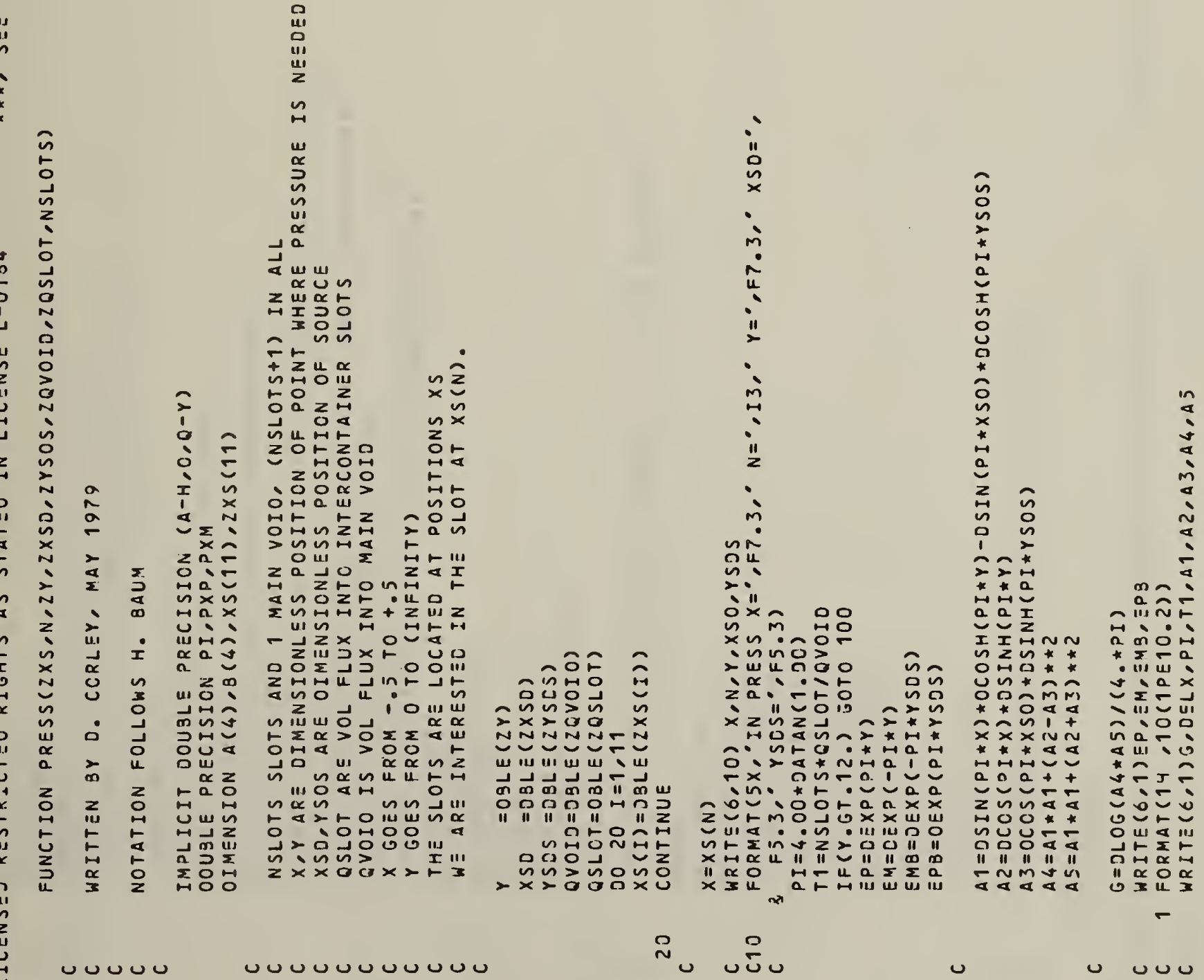

$\cup \quad \cup \cup \cup$ 


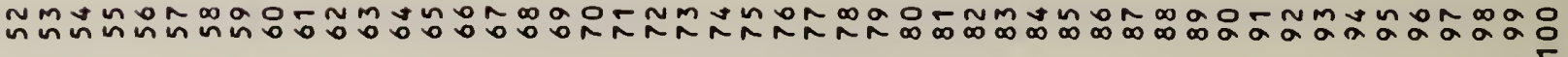<smiles>C1CCC1</smiles>

$$
\stackrel{5}{\stackrel{5}{s}}
$$$$
\text { S゙ }
$$

(1)

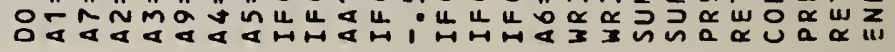




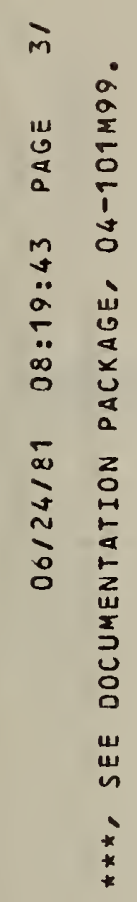

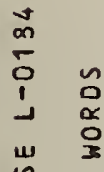

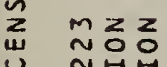

..55

出总

z

에

Iㅣ 웅웅

5

도염ㅇ

政

a

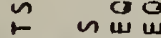

I

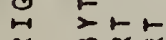

-

iI Nå

与 m

究 离去占

和

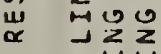

음단

$\circ \sum_{u}^{n}$ u

j

$\propto$

c) $\ddot{0}$ 苛出兄

$\stackrel{9}{H}$ 品忽出

$>>\sum_{a} \alpha$

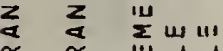

$\stackrel{\circ}{\circ}$

a s

난 는응 
- Nm
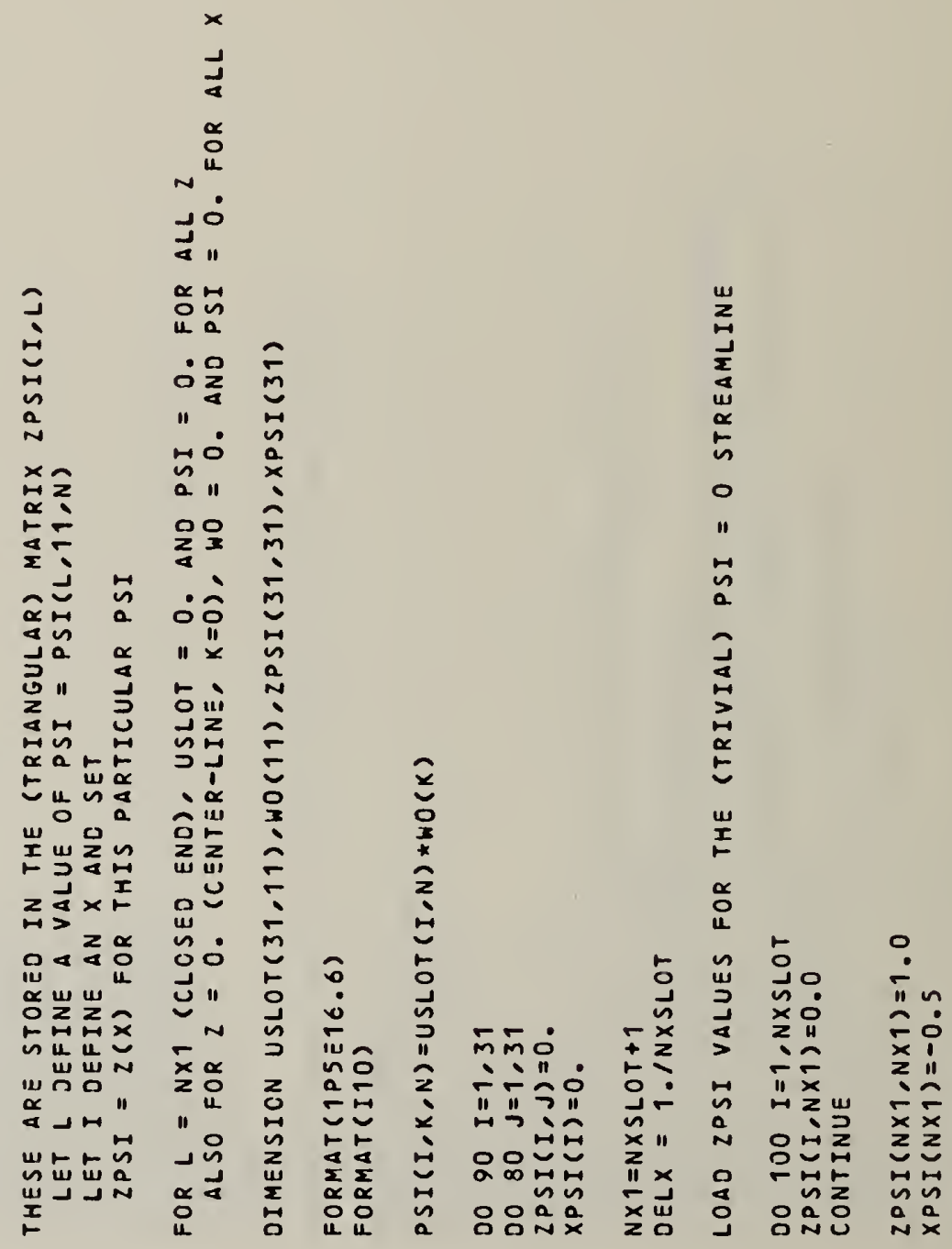

용

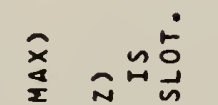

N

$\underset{x \geq 2}{x \geq 2}$

ă

ज䓃I

든

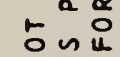

ज标

in $\Sigma \bar{x}$

$x \propto N$

10

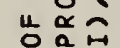

$\Sigma \sim x$

온돈

喈

wํำ $2 \tilde{a}$

x 0 in

矿可品

我立政

出可去

$2 w$ 品

แุ

正

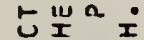

zㄴ.

इ w⿰

过的

出破>

牙甫

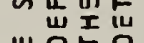

II

III

윤유

옹요

웅
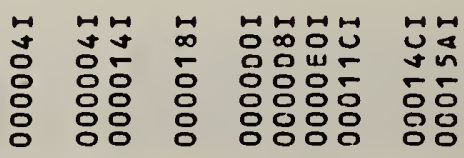

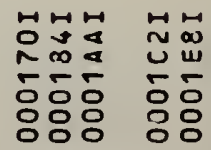

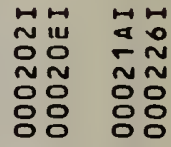

- N 4 แ 
그는

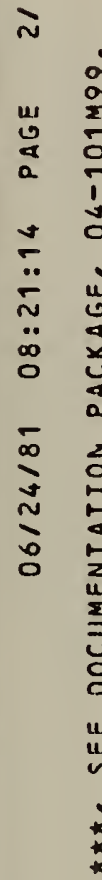

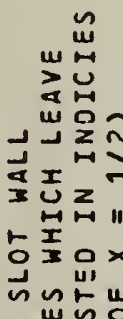

$m \geq u$

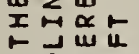

u. $\sum_{i=1}^{\infty} \sum_{i=1}^{u}$

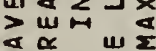

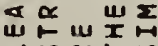

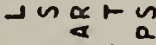

I

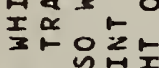

น

$w^{m}$ in $_{\alpha} \alpha$

$\exists \times \check{2}$

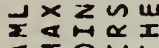

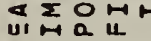

$\stackrel{\sim}{\leftarrow}$ a

次出:

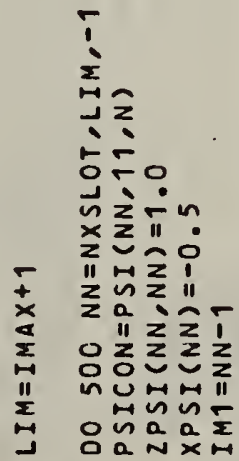

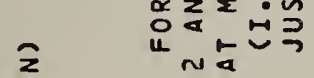

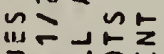

공ำ

$\mapsto \geq ち \geq \Sigma$

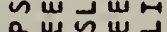

NI玨

또쓴

क

음ำ

웅
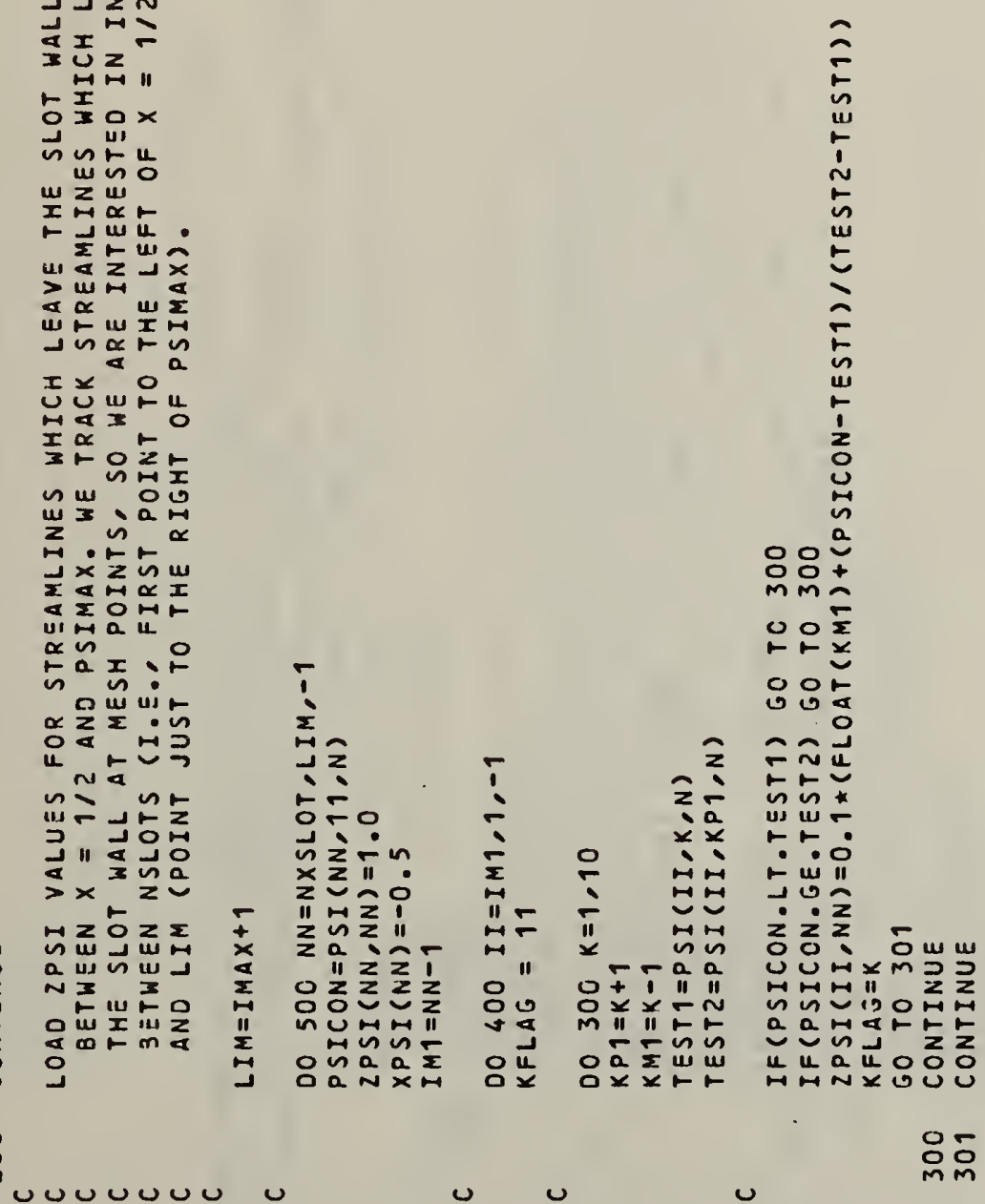

xzo

I당

$\therefore$ uㅡㅁ

w $x$

$z \tilde{H}$

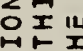

$5 z^{2}$

행뭉

a는

品出

눈웅

J告

또녀

$\leftarrow$ 开

z놈요

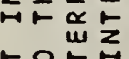

유

옹

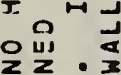

- w品,

$\vdash \quad \omega F$

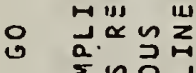

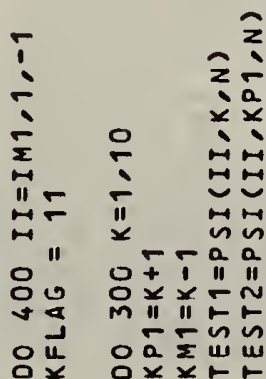

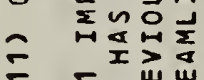

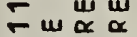

- 盛a

ư

- 正北

웅은

出的文。

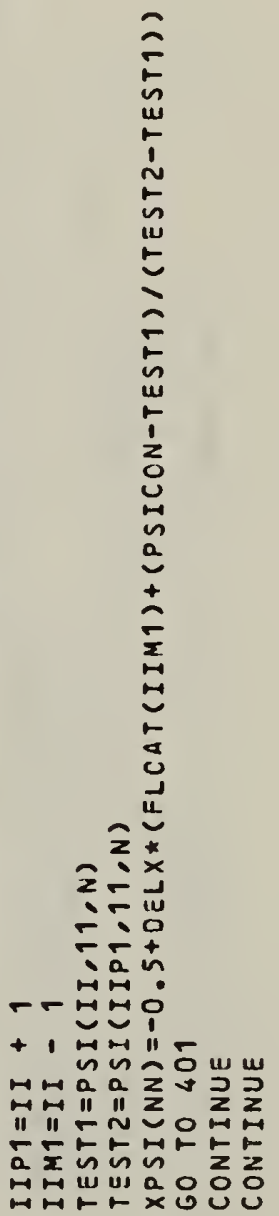

응음

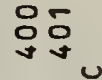

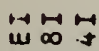

«

ำ

응응

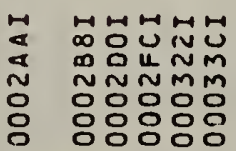

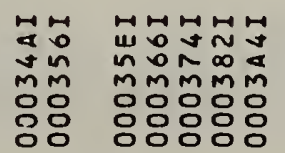

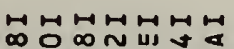

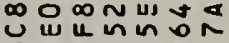

mim

응응응응

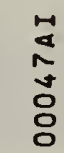

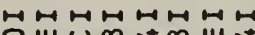

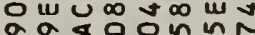

t范葆的的

응응ㅇㅇㅇㅇㅇㅇㅇㅇㅇㅇㅇㅇㅇㅇㅇ

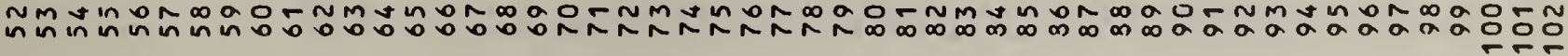




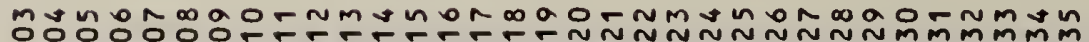

ำกำ

20

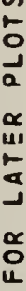

$\ddot{\infty}$

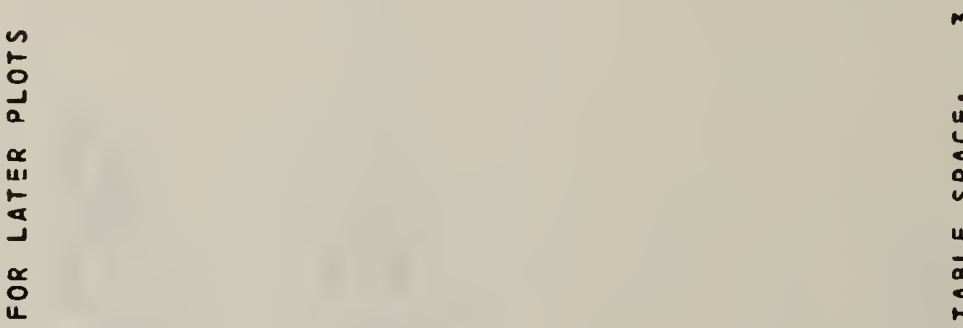

$\begin{array}{ll}5 & 5 \\ 0 & 0 \\ 0 & \frac{5}{x}\end{array}$

$\overrightarrow{\vec{a}}$

$u$
$u$
$a$
$a$
$\sim$
$u$
$a$
$a$
$a$

$\stackrel{\infty}{m}$

융람

$\rightarrow$

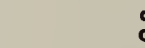

N芯

य。

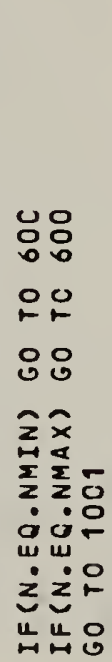

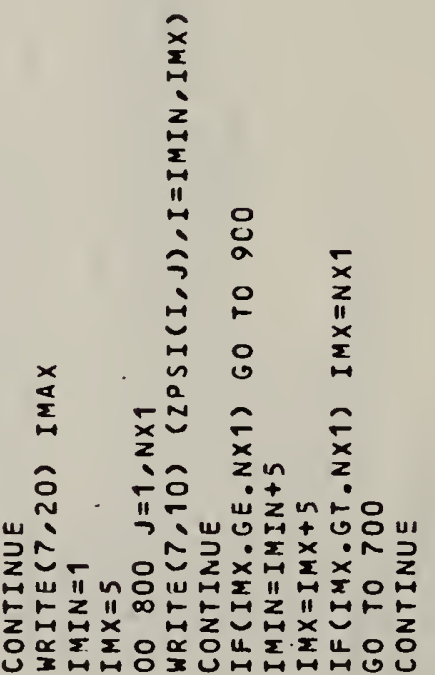

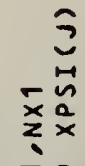

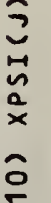

눈

路焉究

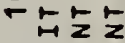

웅ㅇㅇㅇ

荡 $2 \frac{\alpha}{3}$

$: \quad:$

:

:

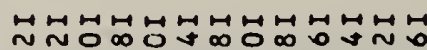

누ㄴㅕㅕ

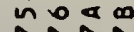

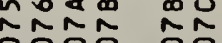
ถั 눈 iij

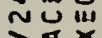

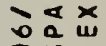
$\times$ 운 过。 立 w。 两 วิ๊ ล ฯ $m$ ? $m$ 路 แू I绐 응 i $\propto \ddot{\alpha z}$ 뻥 uㅡㄴ แ้ in mu $\tilde{x} \leftarrow \alpha$ 要 $\propto \sum u$ w $\sum_{w}$

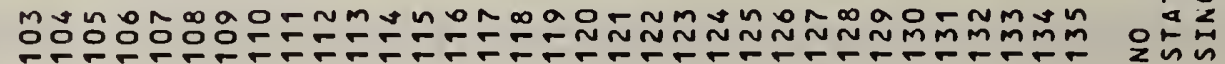


- N
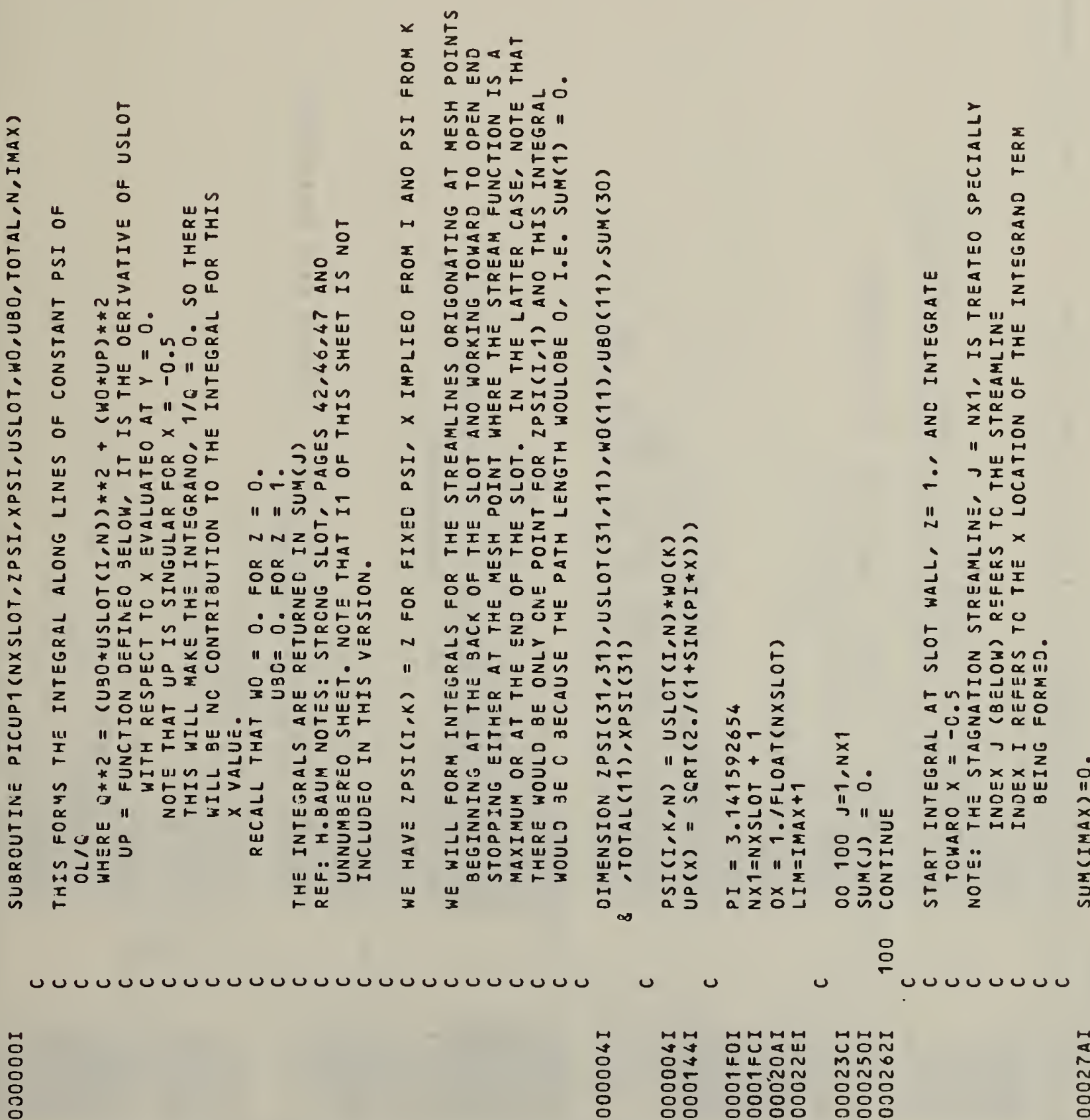

$\therefore$

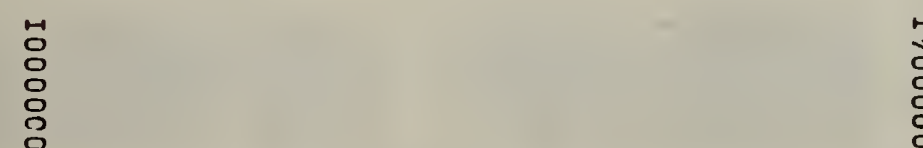

-NMUM 
2

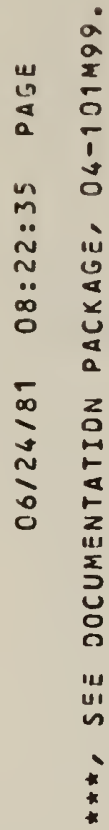

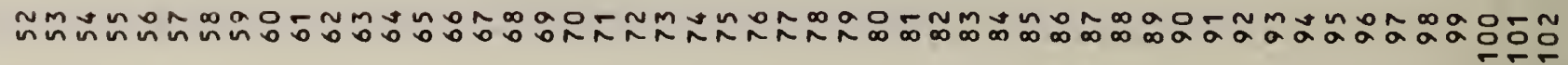

$\infty$

ș

$\ddot{\sim}$

$\sum_{u}^{n}$

ב.

2

은

\&

告
8 z

i

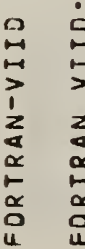

บงังิังที

\& 0 U

NNNNN

응응응응

$\cup \cup \cup \cup$

崩

II

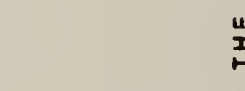

$\underset{5}{ \pm}$

눙

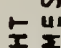

종

通

II

๒゚。ّ

:

岂

is

$\underset{0}{\frac{2}{0}}$

茨

क

난

$$
\text { 㟧 }
$$$$
\text { (1) }
$$

I ${ }^{2}$ H-

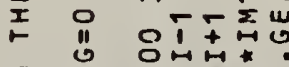

에

도듬ㄴ

x마

气」I

可

出

옹

球

正

咩品

造安

Iuㅗㅇ

$4 z^{\circ}$

运告

㟧出

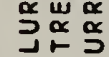

范的

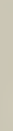

은 出出

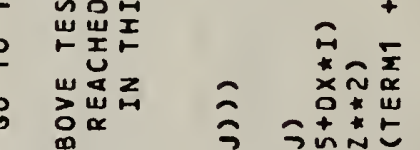

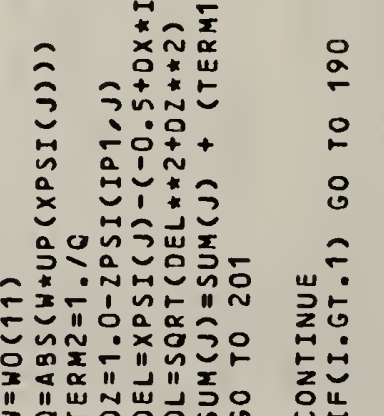

zo

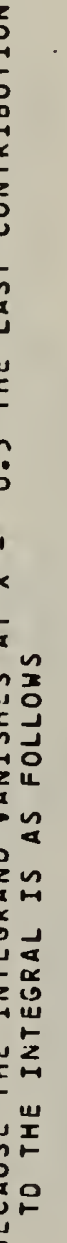

u
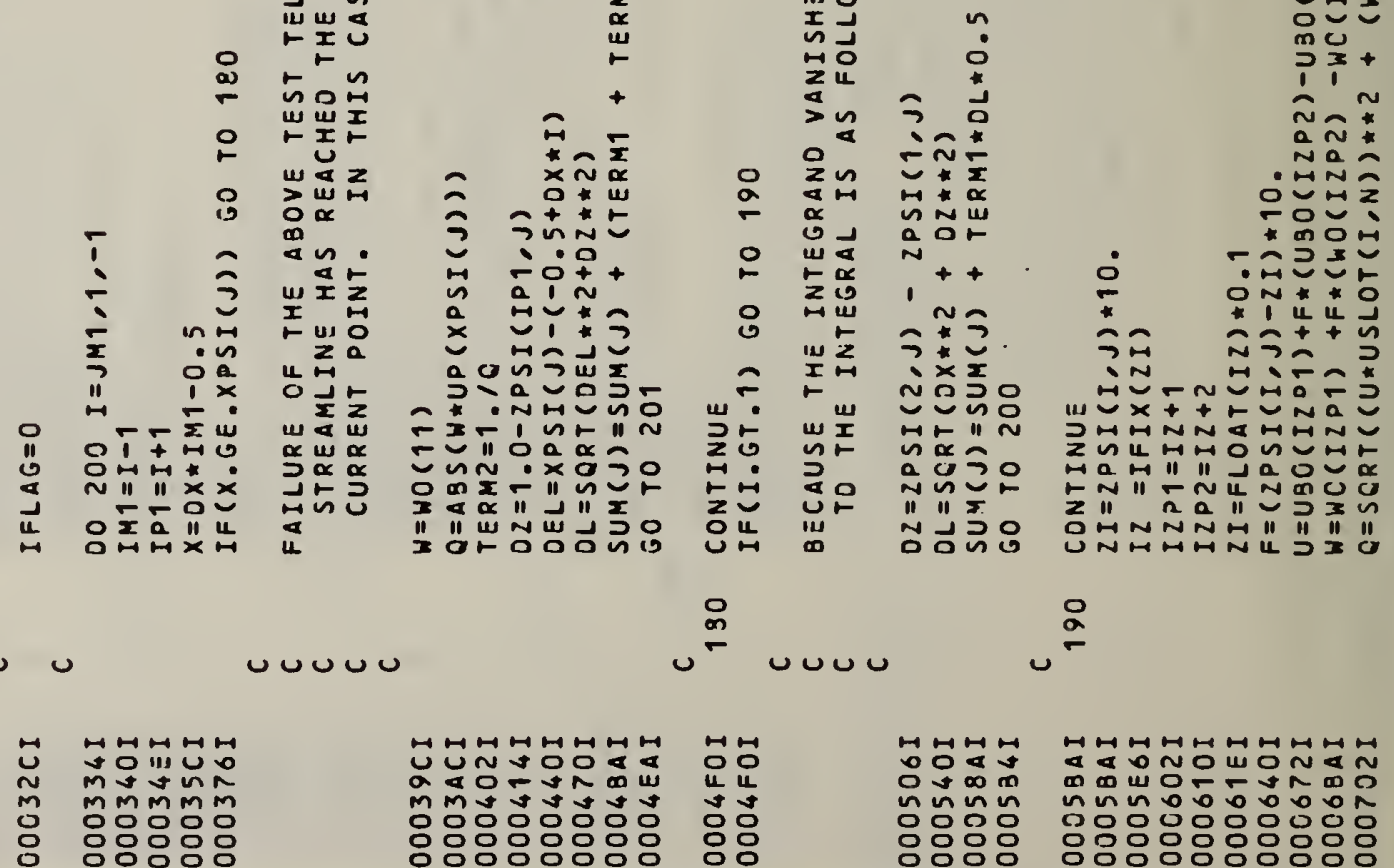

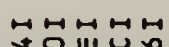

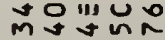

mmmmm

ㅇㅇㅇㅇㅇㅇㅇㅇㅇㅇㅇ

$\cup \cup \cup \cup \cup$

טu ט

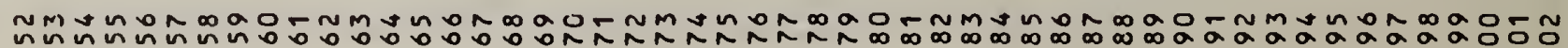

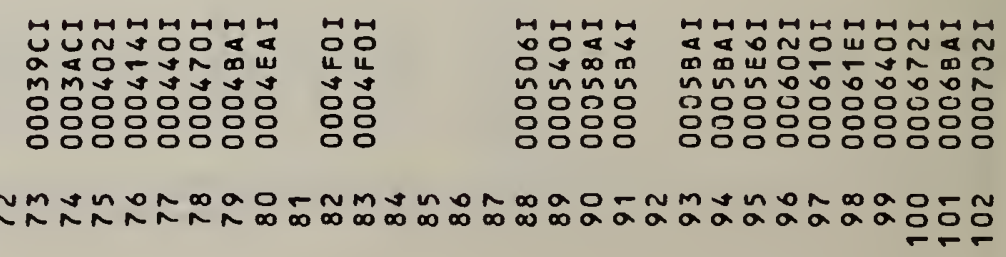


ì

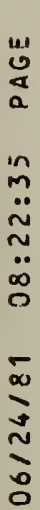

ํํำํำ

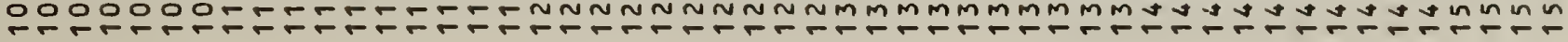

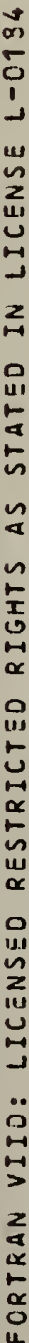
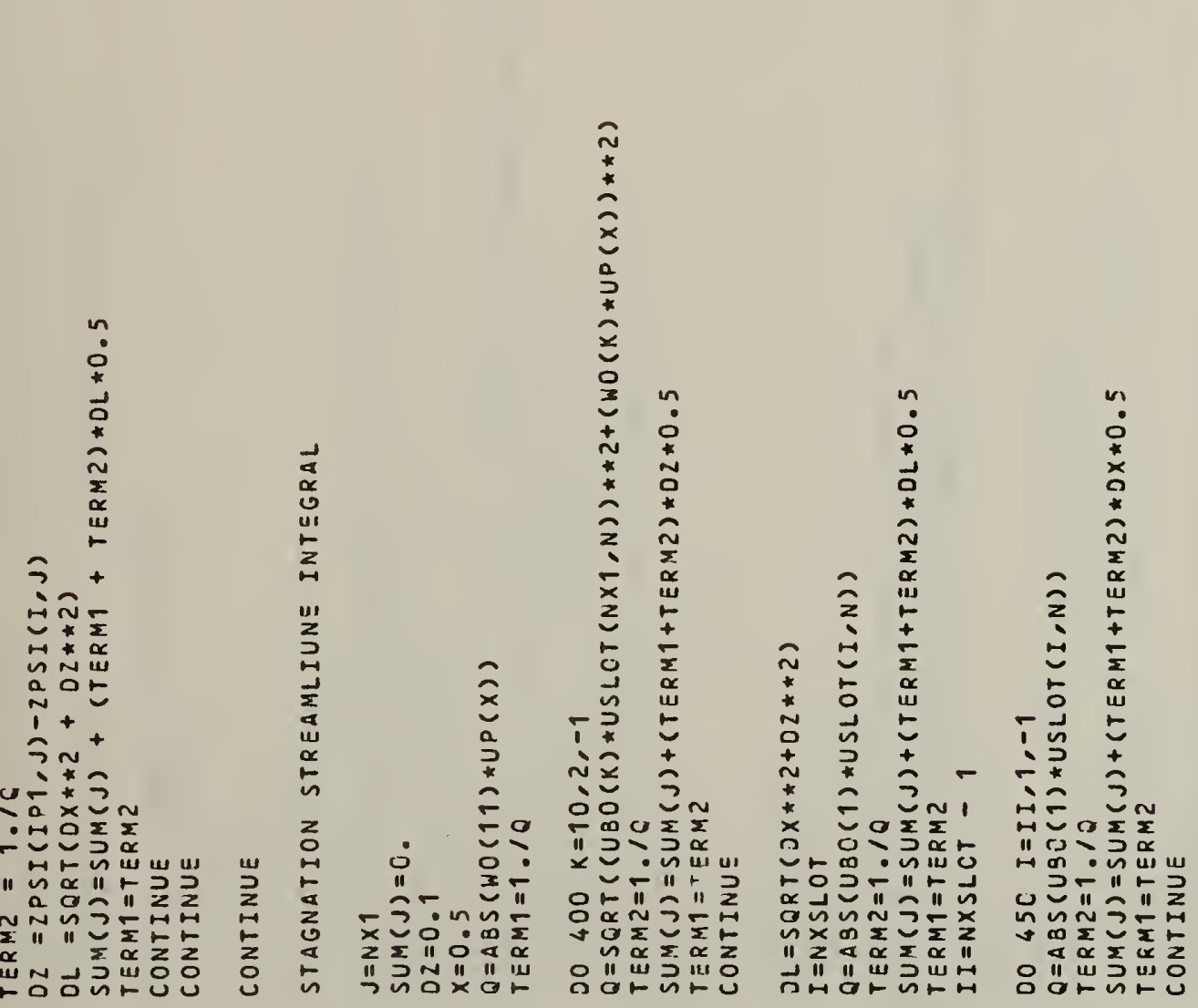

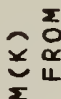

紋

पू

स्य

尔

尊

悉

$w \sum_{2}^{2}$

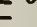

w

U⿺辶一

з出定

的

䑻

ํㅡㄹ

?口i

㟧出

a z

ผู้ง

气ุ:

天出些

का

ब

令故

OU m经

봎

견도

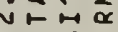

"은문

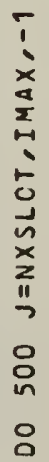

1
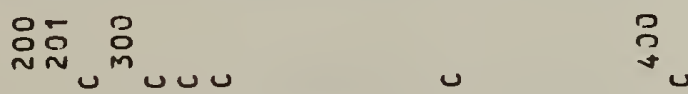

옹 I

(n)

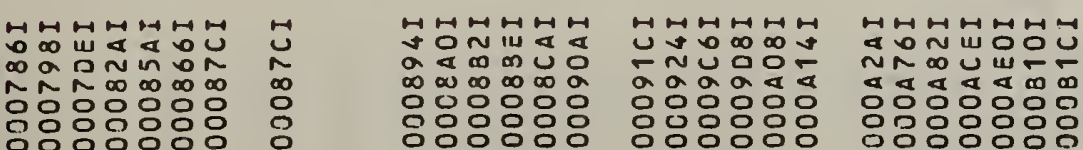

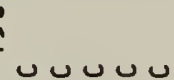

๕苟苟芺苂 N⿴囗十丁 \% 응용응용응 


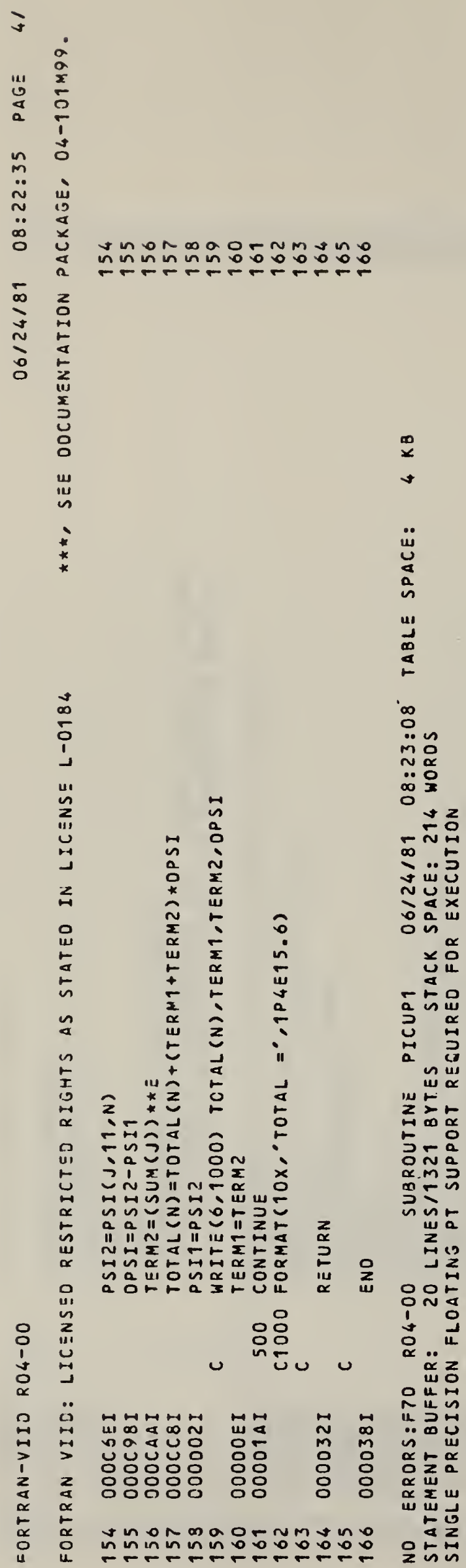




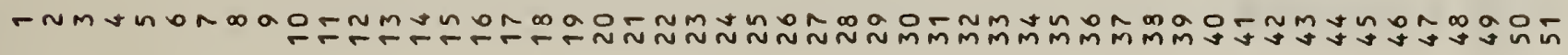

전 

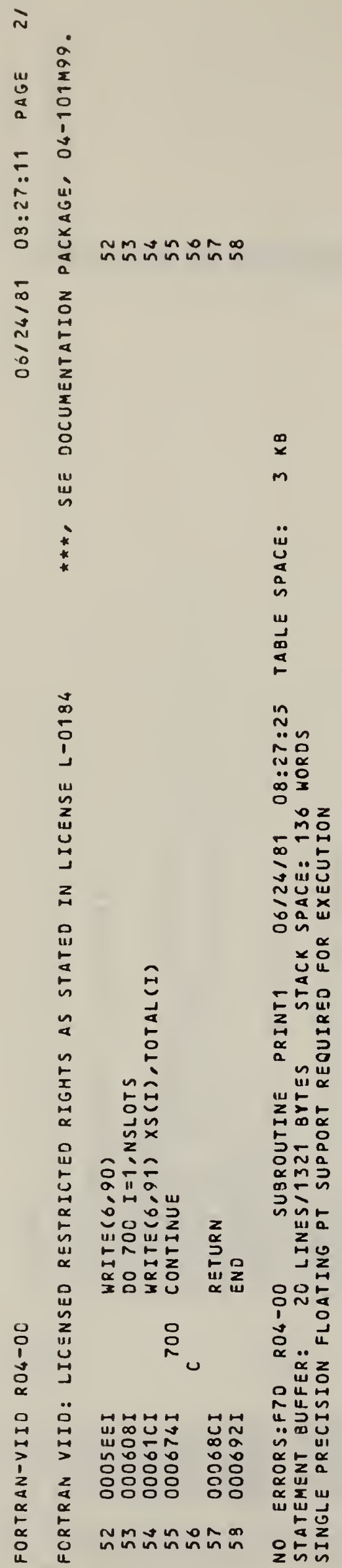


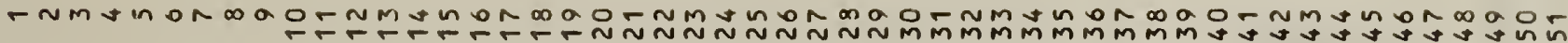

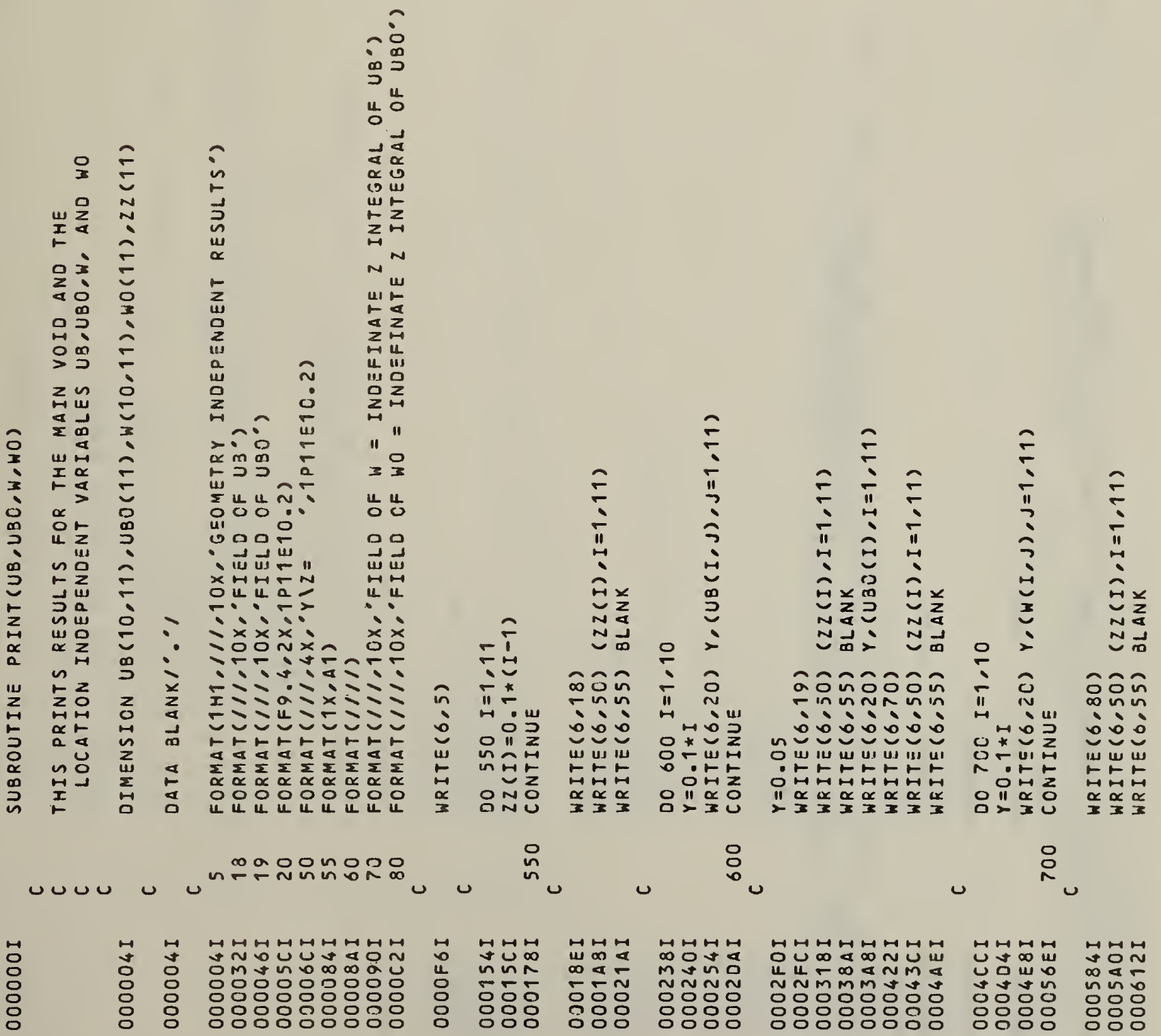



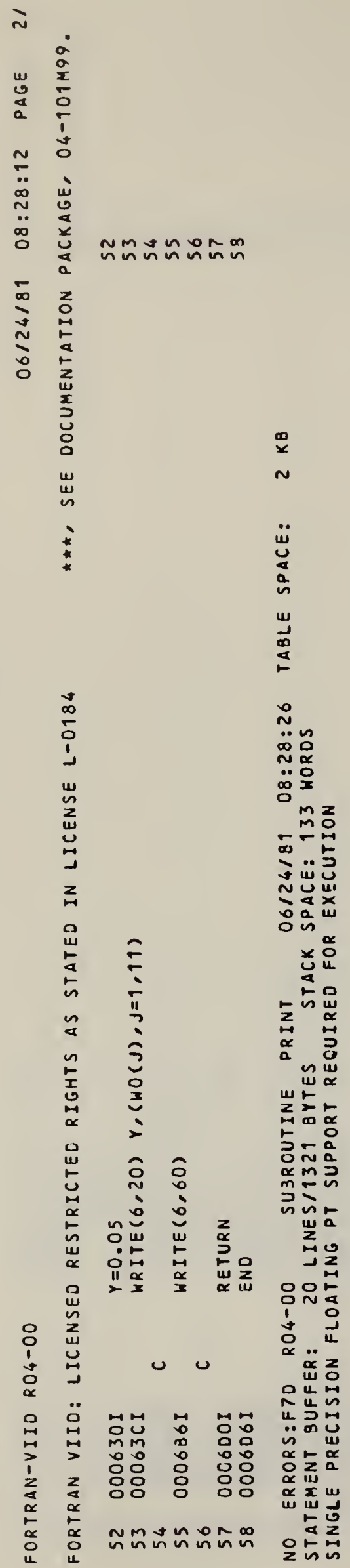

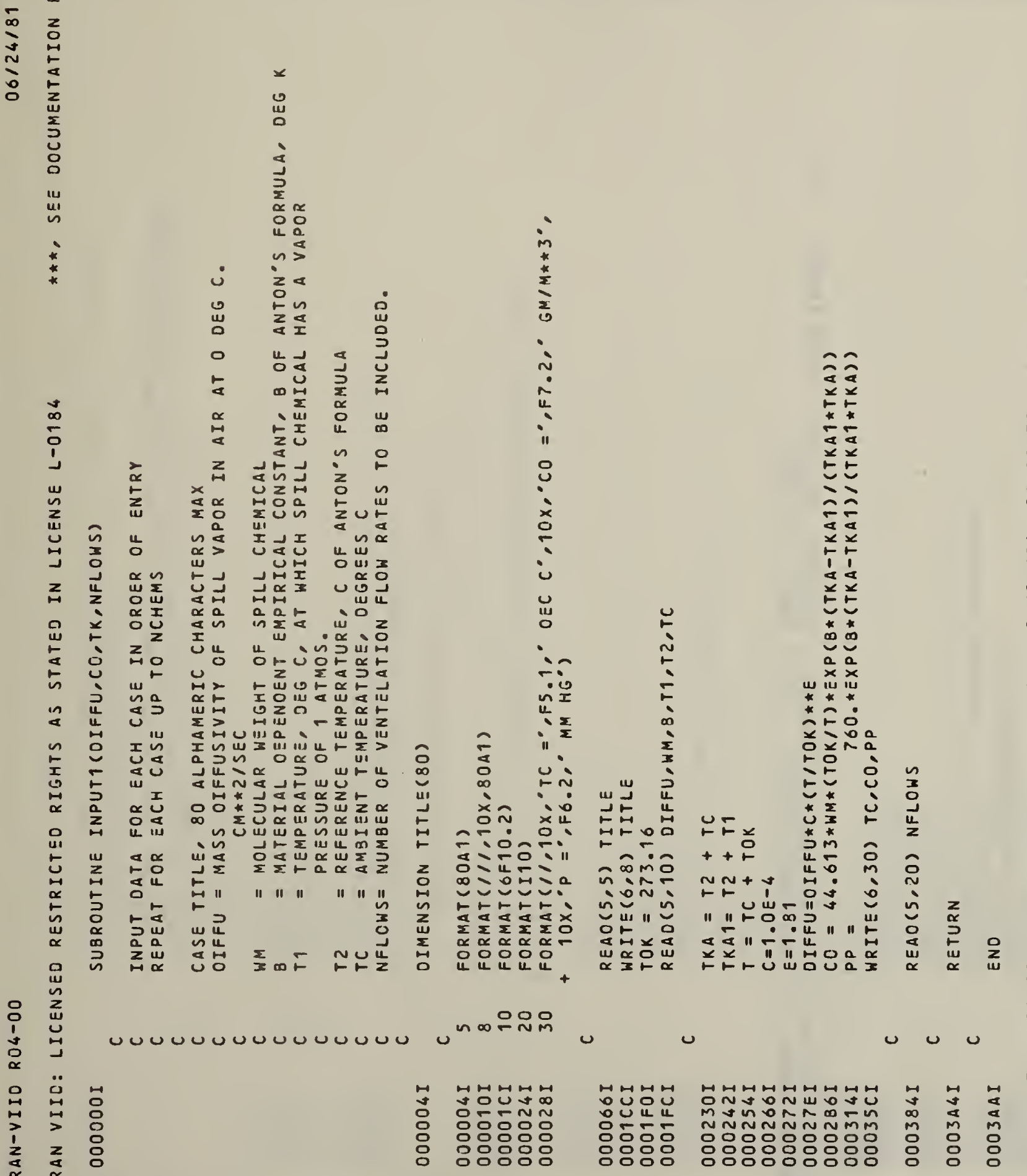

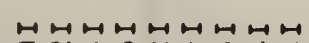

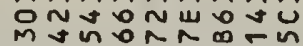

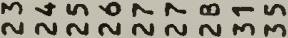
ㅇํㅇㅇํㅇㅇํㅇ

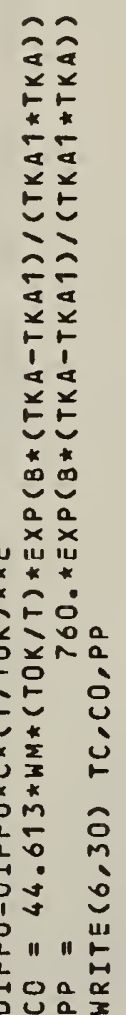

$\ddot{u}$
$u$
$a$
$u$
$u$
a
$a$

욤

$\ddot{a} \tilde{a}$

$\underset{0}{0}$

$\ddot{\infty}$ 옹

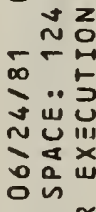

葆茫

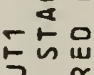

角总

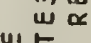

$\sum_{\substack{\infty \\ \infty}}$

5-:

음

皮要

光落

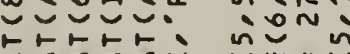

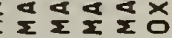

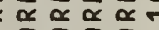

药"

还出并要

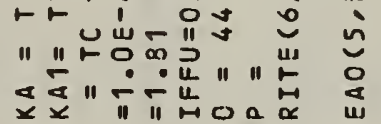

wa

出识 웅음 : $\propto \ddot{\alpha z}$

은도

… 虫 웅훙 政打 


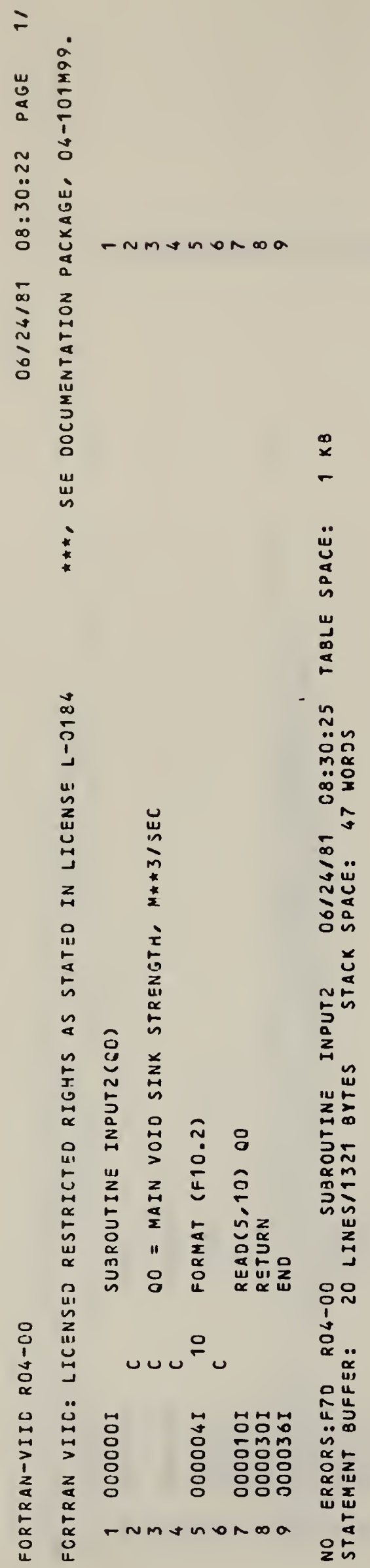




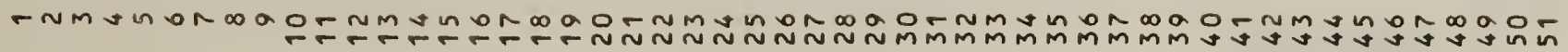

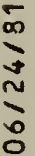

3

高出

II

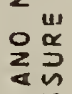

$\varangle \tilde{n}$

$\sum_{i=1}^{\infty u}$

$\sum^{2} a$

$2 \sum_{n=1}^{10}$

点点

需

品

œ广

a

แัฒ

艾点

ทัญ

ша

a

iक i०

넘넘

5 แ世

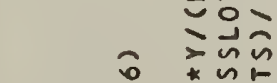

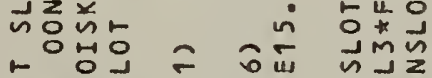

눙

d $\infty<a$

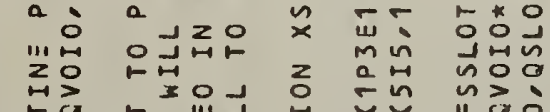

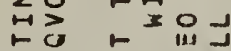

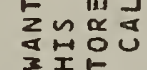

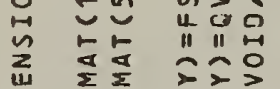

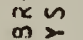

जे

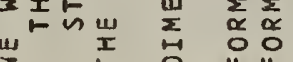

¿こ

$>a$
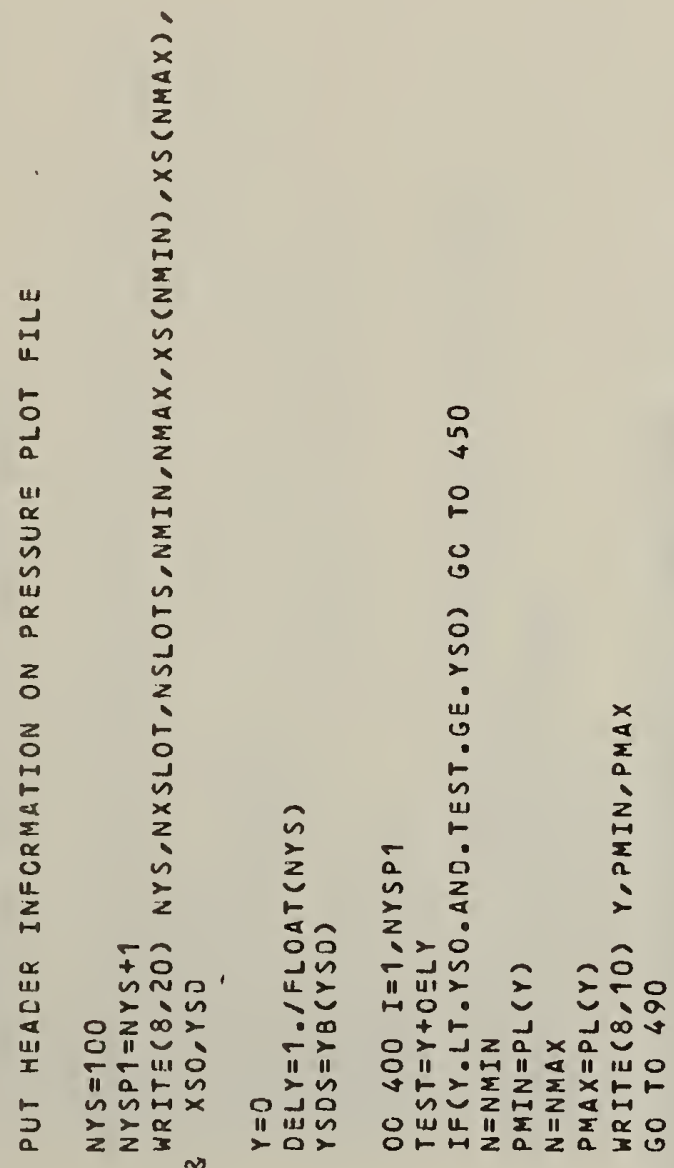

$u$
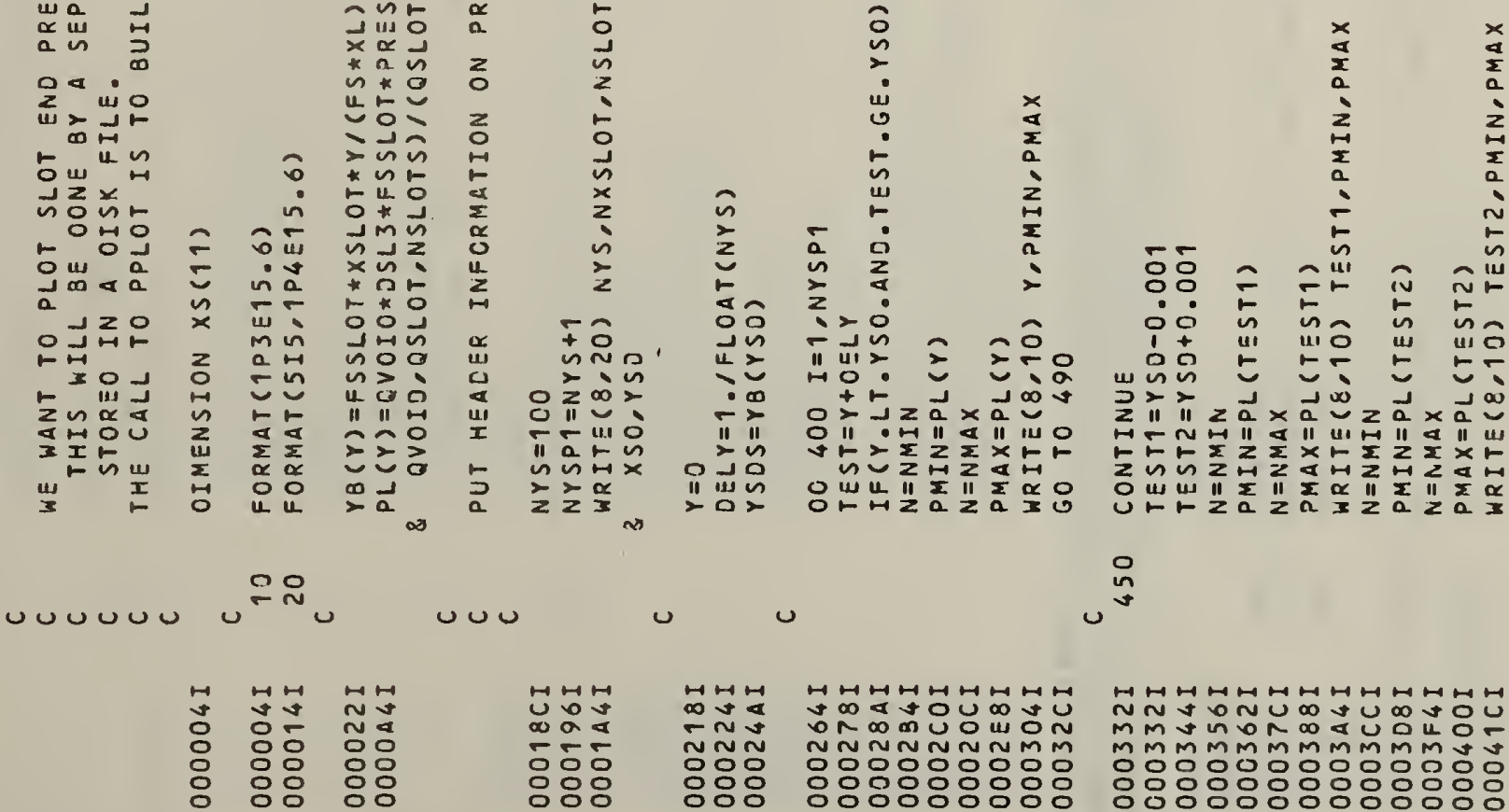

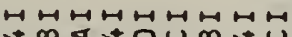

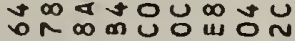

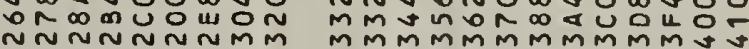
nNNNNNMm mmmmmmmmmmm

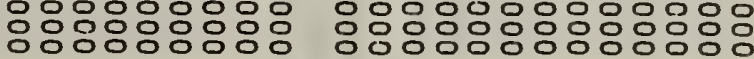

-NMUル 

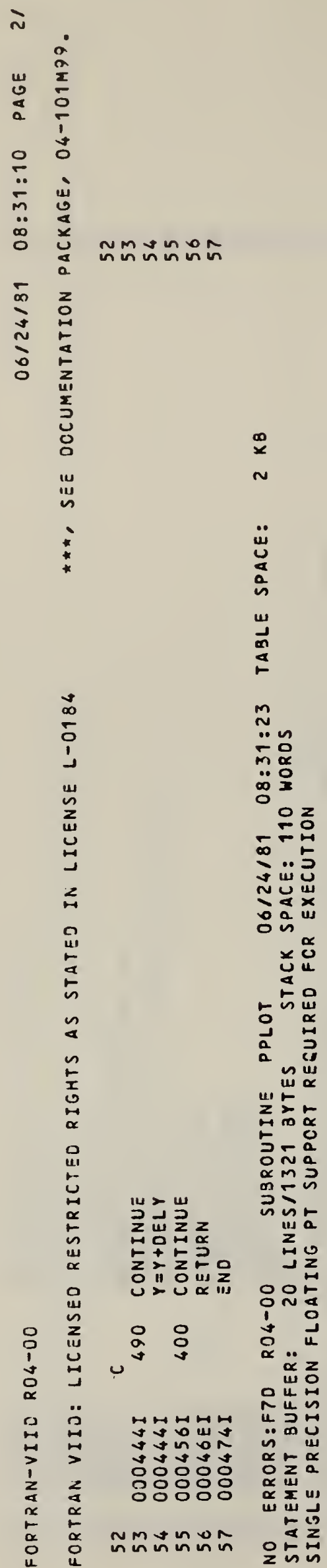
- Nm
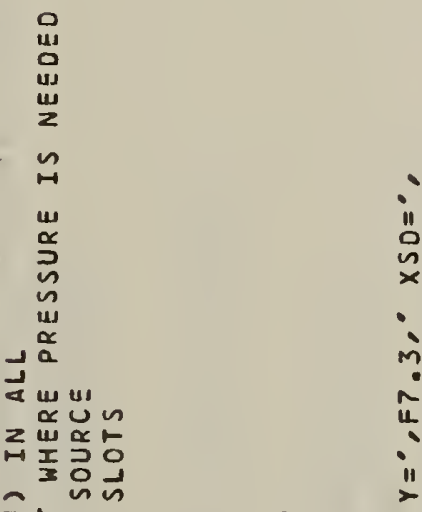

$+\sum_{i=1}^{\infty} \prod_{0}^{\infty}$

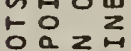
जuํ.

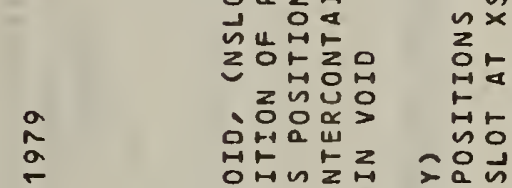

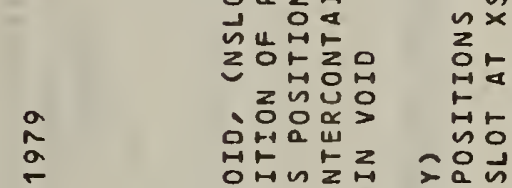

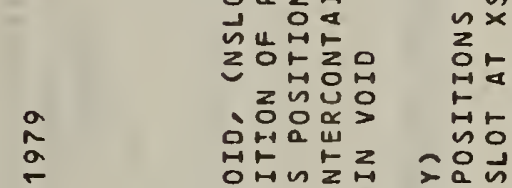

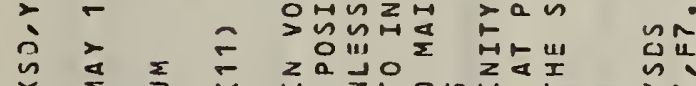

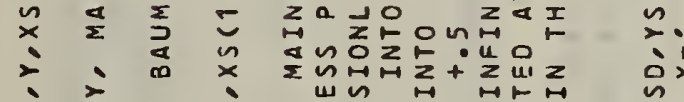

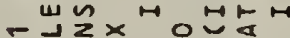

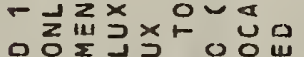

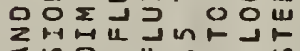
$\& \sum_{0} 0,0$ แ

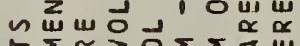

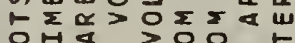

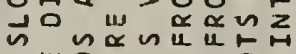

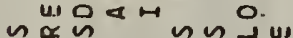

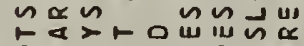
เ๘>

को⿲丿丨

xn inu

za!

$\dot{x} \ddot{n}=9.9$

\section{טum}

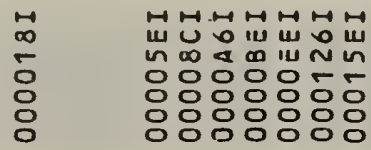

HคH

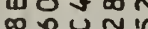
runin

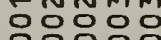
ㅇํㅇ용
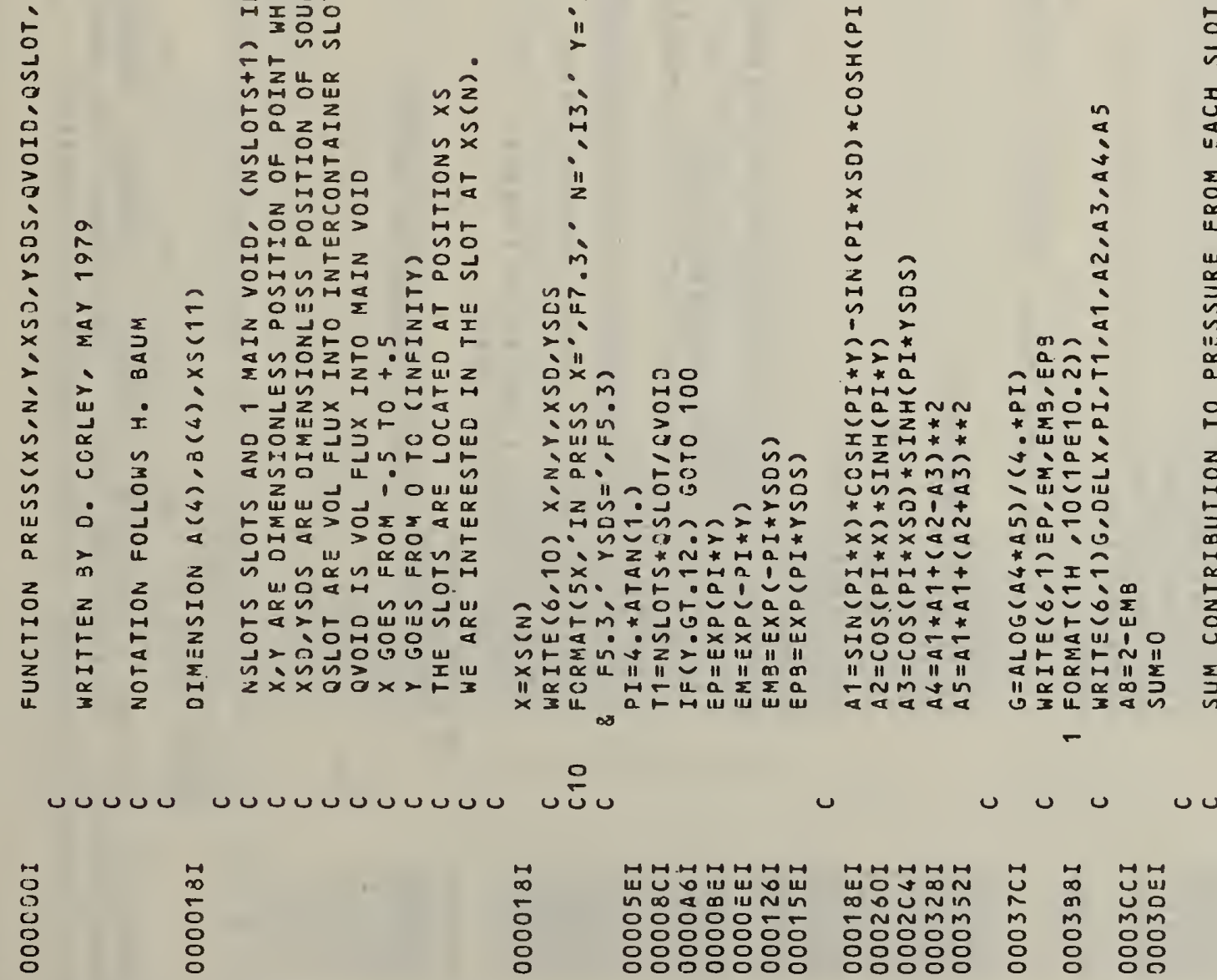

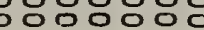

rNm $\ln$ M 


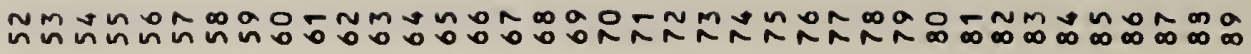


rnm + N

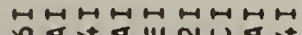




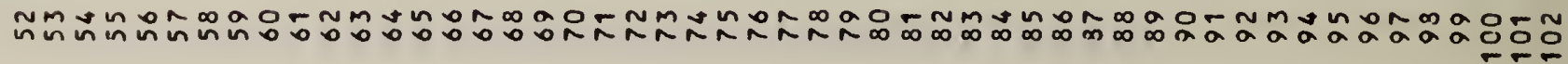

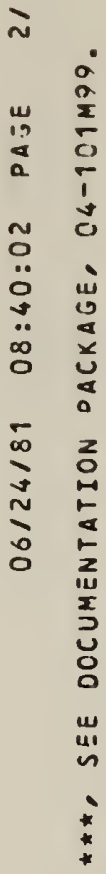

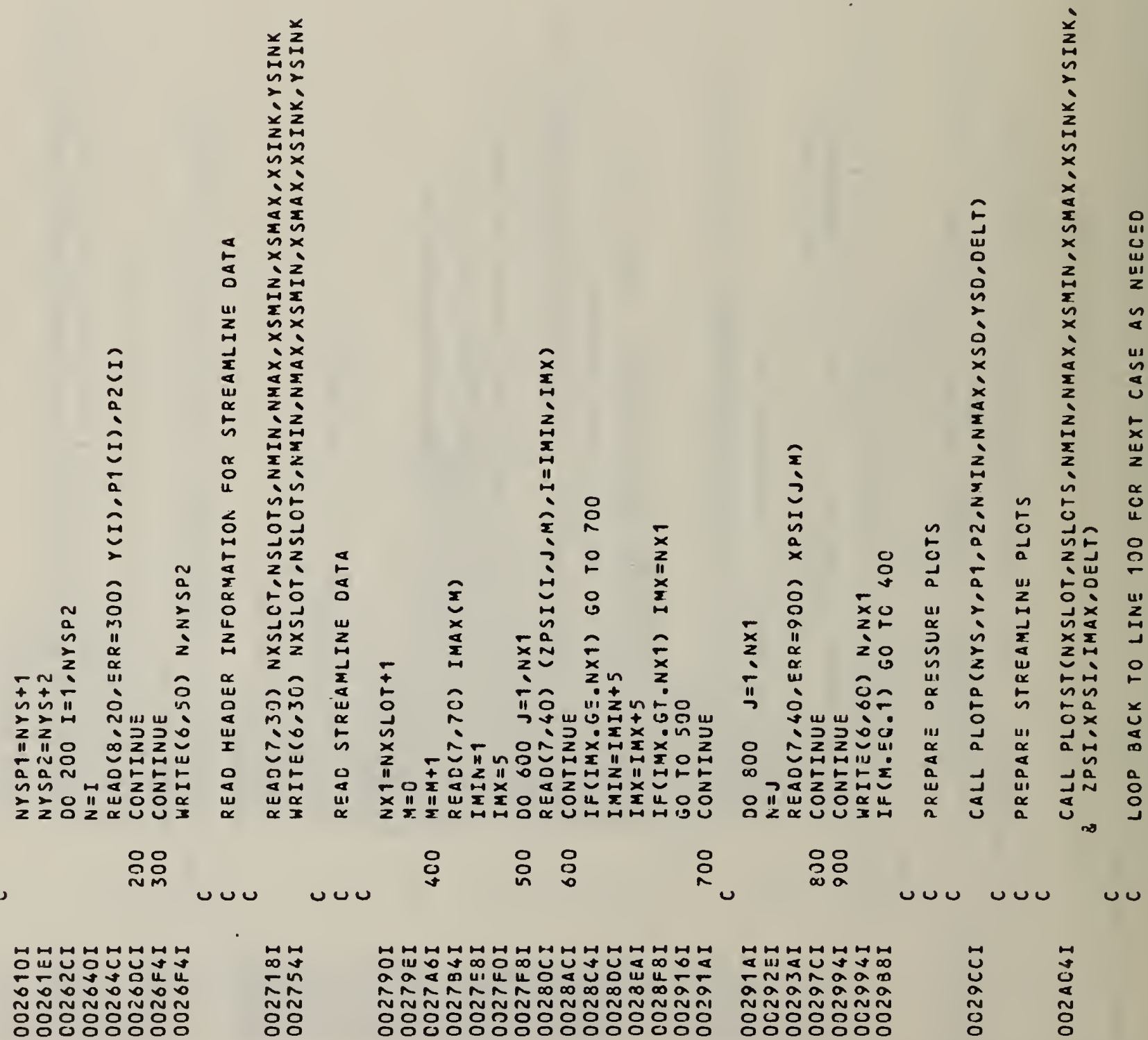




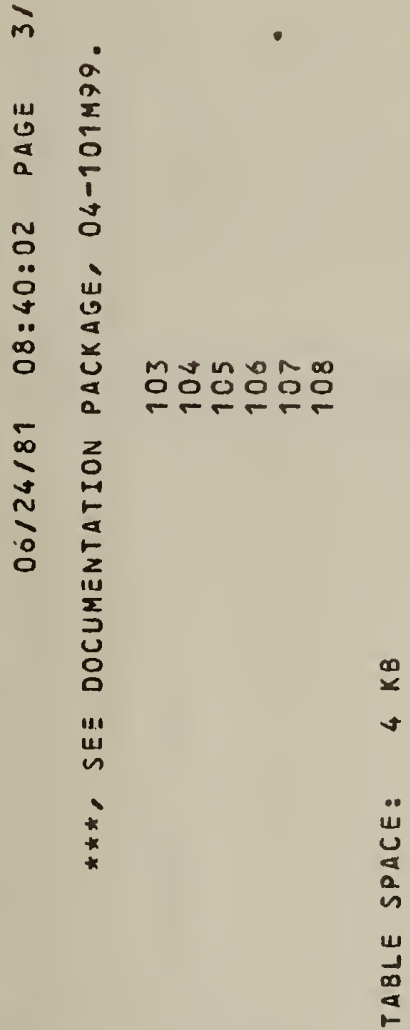

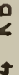

$u$
$u$
$a$
$a$
$n$
$w$
0
$a$
-

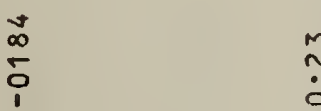

萡

获

$\ddot{\infty}$ 오

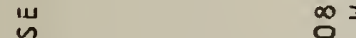

出

$\exists \quad \infty$

$\sum_{-1} \quad \approx \frac{a}{a}$

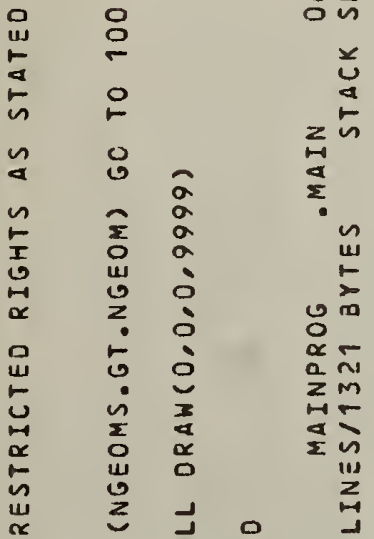

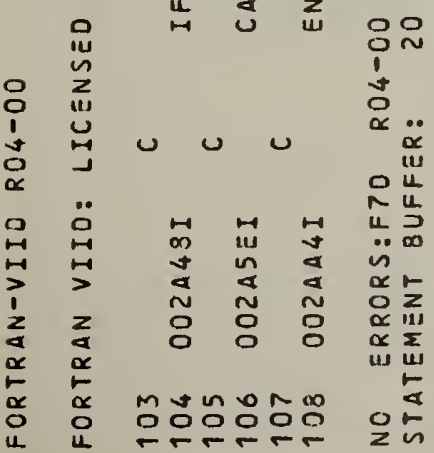




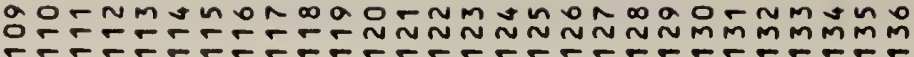

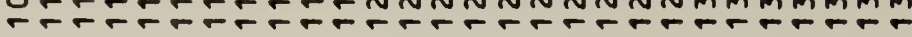

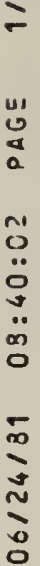

z



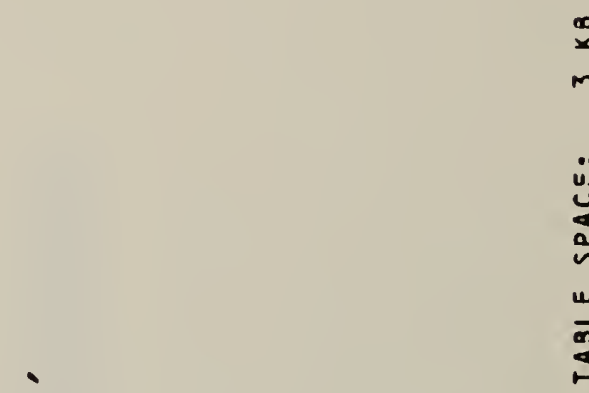

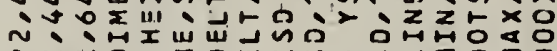

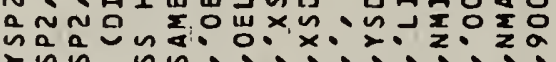

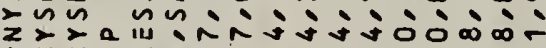

izz?

$\therefore=$ -

$\therefore$ -

5i

นaลã

†

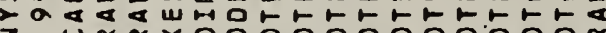

z

1 a

물

a

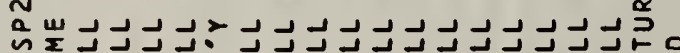

우

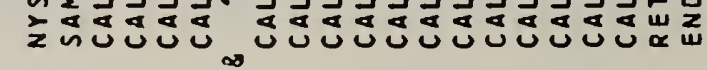

ט

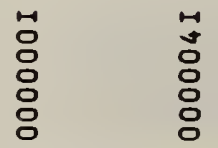

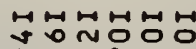

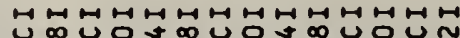
U4

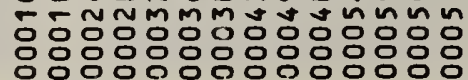

m

$\infty=$

วิทีเ

แำ

ज 응윤 1 
n maornmumbrwaornm

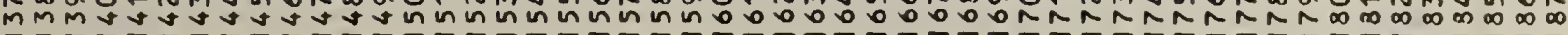




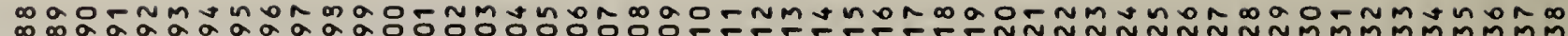

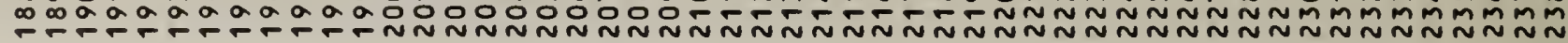

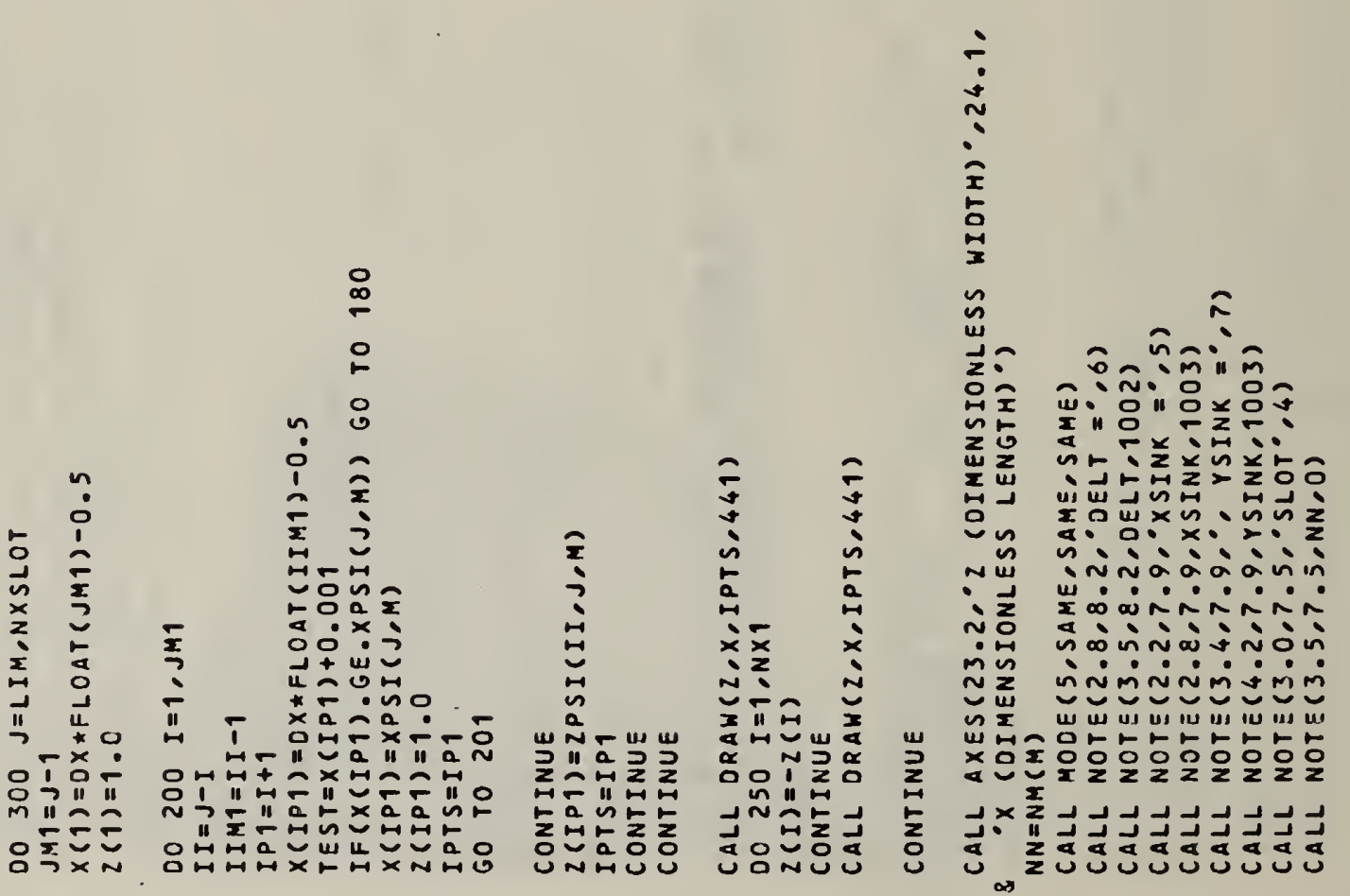

$\stackrel{\leftarrow}{\sim}$

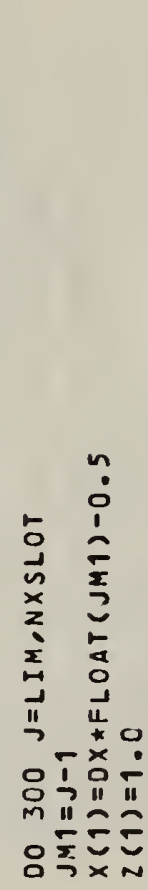

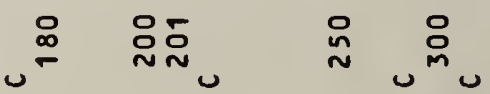

$\bullet \cup \cup \cup$

\section{ロேロロ

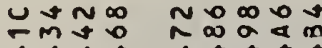 Tot 응ㅇㅇㅇㅇㅇㅇ

붕부녕요

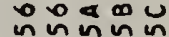
용용ㅇㅇㅇㅇㅇㅇ
본보연 岂出용용 응응응

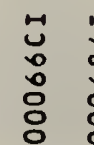

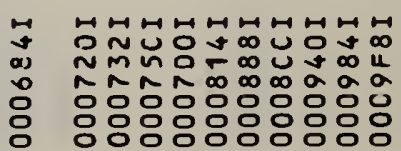

un un

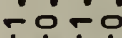
11" ระกิ 즌

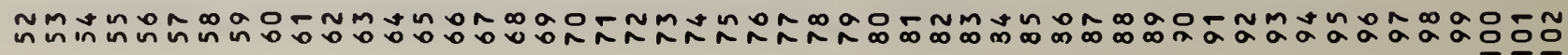



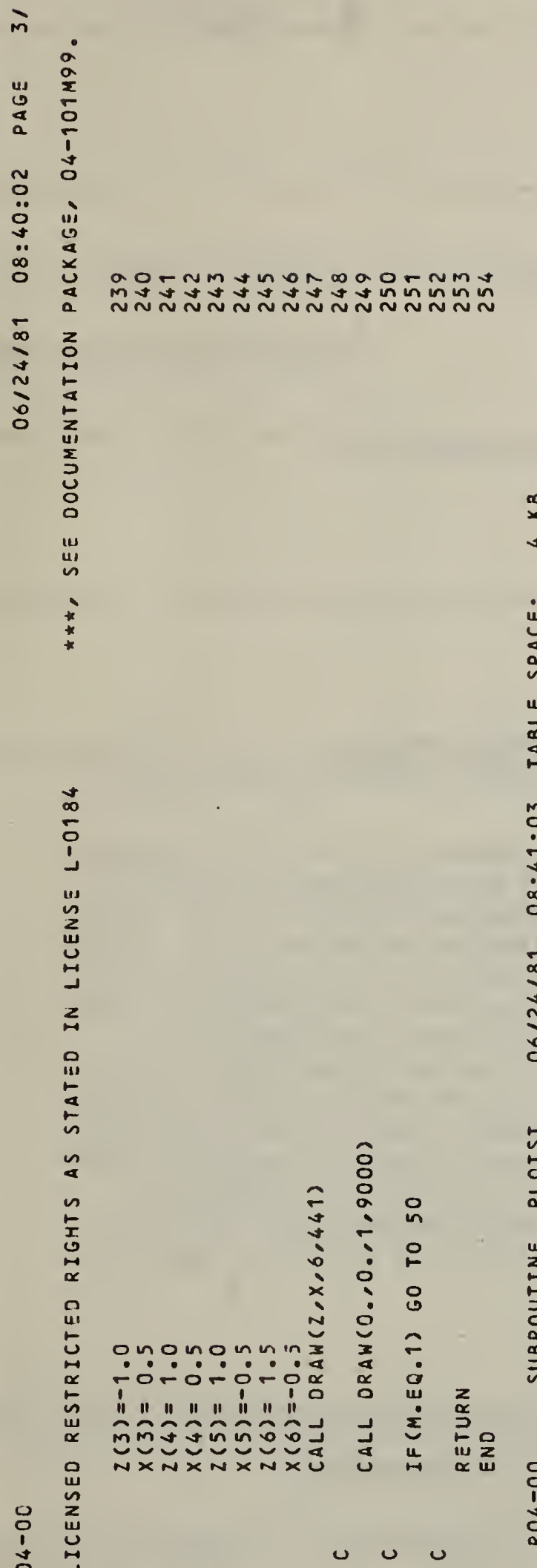
NBS-114A (REV. 2-8C)

U.S. OEPT. OF COMM.

BIBLIOGRAPHIC DATA

SHEET (See instructions)

1. PUBLICATION OR REPORT NO.

NBSIR 83-2665

4. TITLE AND SUBTITLE

An Investigation of the Forced Ventilation

in Containership Holds

\section{5. $\operatorname{AUTHOR}(S)$}

Howard R. Baum and John A. Rockett

6. PERFORMING ORGANIZATION (If joint or other than NBS, see instructions)

7. ContracV Grant No.

NATIONAL BUREAU OF STANDARDS

DEPARTMENT OF COMMERCE

WASHINGTON, D.C. 20234

\section{SPONSORHIC ORGANIZATION NALE AND COMPLETE ADDRESS (Street, CHY, STOL, ZIF)}

U.S. Coast Guard

400 Seventh Street, SW.

Washington, D.C. 20590

10. SUPPLEMENTARY NOTES

[] Document describes a computer program; SF-185, FIPS Software Summary, is attached.

11. ABSTRACT (A 200-word or less factual summary of most significant information. If document includes a significant bibliography or literature survey. mention it here)

An analysis of the fluid flow and mass transfer induced by ventilation systems in containership holds was carried out. The work was performed in support of the U.S. position before a committee of the International Convention on Safety to Life at Sea. The analysis consists of a detailed calculation of the forced motion through an interconnected set of narrow, stably stratified vertical air passages which represent an idealized containership holds the results of this calculation are then used in a study of the concentration boundary layers formed by the pickup of spill material assumed to lie at the bottoms of the air passages. The result is a set of formulae which determine the rate of extraction of spill material as a function of hold geometry, ventilation parameters, and ambient stratification. The results are incorporated in a computer program which is described in detail. A variety of computed results are presented, together with a listing of the program. The results indicate the crucial importance of locating the extractor as close to the hold bottom as technically possible.

12. KEY WORDS (Six to twelve entries; alphabetical order; capitalize only proper names; and separate key words by semicolons) Cargo ships; fires hazardous materials; modeling; stratified flow; ventilation

13. AVAILABILITY

[X] Unlimited

$\square$ For Official Distribution. Do Not Release to NTIS

$\square$ Order From Superintendent of Documents, U.S. Government Printing Office, Washington, D.C. 20402.

X] Order From National Technical Information Service (NTIS), Springfield, VA. 2216I

14. NO. OF PRINTED PAGES 175

15. Price

$\$ 16.00$ 

